\title{
Response of Variable-Depth Reinforced Concrete Pier Cap Beams
}

\author{
by \\ Christopher Orcutt \\ Department of Civil Engineering and Applied Mechanics \\ McGill University, Montreal
}

April 2019

A thesis submitted to McGill University in partial fulfilment of the requirements of the degree of Master of Engineering

(C) Christopher Orcutt, 2019 


\section{ABSTRACT}

Four variable-depth pier cap beams were constructed and tested. These specimens were designed to have reinforcement details similar to types 04A and 168 pier cap beams used in the existing Champlain Bridge. The primary objectives were to examine and compare the behavior of variable depth cap beams at service loading and at failure, to analyze the effectiveness of crack control reinforcement, and to investigate the influence of external horizontal post-tensioning. Additionally, the observed cap beam responses were compared with three prediction models: sectional analyses, strut-and-tie models, and non-linear finite element analyses.

It was concluded that the amount of crack control reinforcement was important in controlling crack widths at service load level. The inclined shear reinforcement was found to be effective in resisting shear. Horizontal post-tensioning was effective in reducing crack widths and the overall stiffness of the pier cap beams, but did not lead to significant increases in strength. Failure shears predicted by the sectional analyses were conservative and better than those predicted by the strutand-tie model. Non-linear finite element analyses gave very good predictions of the complete behavior and strength of the pier cap beams. 


\section{RÉSUMÉ}

Quatre chevêtres en poutre de profondeur variable ont été construites et testées. Ces spécimens ont été construits avec des armatures semblables à celles utilisées dans les chevêtres du pont Champlain existant, spécifiquement 04A et 168. Un des objectifs était d'examiner et de comparer le comportement des chevêtres lors des chargements de service et au moment de la rupture. De plus, l'efficacité de l'armature pour contrôler la fissuration et l'influence de la précontrainte horizontale externe ont été examinées. Les réponses observées des spécimens ont été comparées à trois modèles de prédiction : les analyses en coupe, les modèles bielle-tirant, et les analyses par éléments finis non linéaires.

En conclusion, la quantité d'armature pour contrôler la fissuration était performante dans la maîtrise de la largeur des fissures lors de chargements de service. L'armature de cisaillement inclinée s'est avérée efficace pour résister au cisaillement. La précontrainte horizontale a été efficace pour réduire la largeur des fissures et la rigidité des chevêtres en poutre, mais sans augmentation de la résistance. Les cisaillements maximaux prédits par les analyses en coupe étaient conservateurs et meilleurs à ceux prédits par le modèle bielle-tirant. Les analyses des éléments finis non linéaires ont très bien prédit le comportement et la résistance des chevêtres en poutre. 


\section{ACKNOWLEDGEMENTS}

The author would like to thank Professor Denis Mitchell for his guidance, support, encouragement, and invaluable supervision throughout this research program. The author would also like to thank Dr. William Cook for his considerable assistance and support to this research program, especially throughout the experimental and analysis phases.

Appreciation is extended to John Bartczak and Damon Kiperchuk for their valuable assistance and guidance in preparing the experiments. The author would also like to thank Julia Bond, Omar Shemy, Ryan Tack, and Marta Calitoiu for their contributions in the construction, preparation, and testing of the specimens.

Furthermore, the author would like to thank his family and friends for their immense support and encouragement throughout the completion of this research program.

The financial support provided by Les Ponts Jacques Cartier et Champlain Incorporée (PJCCI) and by McGill University throughout this research program was greatly appreciated. 


\section{TABLE OF CONTENTS}

ABSTRACT

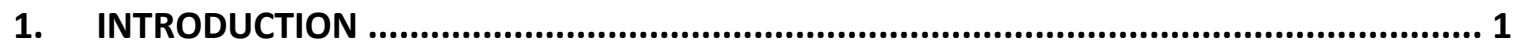

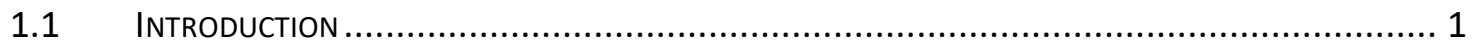

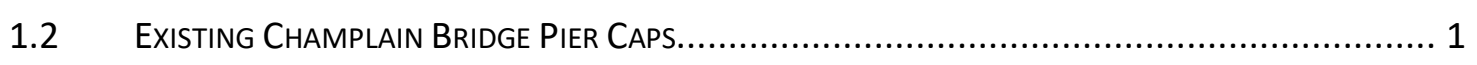

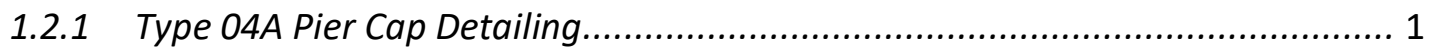

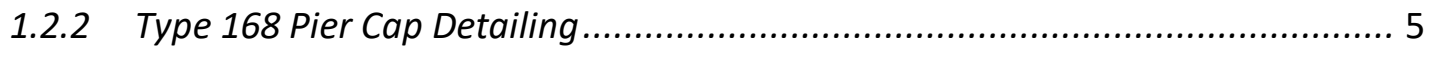

1.2.3 Observed Distress in Pier Cap Beams ........................................................ 7

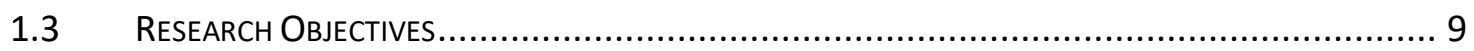

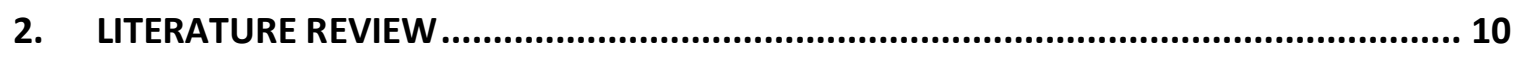

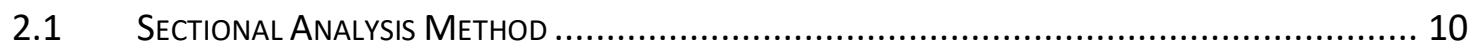

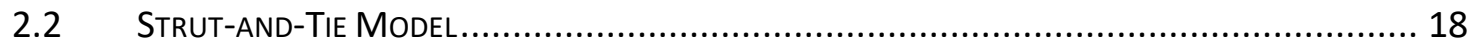

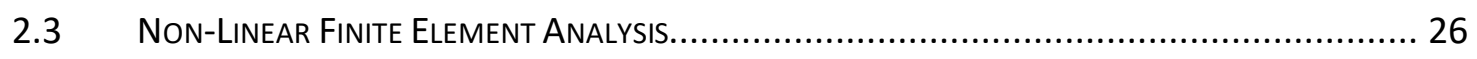

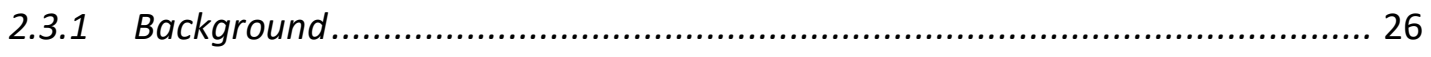

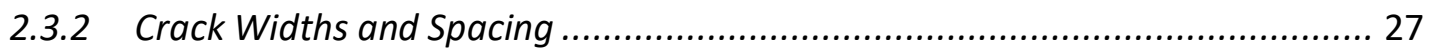

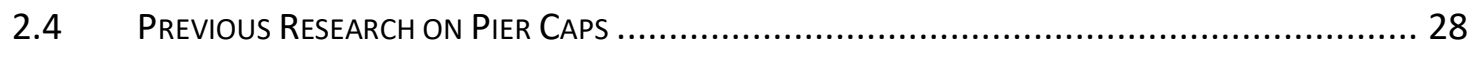

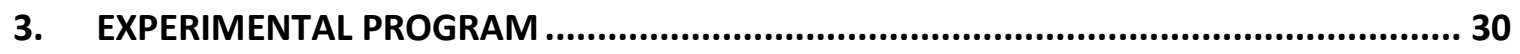

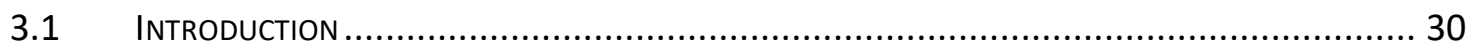

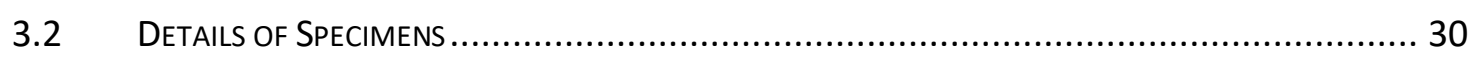

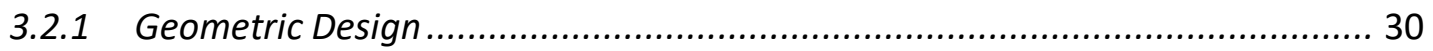




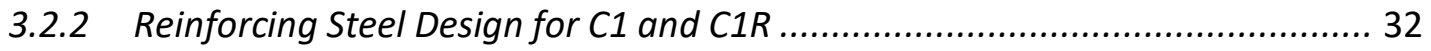

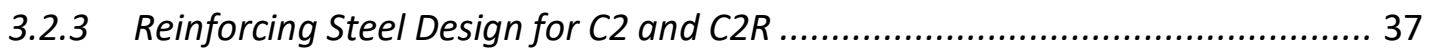

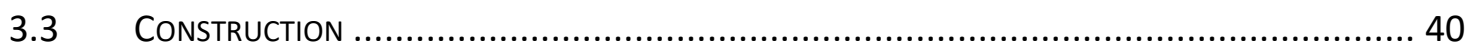

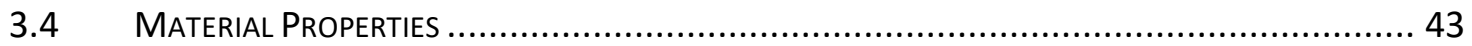

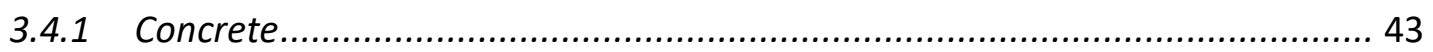

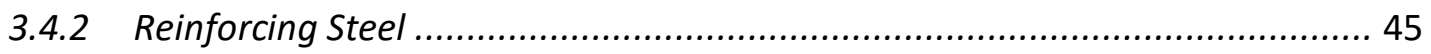

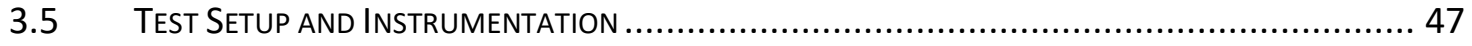

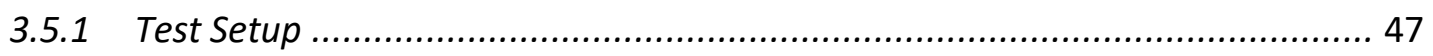

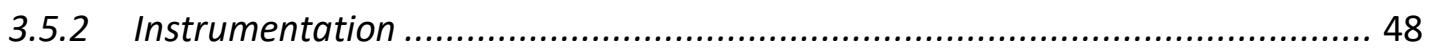

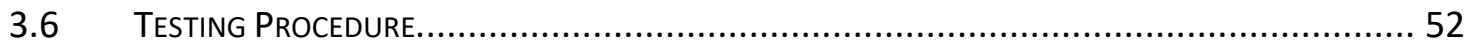

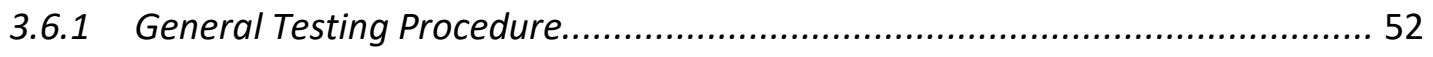

3.6.2 Application of External Shear Clamps .................................................... 53

3.6.3 Horizontal Post-Tensioning of Pier Caps C1R and C2R ............................... 54

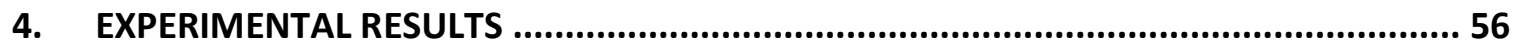

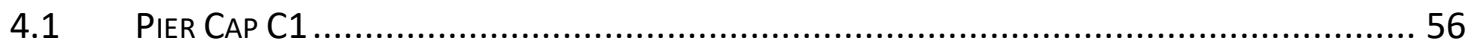

4.1.1 Shear-Deflection Response ................................................................. 56

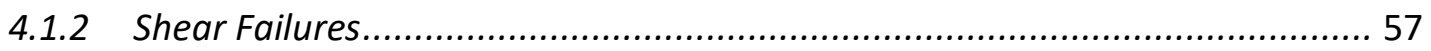

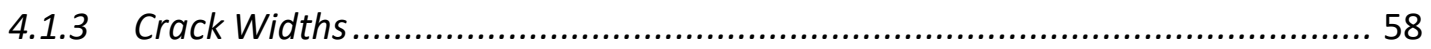

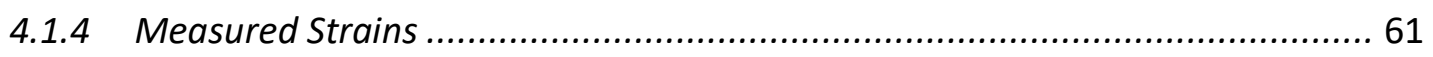

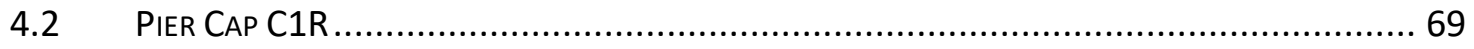

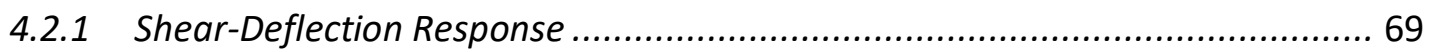

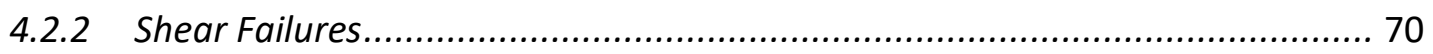

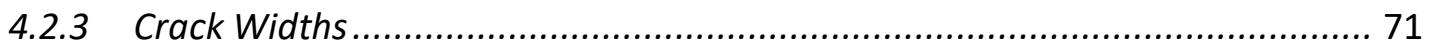

4.2.4 Measured Strains ............................................................................... 75

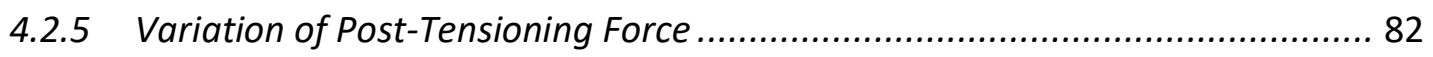

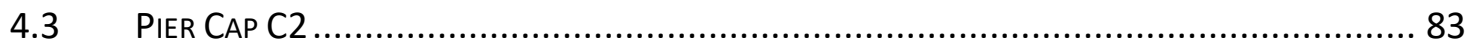

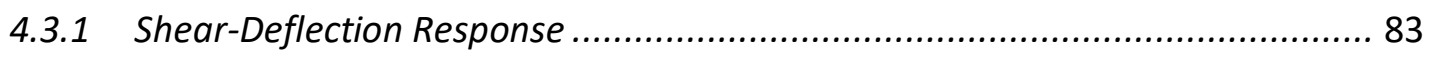

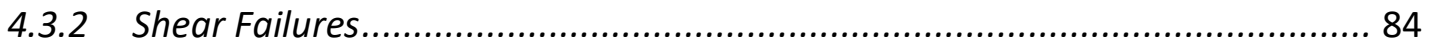

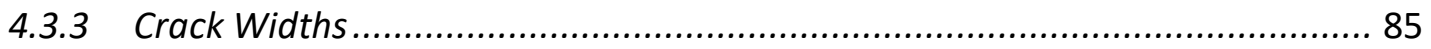

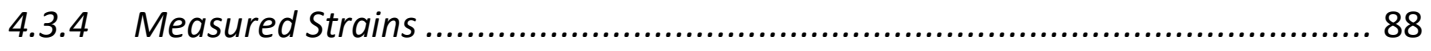




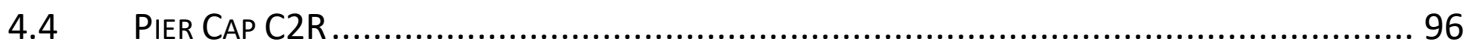

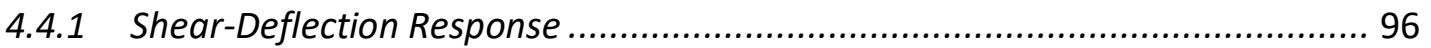

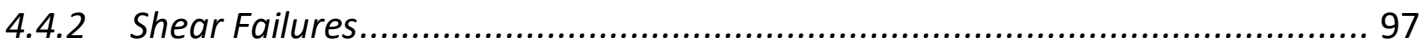

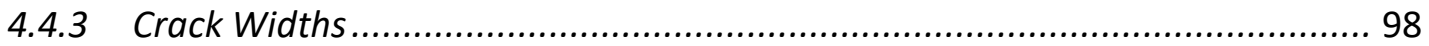

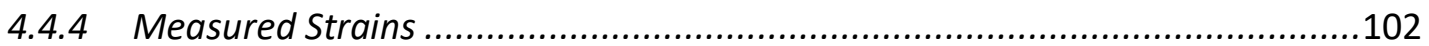

4.4.5 Variation of Post-Tensioning Force ........................................................ 109

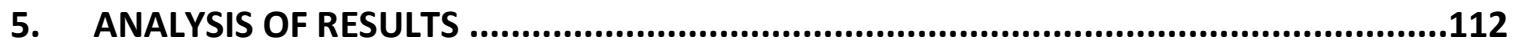

5.1 DISCUSSION AND COMPARISON OF EXPERIMENTAL RESULTS ..........................................112

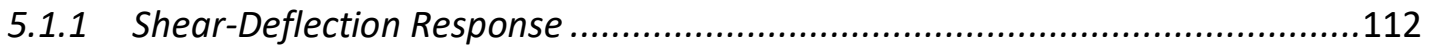

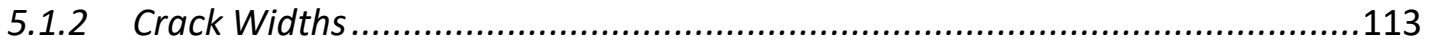

5.2 Predicted Behavior from Sectional Analysis.................................................... 120

5.2.1 Determining Locations of Critical Sections ...............................................120

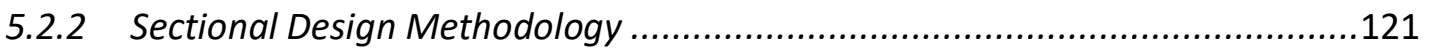

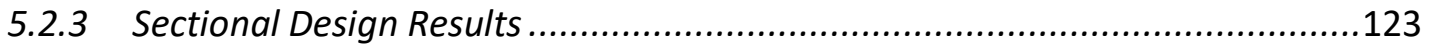

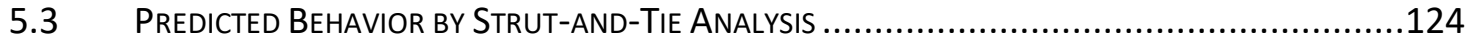

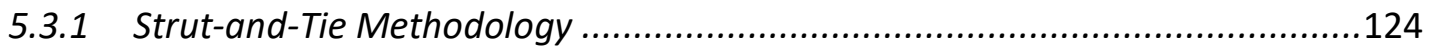

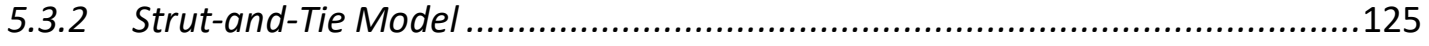

5.4 Predicted Behavior by Non-Linear Finite Element Analysis ...............................127

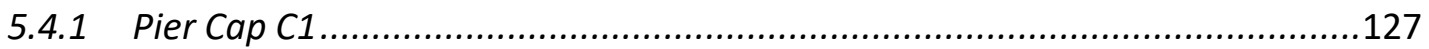

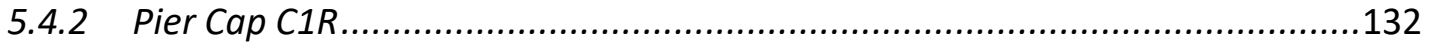

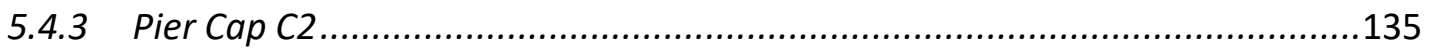

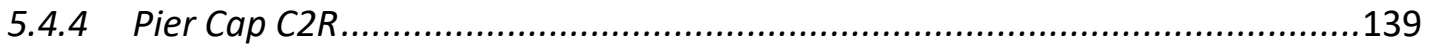

5.4.5 Summary of Non-Linear Finite Element Analysis Predictions .........................142

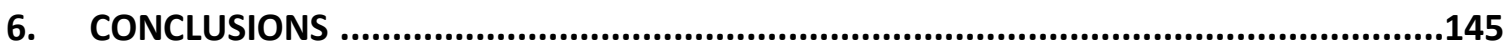

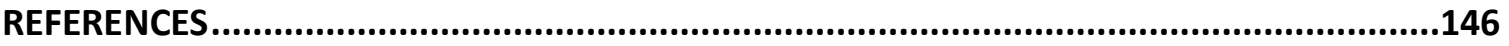




\section{LIST OF FIGURES}

1.1 Drawing 12942-EE-4A - Reinforcement and bearing details for pier cap type 04A for

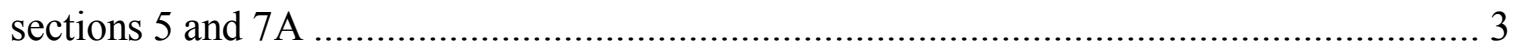

1.2 Drawing 12942-EE-5A - Elevation view of pier cap type 04A for sections 5 and 7A ….. 4

1.3 Drawing 12942-L-168 - Reinforcement and bearing details for pier cap Type 168 in

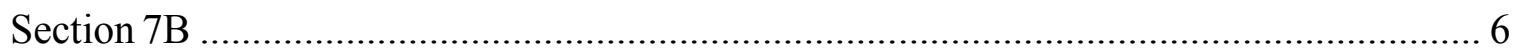

1.4 Flexural cracks, shear cracks and concrete delamination in pier cap $36 \mathrm{~W}$ in 2000 .......... 7

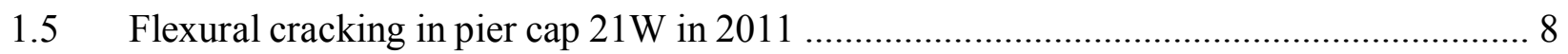

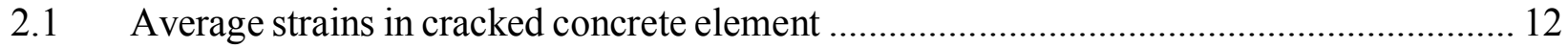

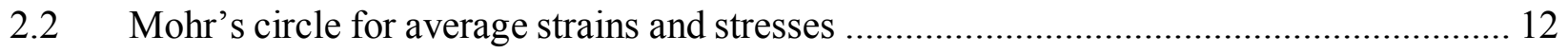

2.3 Shear stresses transmitted across a crack via aggregate interlock .................................... 13

2.4 Free body diagram of shear resistance contributions ...................................................... 15

2.5 Simplified diagonal crack width equation compared to the relationship from the

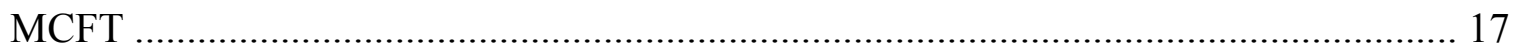

2.6 The CSA A23.3 2004 theta equation compared to upper and lower limits ....................... 18

$2.7 \quad$ Strut-and-tie model for a reinforced concrete deep beam .................................................. 19

$2.8 \quad$ Typical compression fields in disturbed regions ............................................................ 20

2.9 Examples of strut-and-tie models of stress paths in disturbed regions ............................... 21

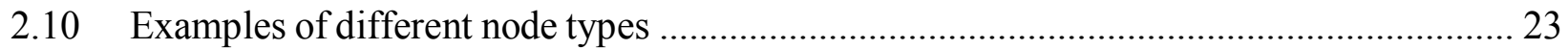

2.11 Influence of the tension tie angle on the crushing strength of the compressive strut ........ 25

2.12 Comparison of strut-and-tie and sectional model strength predictions with observed strengths for beams of varying shear-span-to-depth ratios tested by Kani et al., 1979 ..... 26

3.1 Geometry of pier cap beams (dimensions in $\mathrm{mm}$ ) ……............................................... 31

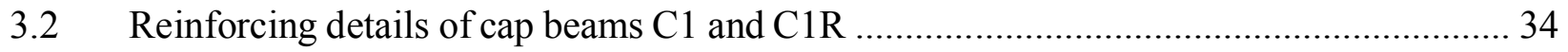

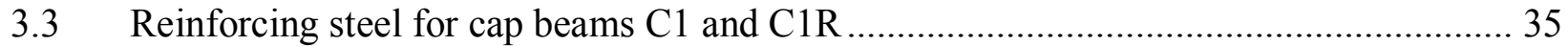

3.4 Reinforcing steel in south cantilever for cap beams C1 and C1R ................................... 35

3.5 Reinforcing steel in north cantilever for cap beams C1 and C1R .................................... 36

3.6 Details of $90^{\circ}$ hook anchorages for concentrated reinforcement layers ............................ 36 


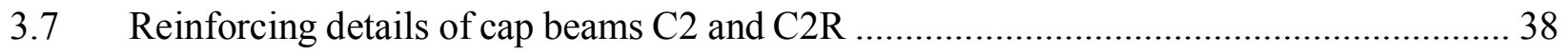

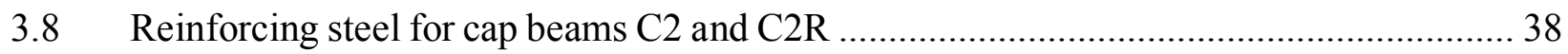

3.9 Reinforcing steel in south cantilever for cap beams C2 and C2R …….......................... 39

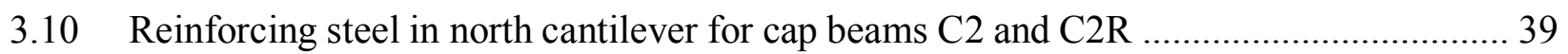

3.11 Top view of reinforcing steel for cap beams $\mathrm{C} 2$ and $\mathrm{C} 2 \mathrm{R}$................................................. 40

3.12 Placement of cap beams C1 and C1R in inverted position ........................................... 41

3.13 Formwork for casting cap beams in inverted position .................................................. 42

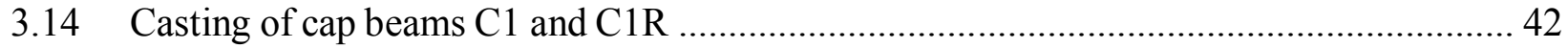

3.15 Typical concrete compressive stress-strain curve for batches 1 and 2 ............................. 45

3.16 Typical tensile stress-strain relationships for the reinforcing bars ................................... 46

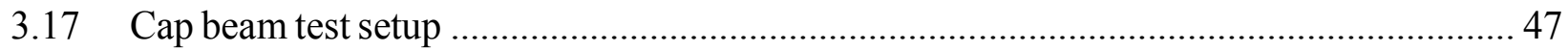

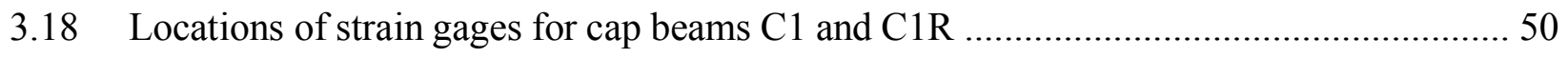

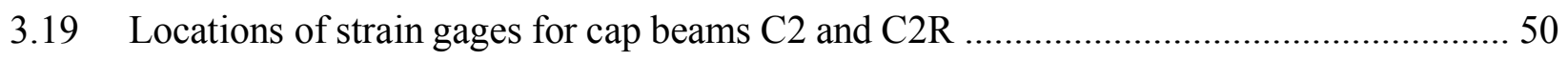

3.20 Locations of LVDTs for cap beams C1 and C1R ....................................................... 51

3.21 Locations of LVDTs for cap beams C2 and C2R ........................................................ 51

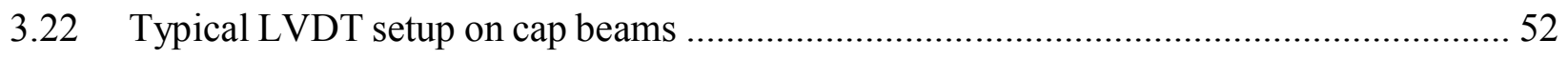

3.23 Shear clamps applied to the north cantilever of cap beam $\mathrm{C} 1$ …..................................... 53

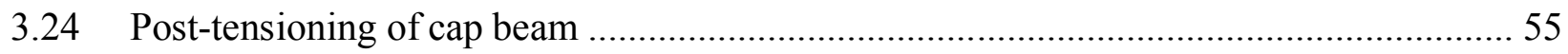

3.25 Jacking end (left) and dead end (right) for post-tensioning ............................................ 55

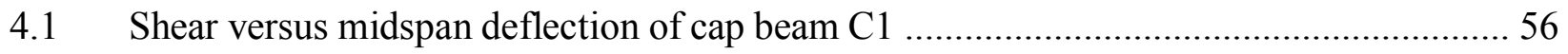

4.2 Shear failure of north cantilever of cap beam $\mathrm{C} 1$.......................................................... 57

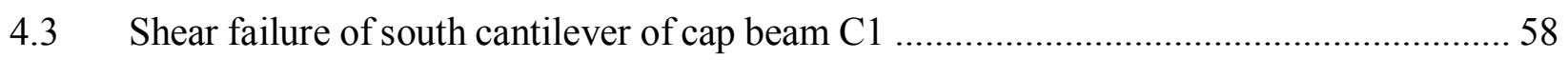

4.4 Shear versus maximum crack widths for north cantilever of cap beam C1 ..................... 59

4.5 Shear versus maximum crack widths for south cantilever of cap beam $\mathrm{C} 1$...................... 59

4.6 Crack pattern and widths at service loading for north cantilever of cap beam C1 ............ 60

4.7 Crack pattern and widths at service loading for south cantilever of cap beam C1 ........... 60

4.8 Average longitudinal strains measured along the centroid of the concentrated tension

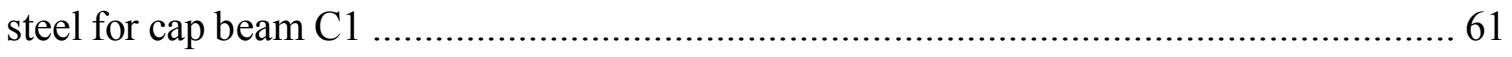

4.9 Shear versus average longitudinal strain on the south cantilever of cap beam C1 ............ 62

4.10 Shear versus average longitudinal strain on the north cantilever of cap beam C1 ............ 62

4.11 Shear versus strain for stirrups in north cantilever of cap beam C1 ................................ 64 
4.12 Shear versus strain for stirrups in south cantilever of cap beam $\mathrm{C} 1$.................................6 65

4.13 Shear versus compressive strain at re-entrant corners of cap beam $\mathrm{C} 1$...............................6 66

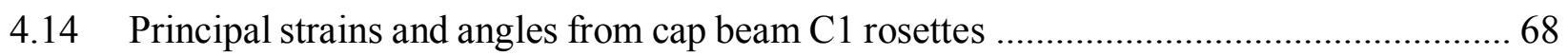

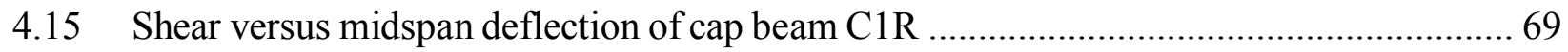

4.16 Shear failure of south cantilever of cap beam C1R ...................................................... 70

4.17 Shear failure of north cantilever of cap beam C1R ……............................................ 71

4.18 Shear versus maximum crack widths for north cantilever of cap beam C1R ................... 72

4.19 Shear versus maximum crack widths for south cantilever of cap beam C1R .................. 72

4.20 Crack pattern and widths at service loading for north cantilever of cap beam C1R ......... 73

4.21 Cracks at service loading after post-tensioning for north cantilever of cap beam C1R .... 73

4.22 Crack pattern and widths at service loading for south cantilever of cap beam C1R ......... 74

4.23 Cracks at service loading after post-tensioning for south cantilever of cap beam C1R .... 74

4.24 Average longitudinal strains measured along the centroid of the concentrated tension

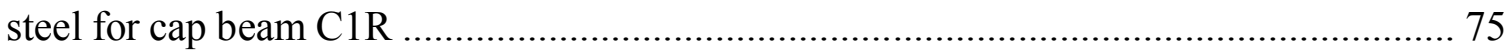

4.25 Shear versus average longitudinal strain in the south cantilever of cap beam C1R .......... 76

4.26 Shear versus average longitudinal strain in the north cantilever of cap beam C1R .......... 77

4.27 Shear versus strain for stirrups in north cantilever of cap beam C1R ………………...... 79

4.28 Shear versus strain for stirrups in south cantilever of cap beam C1R ………………...... 80

4.29 Shear versus compressive strain at re-entrant corners on cap beam C1R ....................... 81

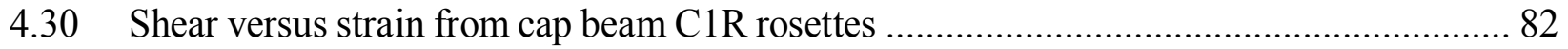

4.31 Shear versus total force in post-tensioning rods in cap beam C1R …………………...... 82

4.32 Shear versus midspan deflection of cap beam C2 ……............................................... 83

4.33 Shear failure of north cantilever of cap beam C2 …....................................................... 84

4.34 Shear distress and concrete crushing of south cantilever of cap beam C2 …................... 85

4.35 Shear versus maximum crack widths for north cantilever of cap beam C2 …................. 86

4.36 Shear versus maximum crack widths for south cantilever of cap beam $\mathrm{C} 2$ ….................. 86

4.37 Crack pattern and widths at service loading for north cantilever of cap beam C2 ........... 87

4.38 Crack pattern and widths at service loading for south cantilever of cap beam C2 ............ 87

4.39 Average longitudinal strains measured along the centroid of the concentrated tension

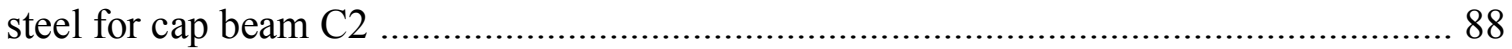

4.40 Shear versus average longitudinal strain in the south cantilever of cap beam C2 ............. 89 
4.41 Shear versus average longitudinal strain in the north cantilever of cap beam C2 _.......... 89

4.42 Shear versus strain for stirrups and inclined bars in north cantilever of cap beam C2 ..... 91

4.43 Shear versus strain for stirrups and inclined bars in south cantilever of cap beam C2 .... 92

4.44 Shear versus compressive strain at re-entrant corners on cap beam C2 ...................... 93

4.45 Buckling of primary compressive reinforcement on the north side of cap beam C2 _...... 94

4.46 Principal strains and angles from cap beam $\mathrm{C} 2$ rosettes .............................................. 95

4.47 Shear versus midspan deflection of cap beam C2R .................................................. 96

4.48 Shear failure of north cantilever of cap beam C2R .................................................. 97

4.49 Shear failure of south cantilever of cap beam C2R .................................................. 98

4.50 Shear versus maximum crack widths for north cantilever of cap beam C2R ................ 99

4.51 Shear versus maximum crack widths for south cantilever of cap beam C2R ............... 99

4.52 Crack pattern and widths at service loading for north cantilever of cap beam C2R ....... 100

4.53 Cracks at service loading after post-tensioning for north cantilever of cap beam C2R ... 100

4.54 Crack pattern and widths at service loading for south cantilever of cap beam C2R ....... 101

4.55 Cracks at service loading after post-tensioning for south cantilever of cap beam C2R ... 101

4.56 Average longitudinal strains measured along the centroid of the concentrated tension

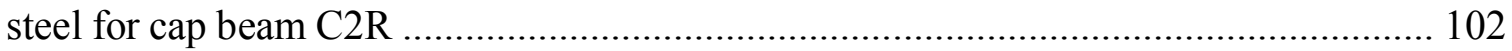

4.57 Shear versus average longitudinal strain in the south cantilever of cap beam C2R ........ 103

4.58 Shear versus average longitudinal strain in the north cantilever of cap beam C2R ........ 104

4.59 Shear versus strain for stirrups and inclined bars in north cantilever of cap beam $\mathrm{C} 2 \mathrm{R}$

4.60 Shear versus strain for stirrups and inclined bars in south cantilever of cap beam $\mathrm{C} 2 \mathrm{R}$

4.61 Shear versus compressive strain at re-entrant corners on cap beam C2R 108

4.62 Principal strains and angles from cap beam C2R rosettes ....................................... 110

4.63 Shear versus total force in post-tensioning rods in cap beam C2R ............................ 111

$5.1 \quad$ Shear-deflection response of cap beams ............................................................. 113

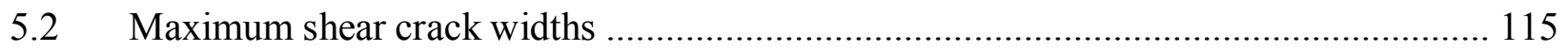

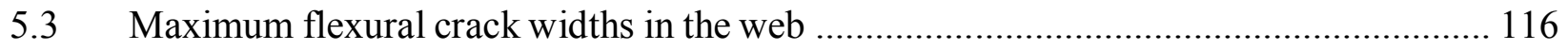

5.4 Maximum flexural crack widths in the primary tension reinforcement ...................... 117

5.5 Maximum horizontal splitting crack widths for $45^{\circ}$ inclined reinforcing bars in cap 
beams $\mathrm{C} 2$ and $\mathrm{C} 2 \mathrm{R}$ 118

5.6 Inclined reinforcement hook at primary tension steel layer on north side of $\mathrm{C} 2$

5.7 Inclined reinforcement hook at primary compression steel layer on north side of C2 .. 119

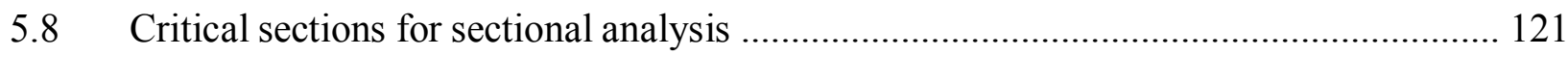

5.9 Strut-and-tie model of cap beam $\mathrm{Cl}$, with forces in $\mathrm{kN}$ and dimensions in $\mathrm{mm}$............. 126

5.10 Finite element model for cap beam C1 .................................................................. 129

5.11 Predicted cracking pattern for cap beam $\mathrm{C} 1$ at service loading .................................... 130

5.12 Predicted crack widths for cap beam $\mathrm{C} 1$ at service loading ............................................ 130

5.13 Predicted cracking pattern for cap beam $\mathrm{C} 1$ at failure ...................................................... 131

5.14 Predicted crack widths for cap beam $\mathrm{C} 1$ at failure ...................................................... 131

5.15 Predicted principal compressive stress for cap beam C1 at failure ............................... 132

5.16 Finite element model for cap beam C1R indicating applied post-tensioning force

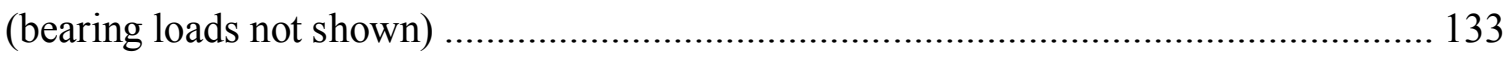

5.17 Predicted cracking pattern for cap beam C1R at service loading after post-tensioning ... 133

5.18 Predicted crack widths for cap beam C1R at service loading after post-tensioning ........ 134

5.19 Predicted cracking pattern for cap beam C1R at failure .............................................. 134

5.20 Predicted crack widths for cap beam C1R at failure ................................................. 135

5.21 Predicted principal compressive stress for cap beam C1R at failure .............................. 135

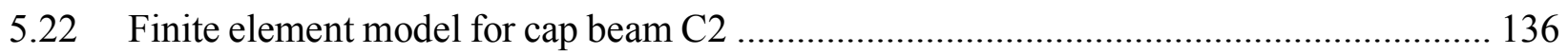

5.23 Predicted cracking pattern for cap beam C2 at service loading ..................................... 137

5.24 Predicted crack widths for cap beam C2 at service loading ......................................... 137

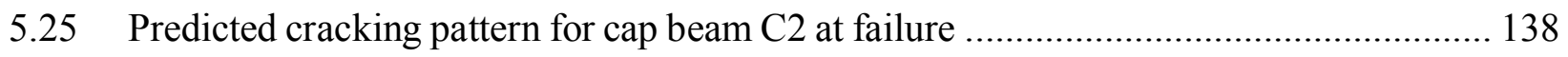

5.26 Predicted crack widths for cap beam C2 at failure ...................................................... 138

5.27 Predicted principal compressive stress for cap beam C2 at failure ............................... 139

5.28 Finite element model for cap beam C2R indicating applied post-tensioning force

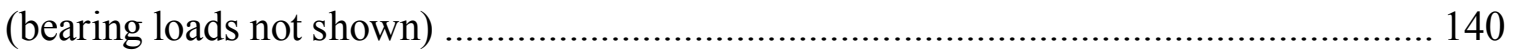

5.29 Predicted cracking pattern for cap beam C2R at service loading after post-tensioning ... 140

5.30 Predicted crack widths for cap beam C2R at service loading after post-tensioning ........ 141

5.31 Predicted cracking pattern for cap beam C2R at failure ............................................. 141

5.32 Predicted crack widths for cap beam C2R at failure ................................................... 142

5.33 Predicted principal compressive stress for cap beam C2R at failure ............................. 142 


\section{LIST OF TABLES}

1.1 Crack control reinforcement ratios in region of cap beams above piers ............................ 8

3.1 Comparison of the geometry of the existing Champlain Bridge and the test pier cap

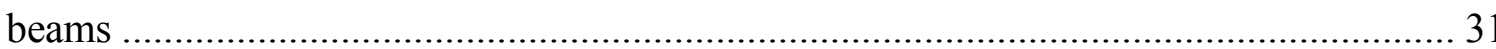

3.2 Reinforcement ratios of crack control reinforcement in the north and south cantilevers for pier caps $\mathrm{C} 1$ and $\mathrm{C} 1 \mathrm{R}$

3.3 Reinforcement ratios of crack control reinforcement in the north and south

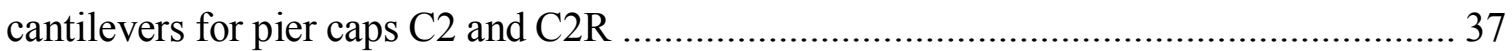

$3.4 \quad$ Concrete mix proportions …………………............................................................... 43

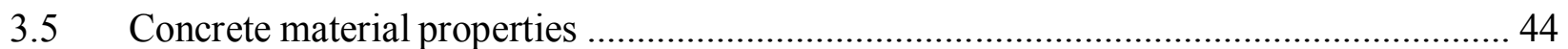

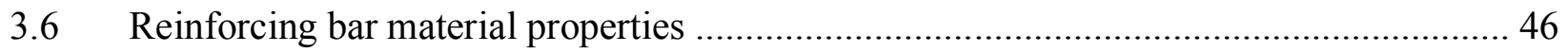

5.1 Comparison of peak shear and deflections between cap beams ..................................... 113

5.2 Comparison of predicted shear capacities from the sectional analysis with shear capacities achieved during testing .............................................................................. 124

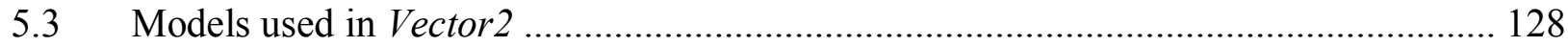

5.4 Comparison of predicted shear capacities from non-linear finite element analyses with shear capacities achieved during testing

5.5 Comparison of predicted maximum shear crack widths from the VecTor2 analysis with those observed during testing

5.6 Comparison of predicted maximum flexural web crack widths from the VecTor2 analysis with those observed during testing

5.7 Comparison of predicted maximum flexural crack widths in the region of concentrated tension reinforcement from the VecTor2 analysis with those observed during testing 


\section{LIST OF SYMBOLS}

\begin{tabular}{|c|c|}
\hline$a$ & shear span \\
\hline$A_{c, e f}$ & area of effective embedment zone \\
\hline$A_{c s}$ & effective cross-sectional area of a strut \\
\hline$a_{g}$ & maximum aggregate size \\
\hline$A_{p}$ & area of prestressing \\
\hline$A_{s}$ & area of reinforcing steel \\
\hline$A_{s}$ & area of effective steel in CEB-FIP crack spacing equation \\
\hline$A_{s t}$ & area of reinforcing steel required \\
\hline$A_{v}$ & area of transverse reinforcement \\
\hline$A_{v i}$ & area of inclined reinforcement \\
\hline$b_{v}$ & effective shear width \\
\hline$b_{w}$ & width of web \\
\hline$c$ & clear concrete cover \\
\hline$C$ & nominal applied compressive force in a strut \\
\hline$C_{f}$ & factored applied compressive force in a strut \\
\hline$C_{n}$ & nominal compressive resistance of a strut \\
\hline$C_{r}$ & factored compressive resistance of a strut \\
\hline$d$ & effective depth \\
\hline$d b$ & diameter of reinforcing bars \\
\hline$d_{v}$ & effective shear depth \\
\hline
\end{tabular}




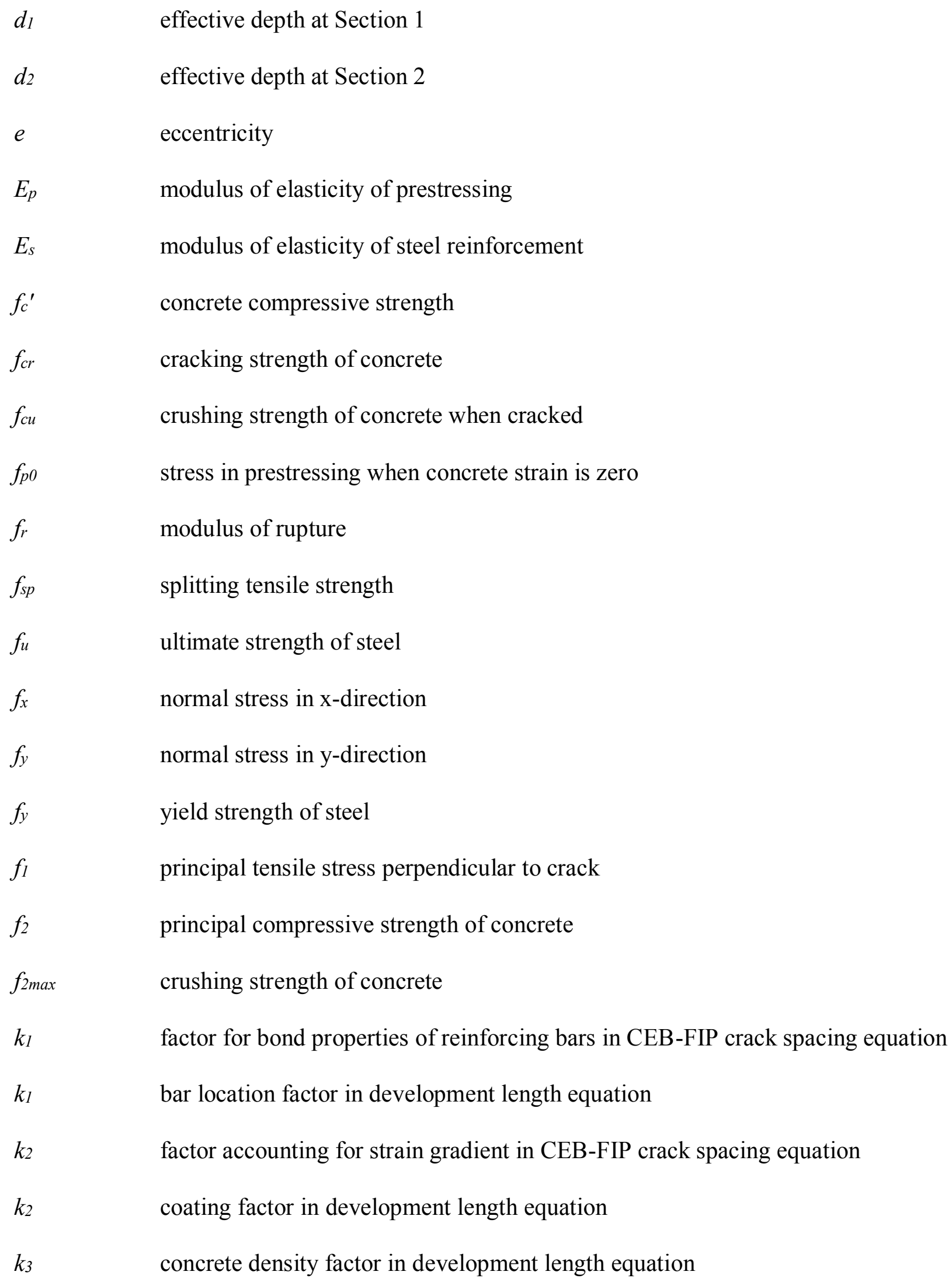




\begin{tabular}{|c|c|}
\hline$k_{4}$ & bar size factor in development length equation \\
\hline$l_{d}$ & development length \\
\hline$M$ & nominal applied moment \\
\hline$M_{f}$ & factored applied moment \\
\hline$N_{f}$ & factored applied axial load \\
\hline$P$ & nominal applied load at support \\
\hline$P$ & external unbonded post-tensioning force \\
\hline$s$ & maximum spacing of longitudinal/transverse reinforcement \\
\hline$s_{i}$ & spacing of inclined reinforcement \\
\hline$S m$ & average crack spacing \\
\hline$S_{\max }$ & maximum spacing \\
\hline$S_{\min }$ & minimum spacing \\
\hline$s_{z}$ & crack spacing \\
\hline$s_{z e}$ & effective crack spacing \\
\hline$T$ & nominal applied tensile force in a tie \\
\hline$T_{f}$ & factored applied tensile force in a tie \\
\hline$T_{n}$ & nominal tensile resistance of a tie \\
\hline$T_{r}$ & factored tensile resistance of a tie \\
\hline$v$ & shear stress \\
\hline V & nominal shear resistance \\
\hline$V_{c}$ & concrete contribution to shear strength \\
\hline$v_{c i}$ & shear across crack \\
\hline$V_{f}$ & factored applied shear force \\
\hline
\end{tabular}




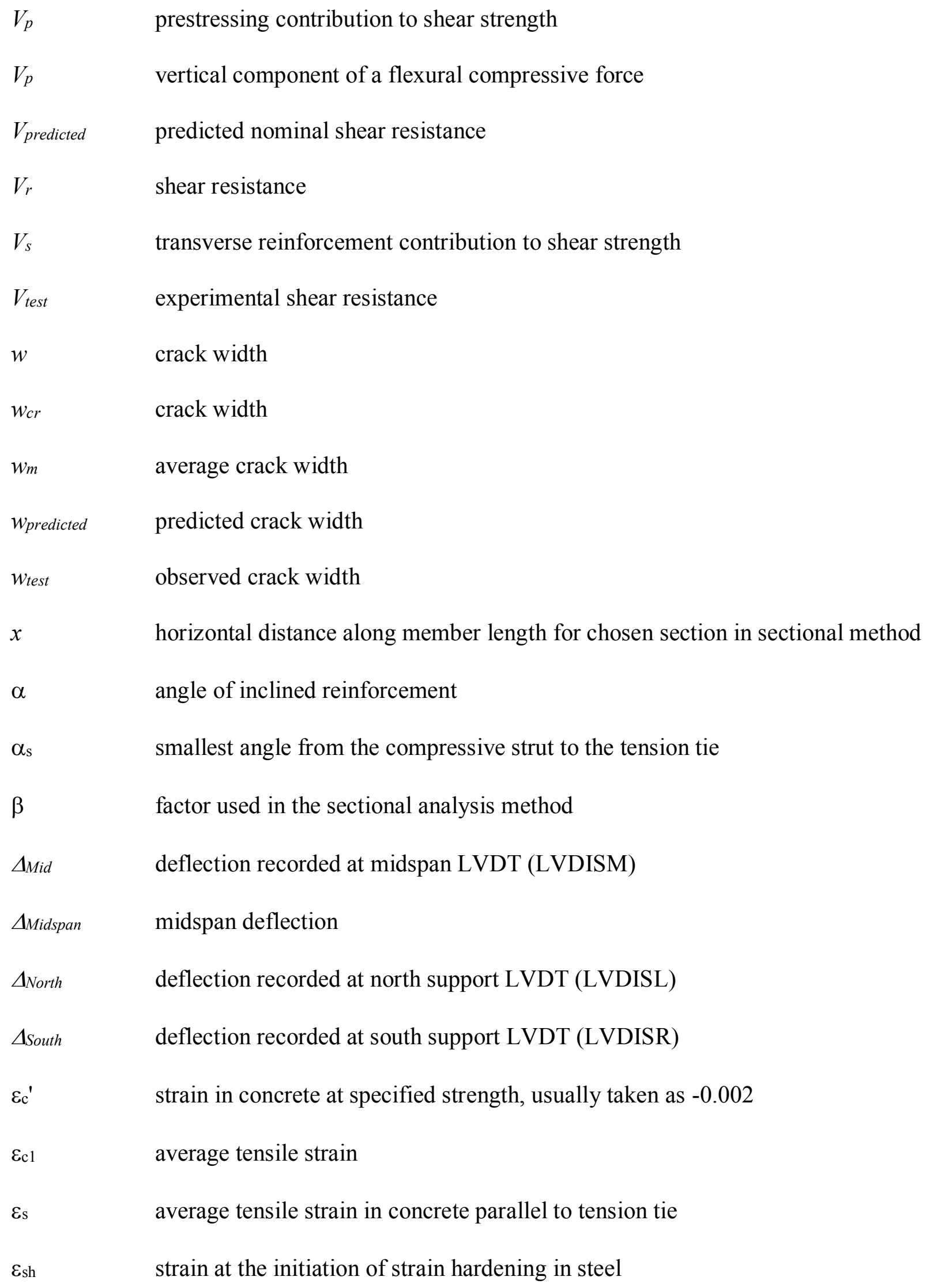


strain at ultimate strength of steel

longitudinal strain

$45^{\circ}$ diagonal strain measured by LVD1 and LVD2

normal strain in y-direction

yielding strain of steel

principal tensile strain (perpendicular to crack)

largest tensile strain in the effective embedment zone

principal compressive strain (parallel to crack)

smallest tensile strain in the effective embedment zone

material resistance factor for concrete

material resistance factor for prestressing

material resistance factor for reinforcing steel

shear strain

angle of strut in truss model

principal angle

reinforcement ratio

effective reinforcement ratio

reinforcement ratio of horizontal steel

reinforcement ratio of vertical steel 


\section{CHAPTER 1}

\section{INTRODUCTION}

\subsection{Introduction}

The existing Champlain Bridge was constructed from 1957-1962 as a crucial link to the city of Montréal, Canada, over the St. Lawrence River. In a 2011 investigation the bridge was found to be "functionally deficient" for both current and future volumes of traffic, with several elements of the bridge such as the pier caps in their unrepaired state deemed in 'poor' condition (Delcan, 2011). This thesis is a study of certain features of two pier cap beam designs used in the existing Champlain Bridge.

\subsection{Existing Champlain Bridge Pier Caps}

\subsubsection{Type 04A Pier Cap Detailing}

Figures 1.1 and 1.2 illustrate the geometry and reinforcing details of a type 04A pier cap beam of the existing Champlain Bridge, as originally designed and constructed. These design drawings were provided by Les Ponts Jacques Cartier et Champlain Incorporée (PJCCI), which also provided funding for this research program. The design details shown in these drawings were used for the construction of the piers in section 5 and $7 \mathrm{~A}$ except for piers $37 \mathrm{~W}$ to $43 \mathrm{~W}$. The specified 28-day concrete compressive strength was 3500 psi (24.1 MPa).

The overall length of the pier cap beam is $77^{\prime}-5$ " $(23.6 \mathrm{~m})$ and cantilevers out from the pier supports by a distance of 26'-6" (8.077 $\mathrm{m})$ on either side. The cap beam has a uniform thickness of 6'-4" (1930 mm). The top surface of the cap beam is sloped downwards along the length from the centerline of the pier, and also sloped in the perpendicular direction for drainage. The bottom faces of the cantilevers have constant slopes of 1:4, resulting in a depth of 4'-11.2" (1503 $\mathrm{mm})$ at the cap beam ends increasing to a depth of 11'-6" (3507 mm) at the pier supports. 
The cap beam has primary longitudinal tension reinforcement located along the top of the beam consisting of four layers of \#18 reinforcing bars. These bars have several cut-off locations as can be seen in Figure 1.1, and some of the bars at the cantilever ends are anchored with 90 degree bend hooks. At the critical section located at the face of the support there are a total of 38 \#18 bars distributed in four layers. The transverse reinforcement consists of stirrups located throughout the cantilevered spans in two different design regions. The region within a distance of $3.4 \mathrm{~m}$ from the support face is more critical and hence has more densely spaced stirrups. The design consists of alternating sets of 14 legs of \#6 bars and sets of 10 legs of \#6 bars, each with a spacing varying from 11 to $13 \mathrm{in.} \mathrm{(279} \mathrm{to} 330 \mathrm{~mm}$ ). This stirrup arrangement can be averaged as 12 legs of \#6 bars at a spacing varying from 5.5 and 6.5 in. (140 to $165 \mathrm{~mm}$ ). Outside of this region the same stirrups are used but at a spacing varying from 15 to 20 in. (381 to $508 \mathrm{~mm}$ ). Similarly, this stirrup arrangement can be averaged to 12 legs of \#6 bars at a spacing varying from 7.5 to 10.0 in. (191 to $254 \mathrm{~mm}$ ). The uniformly distributed longitudinal reinforcement consists of $8 \# 8$ bars and $4 \# 4$ bars that are slightly inclined. 


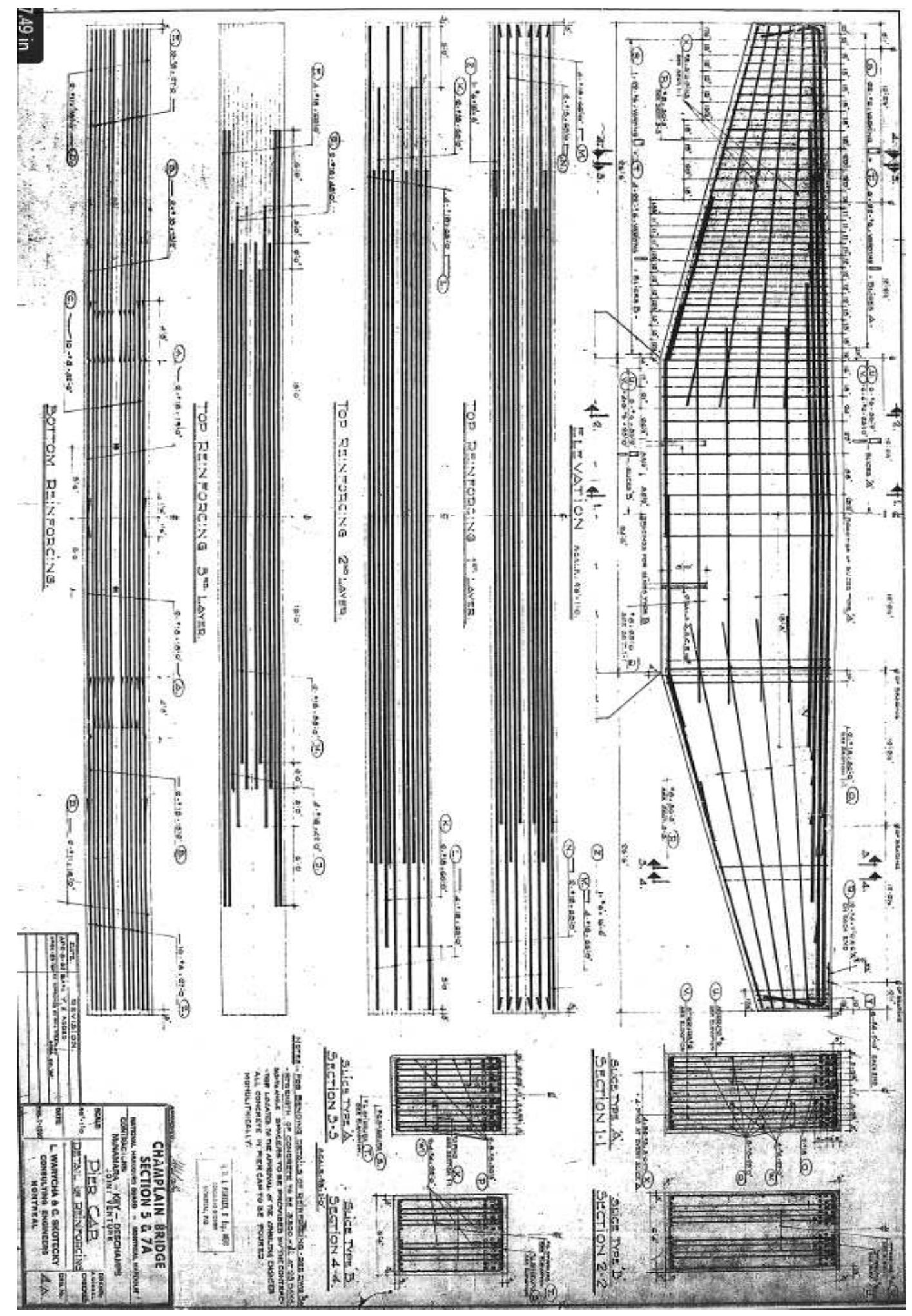

Figure 1.1: Drawing 12942-EE-4A - Reinforcement and bearing details for pier cap type 04A for sections 5 and 7A (PJCCI, 1960) 


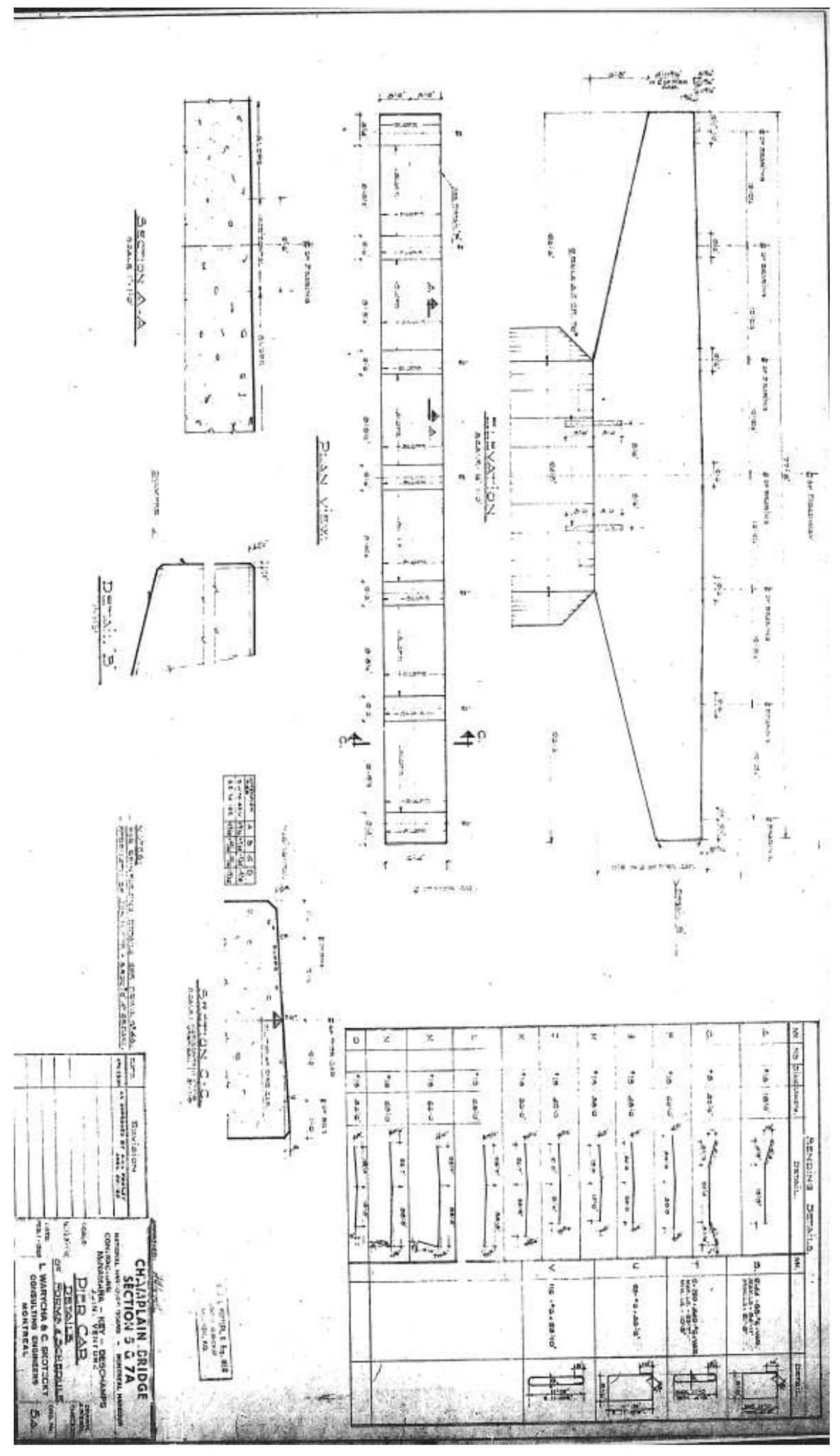

Figure 1.2: Drawing 12942-EE-5A - Elevation view of pier cap type 04A for sections 5 and 7A (PJCCI, 1960) 


\subsubsection{Type 168 Pier Cap Detailing}

Figure 1.3 shows the original drawings for pier cap type 168, used for the design of pier cap beams 11E, 12E, and 13E. The general notes of drawing 12942-L-167 indicate a specified 28-day concrete compressive strength of $3500 \mathrm{psi}(24.1 \mathrm{MPa})$, same as for the type 04A pier caps. Additionally, the general geometry of these pier caps is consistent with type 04A. In terms of shear reinforcement, the type 168 design uses inclined reinforcement bars in tandem with conventional stirrups. Although Figure 1.3 indicates that square reinforcing bars are to be used for the inclined reinforcement, there is a note indicating that the 1-1/4 in. and 2 in. square bars are equivalent to \#11 and \#18 bars, respectively. A study of the photographs of the rehabilitation of piers 11E, 12E, and 13E indicate that \#11 bars and \#18 deformed bars were used for the flexural and inclined reinforcement (Mitchell, 2018).

The primary longitudinal tensile reinforcement in the top of the beam at the pier interface consists of three layers of \#18 reinforcing bars. These bars have several cut-off locations as can be seen in Figure 1.3. At the critical section located at the face of the support there are a total of 36 \#18 bars placed in three layers, with 12 bars placed in each layer. The vertical stirrup design in the cantilever portions of the pier cap consists of 10 legs of \#6 bars evenly distributed through the cantilever at a spacing of $7 \mathrm{in.}(178 \mathrm{~mm})$. In addition, six pairs of \#18 inclined bars were provided for a length of about $2 / 3$ of the cantilever, with an additional two pairs of \#11 inclined bars provided in the remaining end portion of each cantilever. The uniformly distributed longitudinal reinforcement is the same as in the type 04A design, and the effective amount of transverse reinforcement in this type 168 design is $90 \%$ of the type $04 \mathrm{~A}$ effective stirrups. Additional vertical post-tensioned reinforcement provided in type 04 cap beams was not provided in the Type 168 cap beams. 


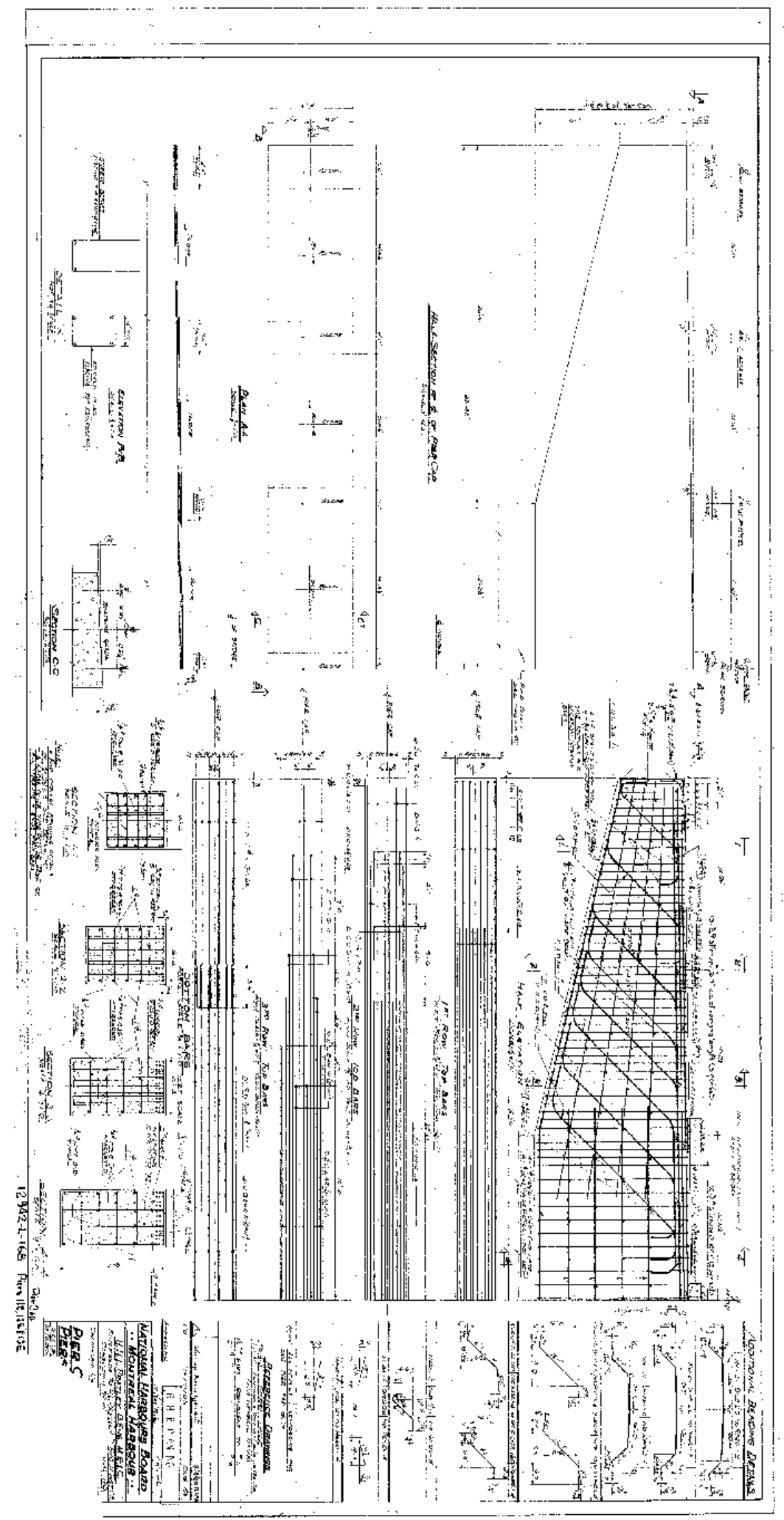

Figure 1.3: Drawing 12942-L-168 - Reinforcement and bearing details for pier cap Type 168 in Section 7B (PJCCI, 1960) 


\subsubsection{Observed Distress in Pier Cap Beams}

Figure 1.4 shows the observed damage in pier cap 36W. Significant inclined shear cracking can be seen in the cantilevered portion of the cap beam in addition to significant vertical flexural cracking and delamination of the concrete cover. Figure 1.5 demonstrates the flexural cracking damage observed on pier cap $21 \mathrm{~W}$. This flexural cracking damage can be seen in the central region above the piers as well as just below the concentrated \#18 reinforcement layers where there was little crack control reinforcement. Table 1.1 summarizes the amount of crack control reinforcement in the vertical and horizontal directions at the region of the cap beams above the piers. It is noted that the 2014 Canadian Highway Bridge Design Code (CSA 2014) requires a reinforcement ratio, $\rho$, of 0.003 in both directions. Table 1.1 demonstrates that only the vertical stirrup reinforcement in pier caps type 04A had adequate crack control reinforcement in accordance with current standards.

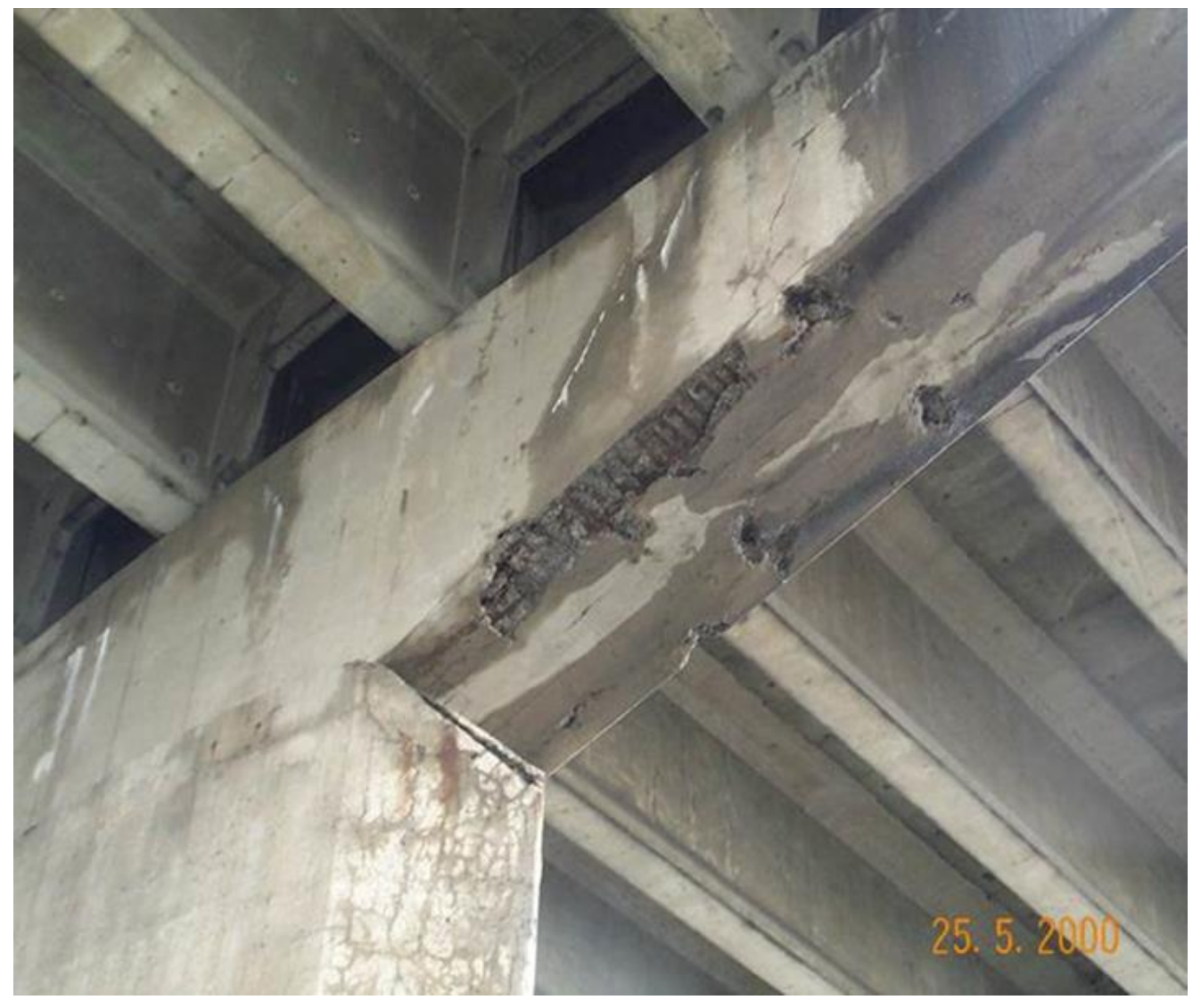

Figure 1.4: Flexural cracks, shear cracks and concrete delamination in pier cap $36 \mathrm{~W}$ in 2000 (courtesy of PJCCI) 


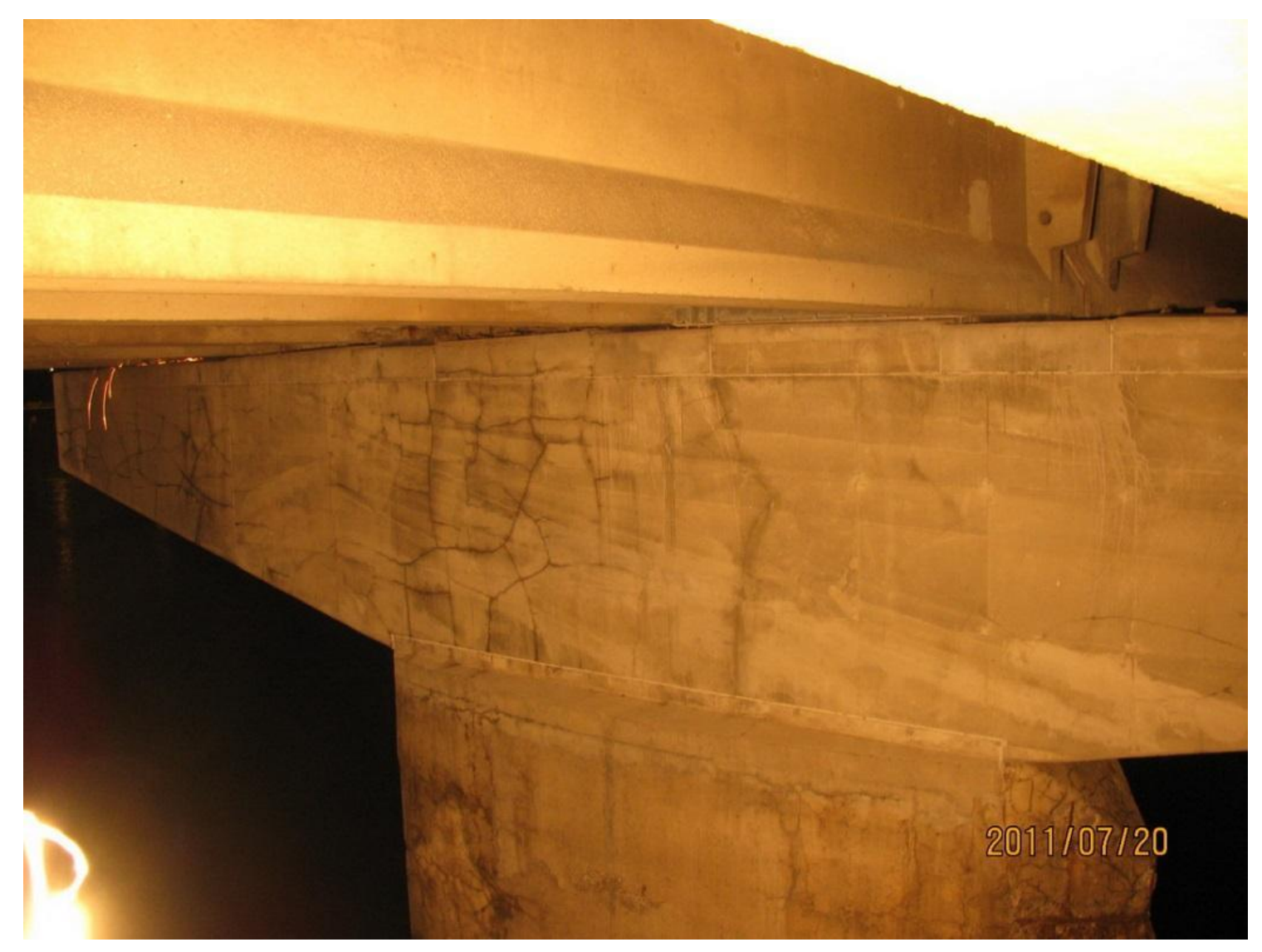

Figure 1.5: Flexural cracking in pier cap $21 \mathrm{~W}$ in 2011 (courtesy of PJCCI)

Table 1.1: Crack control reinforcement ratios in region of cap beams above piers

\begin{tabular}{|c|c|c|}
\hline Type & $\begin{array}{c}\text { Stirrups } \\
\rho_{v}\end{array}$ & $\begin{array}{c}\text { Horizontal bars } \\
\rho_{h}\end{array}$ \\
\hline 04A & 0.00573 & 0.00092 \\
\hline 168 & 0.00193 & 0.00104 \\
\hline
\end{tabular}




\subsection{Research Objectives}

The objectives of this research program were to study several features of the type $04 \mathrm{~A}$ and type 168 pier cap beams used in the existing Champlain Bridge. These objectives were to:

1. Examine the behavior of pier cap beam cantilevers of variable depth.

2. Develop predictions of the flexural strength and the shear strength.

3. Examine the performance of crack control reinforcement.

4. Study the effectiveness of inclined reinforcement.

5. Study the effectiveness of the horizontal post-tensioning retrofit.

6. Compare analyses predictions using the sectional design approach, strut-and-tie models, and by non-linear finite element analyses. 


\section{CHAPTER 2}

\section{LITERATURE REVIEW}

\subsection{Sectional Analysis Method}

Before the 1984 Canadian Standards Association (CSA) A23.3 Standard, shear design was largely performed based upon provisions set by the American Concrete Institute (ACI, 1983). The traditional ACI code approach for shear design considered a concrete contribution, $\mathrm{V}_{\mathrm{c}}$, and a contribution from the stirrups, $\mathrm{V}_{\mathrm{s}}$. The concrete contribution was determined from empirical expressions representing the concrete cracking shear. To determine the shear carried by the stirrups, the ACI code assumed an angle of principal compression, $\theta$, of $45^{\circ}$. This angle was allowed to vary based off Kupfer's (1964) variable-angle truss model assuming both the reinforcement and concrete were linearly elastic.

The 1984 CSA A23.3 Standard proposed a sectional analysis method that differed from the traditional ACI methodology. This "General Method" was based off of the Compression Field Theory developed by Mitchell and Collins (1974) for pure torsion, which analyzed the behavior of concrete once cracked where it no longer behaves elastically. This theory is based off the assumption that the principal tensile stress, $f_{l}$, in the concrete after cracking was negligible. The angle of principal compression was allowed to vary between $15-75^{\circ}$ at the discretion of the designer, though an upper bound to $\theta$ was given based off of when the principal compressive stress in the concrete, $f_{2}$, reaches its crushing strength, $f_{2, \max }$ (Collins and Mitchell, 1986).

The Modified Compression Field Theory (MCFT) introduced by Vecchio and Collins (1986) involved analyzing the stress-strain relationships of cracked concrete, taking into account the tensile stress behavior between cracks previously assumed to be negligible. This theory was first implemented into the General Method in the 1994 CSA A23.3 Standard and has become fundamental to modern shear design. 
The MCFT was able to determine the relationship between strains and stresses by making the key assumption that the concrete and reinforcement were perfectly bonded, thus having equal strain. It also assumes that average stress and strain values can be used if taken over a large area with multiple cracks (Vecchio and Collins, 1986). A Mohr circle was derived for each of the compatibility conditions and equilibrium conditions, which were then used to relate the normal strains and stresses to the principal strains and stresses (see Figure 2.2(a)). The normal strains are designated $\varepsilon_{\mathrm{x}}$ and $\varepsilon_{\mathrm{y}}$ and signify the strain in the concrete in the plane $\mathrm{x}-\mathrm{y}$ directions. Principal strains $\varepsilon_{1}$ and $\varepsilon_{2}$ are then strains oriented with respect to the crack angle $\theta$, where $\varepsilon_{1}$ is the strain perpendicular to the direction of principal compression and $\varepsilon_{2}$ is the strain parallel to the direction of principal compression (see Figure 2.1). Each strain then has a corresponding stress, designated $f_{x}, f_{y}, f_{1}$, and $f_{2}$, with a separate Mohr circle as shown in Figure 2.2(b). Assuming a linear stress-strain relationship until yielding and that the principal strain and stress angles are equal, some fundamental equations were derived:

$$
\begin{aligned}
& f_{2}=f_{2 \max }\left[\frac{2 \varepsilon_{2}}{\varepsilon_{c}^{\prime}}-\left(\frac{\varepsilon_{2}}{\varepsilon_{c}^{\prime}}\right)^{2}\right] \\
& f_{1}=\frac{f_{c r}}{1+\sqrt{500 \varepsilon_{1}}} \\
& \varepsilon_{1}=\varepsilon_{x}+\left(\varepsilon_{x}-\varepsilon_{2}\right) \cot ^{2} \theta
\end{aligned}
$$

where: $f_{1} \quad=$ average tensile stress after cracking. Before cracking $f_{l}=E_{c} \varepsilon_{l}$.

$f_{2}=$ principal compressive strength of concrete

$f_{2, \max }=$ crushing strength of concrete

$f_{c r} \quad=$ cracking strength of concrete, taken as $0.33\left(f_{c}^{\prime}\right)^{1 / 2}$

$\varepsilon_{c^{\prime}}=$ strain in concrete at specified strength, usually taken as -0.002

These equations are based upon average values and thus do not give any indication as to the shear stresses on the crack. Walraven (1981) analyzed the cracking behavior of concrete and developed an equation to determine the shear stress across a crack, $v_{c i}$, as:

$$
v_{c i}=\frac{0.18 \sqrt{f_{c}^{\prime}}}{0.31+24 w /\left(16+a_{g}\right)} \quad(\text { MPa and } \mathrm{mm})
$$


This equation is based on the concrete compressive strength $\left(f_{c}^{\prime}\right)$, the average crack width $(w)$, and also the maximum aggregate size $(a g)$. Concrete cracks typically form along the weaker interface between the cement paste and aggregates, forming rough, jagged cracks (see Figure 2.3). Thus, this phenomenon of aggregate interlock creates shear stresses and must be taken into account.

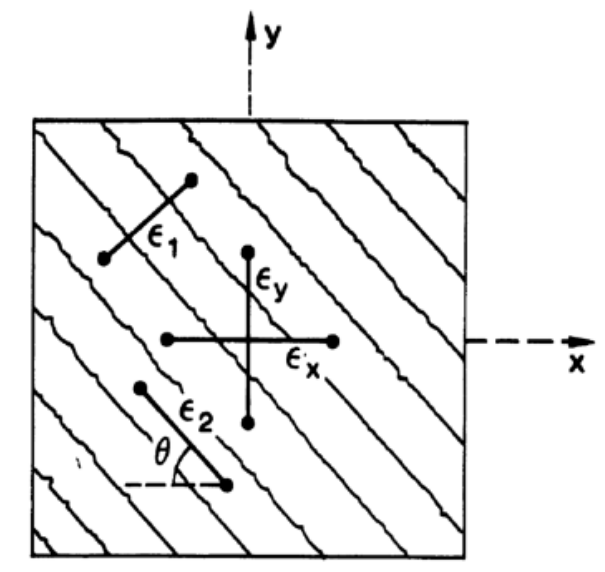

Figure 2.1: Average strains in cracked concrete element (Vecchio and Collins, 1986)

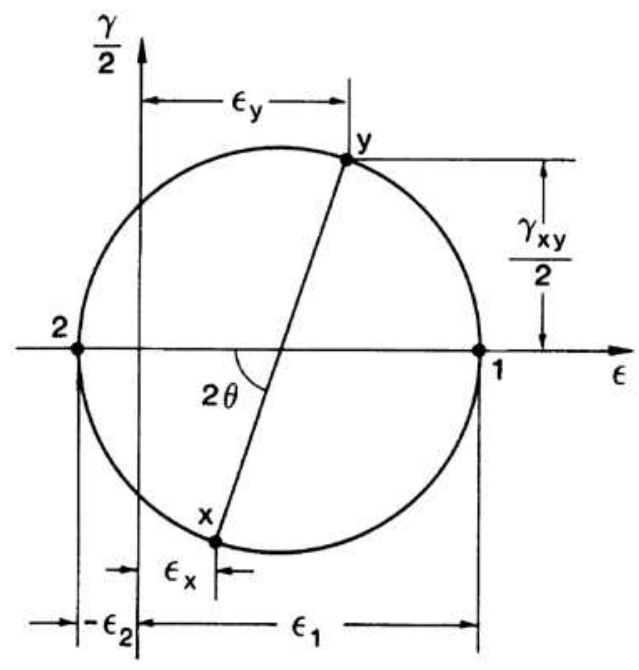

(a) Average strain

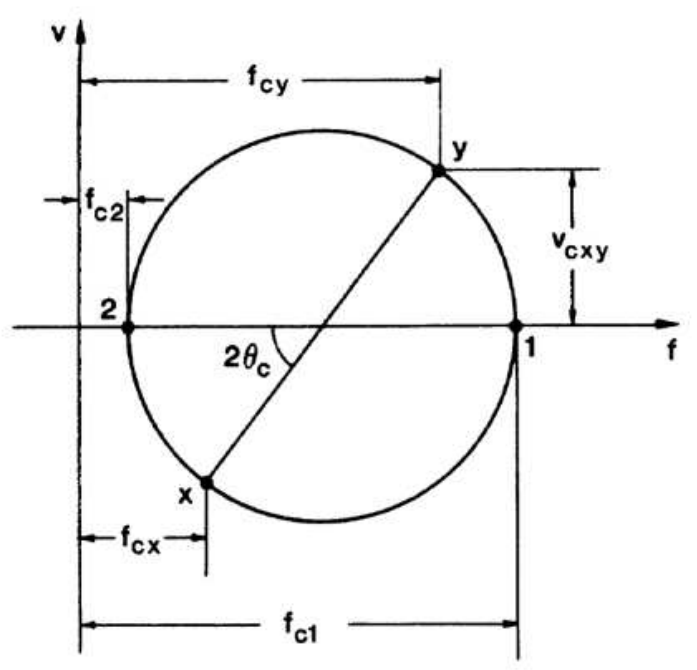

(b) Average stress

Figure 2.2: Mohr's circle for average strains and stresses (Vecchio and Collins, 1986) 


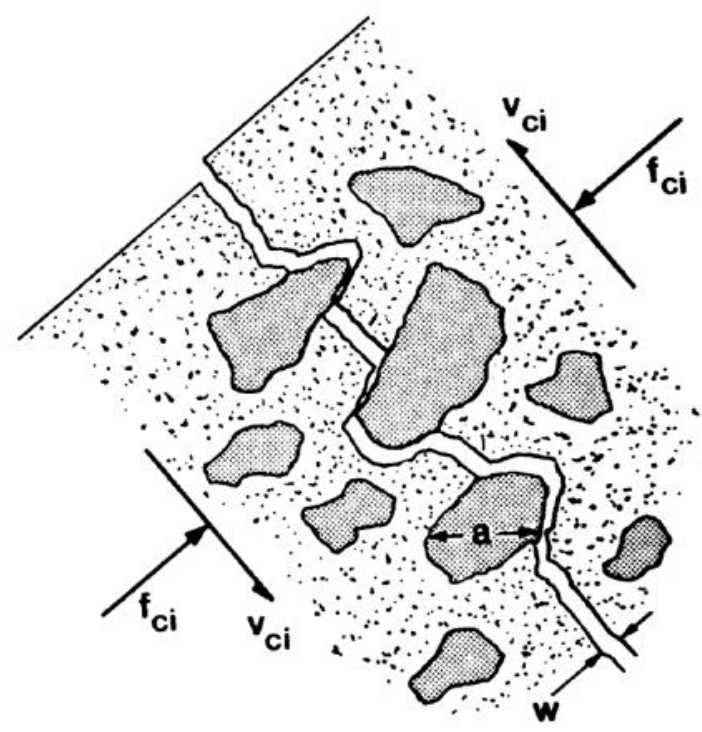

Figure 2.3: Shear stresses transmitted across a crack via aggregate interlock

(Vecchio and Collins, 1986)

The MCFT was first developed into a practical shear design method by Collins and Mitchell (1991) which was subsequently used in the CSA A23.3 1994 Standard and later editions. It has been implemented in several codes including the AASHTO LRFD (2014) and the Canadian Highway Bridge Design Code (CSA, 2014). This paper will focus on the current CSA S6-14 Canadian Highway Bridge Design Code (CSA, 2014) requirements.

Collins et al. (1996) and Bentz and Collins (2006) describe the shear design equations used in detail. The shear resistance of a member, $V_{r}$, is given by,

$$
V_{r}=V_{c}+V_{s}+V_{p}
$$

Where $V_{c}, V_{s}$, and $V_{p}$ are the shear contribution of the concrete, transverse reinforcement, and vertical component of prestressing, respectively. This is shown in a free body diagram in Figure 2.4. The $V_{c}$ and $V_{s}$ contributions are determined by:

$$
\begin{aligned}
& V_{c}=f_{1} b_{v} d_{v} \cot \theta \\
& V_{s}=\frac{f_{y} A_{v} d_{v} \cot \theta}{s}
\end{aligned}
$$


Where $b_{v}$ and $d_{v}$ are the effective shear width and depth, respectively, $f_{y}$ is the reinforcement yield strength, and $A v$ and $s$ are the area and spacing of the transverse reinforcement. Using an effective area $b_{v} d_{v}$ for the concrete assumes that the shear stress over this area is uniform. This was shown to be an adequate, slightly conservative assumption by Vecchio and Collins (1988). The effective shear depth $d_{v}$ is usually taken as $0.9 d$, where $d$ is the effective depth from the top compressive surface to the centroid of the bottom tensile steel. This reduction is performed due to the top surface resisting little to no shear stress. From Equation 2.2, $V_{c}$ is simplified to:

$$
V_{c}=\beta \sqrt{f_{c}^{\prime}} b_{v} d_{v}
$$

where:

$$
\beta=\frac{0.33 \cot \theta}{1+\sqrt{500 \varepsilon_{1}}} \quad(\text { MPa and } \mathrm{mm})
$$

The principal strain $\varepsilon_{1}$ is determined from Equation 2.3, where the longitudinal strain $\varepsilon_{\mathrm{x}}$ is calculated as:

$$
\varepsilon_{x}=\frac{\frac{M_{f}}{d_{v}}+V_{f}-V_{p}+0.5 N_{f}-A_{p} f_{p 0}}{2\left(A_{s} E_{S}+A_{p} E_{p}\right)}
$$

where: $M_{f} \quad=$ factored applied moment

$V_{f} \quad=$ factored applied shear

$N_{f} \quad=$ factored applied axial load

$A_{p} \quad=$ area of prestressing steel

$A_{s} \quad=$ area of reinforcing steel

$f_{p 0}=$ stress in prestressing when concrete strain is zero

$E_{p} \quad=$ modulus of elasticity of prestressing

$E_{s} \quad=$ modulus of elasticity of steel

Before the 2004 CSA A23.3 Standard the $V_{f}$ in the longitudinal strain parameter equation was instead $0.5 V_{f} \cot \theta$. This was conservatively assumed to be equal to $V_{f}$ so as to remove $\theta$ from the equation and correspondingly the requirement for iterations (Bentz and Collins, 2006). Additionally, $V_{f}, N_{f}$, and $M_{f}$ are calculated at the section being analyzed at a chosen $x$ distance 
along the member length (see Figure 2.4). The first location to check is at a length $d_{v}$ from the face of a support or bearing area. As noted by Collins et al. (1996), when a shear failure is caused by yielding of stirrups, the longitudinal reinforcement will generally yield over an approximate length of $0.5 d_{v} \cot \theta$. Assuming that $0.5 \cot \theta$ is approximately equal to one, the critical shear section will be about a length $d_{v}$ from the face of a bearing or support area.

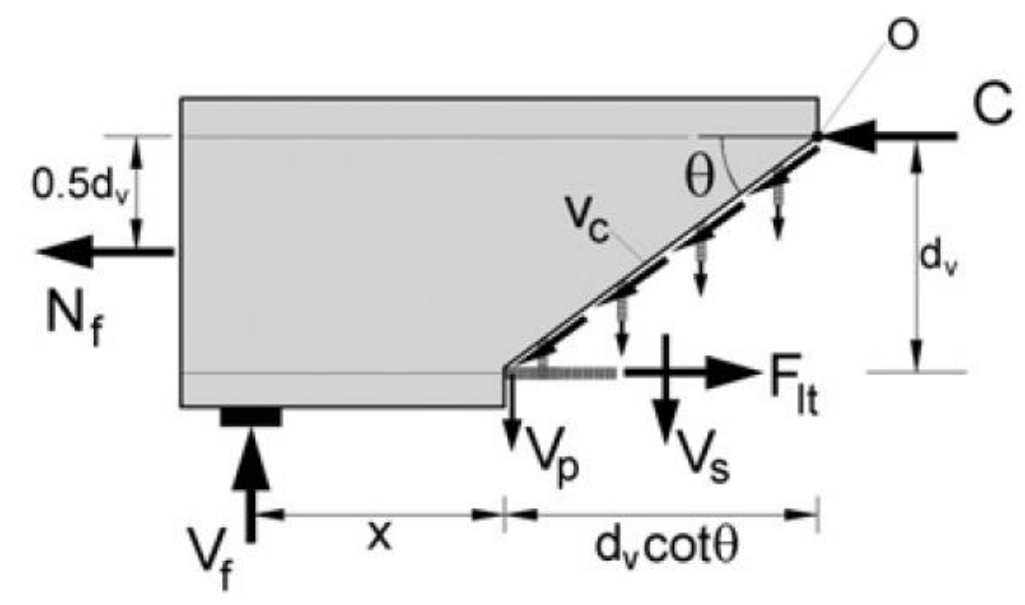

Figure 2.4: Free body diagram of shear resistance contributions (Bentz and Collins, 2006)

Considerable research has been carried out in determining the $\theta$ and the corresponding $\beta$ value. Collins et al. (1996) proposed a tabulated approach, where for members with web reinforcement, different values of $\nu / f_{c}^{\prime}$ and $\varepsilon_{\mathrm{x}}$ would give corresponding $\theta$ and $\beta$ values. The values were chosen so that the stirrup strain was at least greater than 0.002 while ensuring that the crushing strength, $f_{2, \max }$, was not exceeded. The longitudinal strain $\varepsilon_{\mathrm{x}}$ would be determined from Equation 2.10, and the shear stress, $v$, from,

$$
v=\frac{V_{r}-V_{p}}{b_{v} d_{v}}
$$

This tabulated approach also ensured $\beta$ did not exceed Equation 2.4 divided by $\sqrt{f_{c}^{\prime}}$. A maximum aggregate size of $19 \mathrm{~mm}$ and crack spacing of $305 \mathrm{~mm}$ were deemed adequate. For members without web reinforcement the crack spacing assumption was found to be non-conservative as typically the crack spacing was wider for these members. As such a separate table was formed for members without web reinforcement dependent on the longitudinal strain $\varepsilon_{\mathrm{x}}$ and the crack 
spacing, $s_{z}$. The crack spacing could be approximated as the critical shear depth $d_{v}$. This approximation was made to take into account the size effect, where the crack spacing of a member increases almost proportionally with the depth of the member (Shioya et al., 1990). For a member with a maximum aggregate size, ag, different from the assumed $19 \mathrm{~mm}$ a correction factor could be applied to find the effective crack spacing, $s_{z e}$ :

$$
S_{z e}=S_{z} \frac{35}{15+a_{g}}
$$

Though $s_{z e}$ should not be taken as less than $0.85 s_{z}$ (Bentz and Collins, 2006). This tabulated approach of determining $\theta$ and $\beta$ was incorporated into the 1994 CSA A23.3 Standard, among others.

For the 2004 CSA A23.3 Standard, Bentz and Collins (2006) derived straightforward equations for determining $\theta$ and $\beta$ that would replace the aforementioned tabular approach. Looking first at $\beta$, an equation independent of $\theta$ was desired. Assuming an effective crack spacing of $300 \mathrm{~mm}$ and the absence of transverse reinforcement, the relationship between the crack width $w$ and longitudinal strain $\varepsilon_{\mathrm{x}}$ was determined based on Equation 2.4 for members with varying compressive strengths. From this analysis a simplified crack width equation was determined,

$$
w=0.2+1000 \varepsilon_{x}
$$

This crack width equation was graphed relative to the MCFT crack width-longitudinal strain relationship in Figure 2.5. Substituting this equation into Equation 2.4 gives,

$$
v_{c i}=\frac{0.4 \sqrt{f_{c}^{\prime}}}{1+1500 \varepsilon_{x}}
$$

for a compressive strength in MPa units. Thus, an equation for $\beta$ was derived from Equation 2.14 with an additional size correction factor to accommodate a member with an effective crack spacing greater than $300 \mathrm{~mm}$. The equation formulated was,

$$
\beta=\frac{0.4}{1+1500 \varepsilon_{x}}\left(\frac{1300}{1000+s_{z e}}\right)
$$


Figure 2.5 gives some insight as to the usability of this $\beta$ equation. This equation only works for longitudinal strains larger than $-0.2 \times 10^{-3}$, as values lower than this result in negative crack widths. Additionally, it is important to note that at high longitudinal strains the crack width equation becomes very conservative when compared to the MCFT.

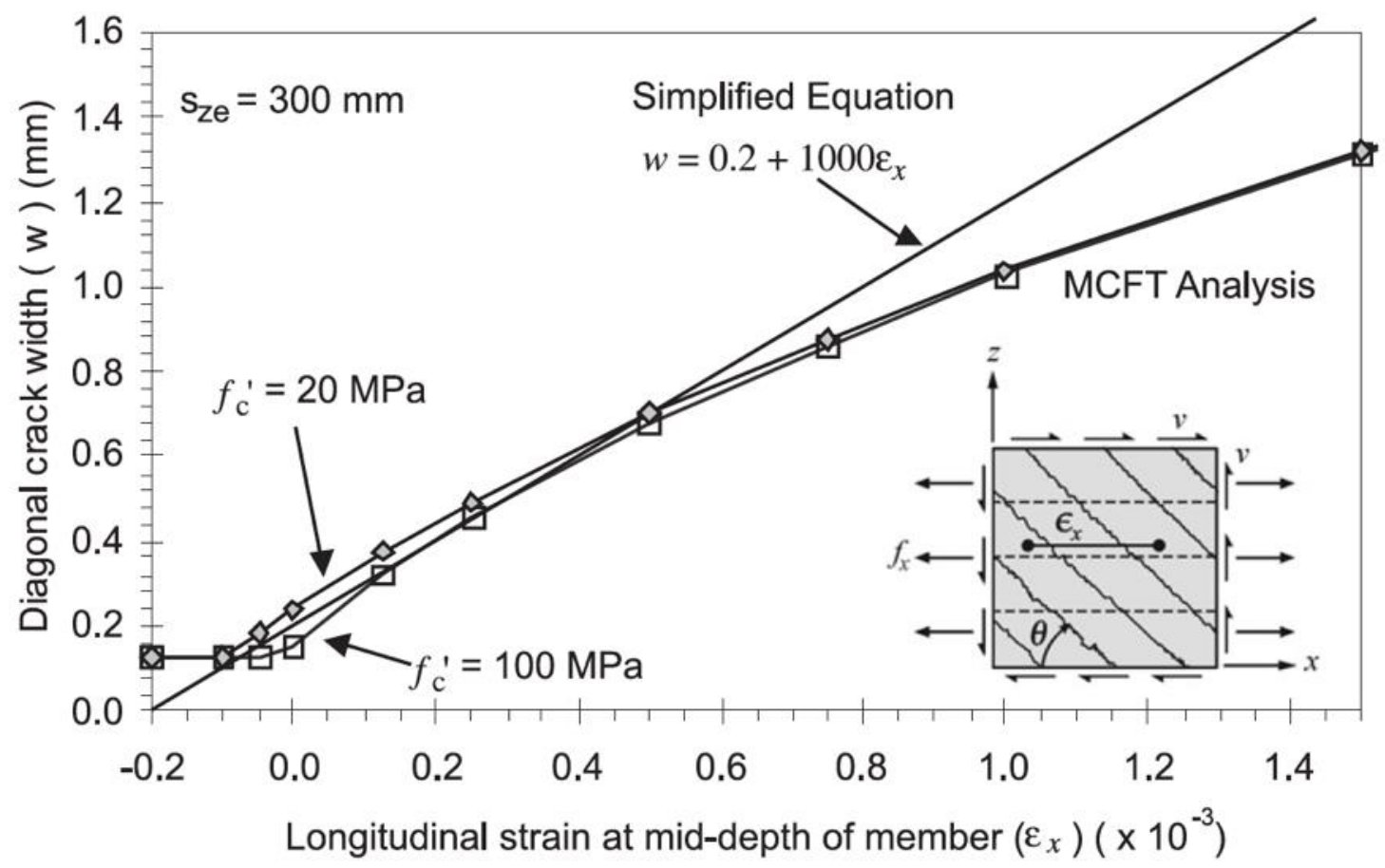

Figure 2.5: Simplified diagonal crack width equation compared to the relationship from the MCFT (Bentz and Collins, 2006)

Bentz and Collins (2006) based the $\theta$ equation on a member with a significant amount of transverse reinforcement, where $v / f_{c}{ }^{\prime}=0.25$. Curves relating $\theta$ to $\varepsilon_{\mathrm{x}}$ for concrete with differing compressive strengths were determined (See Figure 2.6). One set of curves signified a lower bound for $\theta$, being the situation where concrete crushes. The upper bound signifies the situation where shear failure occurs without stirrup yielding. A suitable equation for $\theta$ was then determined that fit between these two bounds:

$$
\theta=29^{\circ}+7000 \varepsilon_{x}
$$

With Equations 2.15 and 2.16, $\theta$ and $\beta$ could be determined with more simplicity than the previous tabular approach. Though $\beta$ is based on a member with no stirrups and $\theta$ is based on a 
member with a large amount of shear reinforcement, for an amount of stirrups between these two extremes Bentz and Collins (2006) showed that combinations of $\theta$ and $\beta$ give appropriate conservative values.

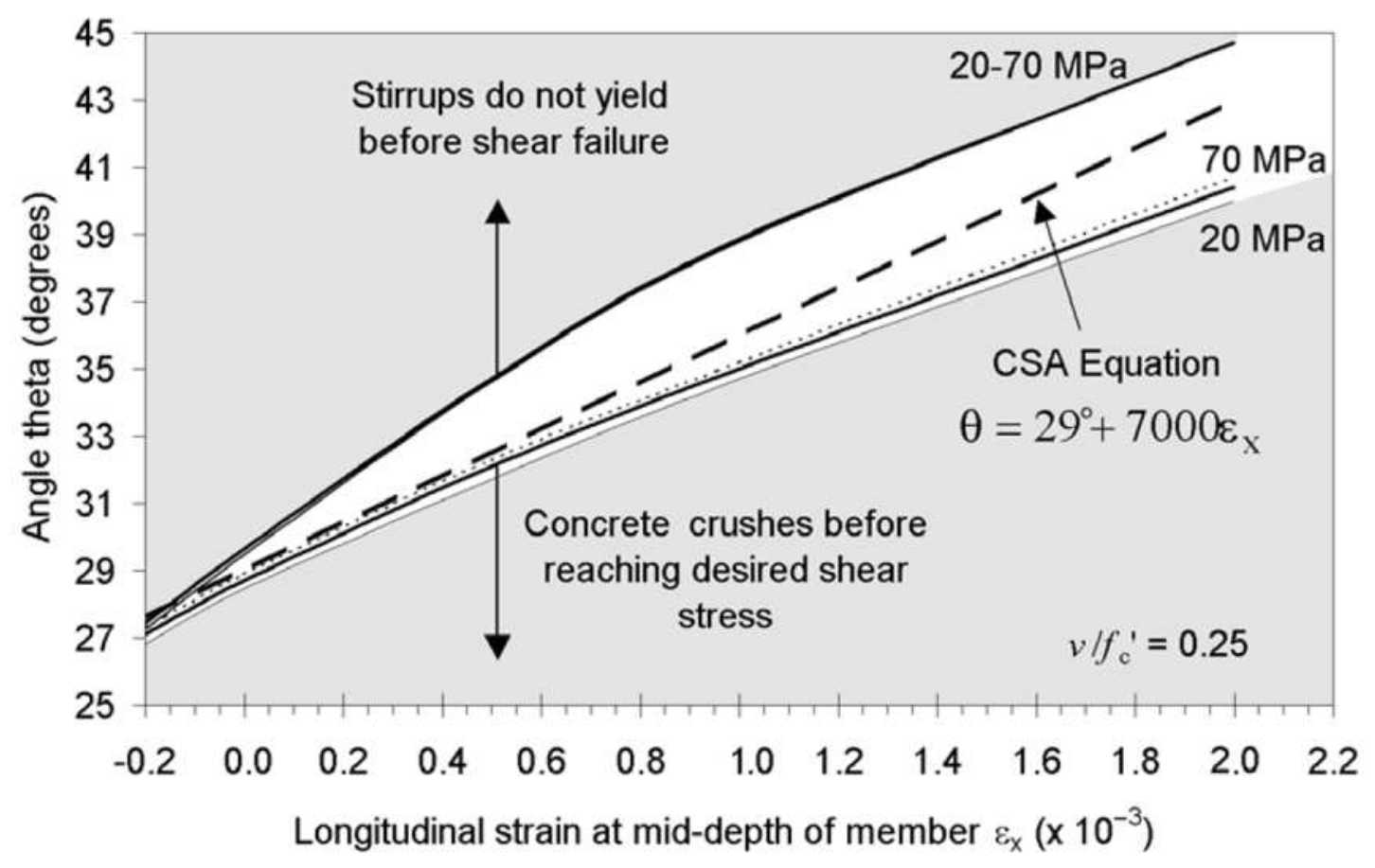

Figure 2.6: The CSA A23.3 2004 theta equation compared to upper and lower limits (Bentz and Collins, 2006)

\subsection{Strut-and-Tie Model}

Strut-and-tie models were first based upon the early truss model developed by Ritter (1899) and Mörsch (1909). This model approximated the behavior of concrete after cracking as a truss, where vertical tensile forces were carried by transverse reinforcement, horizontal forces were carried by longitudinal compressive or tensile chords, and diagonal compressive forces were carried by diagonal concrete struts.

The strut-and-tie model can be visualized as an idealized truss diagram where each strut or tie is a linear representation of the compressive or tensile stress flow through the structure. Struts are representative of the compressive stress paths carried by the concrete, and ties are 
representative of the tensile stresses carried by the reinforcement. Nodes are formed at the intersection of struts or the intersection of struts and ties. Nodes also occur at locations of highly concentrated forces or reactions, such as at an abrupt change in geometry or for a region under concentrated loading (Schlaich et al., 1987). A typical strut and tie model for a deep beam is shown in Figure 2.7. In this case the primary bottom tension reinforcement is modelled as a tension tie, the flow of compression forces from loading plates to bearing plates modelled as struts, and nodal zones placed at the intersections of struts with other struts and at the intersection of struts and ties.

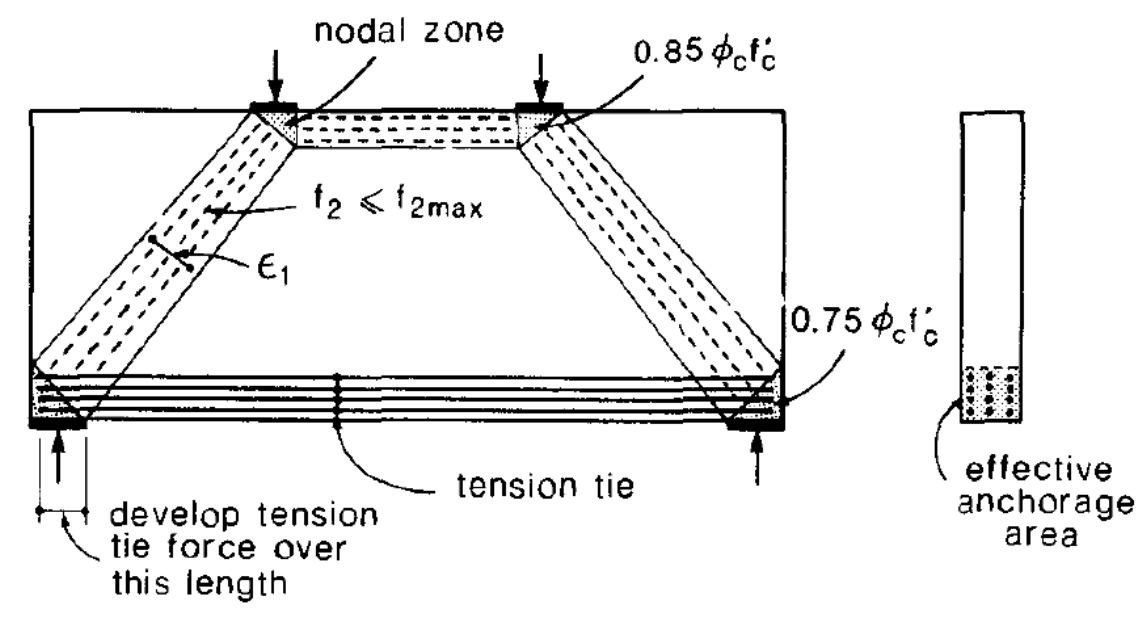

(a) Flow of forces

(b) End view

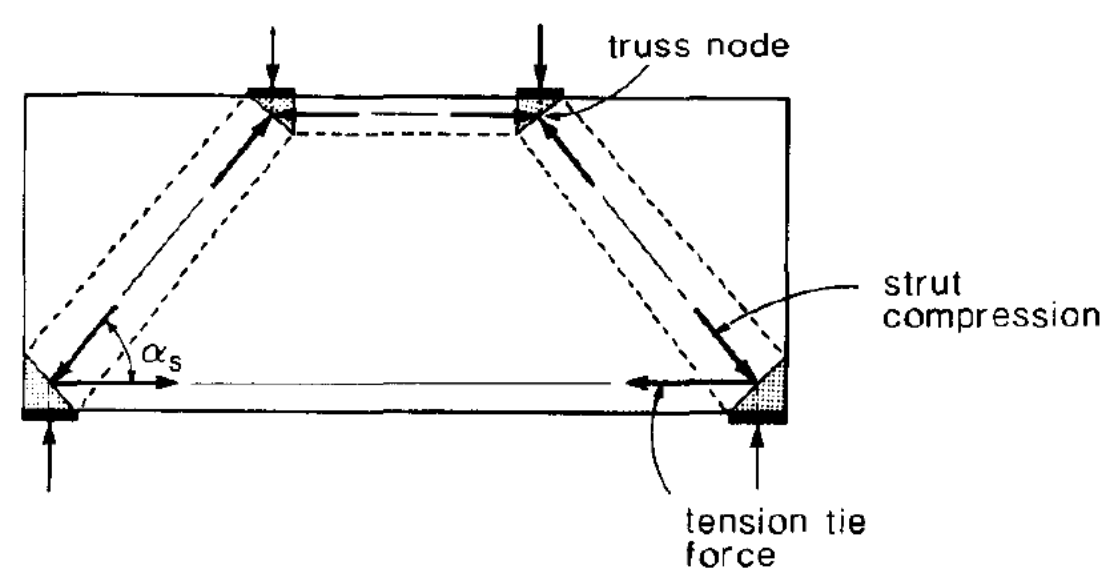

(c) Truss model

Figure 2.7: Strut-and-tie model for a reinforced concrete deep beam (Collins and Mitchell, 1986) 
Several design codes have adopted the strut-and-tie method described by Collins and Mitchell (1986) for the design of disturbed regions (D-regions). The first of these was the CSA A23.3 in its 1984 Design Code, followed in later years by the Canadian Highway Bridge Design Code (CSA, 2014), the AASHTO LRFD (2014), and the ACI Design Code (2014).

The design of a strut-and-tie model involves several key steps, the first of which is to visualize the flow of stresses through the D-region. Depending on the geometry and loading of the structure the compression fields will typically take one of three forms: the "fan", the "bottle", or the "prism", as shown in Figure 2.8 (Schlaich et al., 1987). These compressive stresses are to be drawn in the form of representative linear struts, with tension ties added in locations to ensure equilibrium. As these tension ties are representative of the reinforcing steel, care should be taken to ensure that the centroid of each tension tie is compliant with spacing and cover requirements. Several examples of stress flows in disturbed regions and their corresponding strut-and-tie models are shown in Figure 2.9. In these examples the dashed lines show the flow of the compressive forces, and the darker dashed and solid lines are the representative struts and ties, respectively. With the truss idealized, the next step is to apply the factored loads to the model and determine the forces carried by each strut and tie. For statically determinate structures this can be done with basic statics. Statically indeterminate structures are represented by statically indeterminate strut-and-tie models and thus require a more advanced method of elastic analysis or stiffness assignation to determine the forces (Mitchell et al., 2004).

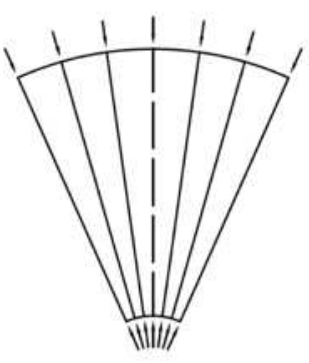

(a) The "fan"

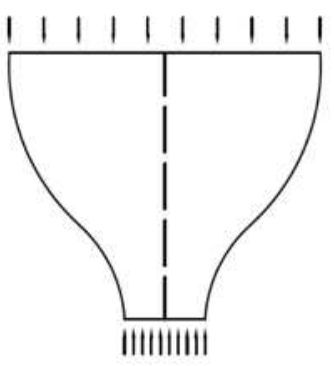

(b) The "bottle"

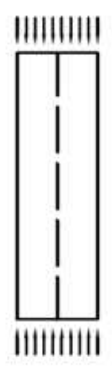

(c) The "prism"

Figure 2.8: Typical compression fields in disturbed regions (Adapted from Schlaich et al., 1987) 


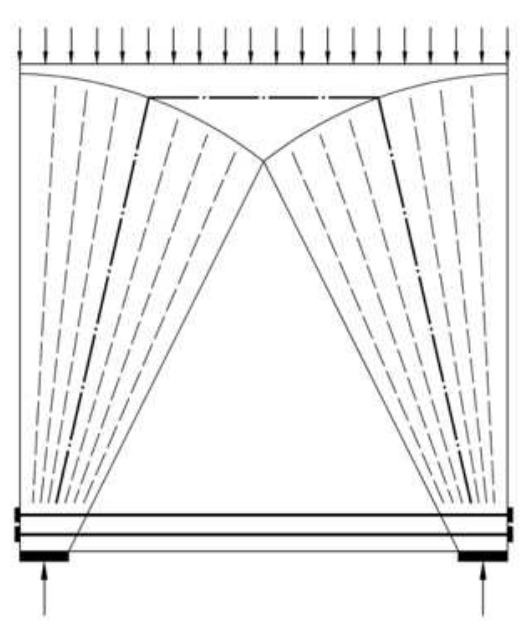

(a) Deep beam

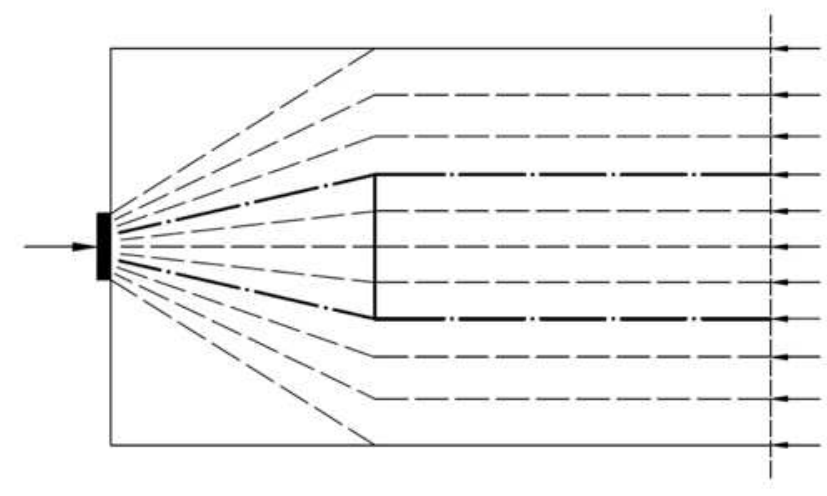

(b) Anchor zone

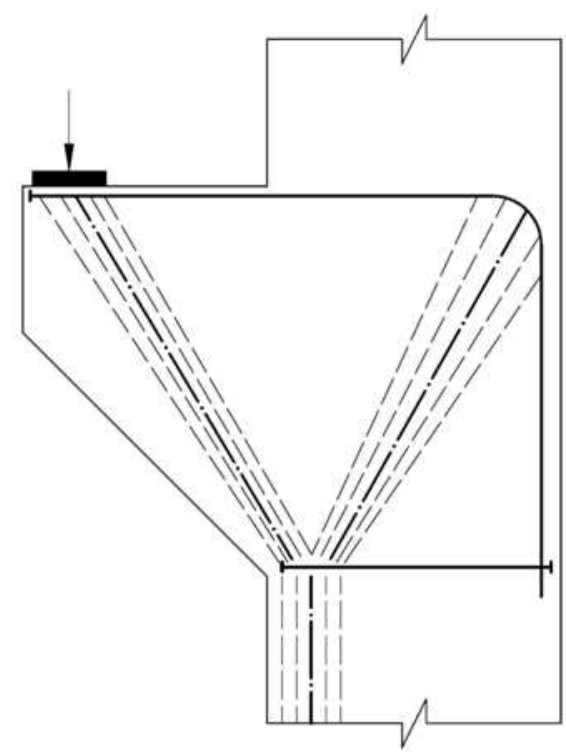

(c) Corbel

Figure 2.9: Examples of strut-and-tie models of stress paths in disturbed regions (Adapted from Collins and Mitchell, 1991) 
Next, for each tension tie the required area of reinforcement, $A_{s t}$, to resist the factored force in the tie, $T_{f}$, is determined. This is done by ensuring the resisting tensile force, $T_{r}$, is greater than the factored force in the tie. That is,

$$
T_{r}=\phi_{s} A_{s t} f_{y} \geq T_{f}
$$

The nodal zones also need to be checked. As shown in Figure 2.10, depending on the struts and ties in the nodal zone three different types are possible (Mitchell et al., 2004):

1. CCC: Nodal zone containing only compressive struts or bounded by bearing areas

2. CCT: Nodal zone containing one tension tie

3. CTT: Nodal zone containing two tension ties in different directions

Each type of node has a different stress limit that the struts and bearing areas intersecting the nodal zone cannot exceed. This is done to ensure that the concrete in the nodal zone does not get overstressed. For the CSA S6-14 Standard (2014) and the AASHTO LFRD code (2014) these stress limits are $0.85 \phi_{c} f_{c}{ }^{\prime}, 0.75 \phi_{c} f_{c}{ }^{\prime}$, and $0.65 \phi_{c} f_{c}{ }^{\prime}$ for CCC, CCT, and CTT nodes respectively. At loading or support locations the factored reaction divided by the bearing area must be less than the applicable stress limit. For struts and ties, the force being carried by the given strut or tie divided by the area of the nodal zone at the strut or tie intersection must be less than the applicable stress limit. 

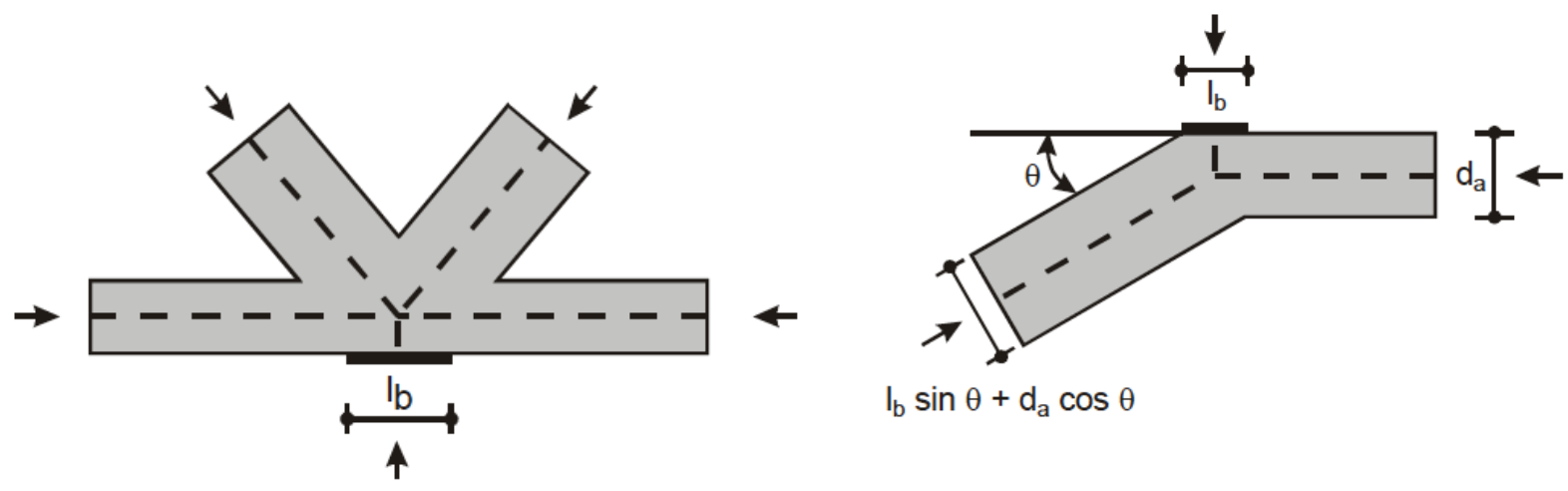

(a) CCC nodes (stress limit $=0.85 \phi_{c} f_{c}{ }^{\prime}$ )

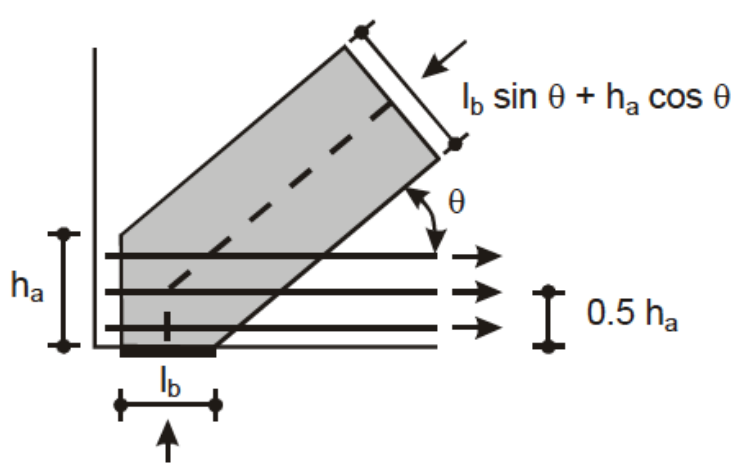

(b) CCT node (stress limit $=0.75 \phi_{c} f_{c}^{\prime}$ )

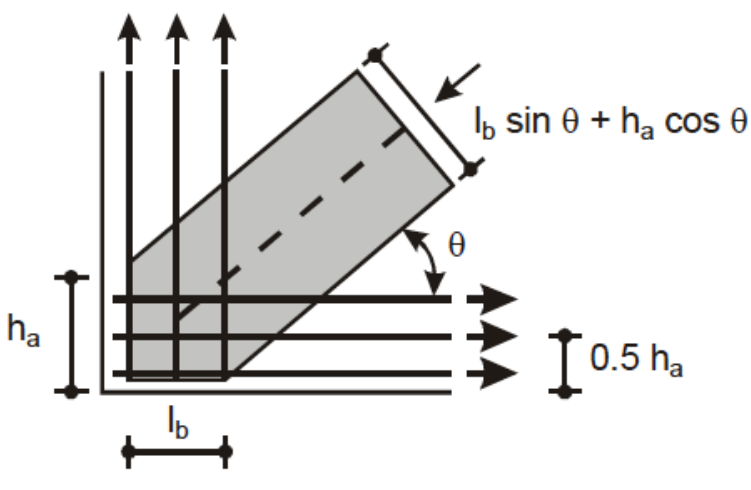

(c) CTT node (stress limit $\left.=0.65 \phi_{c} f_{c}^{\prime}\right)$

Figure 2.10: Examples of different node types (Mitchell et al., 2004)

The strengths of the struts must also be checked to ensure that concrete crushing does not occur. That is,

$$
C_{r}=\phi_{c} f_{c u} A_{c s} \geq C_{f}
$$

where $C_{r}$ is the compressive resistance of the strut, $C_{f}$ is the applied compressive force in the strut, $A_{c s}$ is the effective cross-sectional area of the strut, and $f_{c u}$ is the crushing strength of the concrete when cracked. The crushing strength, $f_{c u}$, is equivalent to $f_{2, \max }$ used in sectional analysis. From the MCFT, Vecchio and Collins (1986) found that, 


$$
f_{2, \max }=\frac{f_{c}^{\prime}}{0.8-0.34 \varepsilon_{1} / \varepsilon_{c}^{\prime}}
$$

If the strain at peak compressive strength is assumed to be -0.002 , then Equation 2.19 becomes:

$$
f_{c u}=f_{2, \max }=\frac{f_{c}^{\prime}}{0.8+170 \varepsilon_{1}}
$$

where $\varepsilon_{1}$ is derived from Equation 2.3 as,

$$
\varepsilon_{1}=\varepsilon_{s}+\left(\varepsilon_{s}+0.002\right) \cot ^{2} \alpha_{s}
$$

In this equation $\varepsilon_{s}$ is the average tensile strain in concrete parallel to the tension tie, and $\alpha_{s}$ is the smallest angle from the compressive strut to the tension tie. It is important to note that as the tensile strain in the concrete due to the tension tie increases, the crushing strength of concrete and hence also its compressive stress capacity decreases (Collins and Mitchell, 1991). Additionally, Figure 2.11 shows that as the tension tie angle $\alpha_{\mathrm{s}}$ decreases, the concrete crushing strength decreases as well. The crushing strength $f_{c u}$ is limited to a maximum value of $0.85 f_{c}^{\prime}$.

Lastly the anchorage of the ties must be checked to ensure that the reinforcement can properly carry the applied forces. This anchorage can be in the form of mechanical anchorage such as a hook, or simply ensuring that the reinforcement has adequate development length, $l_{d}$, to carry the applied forces in the steel at the edge of the strut in the given nodal region (Mitchell et al., 2004). 


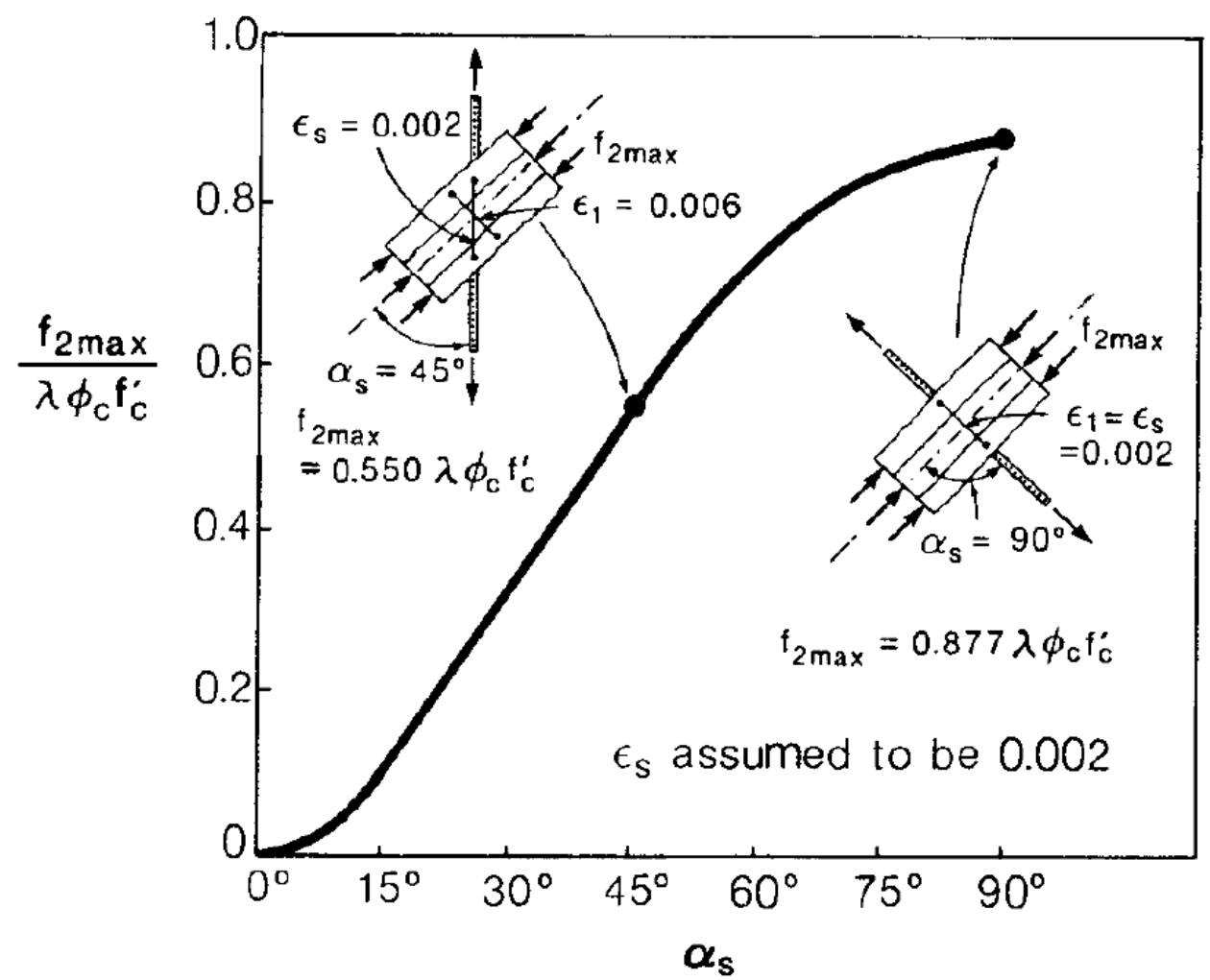

Figure 2.11: Influence of the tension tie angle on the crushing strength of the compressive strut (Collins and Mitchell, 1986)

In 1979 Kani et al. performed significant research in comparing the sectional method with the strut-and-tie analysis. Several reinforced concrete beams were tested, with each beam having a different shear-span-to-depth ratio $(a / d)$. Each beam was tested to failure in order to determine their shear strengths, and the shear strength versus shear-span-to-depth ratio of each beam was plotted as shown in Figure 2.12. These were then compared with curves representing results from the strut-and-tie and sectional model predictions. It was observed that for shearspan-to-depth ratios less than about 2.5 the shear strength was much better predicted by the strutand-tie model, as the failure for these beams were more heavily influenced by details in the disturbed regions. For shear-span-to-depth ratios higher than 2.5 the sectional model using the MCFT gave better predictions, as for beams in this region the strength was more dependent on conditions outside of the disturbed regions. 


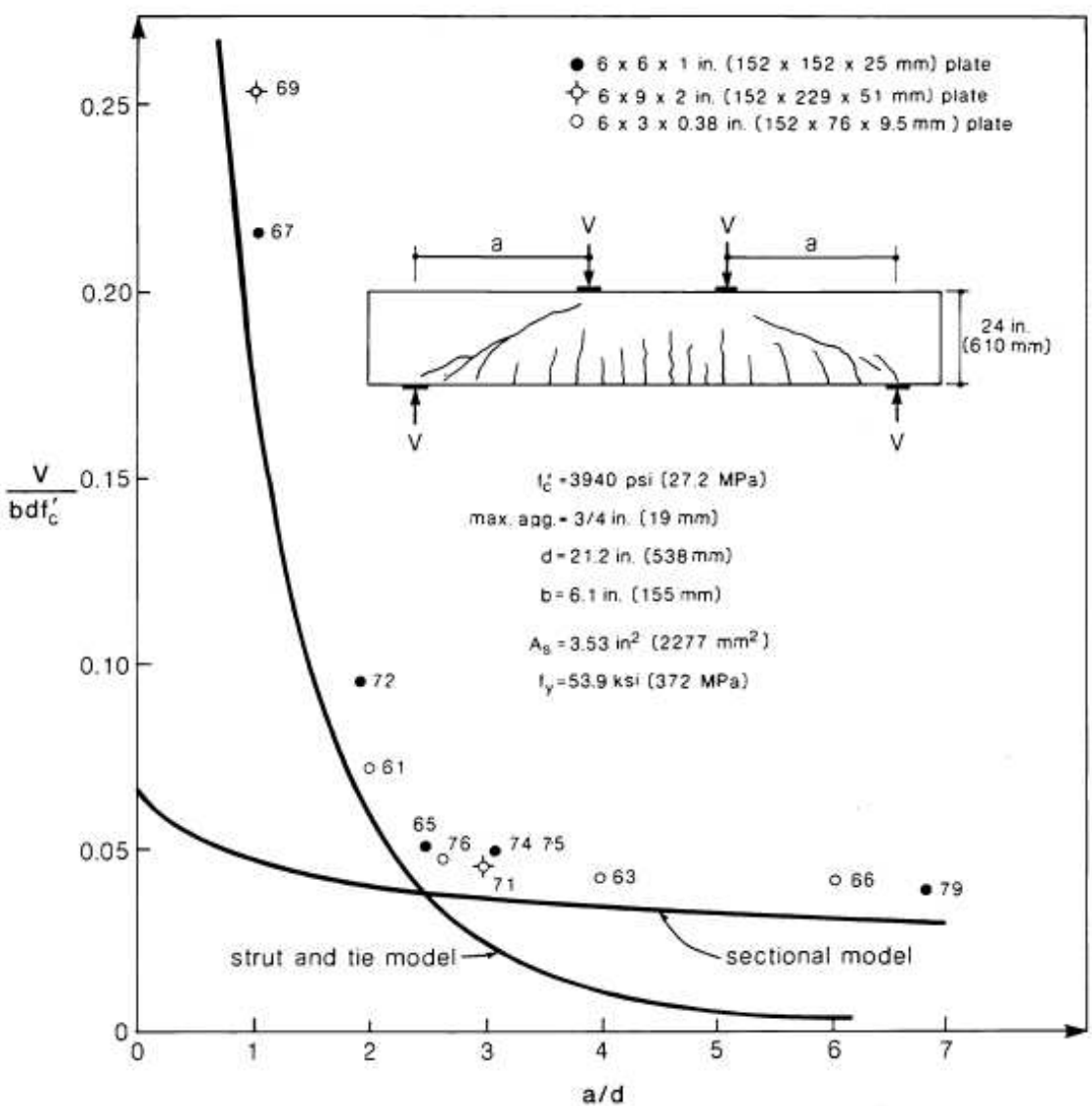

Figure 2.12: Comparison of strut-and-tie and sectional model strength predictions with observed strengths for beams of varying shear-span-to-depth ratios tested by Kani et al., 1979 (Collins and Mitchell, 1991)

\subsection{Non-Linear Finite Element Analysis}

\subsubsection{Background}

VecTor2 (Vecchio, 2018) is a non-linear finite element program developed by the University of Toronto for analyzing the response of two-dimensional models of reinforced concrete structures (Wong et al., 2013). This program performs its post-cracking analysis based on two foundational theories: The Modified Compression Field Theory as described earlier, and the Disturbed Stress Field Model (DSFM). The DSFM was developed by Vecchio (2000) as a revised model to the earlier MCFT, and as such is similar to the MCFT in many respects. The primary difference is that the DSFM takes into consideration crack shear slip which can be especially significant in lightly reinforced members. By including crack shear slip the 
assumption that principal stresses and principal strains have the same direction is no longer correct, as the principal strains change in direction faster than the principal stresses. Thus, the model becomes a smeared delayed rotating-crack model (Vecchio, 2000).

Form Works is a pre-processor developed by Wong (2002) specifically designed to be used in tandem with VecTor2. It allows a user to create a two-dimensional finite element model representing a reinforced concrete member, to be then analyzed by VecTor2. FormWorks allows the user to select specific non-linear models for various concrete and reinforcement behaviors. The non-linear models selected are then used in the VecTor2 analysis. A detailed summary of the non-linear models available for use is given by Wong et al. (2013).

Augustus is a post-processor developed by Bentz (2003) that was also specifically developed for use with VecTor2. It provides graphical information from the VecTor2 analysis on key aspects of the member modelled in FormWorks. Such data includes the load-deformation response, stresses and strains in each element, cracking patterns, and the deflection of the member.

\subsubsection{Crack Widths and Spacing}

Crack widths in concrete are quantified by an average crack width parameter, $w_{m}$. An average width is calculated due to the fact that concrete does not crack perfectly, with cracks varying in spacing and width. The expression for average crack width is based off Walraven's (1981) crack width equation:

$$
w_{m}=\varepsilon_{c 1} s_{m}
$$

Where $s_{m}$ is the average crack spacing, and $\varepsilon_{\mathrm{cl}}$ is the average tensile strain. The average tensile strain is determined based on the MCFT or the DSFM. The average crack spacing is determined based on the CEB-FIP Model Code (CEB 1978) as:

$$
s_{m}=2(c+s / 10)+k_{1} k_{2} d_{b} / \rho_{e f}
$$

where: $c \quad=$ clear concrete cover

$d_{b} \quad=$ diameter of reinforcing bars 
$s \quad=$ maximum spacing of longitudinal reinforcement, but no greater than $15 \mathrm{~d} b$

$k_{1}=$ factor for bond properties of reinforcing bars, taken as 0.4 for deformed bars and 0.8 for plain bars

$k_{2}=$ factor accounting for the strain gradient in the concrete

$=0.25\left(\varepsilon_{1}+\varepsilon_{2}\right) / 2 \varepsilon_{1}$

$\varepsilon_{1}, \varepsilon_{2}=$ the largest and smallest tensile strains in $A_{c, e f}$, respectively

$\rho_{e f} \quad=$ effective reinforcement ratio, equal to $A_{s} / A_{c, e f}$

$A_{s} \quad=$ area of effective steel

$A_{c, \text { ef }}=$ area of the effective embedment zone, where the reinforcement has an effect on concrete crack widths. This is taken as a rectangular region with bounds $7.5 d b$ from the center of the reinforcing bars

\subsection{Previous Research on Pier Caps}

MacLeod (1997) performed testing on two full-scale bridge pier caps of identical geometry with differing concrete strengths of 35 and $70 \mathrm{MPa}$. The pier caps were designed according to the strut-and-tie approach, and the uniformly distributed longitudinal and transverse reinforcement varied on either side of the pier caps. From the testing of these pier caps the following conclusions and recommendations were made:

1. For normal-strength concrete pier caps, a reinforcement ratio of 0.002 was sufficient to adequately control cracking at service load levels.

2. For high-strength concrete pier caps, a reinforcement ratio of 0.003 was required to adequately control cracking at service load levels.

3. The high-strength concrete pier cap was slightly stronger and significantly less ductile than the normal-strength concrete pier cap.

4. Cracking was influenced by the size of the pier caps and by restrained shrinkage stresses. The high-strength pier cap cracked at only a slightly higher load than the normal-strength pier cap because of the high-strength concrete having higher shrinkage strains.

5. The simple strut-and-tie models were conservative. 
6. The refined strut-and-tie models gave load estimates closer to the experimental results. This is because it takes the crack control reinforcement into account.

7. Non-linear finite element analyses were accurate in predicting stresses in the primary tension steel, and reasonable for estimating principal tensile strains and crack widths at service load levels.

8. Reasonable flexural crack width predictions could be made based on the principal tensile strains from the non-linear finite element analyses.

9. Future research in terms of predicting inclined crack widths in larger D-regions, or the relationship between high-strength concrete and inclined crack widths, is required.

Al-Soufi (1990) performed testing on six reinforced concrete bridge pier caps with different geometries and reinforcement detailing. Three different geometries were used, and for each geometry two different uniformly distributed reinforcement schemes were tested. One specimen would have more closely spaced crack control reinforcement in only one direction, and the other would have more dispersed crack control reinforcement but in both horizontal and vertical orientations. The pier caps were designed by the strut-and-tie method, and later compared to a non-linear finite element software. From the testing regime the following conclusions and recommendations were made:

1. The reinforcement in large pier caps exhibits significant yielding before failure, due to considerable stress redistribution in the pier cap.

2. The uniformly distributed reinforcement in both directions was effective in increasing the strength and controlling the cracking of the member.

3. Anchoring the main tension reinforcement with $90^{\circ}$ hooks was effective in allowing the reinforcement to properly develop and carry stresses.

4. The crack control in the central region was improved due to the added reinforcement by the central column.

5. Non-linear finite element analyses gave the most accurate predictions for ultimate strength. Simple and refined strut-and-tie models, and plane section analyses gave more conservative results.

6. Future research in terms of investigating the influence of post-tensioning or the amount of uniformly distributed reinforcement for adequate crack control, is required. 


\section{CHAPTER 3}

\section{EXPERIMENTAL PROGRAM}

\subsection{Introduction}

Four pier cap beams were constructed and tested, with reinforcement details similar to the types 04A and 168 pier cap beams used in the existing Champlain Bridge. Pier caps C1 and C1R are similar to the Type 04A pier cap detailed in Section 1.2.1. Pier caps C2 and C2R are similar to the Type 168 pier cap detailed in Section 1.2.2. In all four specimens the amount of longitudinal crack control reinforcement differs in each cantilever. Each specimen was loaded to failure, external shear clamps were applied to the failed side, and reloaded until an additional failure was reached on the opposite side of the pier cap. For pier caps C1R and C2R, posttensioning was installed upon reaching the service load level on the initial failure loading.

\subsection{Details of Specimens}

\subsubsection{Geometric Design}

The outer geometry of the four specimens can be seen in Figure 3.1. Each cantilever has an overall length of $4800 \mathrm{~mm}$ with two cantilevers extending past the column by $2000 \mathrm{~mm}$ each. The distance between the two loading support points is $4200 \mathrm{~mm}$. The cantilevered portions have a depth of $1000 \mathrm{~mm}$ at the column face decreasing to $500 \mathrm{~mm}$ at the beam end. The overall height is $1800 \mathrm{~mm}$, with a uniform width of $600 \mathrm{~mm}$. These research specimens are approximately $1 / 3$ to $1 / 4$ the size of the existing Champlain Bridge (see Table 3.1), with both having the same 1:4 slope on the cantilever bottom. 


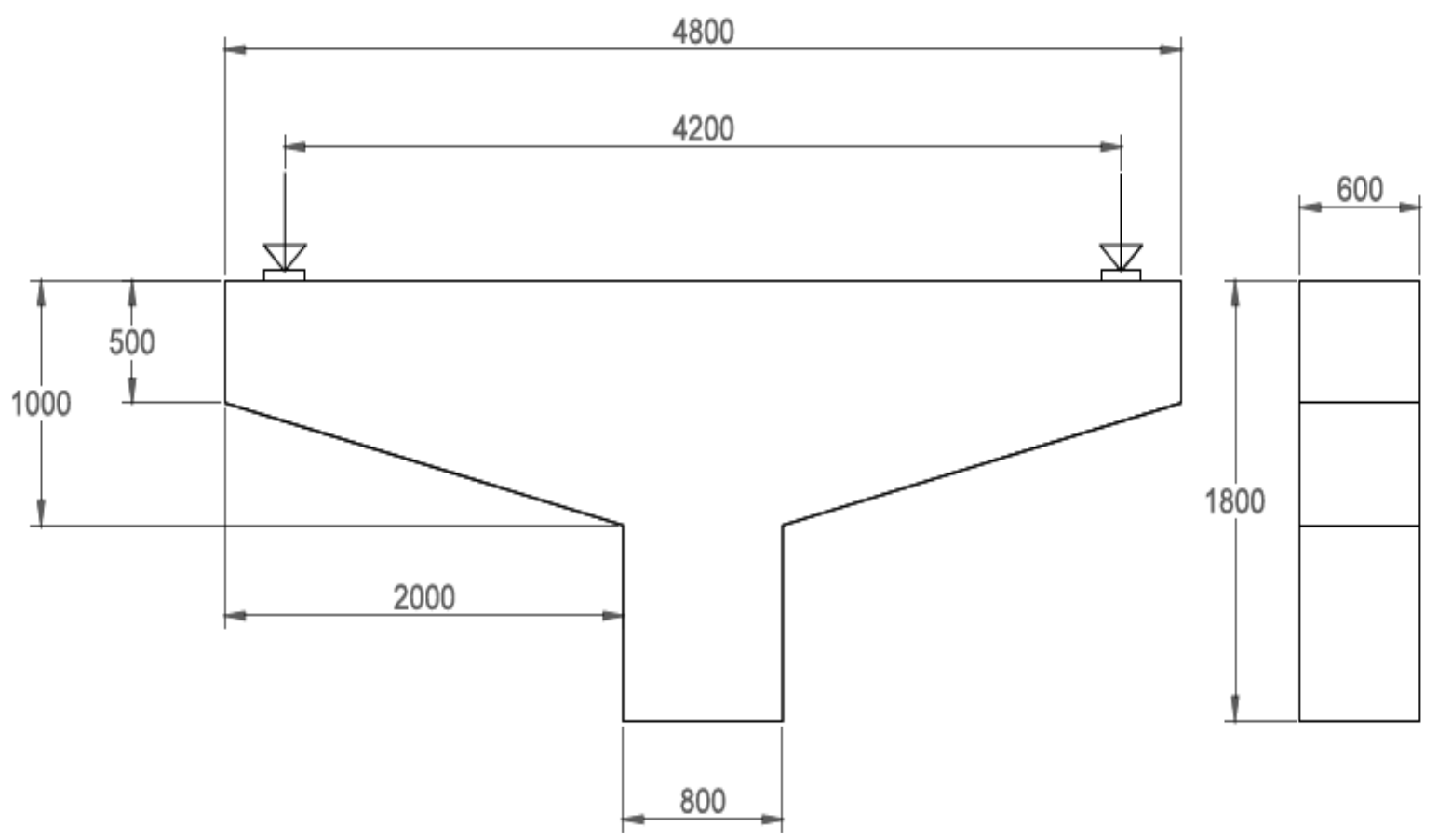

Figure 3.1: Geometry of pier cap beams (dimensions in $\mathrm{mm}$ )

Table 3.1: Comparison of the geometry of the existing Champlain Bridge and the test pier cap beams

\begin{tabular}{|c|c|c|c|}
\hline & Existing Champlain Bridge & Research Specimens & Scale Factor \\
\hline Overall Length (mm) & 23,600 & 4800 & 4.92 \\
\hline Cantilever Length (mm) & 8077 & 2000 & 4.04 \\
\hline $\begin{array}{c}\text { Cantilever Depth @ } \\
\text { column face (mm) }\end{array}$ & 3507 & 500 & 3.51 \\
\hline $\begin{array}{c}\text { Cantilever Depth @ end } \\
\text { (mm) }\end{array}$ & 1503 & 600 & 3.01 \\
\hline Width (mm) & 1930 & & 3.22 \\
\hline
\end{tabular}




\subsubsection{Reinforcing Steel Design for C1 and C1R}

The reinforcing steel design details for pier caps $\mathrm{C} 1$ and $\mathrm{C} 1 \mathrm{R}$ can be seen in Figures 3.2 to 3.6. The primary top longitudinal steel was made up of $18-25 \mathrm{M}$ bars distributed in 2 layers of 9 bars each. These were spaced transversely and vertically to meet the CSA S6-14 (2014) minimum spacing requirement as the maximum of $1.4 \mathrm{db}, 1.4 \mathrm{ag}_{\mathrm{g}}$, or $30 \mathrm{~mm}$. Assuming an $\mathrm{ag}_{\mathrm{g}}$ of 20 $\mathrm{mm}$ the $1.4 d_{b}$ case was most critical having a minimum clear spacing of $35 \mathrm{~mm}$. As such the vertical and transverse clear spacing are both $35 \mathrm{~mm}$. The reinforcement ratio of this steel is 0.081 at the column face, similar to the reinforcement ratio of 0.087 and 0.107 for the primary longitudinal steel at the column face for the existing Champlain Bridge pier types 04A and 168, respectively. The ends of each top steel layer were anchored at $90^{\circ}$ angles. The CSA S6-14 (2014) requires a minimum extension of at least 12 bar diameters as a free extension past the $90^{\circ}$ bend, which in the case of $25 \mathrm{M}$ bars is a $300 \mathrm{~mm}$ extension. The top layer meets this anchorage limit with an extension of $300 \mathrm{~mm}$. The bottom longitudinal steel was made up of $4-20 \mathrm{M}$ bars inclined at a 1:4 slope.

The vertical crack control reinforcement was made up of 4-legs of 10M stirrups at a spacing of $200 \mathrm{~mm}$ in both cantilevers. This spacing was chosen as the reinforcement ratio $\rho_{\mathrm{v}}$ is 0.00333 , thereby just above the 0.003 crack control requirement set by the 2014 Canadian Highway Bridge Design Code (CSA, 2014). This spacing was also checked with the minimum stirrup requirement, ( $\left.\mathrm{A}_{\mathrm{v}} / \mathrm{Smin}\right)$, for the CSA S6-14 (2014). This was calculated as:

$$
\left(\frac{A_{v}}{s}\right)_{\min }=\frac{0.06 \sqrt{f_{c}^{\prime}} b_{w}}{f_{y}}
$$

From this equation and having 4-10M legs per stirrup location, the chosen spacing was found to be acceptable.

The horizontal crack control reinforcement differed in each cantilever. On the north side it consisted of 2 sets of $2-10 \mathrm{M}$ bars at an equal spacing of $270 \mathrm{~mm}$ at the column cross-section, while the south side had the same spacing and consisted of 2 sets of $2-10 \mathrm{M}$ bars with $2-15 \mathrm{M}$ bars. The reinforcement ratios of these crack control reinforcements corresponding to the 1000 mm cap beam depth at the column face can be seen in Table 3.2. The horizontal crack control 
reinforcement in the north cantilever is only $40 \%$ of the 0.003 required, whereas the south side provides $21 \%$ more than required.

Table 3.2: Reinforcement ratios of crack control reinforcement in the north and south cantilevers for pier caps $\mathrm{C} 1$ and $\mathrm{C} 1 \mathrm{R}$

\begin{tabular}{|c|c|c|}
\hline Type & $\begin{array}{c}\text { Stirrups } \\
\rho_{v}\end{array}$ & $\begin{array}{c}\text { Horizontal bars } \\
\rho_{h}\end{array}$ \\
\hline North & 0.00333 & 0.00121 \\
\hline South & 0.00333 & 0.00363 \\
\hline
\end{tabular}

The horizontal crack control reinforcement is well developed into the column, as per the CSA S6-14 (2014) standard the development length required, $l_{d}$, for a $15 \mathrm{M}$ bar (assuming a design value for the concrete strength of $35 \mathrm{MPa}$ ) is:

$$
\begin{aligned}
& l_{d}=0.45 k_{1} k_{2} k_{3} k_{4} \frac{f_{y}}{\sqrt{f_{c}^{\prime}}} d_{b}>300 \mathrm{~mm} \\
& =0.45(1.0)(1.0)(1.0)(0.8) \frac{400}{\sqrt{35}}(15)=365 \mathrm{~mm}
\end{aligned}
$$

where: $\mathrm{k}_{1} \quad=$ bar location factor $=1.0$

$\mathrm{k}_{2}=$ coating factor $=1.0$ for uncoated reinforcement

$\mathrm{k}_{3}=$ concrete density factor $=1.0$ for normal-density concrete

$\mathrm{k}_{4}=$ bar size factor $=0.8$ for $20 \mathrm{M}$ bars and smaller

Likewise, for $10 \mathrm{M}$ bars the required development length is $300 \mathrm{~mm}$. Both of these requirements are easily met as the bars extend approximately $630 \mathrm{~mm}$ into the column.

The central column was designed following the CSA S6-14 (2014) Standard, and was made up of $8-25 \mathrm{M}$ vertical bars confined by sets of 2-10M stirrups at a spacing ranging from 300-320 mm. This spacing was well within the maximum spacing controlled by $16 d_{b}=400 \mathrm{~mm}$. Particular attention was made concerning the compressive reentrant corner, where the column stirrups were required to be within $s_{\max } / 2=200 \mathrm{~mm}$ below the bottom longitudinal steel, as well 
as $s / 2=150 \mathrm{~mm}$ above it. These stirrups were placed $122 \mathrm{~mm}$ above and $178 \mathrm{~mm}$ below this steel layer. Additionally, the first set of vertical stirrups closest to the column face was to be placed within $s / 2=100 \mathrm{~mm}$ of the outermost column bar. As such this set was placed $100 \mathrm{~mm}$ from the outer column bar in both cantilevers for all specimens.

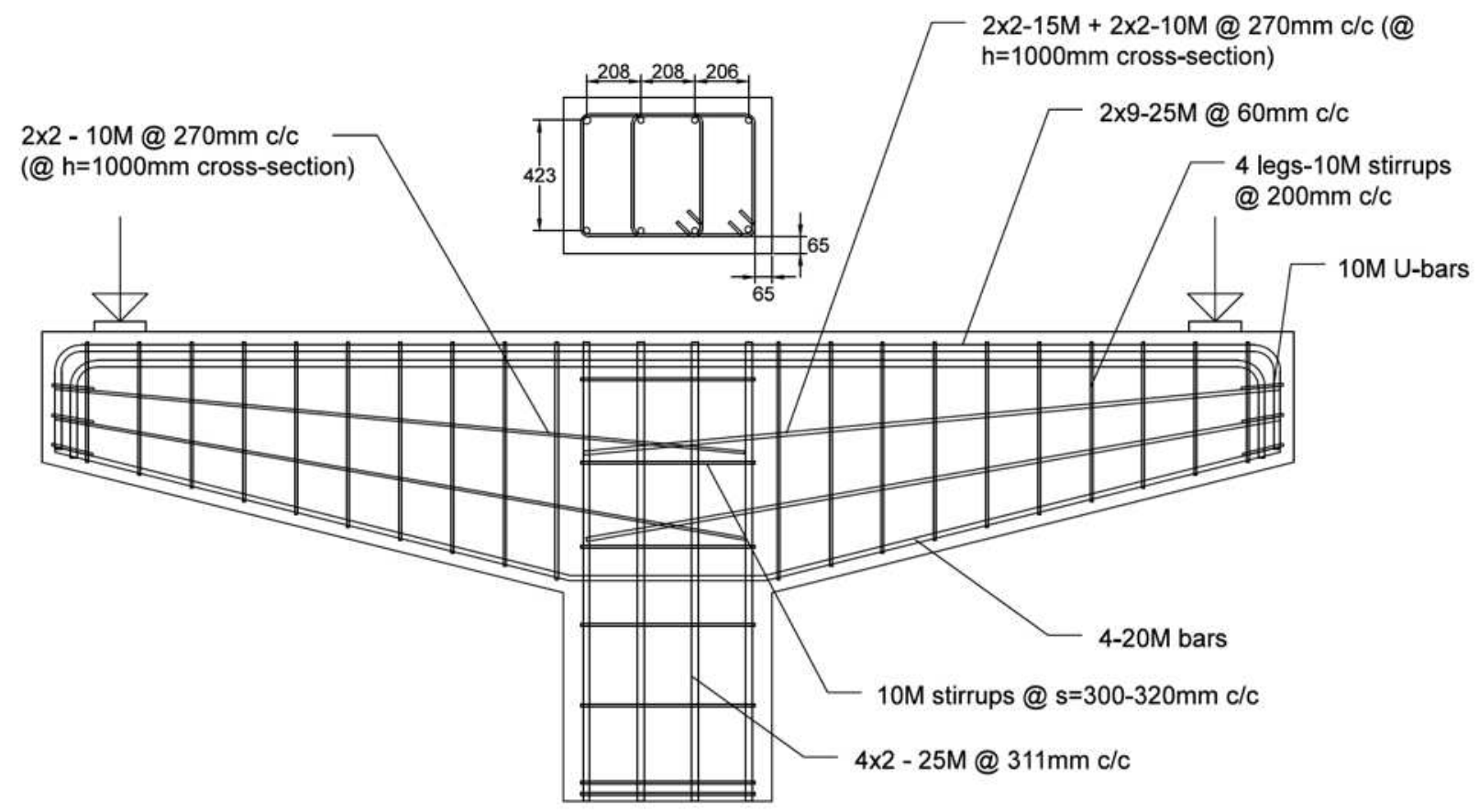

@ $\mathrm{h}=1000 \mathrm{~mm}$ cross-section

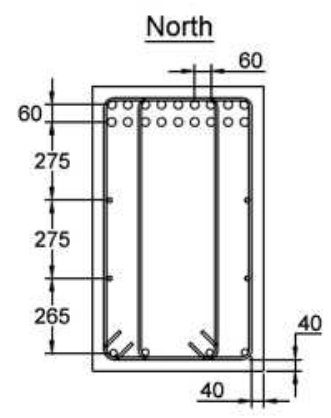

South

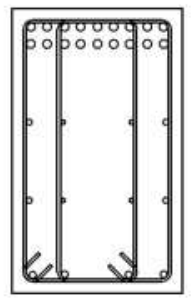

Figure 3.2: Reinforcing details of cap beams $\mathrm{C} 1$ and $\mathrm{C} 1 \mathrm{R}$ 


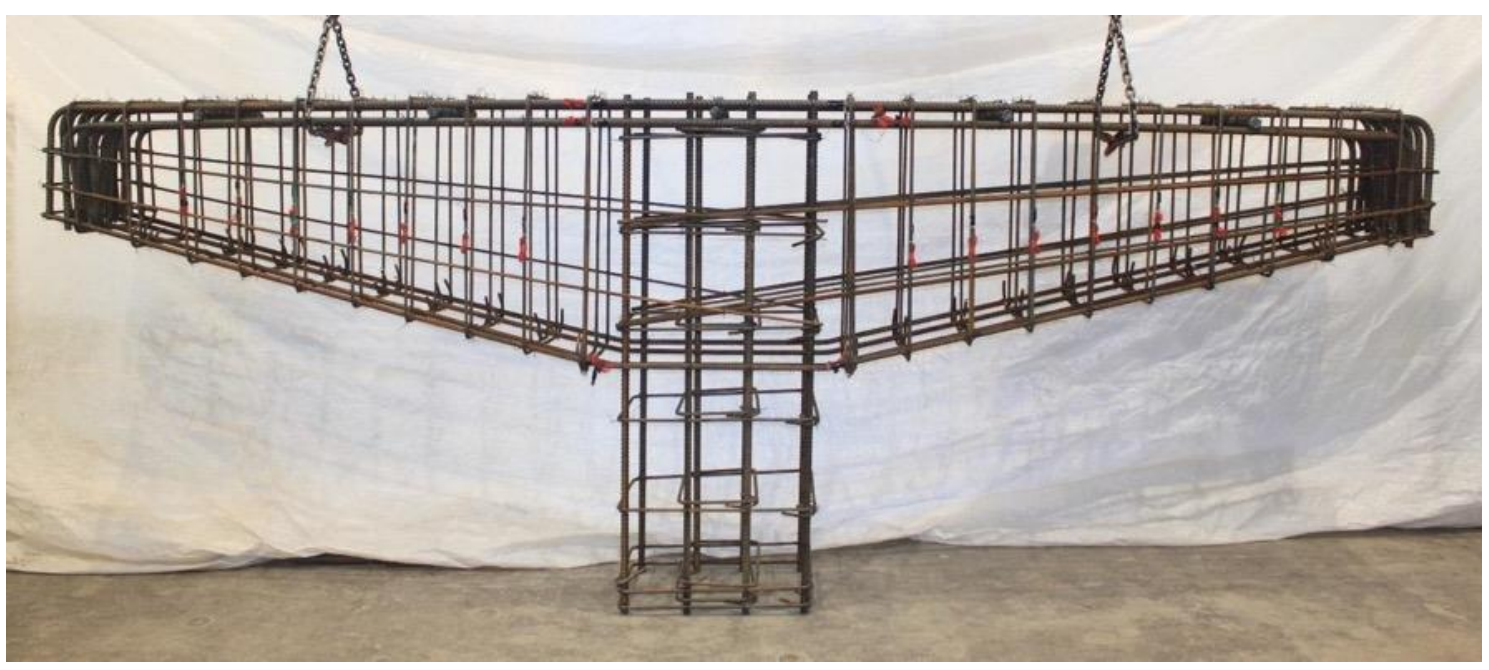

Figure 3.3: Reinforcing steel for cap beams $\mathrm{C} 1$ and $\mathrm{C} 1 \mathrm{R}$

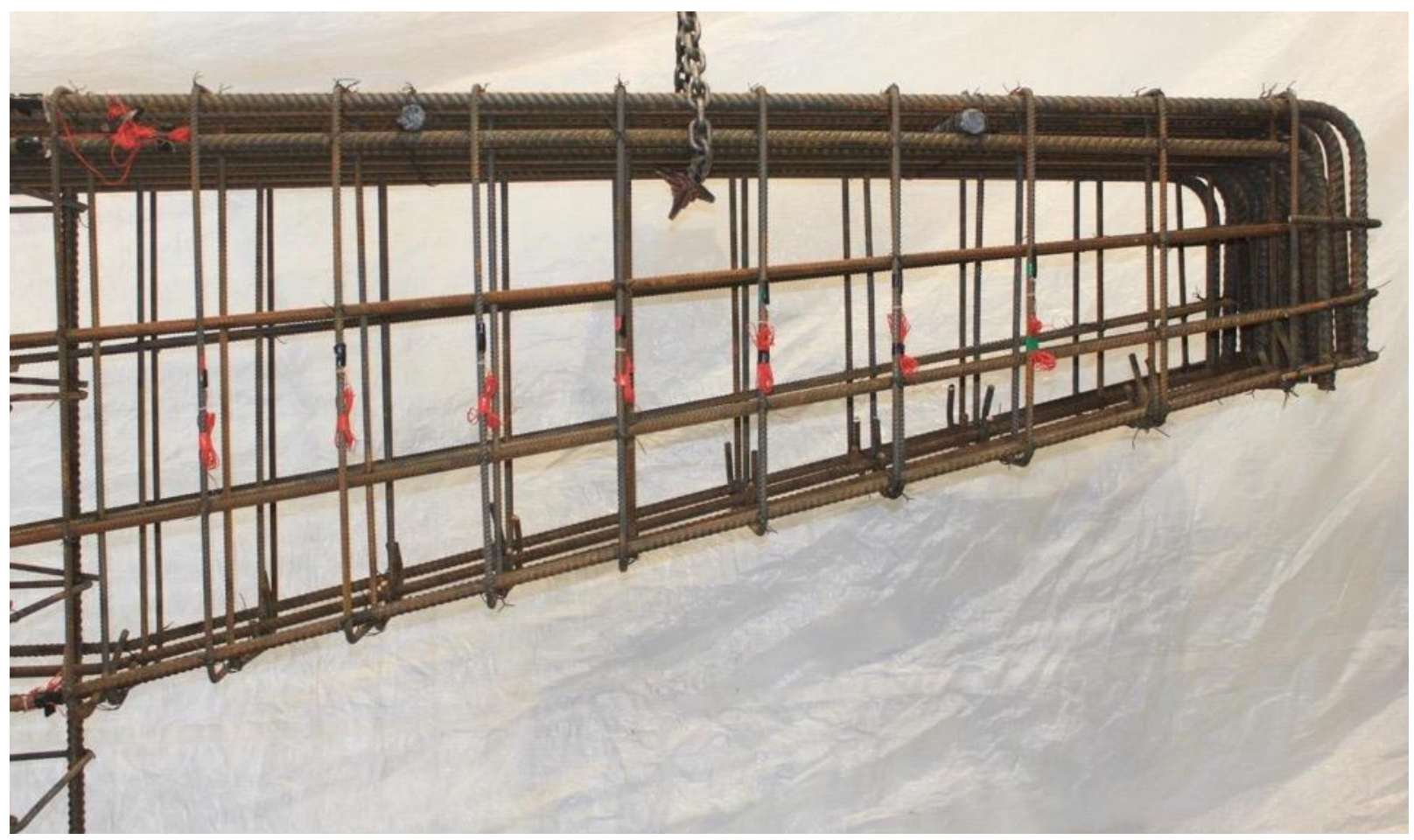

Figure 3.4: Reinforcing steel in south cantilever for cap beams C1 and C1R 


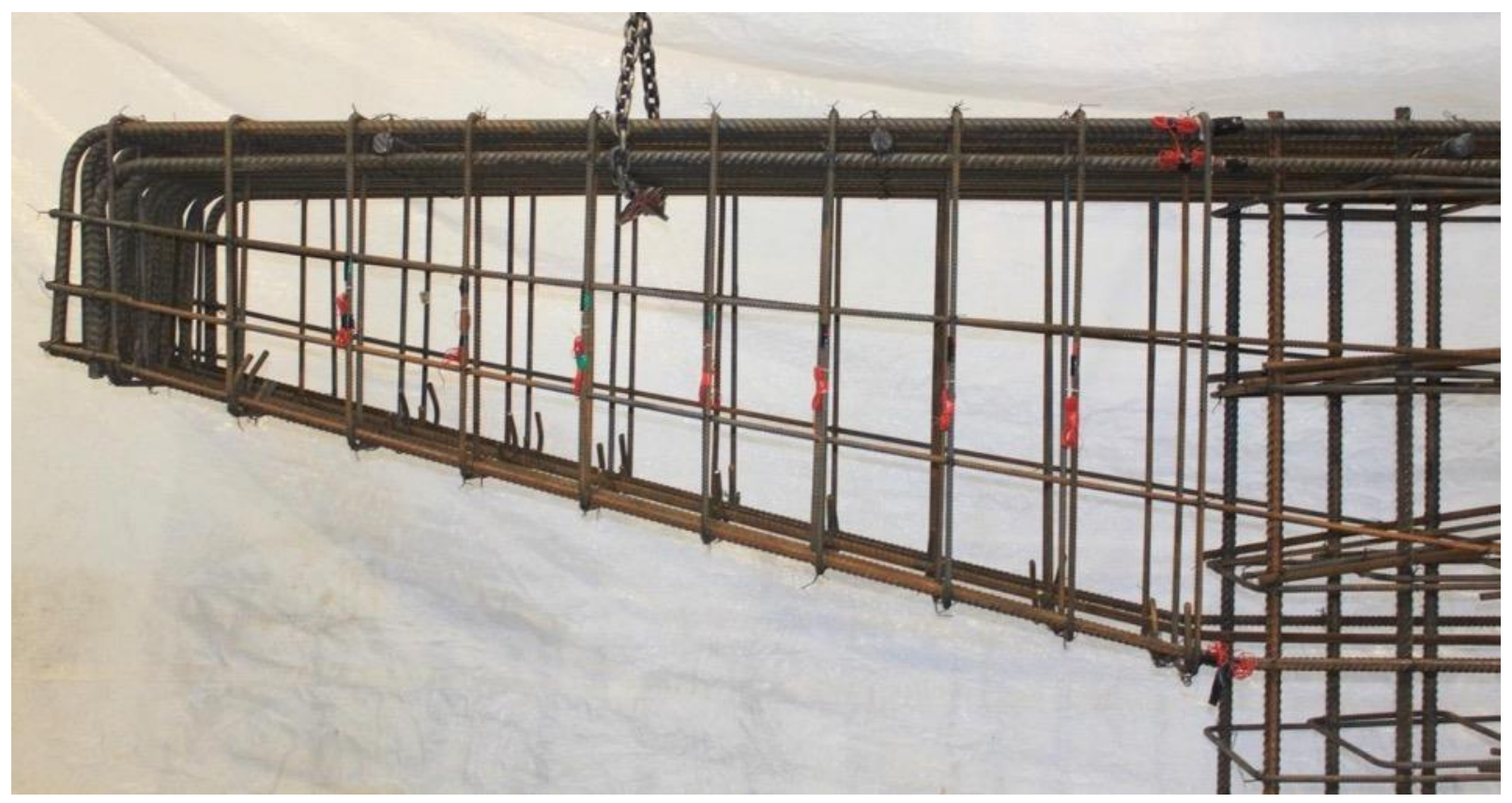

Figure 3.5: Reinforcing steel in north cantilever for cap beams C1 and C1R

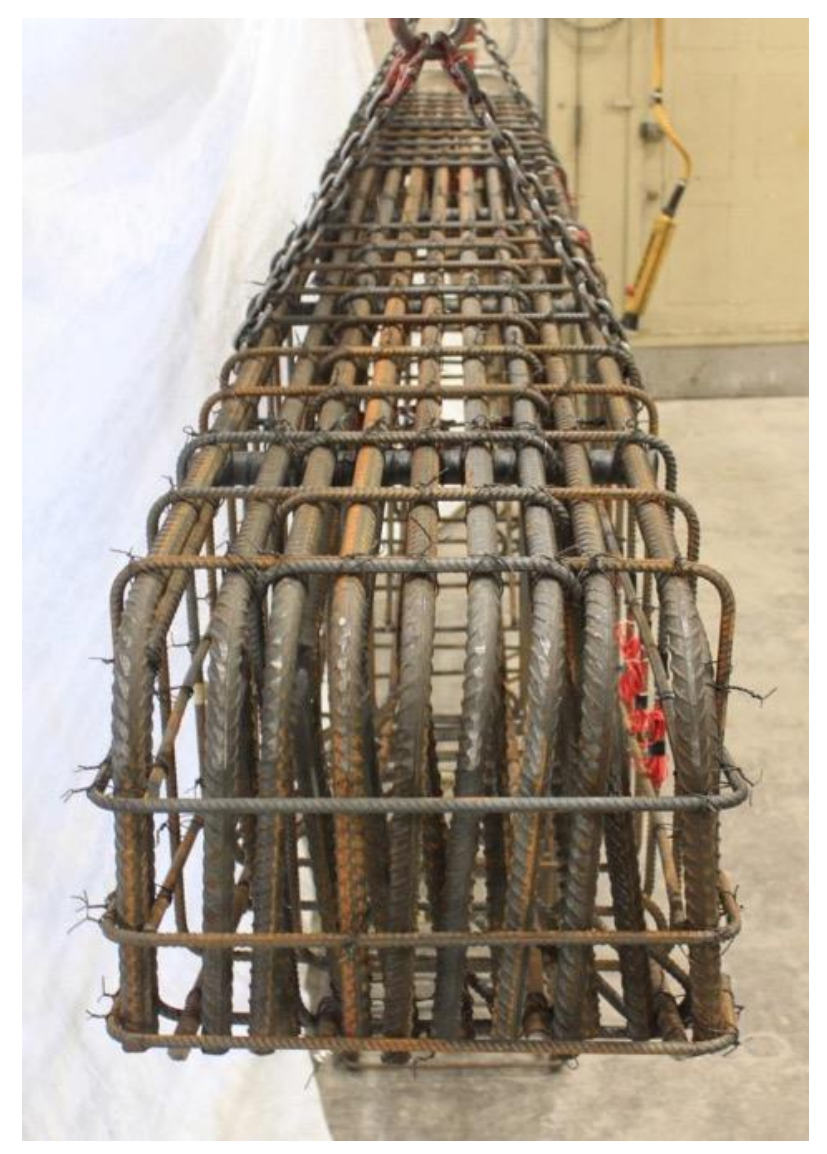

Figure 3.6: Details of $90^{\circ}$ hook anchorages for concentrated reinforcement layers 


\subsubsection{Reinforcing Steel Design for C2 and C2R}

Pier caps $\mathrm{C} 2$ and $\mathrm{C} 2 \mathrm{R}$ are identical to $\mathrm{C} 1$ and $\mathrm{C} 1 \mathrm{R}$ except for the vertical stirrup spacing and the addition of inclined reinforcing bars, as can be seen in Figures 3.7 to 3.11. Three sets of 2-20M inclined bars were placed in each cantilever at a $45^{\circ}$ angle and $630 \mathrm{~mm}$ spacing, extending from the bottom longitudinal steel to the bottom layer of the top longitudinal steel. The stirrups were then placed at a spacing of $300 \mathrm{~mm}$ so that the vertical crack control reinforcement ratio was similar to pier caps $\mathrm{C} 1$ and $\mathrm{C} 1 \mathrm{R}$. Table 3.3 shows the reinforcement ratios corresponding to the $1000 \mathrm{~mm}$ cap beam depth at the column face for pier caps C2 and C2R. The horizontal crack control reinforcement in the north cantilever is deficient at $78 \%$ of the 0.003 required (CSA, 2014), whereas the south side provides 58\% more reinforcement than required.

The inclined reinforcement bars were designed with lap splices meeting the requirements of the CSA S6-14 (2014) Standard. For a Class B tension splice the required splice length is $1.3 l_{d}$, where using Equation 3.2, $l_{d}$ is $487 \mathrm{~mm}$. Thus, the required tensile lap splice length is 633 $\mathrm{mm}$. The required compression lap splice length is taken as the greater of $0.073 f_{y} d_{b}$ or $300 \mathrm{~mm}$, where in this case 0.073(400)(20)=584 $\mathrm{mm}$ controls. As the inclined bars act as shear reinforcement and are extended into regions of compression and tension, these lap splice lengths may be taken from the mid-depth of the pier cap. Lastly the minimum free end extension after a standard hook is $12 d_{b}=12(20)=240 \mathrm{~mm}$. The 2 sets of inclined bars closer to the column have free end extensions of $240 \mathrm{~mm}$, as this was the more critical constraint. The outermost set of inclined bars had extensions of $333 \mathrm{~mm}$ and $263 \mathrm{~mm}$ on the tension and compressive sides respectively, as the lap splice lengths were more critical for these shorter inclined bars.

Table 3.3: Reinforcement ratios of crack control reinforcement in the north and south cantilevers for pier caps $\mathrm{C} 2$ and $\mathrm{C} 2 \mathrm{R}$

\begin{tabular}{|c|c|c|}
\hline Type & $\begin{array}{c}\text { Vertical } \\
\rho_{v}\end{array}$ & $\begin{array}{c}\text { Horizontal } \\
\rho_{h}\end{array}$ \\
\hline North & $\begin{array}{c}0.00222+0.00112= \\
0.00334\end{array}$ & $\begin{array}{c}0.00121+0.00112= \\
0.00233\end{array}$ \\
\hline South & $0.00222+0.00112=$ & $0.00363+0.00112=$ \\
& 0.00334 & 0.00475 \\
\hline
\end{tabular}




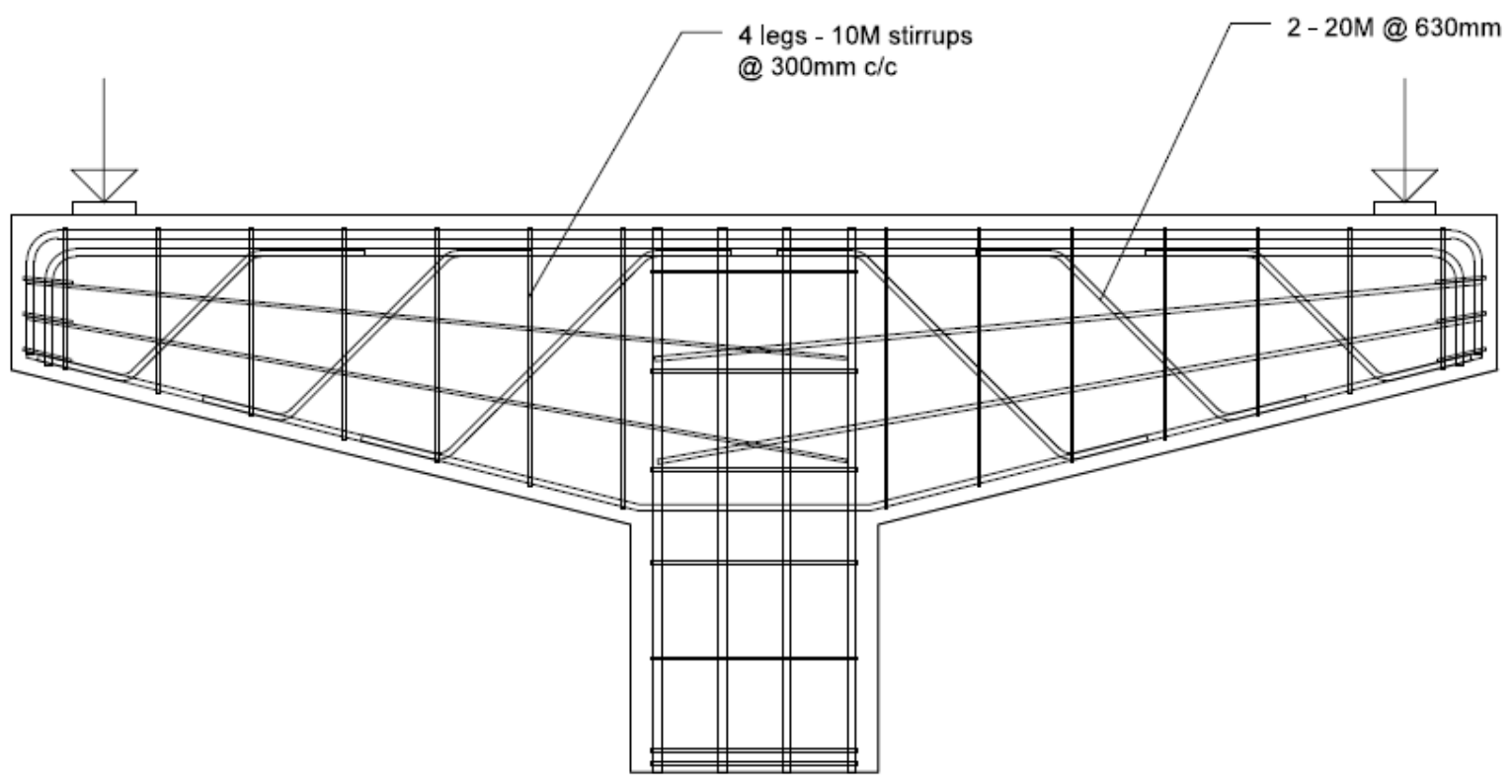

Figure 3.7: Reinforcing details of cap beams $\mathrm{C} 2$ and $\mathrm{C} 2 \mathrm{R}$

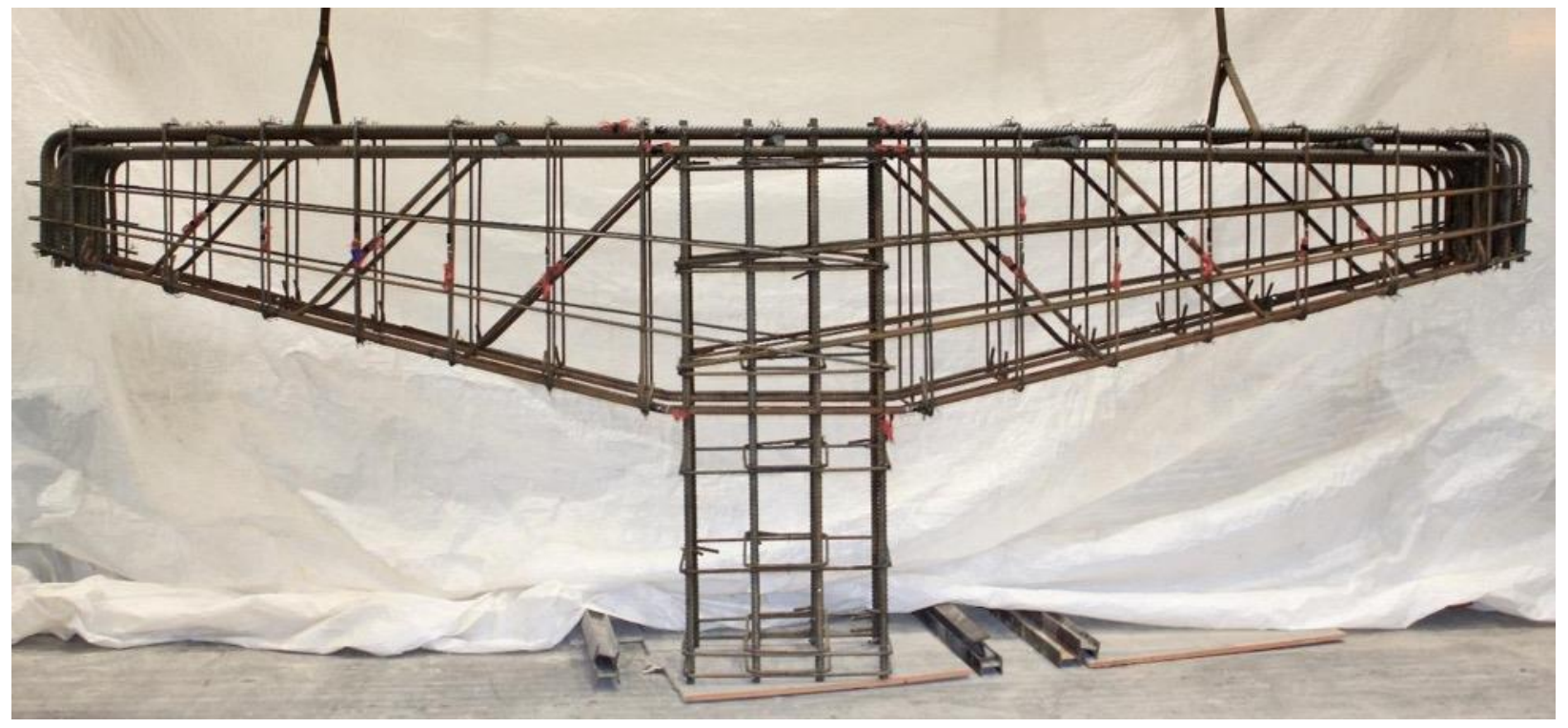

Figure 3.8: Reinforcing steel for cap beams $\mathrm{C} 2$ and $\mathrm{C} 2 \mathrm{R}$ 


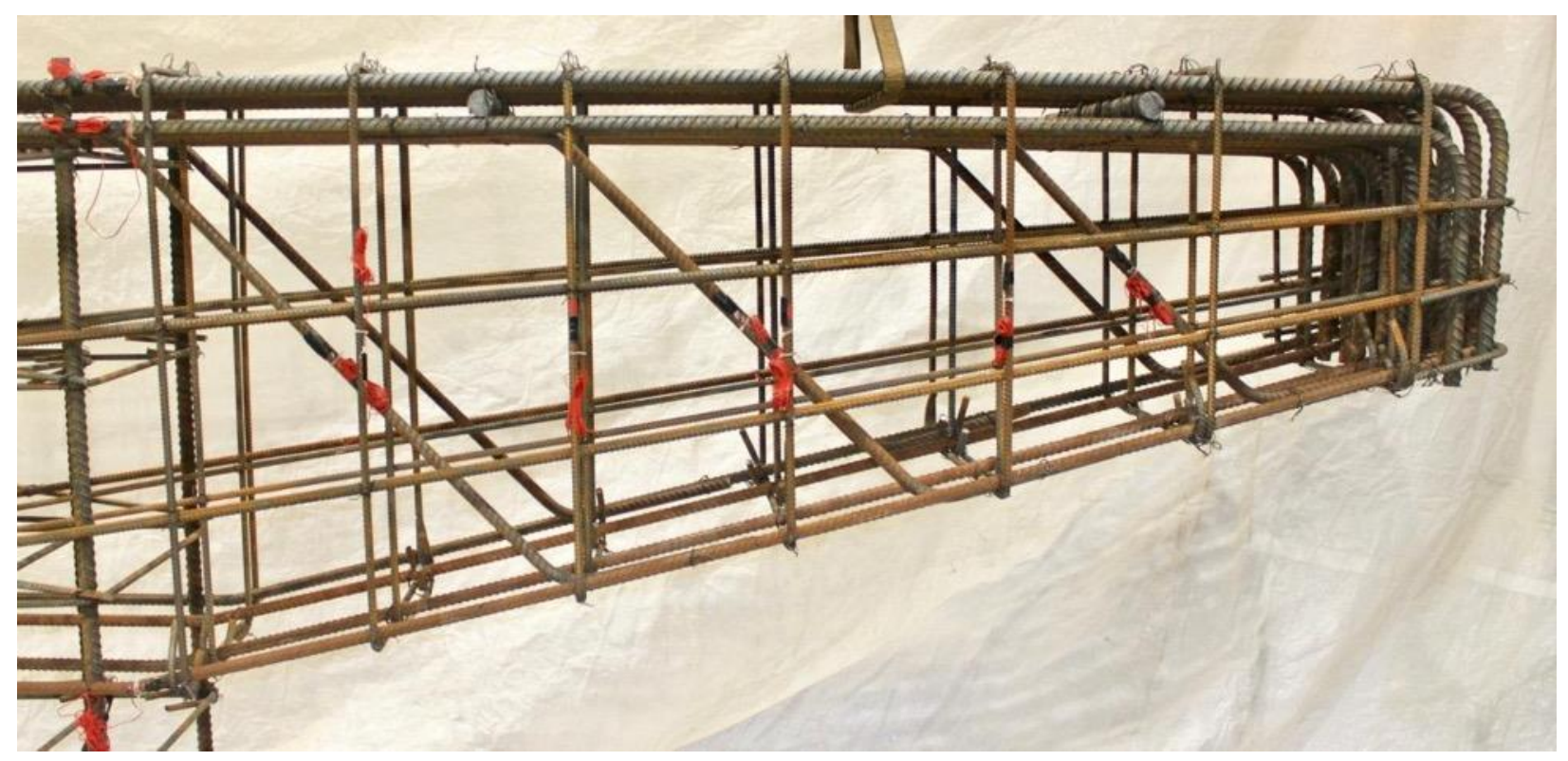

Figure 3.9: Reinforcing steel in south cantilever for cap beams $\mathrm{C} 2$ and $\mathrm{C} 2 \mathrm{R}$

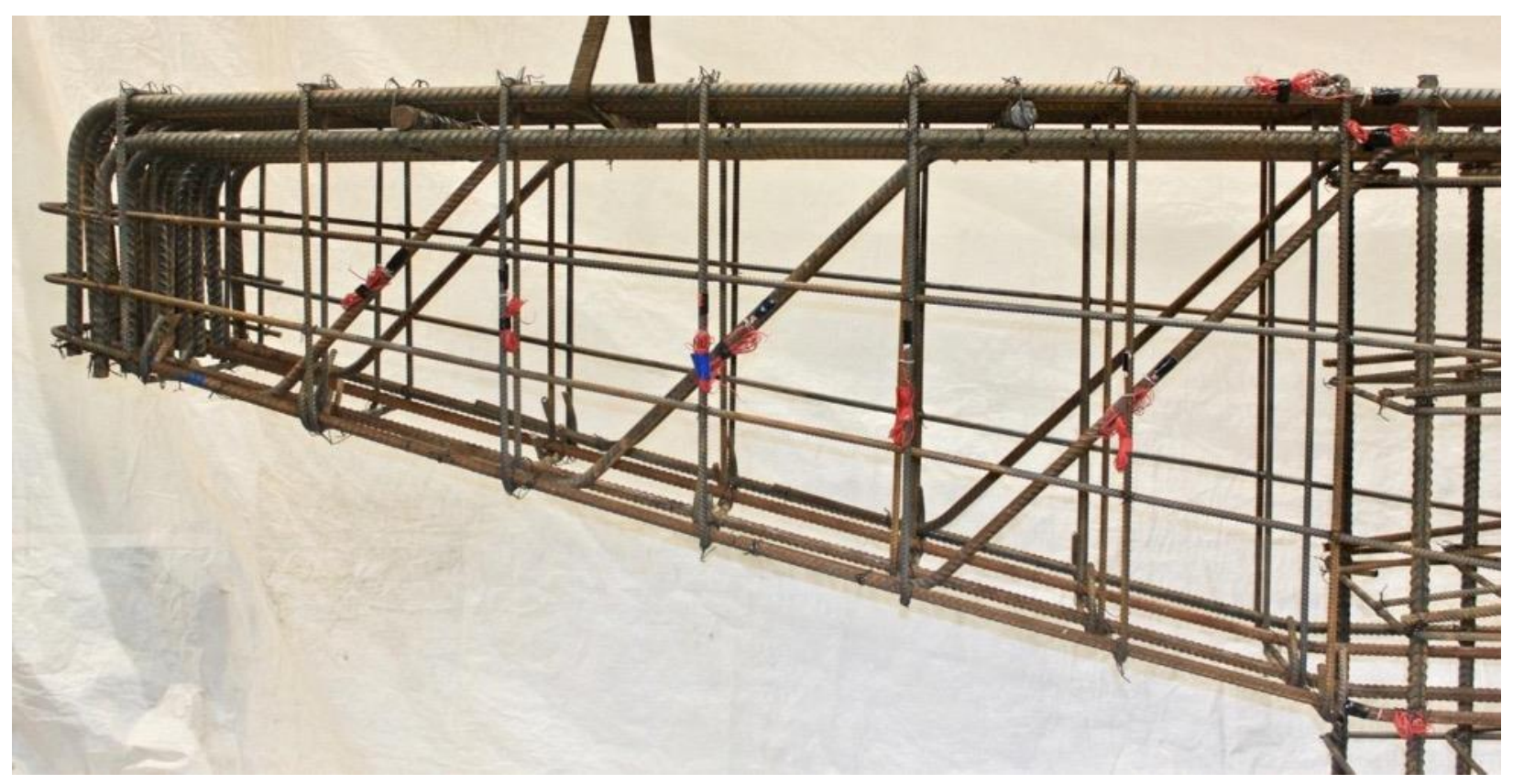

Figure 3.10: Reinforcing steel in north cantilever for cap beams $\mathrm{C} 2$ and $\mathrm{C} 2 \mathrm{R}$ 


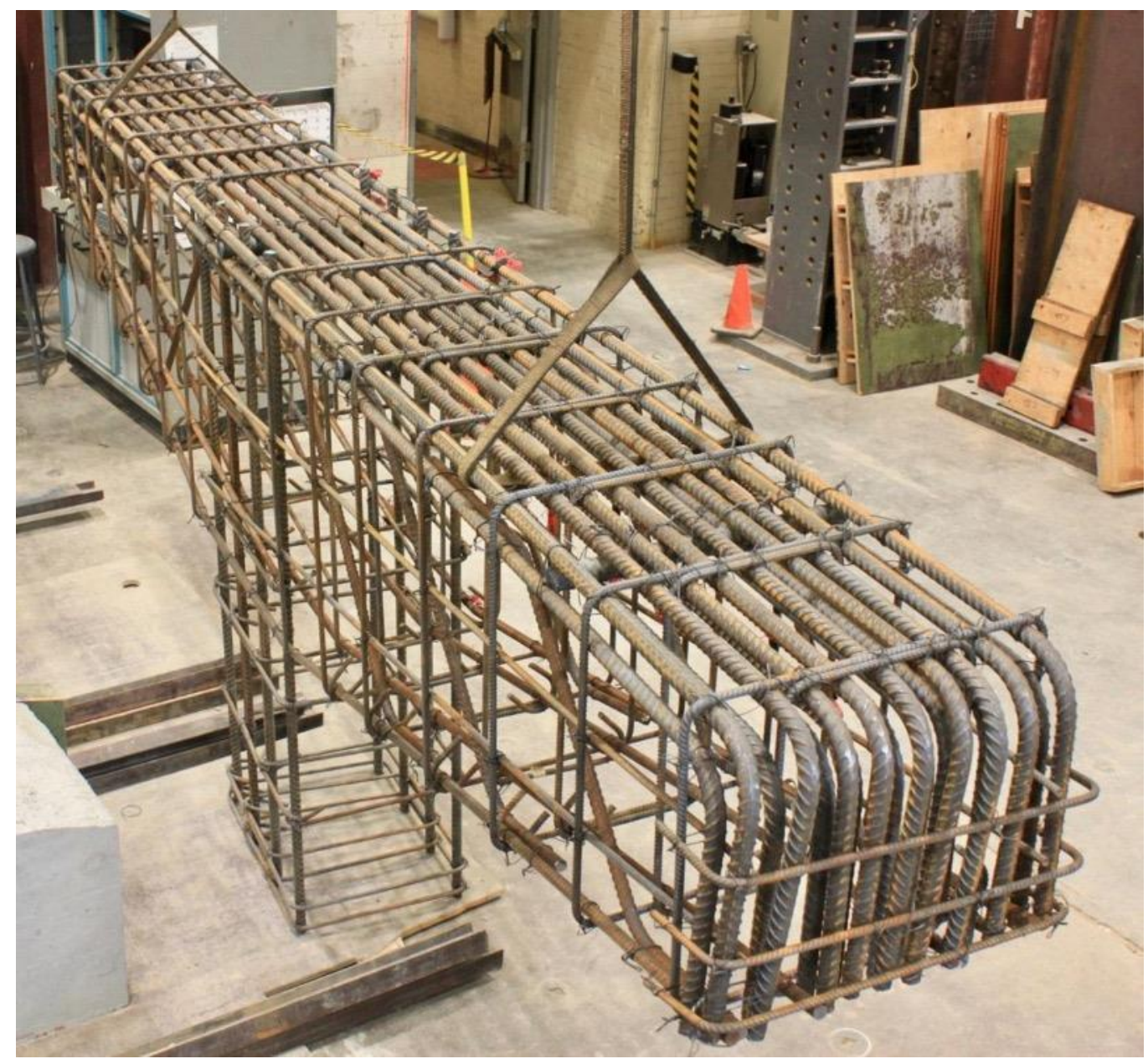

Figure 3.11: Top view of reinforcing steel for cap beams C2 and C2R

\subsection{Construction}

All reinforcing bars were cut and bent in the laboratory, and the reinforcing cages were assembled right-side up for ease of construction. Short lengths of 5-35M bars were placed transversely between the two top longitudinal steel layers at an $800 \mathrm{~mm}$ spacing to act as spacers. After assembly, the reinforcement cages were then flipped $180^{\circ}$ to be cast. Casting the cap beams upside down was advantageous in terms of facilitating formwork design and put each cap beam into the testing orientation. In order to position the reinforcing cage in the formwork, 50 $\mathrm{mm}$ plastic spacers were tied along the exterior of the reinforcing cages, followed by the cages being placed into their respective formwork (see Figure 3.12). The formwork was constructed from 3/4" sheets of form-ply and screws, and two reinforcement cages in their completed formwork are shown in Figure 3.13. To minimize formwork bulging, bracing was provided 
approximately $450 \mathrm{~mm}$ from the base of the cap beams by four threaded steel rods tightened between two steel I-beams on either side of the formwork. Additional bracing was provided for the cap beam column at a height of $1100 \mathrm{~mm}$ using steel angles and threaded rods (see Figure 3.13). Wooden planks were also fixed in place around the perimeter of the cap beam base. Transverse bracing was provided for the column via one 1-inch threaded rod tightened between two steel HSS sections and enclosed in an aluminum pipe spanning the column length. This detail was included to facilitate lifting and moving the pier caps once cast. Pier caps C1 and C1R were cast in tandem, followed by $\mathrm{C} 2$ and $\mathrm{C} 2 \mathrm{R}$. The casting of pier caps $\mathrm{C} 1$ and $\mathrm{C} 1 \mathrm{R}$ and the associated cylinders and beams for material testing is shown in Figure 3.14(a). The cap beams after formwork removal are shown in Figure 3.14(b).

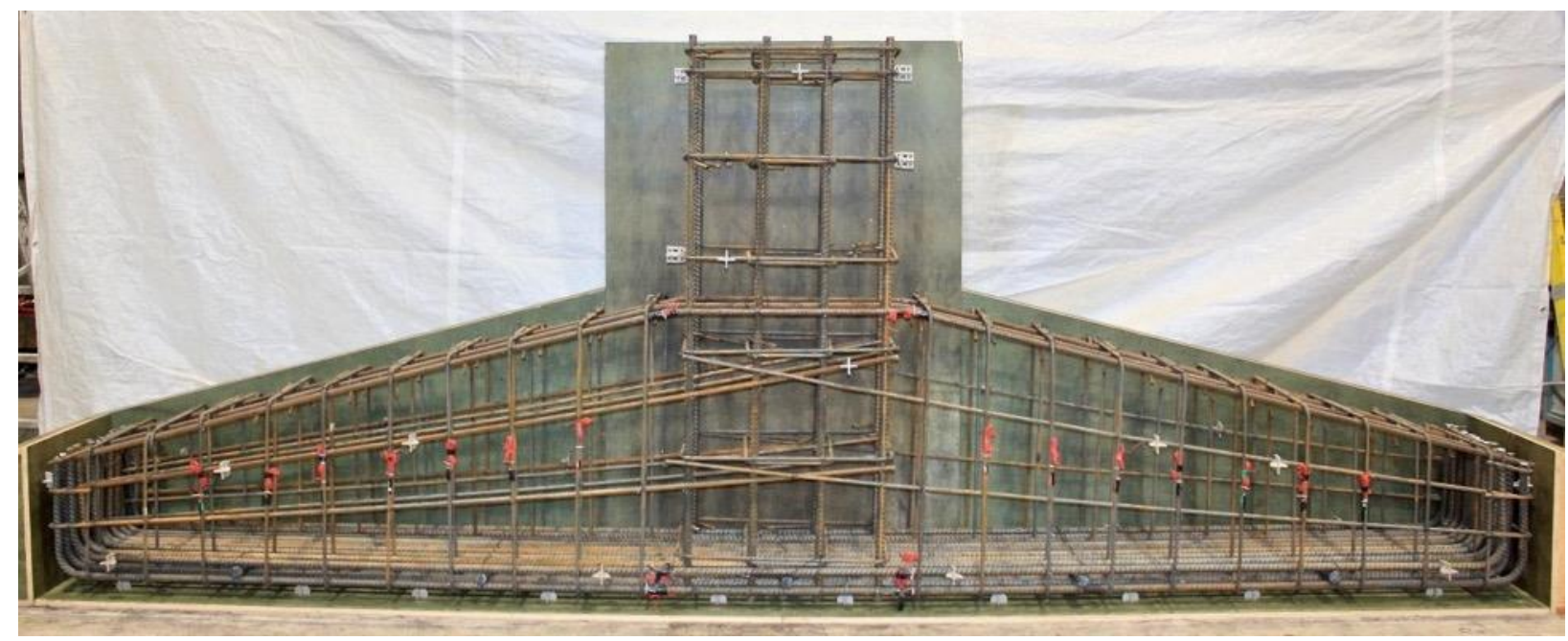

Figure 3.12: Placement of cap beams $\mathrm{C} 1$ and $\mathrm{C} 1 \mathrm{R}$ in inverted position 


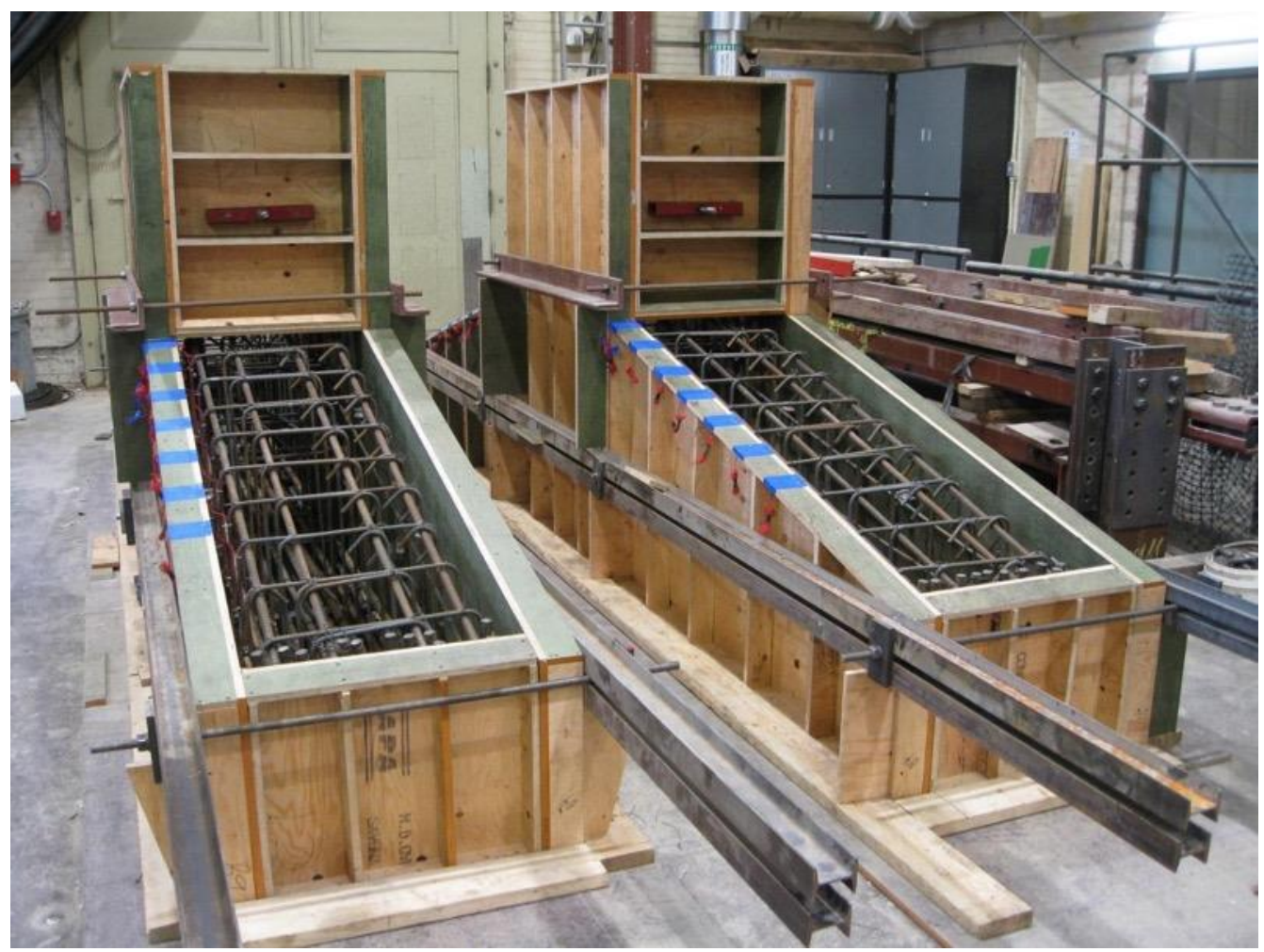

Figure 3.13: Formwork for casting cap beams in inverted position

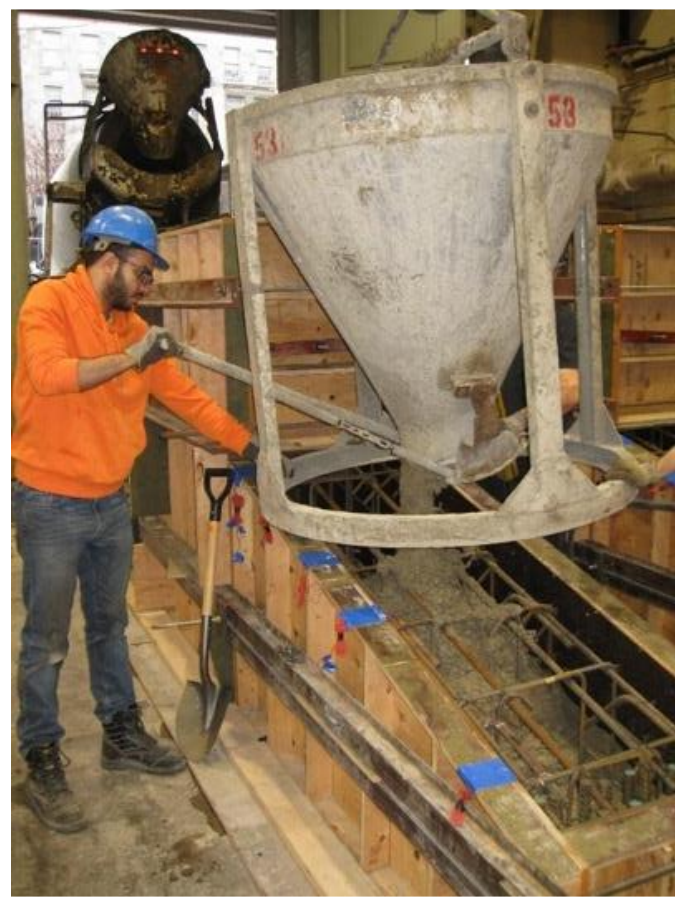

(a) casting of cap beam

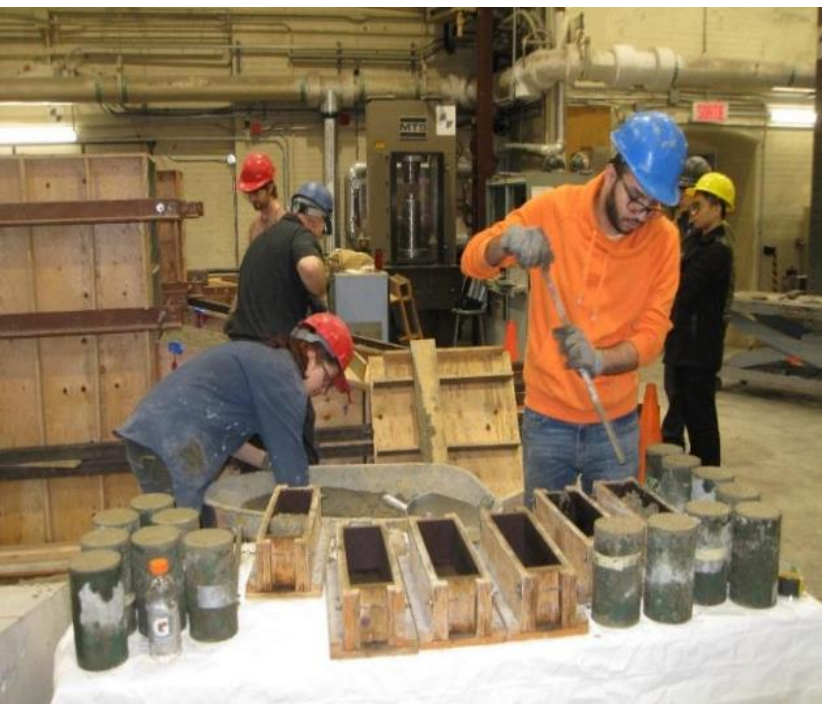

(b) casting of test beams and cylinders

Figure 3.14: Casting of cap beams $\mathrm{C} 1$ and $\mathrm{C} 1 \mathrm{R}$ 


\subsection{Material Properties}

\subsubsection{Concrete}

Two different ready-mix concrete batches were used during casting: Batch 1 for pier caps $\mathrm{C} 1$ and $\mathrm{C} 1 \mathrm{R}$, and Batch 2 for pier caps C2 and C2R. Table 3.4 summarizes the mixture proportions, which were the same for the two batches. A slump test and air content test were performed for the fresh concrete before placement as per the CSA A23.2-5C and CSA A23.2-4C Standards (CSA, 2014) respectively. Batch 1 had a slump of $125 \mathrm{~mm}$ and an air content of $6 \%$, while Batch 2 had a slump of $100 \mathrm{~mm}$ and an air content of 5\%. The specified concrete strength of both batches was $25 \mathrm{MPa}$.

Table 3.4: Concrete mix proportions

\begin{tabular}{|l|c|}
\hline \multicolumn{1}{|c|}{ Component } & Quantity $\left(\right.$ per m $\left.{ }^{3}\right)$ \\
\hline Type GUL Portland cement (granulated slag and silica fume) & $275 \mathrm{~kg}$ \\
\hline Concrete sand & $936 \mathrm{~kg}$ \\
\hline $10-20 \mathrm{~mm}$ limestone aggregate & $541 \mathrm{~kg}$ \\
\hline $5-14$ mm stone & $442 \mathrm{~kg}$ \\
\hline Water & $150 \mathrm{~L}$ \\
\hline Air & $5.5 \%$ \\
\hline Air entraining agent (ml/100 kg) & $22 \mathrm{ml} / 100 \mathrm{~kg}$ \\
\hline Water-reducing admixture & $133 \mathrm{ml} / 100 \mathrm{~kg}$ \\
\hline
\end{tabular}

The pier caps were cast in the formwork and the concrete sufficiently vibrated. The concrete in the cantilever portions were placed first followed by casting the concrete in the column. Two hours after casting the top of the column was covered in wet burlap and a plastic sheeting. The pier caps were moist-cured in the formwork for 7 days, after which the formwork was removed, and the pier caps allowed to cure at standard temperature conditions. 
Concrete cylinders and rectangular beams for material testing were made concurrent with the casting of the pier caps. As with the pier caps, these were covered in wet burlap and plastic sheeting two hours after casting. After curing for 24 hours in this condition they were removed from their forms, and subsequently placed in a curing chamber until testing. The cylinders were cast as per the requirements in the CSA A23.2-12C (CSA, 2014) Standard, each measuring 100 $\mathrm{mm}$ in diameter with a length of $200 \mathrm{~mm}$. These were used in determining the average concrete compressive strength, $f_{c}^{\prime}$, and the splitting tensile strength, $f_{s p}$, from the compression and splitcylinder tests detailed in CSA A23.2-9C and CSA A23.2-13C respectively (CSA, 2014). The rectangular beams were cast as per the CSA A23.2-8C (CSA, 2014) Standard, each measuring $100 \mathrm{~mm}$ in depth, $100 \mathrm{~mm}$ in width, and $300 \mathrm{~mm}$ in length. Four-point bending tests were performed in accordance to this same CSA Standard in order to determine the modulus of rupture, $f_{r}$, of each concrete batch. All material properties were determined from the average of at least 3 test samples. The concrete material properties are summarized in Table 3.5, and a typical stress-strain relationship for the concrete compressive strengths of both batches is shown in Figure 3.15.

Table 3.5: Concrete material properties

\begin{tabular}{|c|c|c|c|c|c|}
\cline { 2 - 5 } \multicolumn{1}{c|}{} & $\begin{array}{c}\text { Age at } \\
\text { Testing }\end{array}$ & $\begin{array}{c}f_{c}{ }^{\prime}(\mathrm{MPa}) \\
(\mathrm{STDEV})\end{array}$ & $\begin{array}{c}\varepsilon_{c^{\prime}} \\
(\mathrm{STDEV})\end{array}$ & $\begin{array}{c}f_{s p}(\mathrm{MPa}) \\
(\mathrm{STDEV})\end{array}$ & $\begin{array}{c}f_{r}(\mathrm{MPa}) \\
(\mathrm{STDEV})\end{array}$ \\
\hline Batch 1 \\
$(\mathrm{C} 1$ \& C1R)
\end{tabular}




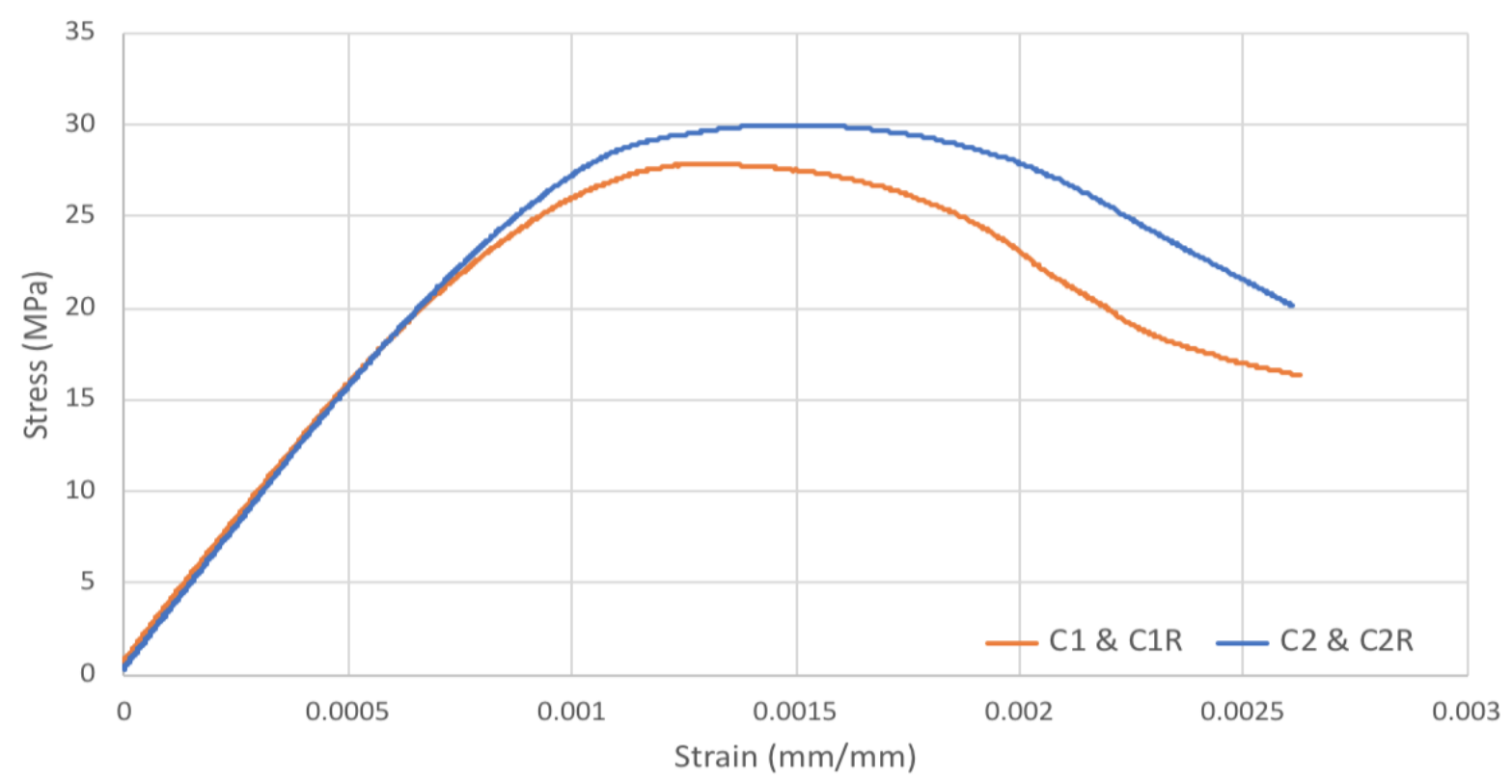

Figure 3.15: Typical concrete compressive stress-strain curve for batches 1 and 2

\subsubsection{Reinforcing Steel}

The reinforcing steel comprised of $10 \mathrm{M}, 15 \mathrm{M}, 20 \mathrm{M}$, and $25 \mathrm{M}$ deformed bars, all of which were specified as Grade 400 with properties in accordance with CSA G30.18 (CSA, 2009). A minimum of 3 tension tests were performed per bar size as per the A615/615M-16 Standard (ASTM, 2016). The loading machine provided axial force values while the axial displacement was recorded by an extensometer. From the stress-strain curves average steel properties were determined for each size of bar, namely the yield strength $\left(f_{y}\right)$, ultimate strength $\left(f_{u}\right)$, and strains at yielding $\left(\varepsilon_{y}\right)$, at the initiation of strain hardening $\left(\varepsilon_{s h}\right)$, and at ultimate strength $\left(\varepsilon_{u}\right)$. Table 3.6 summarizes these properties. Figure 3.16 presents a typical stress-strain curve for each reinforcing bar size. 
Table 3.6: Reinforcing bar material properties

\begin{tabular}{|c|c|c|c|c|c|}
\cline { 2 - 6 } \multicolumn{1}{c|}{} & $\begin{array}{c}f_{y}(\mathrm{MPa}) \\
(\mathrm{STDEV})\end{array}$ & $\begin{array}{c}f_{u}(\mathrm{MPa}) \\
(\mathrm{STDEV})\end{array}$ & $\begin{array}{c}\varepsilon_{y} \\
(\mathrm{STDEV})\end{array}$ & $\begin{array}{c}\varepsilon_{s h} \\
(\mathrm{STDEV})\end{array}$ & $\begin{array}{c}\varepsilon_{u} \\
(\mathrm{STDEV})\end{array}$ \\
\hline $10 \mathrm{M}$ & $\begin{array}{c}461 \\
(22.3)\end{array}$ & $\begin{array}{c}571 \\
(23.6)\end{array}$ & $\begin{array}{c}0.00231 \\
(0.000112)\end{array}$ & $\begin{array}{c}0.0286 \\
(0.00282)\end{array}$ & $\begin{array}{c}0.144 \\
(0.0140)\end{array}$ \\
\hline $15 \mathrm{M}$ & 442 & 551 & 0.00221 & 0.0269 & 0.131 \\
& $(29.1)$ & $(18.0)$ & $(0.000145)$ & $(0.00173)$ & $(0.0141)$ \\
\hline $20 \mathrm{M}$ & 448 & 558 & 0.00224 & 0.0265 & 0.141 \\
& $(8.14)$ & $(6.81)$ & $(0.000038)$ & $(0.00053)$ & $(0.0047)$ \\
\hline $25 \mathrm{M}$ & 465 & 568 & 0.00232 & $\begin{array}{c}0.0218 \\
(0.00048)\end{array}$ & $\begin{array}{c}0.122 \\
(0.0017)\end{array}$ \\
\hline
\end{tabular}

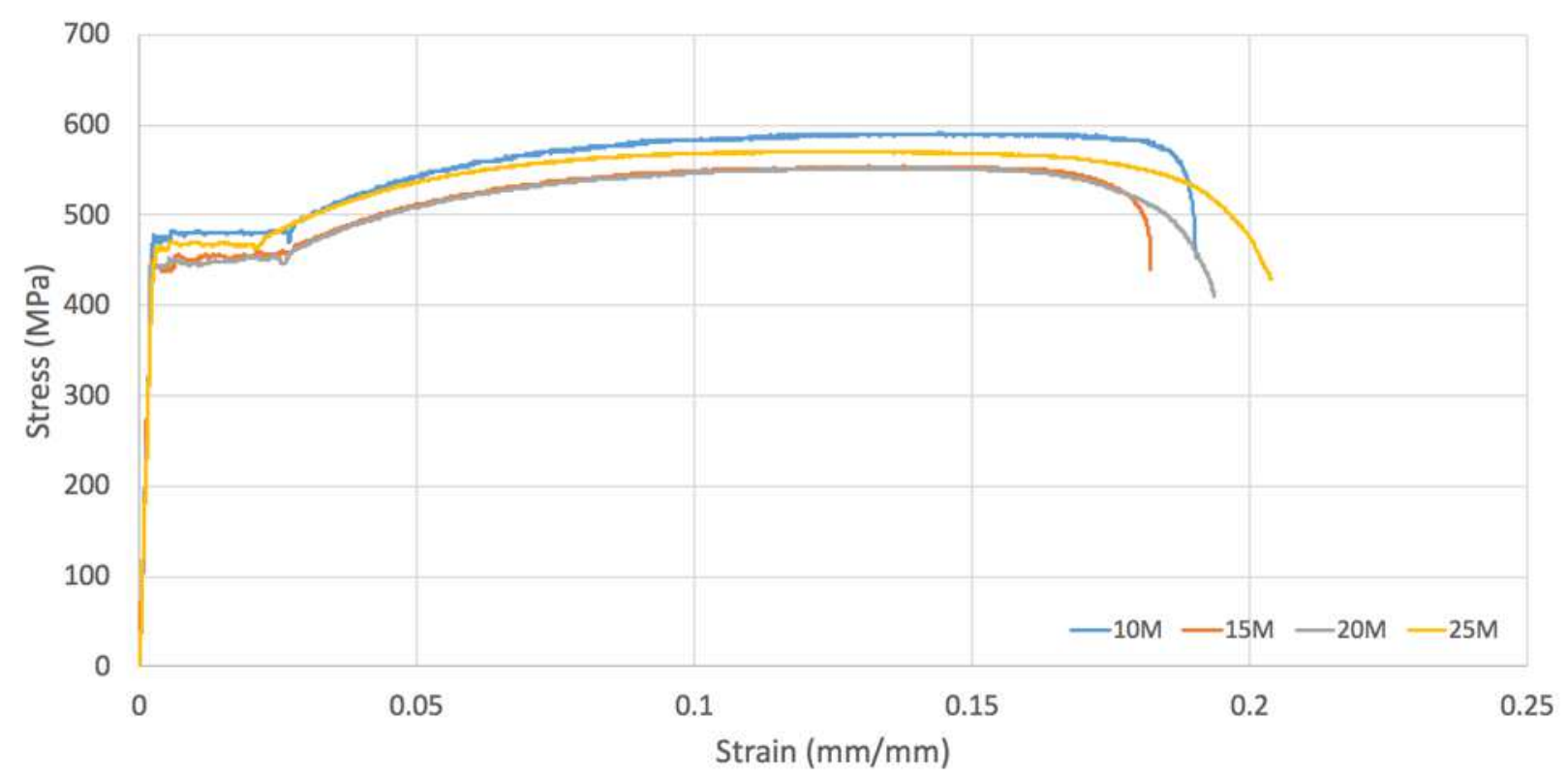

Figure 3.16: Typical tensile stress-strain relationships for the reinforcing bars 


\subsection{Test Setup and Instrumentation}

\subsubsection{Test Setup}

The test setup can be seen in Figure 3.17. Because the self-weight of the cap beams introduces a shear at the critical section of less than $1 \%$ of the failure shear, the cap beams were tested in an inverted position to facilitate testing. The pier caps were loaded by the computercontrolled MTS universal testing machine with a loading capacity of $11,000 \mathrm{kN}$. The machine applied a downwards force via a $559 \mathrm{~mm}$ diameter loading plate fixed to the MTS machine. This then applied loading centered on a rectangular $600 \times 700 \times 40 \mathrm{~mm}$ thick steel plate seated and centered at the top of the column. Capping compound was applied between the plate and column to level the column top surface thereby improving load distribution.

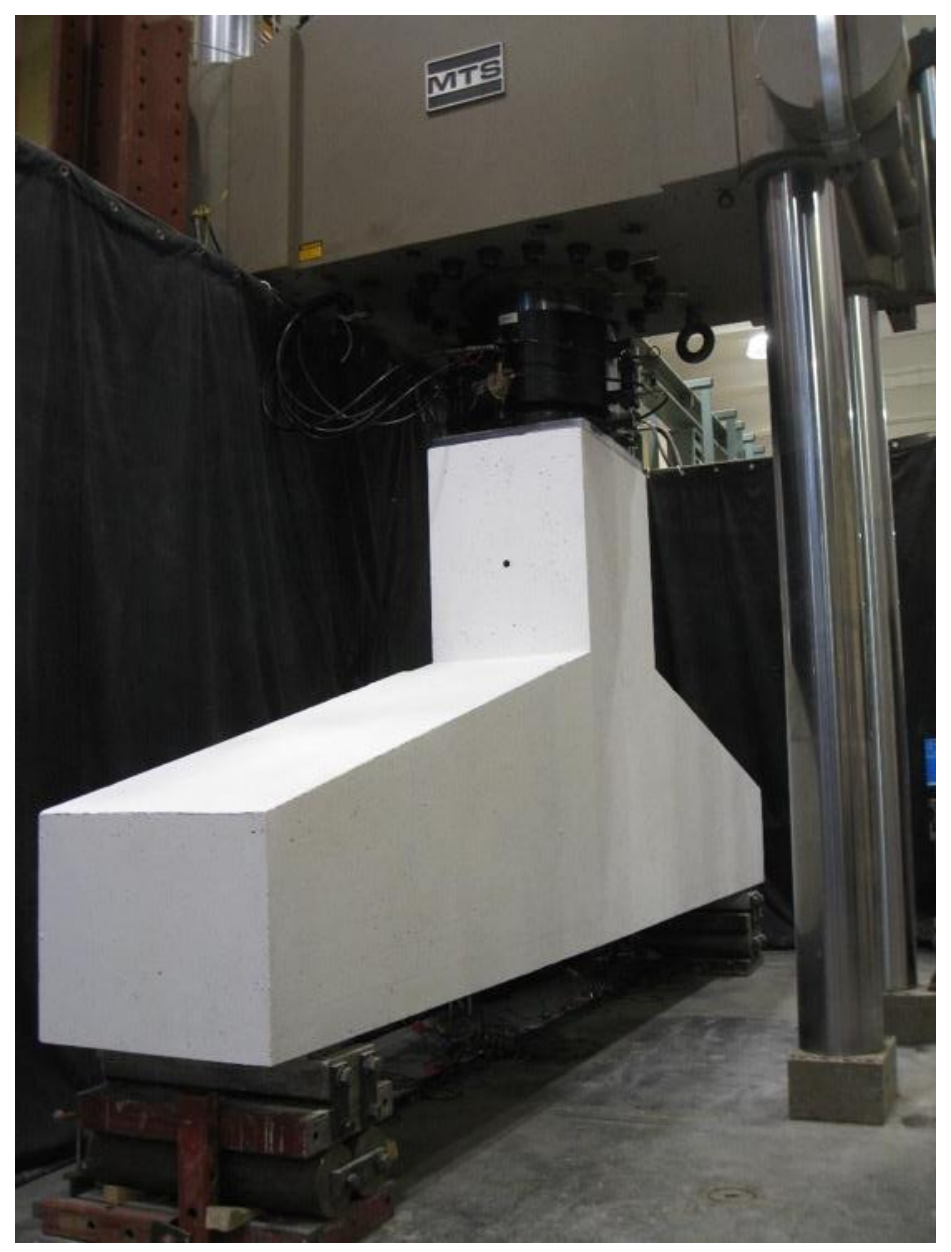

Figure 3.17: Cap beam test setup 
The supports were made up of rockers and rollers located at $4200 \mathrm{~mm}$ center-to-center. Each bearing plate was $200 \mathrm{~mm}$ x $500 \mathrm{~mm}$ x $25 \mathrm{~mm}$ thick, with capping compound applied between the bearing plate and the base of the specimen. Each bearing plate was supported by a $200 \times 600 \times 100 \mathrm{~mm}$ rocker, resting on top of two $75 \mathrm{~mm}$ radius rollers of length $600 \mathrm{~mm}$ sandwiched between two $375 \times 600 \times 75 \mathrm{~mm}$ plates. Overall the base of the specimen was at a height of $437 \mathrm{~mm}$ from the laboratory strong-floor.

\subsubsection{Instrumentation}

The load applied to the pier cap columns was measured by the load cell of the MTS machine. Strains were measured by strain gages installed on the specimen reinforcement before casting, as shown in Figure 3.18 for cap beams C1 and C1R and Figure 3.19 for cap beams C2 and C2R. Each pier caps had six 5-mm strain gages located at the column-cantilever interfaces: one on each cantilever for the primary compressive steel layer and the two primary tensile steel layers. Specimens C1 and C1R had seven additional 2-mm strain gages in each cantilever, located on the centers of outer stirrups 2 through 8 from the column. Specimens C2 and C2R had four 2-mm strain gages located on the centers of outer stirrups 2 through 5 from the column per side, and an additional three 5-mm strain gages per side, each located on the centers of the inclined bars.

Nineteen Linear Voltage Differential Transducers (LVDTs) were used to measure displacements for each specimen, as can be seen in Figure 3.20 for cap beams C1 and C1R and Figure 3.21 for cap beams C2 and C2R. These were installed by drilling $40 \mathrm{~mm}$ deep 1/4" diameter holes at the start and end point of each LVDT. Short threaded rods were then coated with epoxy on one end and hammered into the drilled holes. Plastic LVDT holders or ends were then twisted onto the threaded rods. The LVDTs would then be placed into the holders, tightened in place with nuts, and a steel extension rod attached to each. Figure 3.22 shows a picture of the LVDTs in place.

Three 25-mm LVDTs, designated as LVDISM, LVDISL and LVDISR, were installed on stands and placed vertically at the two support locations and at mid-span. These were used to record deflections from the centroid of the primary tension steel, which were then used in calculating the mid-span deflection as: 


$$
\Delta_{\text {Midspan }}=\Delta_{\text {Mid }}-\frac{1}{2}\left(\Delta_{\text {North }}+\Delta_{\text {South }}\right)
$$

where: $\Delta$ Mid $=$ deflection recorded at mid-span LVDT (LVDISM)

$\Delta_{\text {North }}=$ deflection recorded by north support LVDT (LVDISL)

$\Delta$ south $=$ deflection recorded by south support LVDT (LVDISR)

This was done to remove support settlement recorded by LVDISM. Eight 15-mm LVDTs designated as LV1-LV8 were placed along the centroid of the primary tensile steel from supportto-support with equal lengths of $525 \mathrm{~mm}$. These were installed to determine the average longitudinal strains in the tensile steel. LV9 and LV10 were placed at the center of the primary compressive steel at the column-cantilever interface. Each was a 15-mm LVDT with lengths of $150 \mathrm{~mm}$, with $100 \mathrm{~mm}$ in the cantilever and the remaining $50 \mathrm{~mm}$ in the column. These were used in determining the compressive strains at the reentrant corner. Each pier cap had a rosette in each cantilever, made up of two 15-mm LVDTs in the horizontal and diagonal orientations and one vertical 25-mm LVDT. The center of each rosette was located at the mid-depth of the cantilever, at a horizontal distance of $918 \mathrm{~mm}$ from the center of each support. The gage length of the rosette LVDTs was $500 \mathrm{~mm}$, except for specimens C1R and C2R. LVD1 and LVD2 were adjusted to $565 \mathrm{~mm}$ and LVV1 to $465 \mathrm{~mm}$ for C1R. LVV1 and LVV2 were adjusted to $460 \mathrm{~mm}$ and LVD1 and LVD2 adjusted to $630 \mathrm{~mm}$ for C2R. These changes were made so that the LVDTs would not interfere with the external post-tensioning that was applied later. The rosettes were used to determine principle strains and the angles of principal compressive strains. 


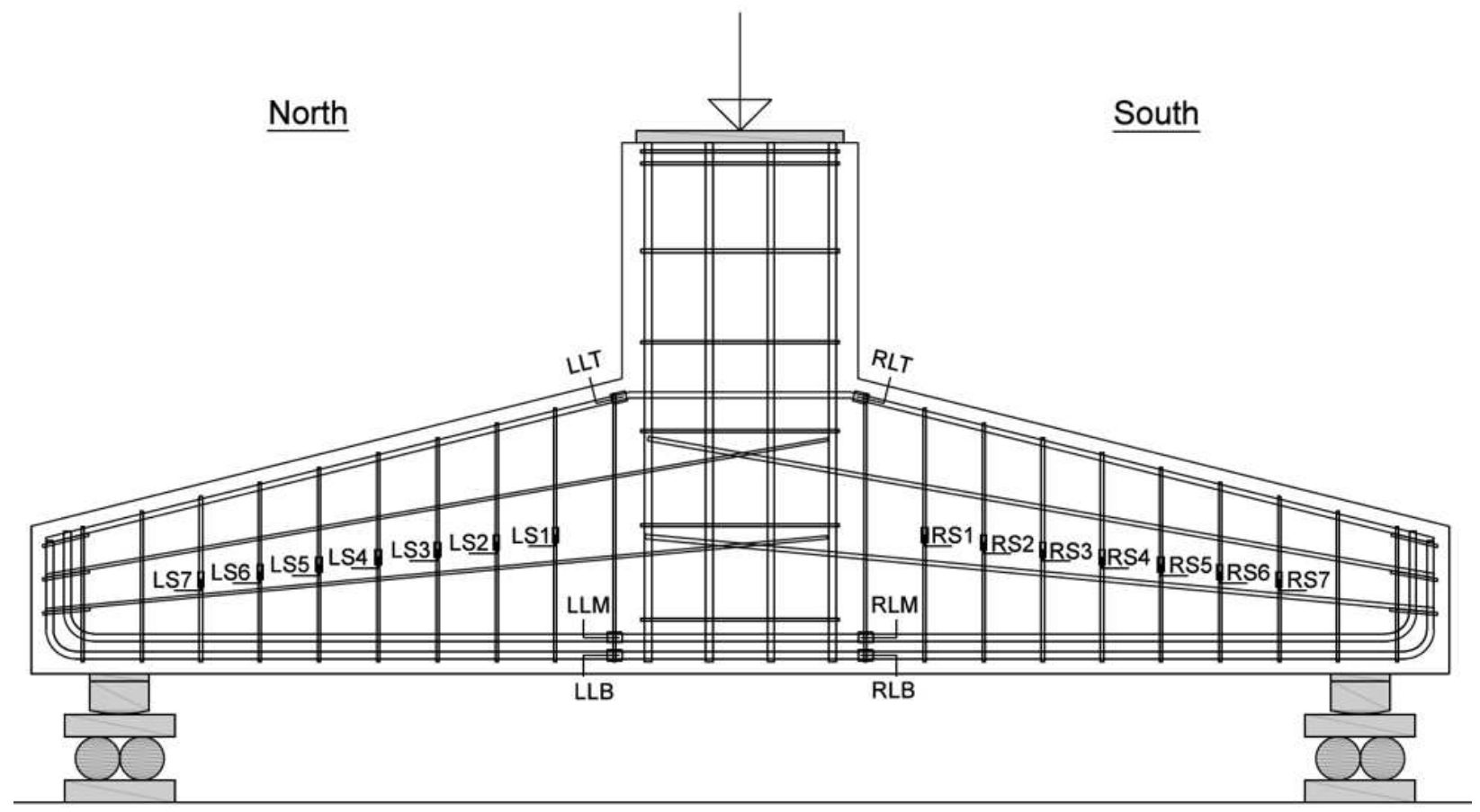

Figure 3.18: Locations of strain gages for cap beams $\mathrm{C} 1$ and $\mathrm{C} 1 \mathrm{R}$

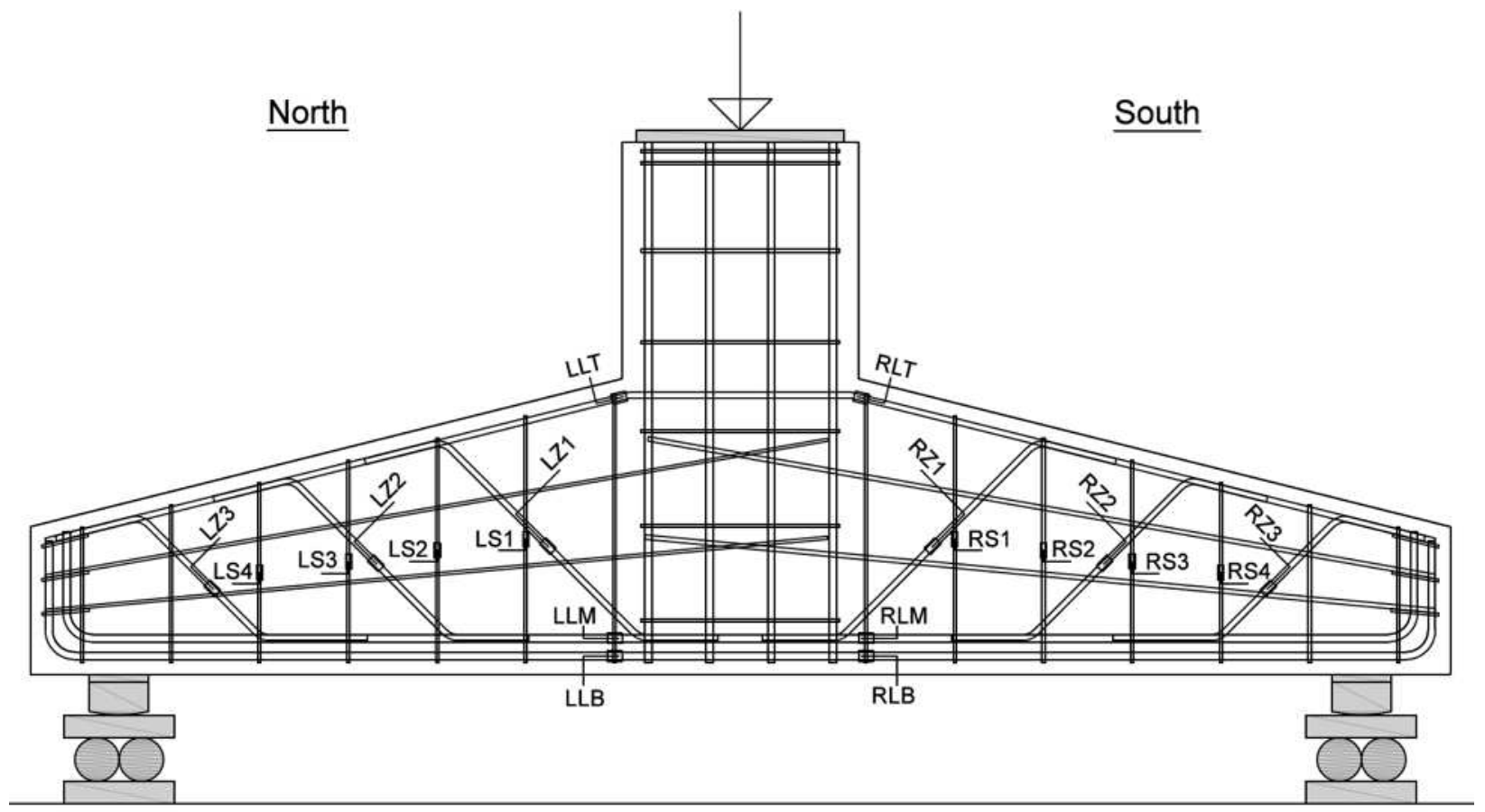

Figure 3.19: Locations of strain gages for cap beams C2 and C2R 


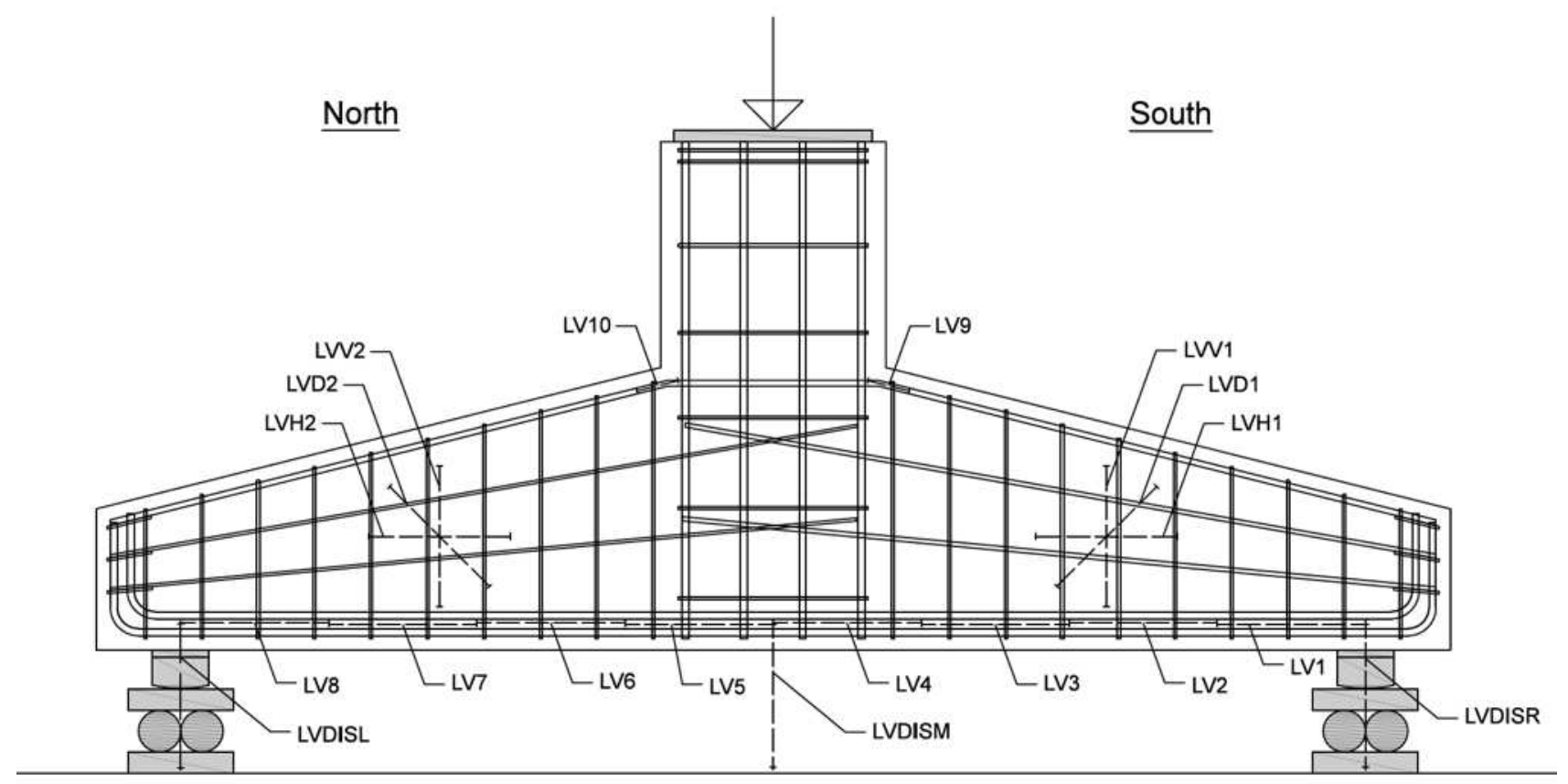

Figure 3.20: Locations of LVDTs for cap beams $\mathrm{C} 1$ and C1R

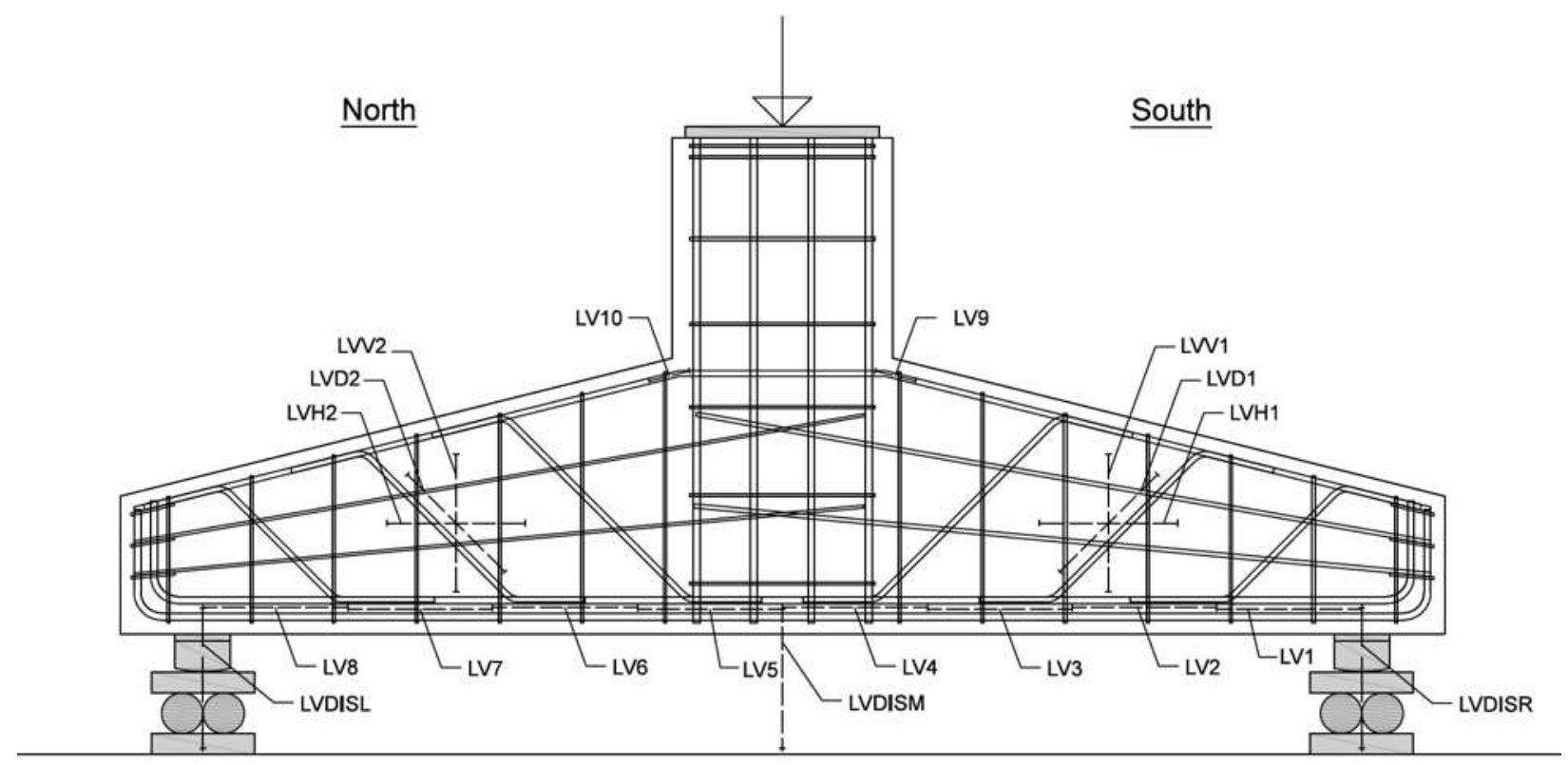

Figure 3.21: Locations of LVDTs for cap beams C2 and C2R 


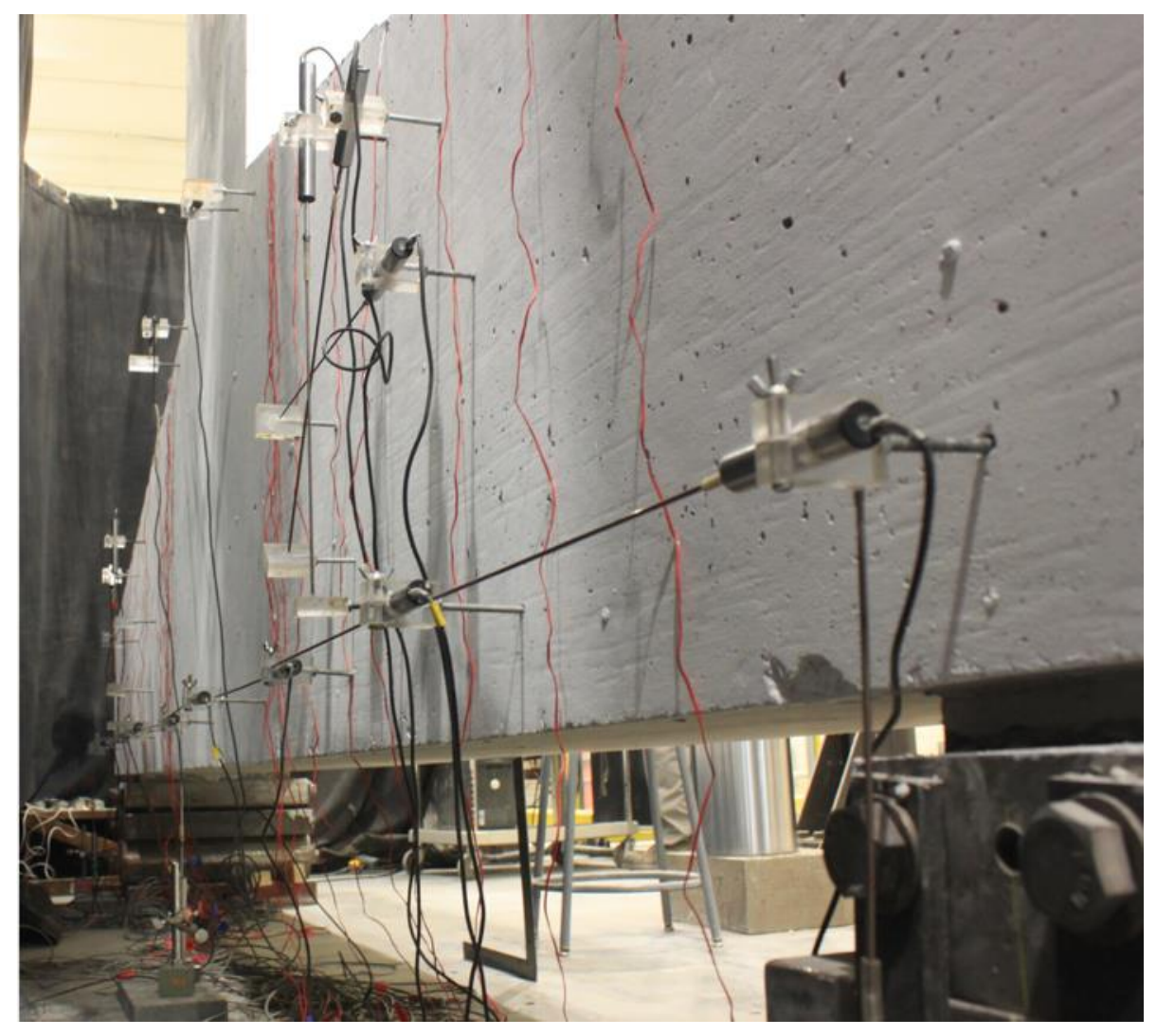

Figure 3.22: Typical LVDT setup on cap beams

\subsection{Testing Procedure}

\subsubsection{General Testing Procedure}

Each pier cap was initially loaded at a rate of $1.5 \mathrm{kN} / \mathrm{s}$ up to the service load of $1050 \mathrm{kN}$ in shear, after which the specimens were loaded in deflection control at a rate of $0.007 \mathrm{~mm} / \mathrm{s}$ for the remainder of the test. Data was recorded at 0.5 second intervals. The service load of $1050 \mathrm{kN}$ was chosen as it is at $70 \%$ of the predicted ultimate factored shear capacity of the cap beam $\mathrm{C} 1$ design. This was deemed reasonable as bridges similar to the existing Champlain Bridge were designed for service loads at about $60-80 \%$ of their ultimate factored shear capacities. Load stages were taken at intervals of $300 \mathrm{kN}$, except near failure when the deflection between two loading stages was not to exceed $2 \mathrm{~mm}$. These loading stages were used to mark and measure crack widths, and to take photographs. The specimens were loaded until failure was observed in one cantilever, after which they were unloaded at a rate of $1.5 \mathrm{kN} / \mathrm{s}$. External shear clamps were then applied to the failed side, where it was then possible to reload the pier cap and fail the 
opposite cantilever. The pier cap was loaded once again at the same rate until this second failure was attained, after which the pier caps were unloaded at $10 \mathrm{kN} / \mathrm{s}$.

\subsubsection{Application of External Shear Clamps}

The external shear clamping was performed with three clamps installed on the cantilever side that experienced shear failure, at locations that would best constrain the shear crack from reopening. Figure 3.23 shows an example of the external shear clamping, in this case applied to the north cantilever of cap beam C1. Each clamp was made up of a pair of 1 in. $(25.4 \mathrm{~mm})$ diameter high strength threaded rods tensioned between two HSS sections. The HSS sections resting on the inclined cantilever surface were placed in bearing against hardwood wedges to account for the slope.

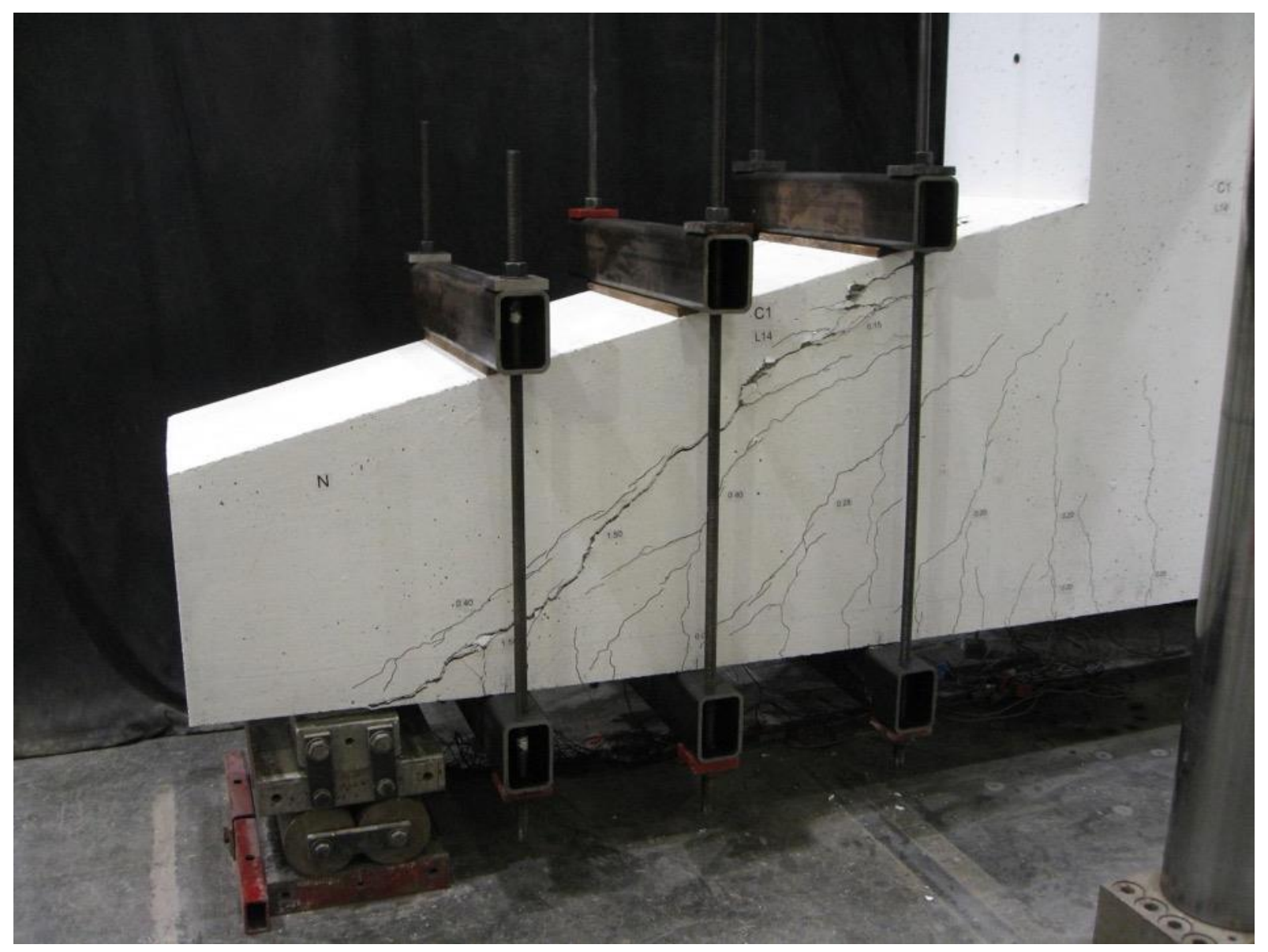

Figure 3.23: Shear clamps applied to the north cantilever of cap beam C1 


\subsubsection{Horizontal Post-Tensioning of Pier Caps C1R and C2R}

Post-tensioning was applied to cap beams C1R and C2R at the service load level. Figure 3.24 shows a cap beam with the post-tensioning installed. Four 1 in. $(25.4 \mathrm{~mm})$ diameter high strength threaded rods were used for the post-tensioning, with each rod anchored by a pair of HSS beams on either side of the pier caps, and each HSS beam in bearing against a $254 \mathrm{~mm}$ high by $500 \mathrm{~mm}$ wide by $25 \mathrm{~mm}$ thick steel plate. The bottom of each plate was covered in capping compound, pressed against the pier cap ends, and fixed in place with screws drilled into the pier cap. The centroid of the post-tensioning was located $167 \mathrm{~mm}$ from the tension face. The north end was the jacking end, with post-tensioning applied by the "turn of nut" method. The rods were tightened to $10 \mathrm{kN}$ each, and then tightened in stages until each rod was at $150 \mathrm{kN}$ for a total post-tensioning force of $600 \mathrm{kN}$. The jacking forces were monitored at the dead end on the south side by $225 \mathrm{kN}$ capacity load cells, and the loading machine held constant at $2100 \mathrm{kN}$ during the post-tensioning operation. After post-tensioning the load cells were used to monitor the change in post-tensioning force as each pier cap was loaded. Figure 3.25 shows the setup for both the jacking end and dead end.

The existing Champlain Bridge used 6-36 mm diameter bars for post-tensioning with a total force representing $16.2 \%$ of the nominal yield force of the primary tension reinforcement. For the specimens discussed in this research 18-25M bars were used as the primary tension reinforcement, with a nominal yield force of,

$$
A_{s} f_{y}=18 \times 500 \mathrm{~mm}^{2} \times 400 \mathrm{MPa}=3,600 \mathrm{kN}
$$

Thus $600 \mathrm{kN}$ was chosen as the post-tensioning force for these pier caps, as it represents $16.7 \%$ of this nominal yield force. 


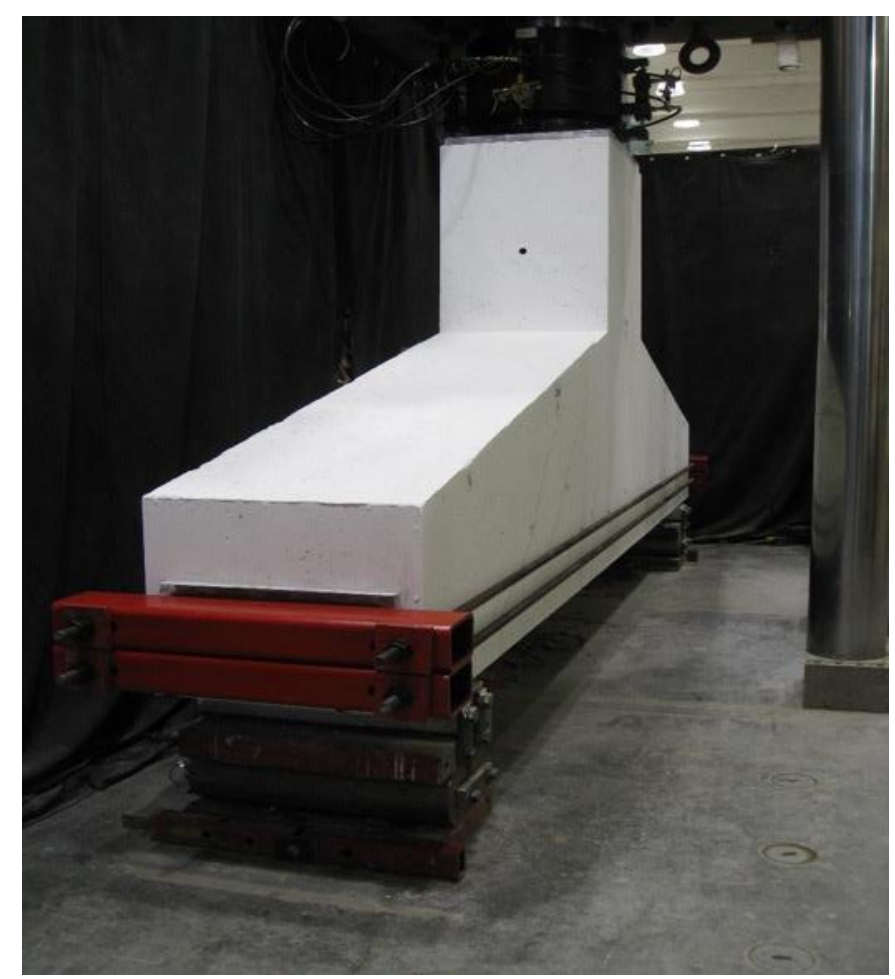

Figure 3.24: Post-tensioning of cap beam

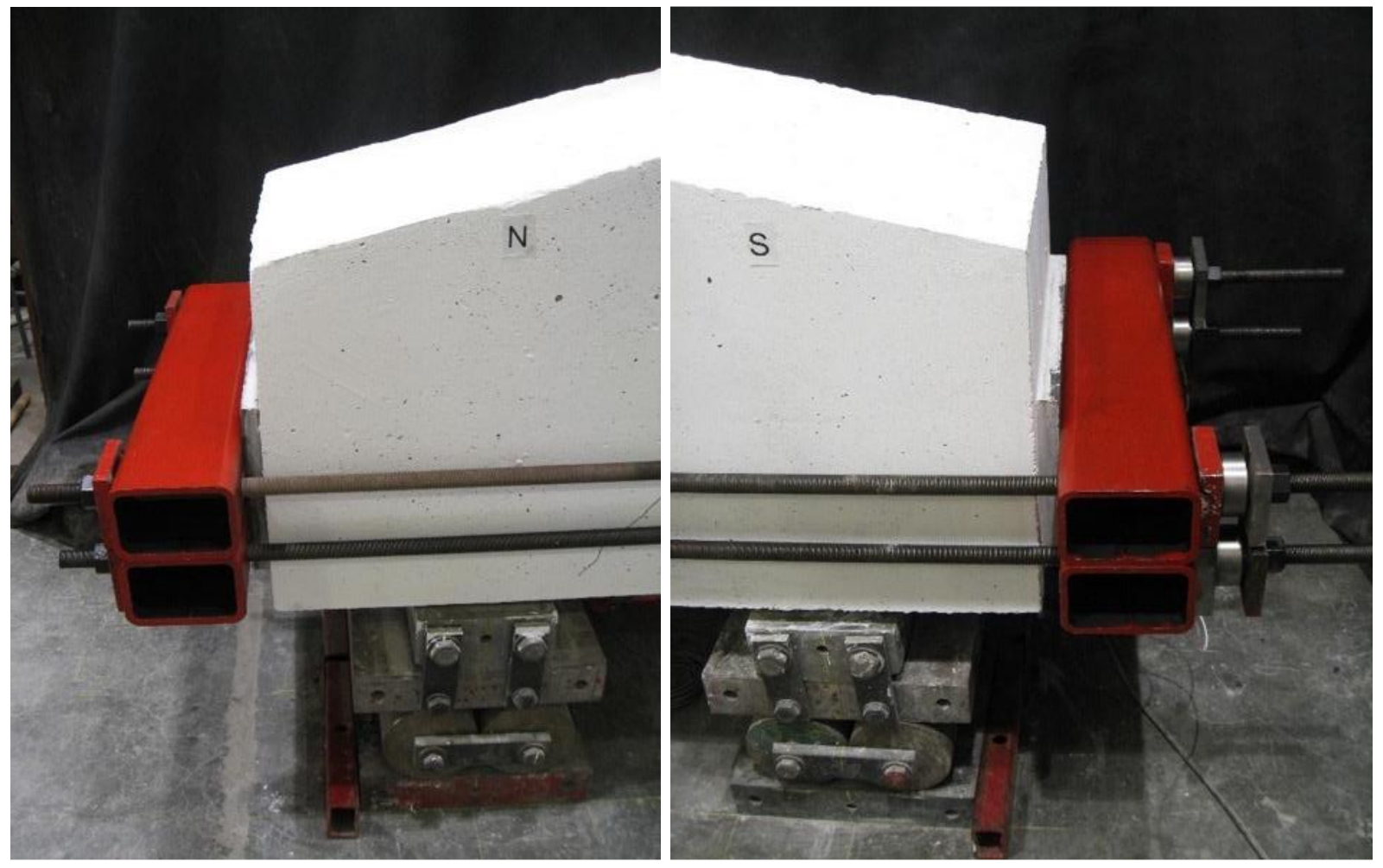

Figure 3.25: Jacking end (left) and dead end (right) for post-tensioning 


\section{CHAPTER 4}

\section{EXPERIMENTAL RESULTS}

\subsection{Pier Cap C1}

\subsubsection{Shear-Deflection Response}

The shear versus midspan deflection response for pier cap C1 is shown in Figure 4.1. The pier cap reached a shear of $1908 \mathrm{kN}$ and a midspan deflection of $17.3 \mathrm{~mm}$ before failing in shear in the north cantilever. After the installation of shear clamps on the north cantilever the pier cap reached a shear of $1885 \mathrm{kN}$ and a midspan deflection of $27.6 \mathrm{~mm}$ before failing in the south cantilever. The south cantilever had reached a higher shear of $1908 \mathrm{kN}$ on the initial loading cycle.

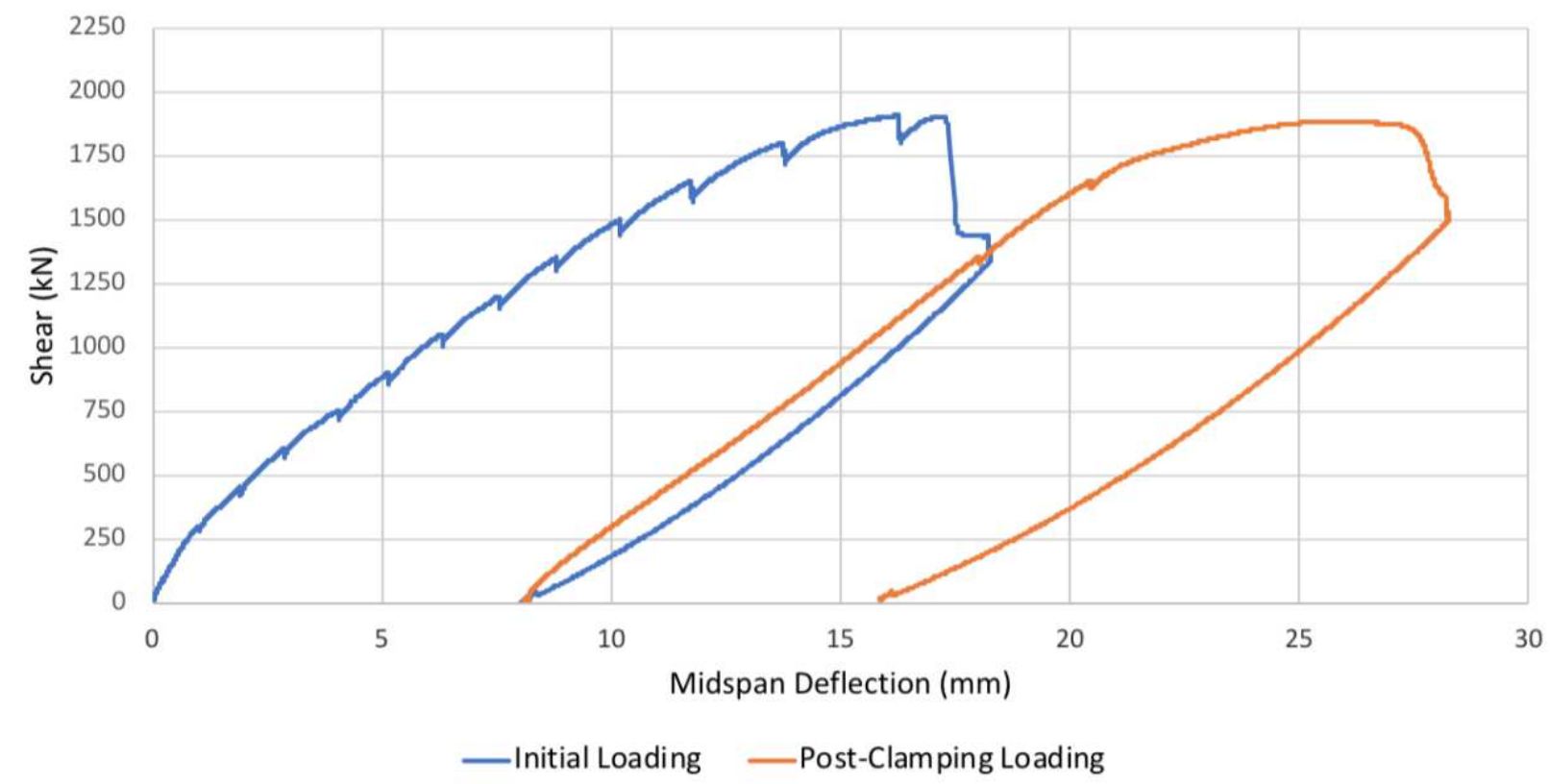

Figure 4.1: Shear versus midspan deflection of cap beam C1 
First flexural cracking in the region of the concentrated steel was observed at a shear of $413 \mathrm{kN}$ near the column-cantilever interface on both sides. Figure 4.1 seemed to indicate cracking at a shear of $250 \mathrm{kN}$ as the stiffness decreased considerably, however this was likely missed due to a thicker coat of paint on the first specimen. The first flexural web cracks were observed at $525 \mathrm{kN}$ and $475 \mathrm{kN}$ in the north and south sides respectively, and the first shear cracks were observed at $725 \mathrm{kN}$ in both cantilevers.

\subsubsection{Shear Failures}

The initial failure of the north cantilever can be seen in Figure 4.2. The specimen failed in a combination of crushing on the inclined face and shear with the $1.50 \mathrm{~mm}$ critical shear crack starting $50 \mathrm{~mm}$ from the center of the roller support on the bottom face and ending $400 \mathrm{~mm}$ from the column face on the top surface. The stirrups experienced considerable yielding before shear failure occurred.

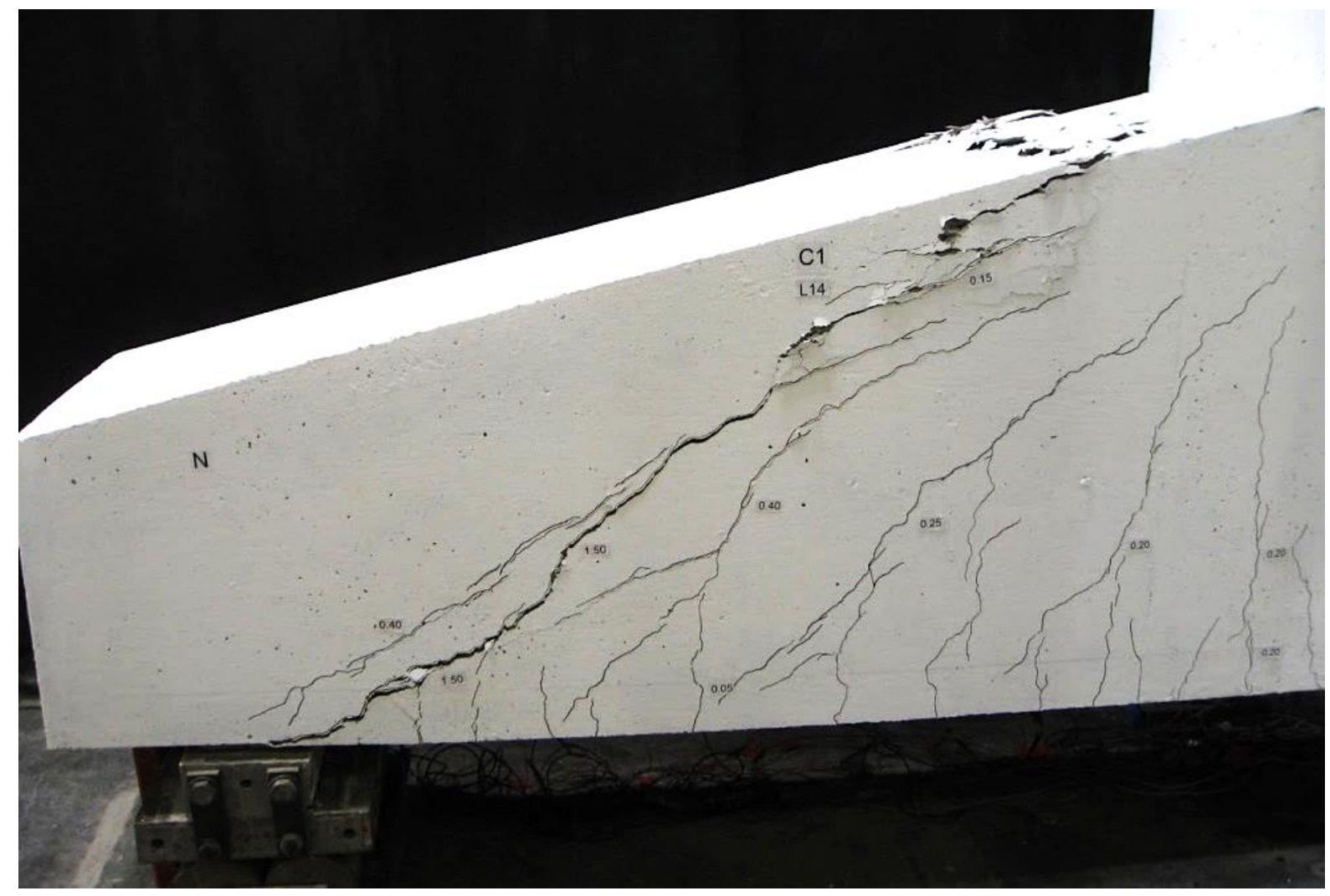

Figure 4.2: Shear failure of north cantilever of cap beam C1 
The failure on the south cantilever can be seen in Figure 4.3. The specimen failed in a combination of crushing on the inclined face and shear with the $2.50 \mathrm{~mm}$ critical shear crack starting at the roller support face and ending $100 \mathrm{~mm}$ from the column face. The stirrups experienced considerable yielding before shear failure occurred.

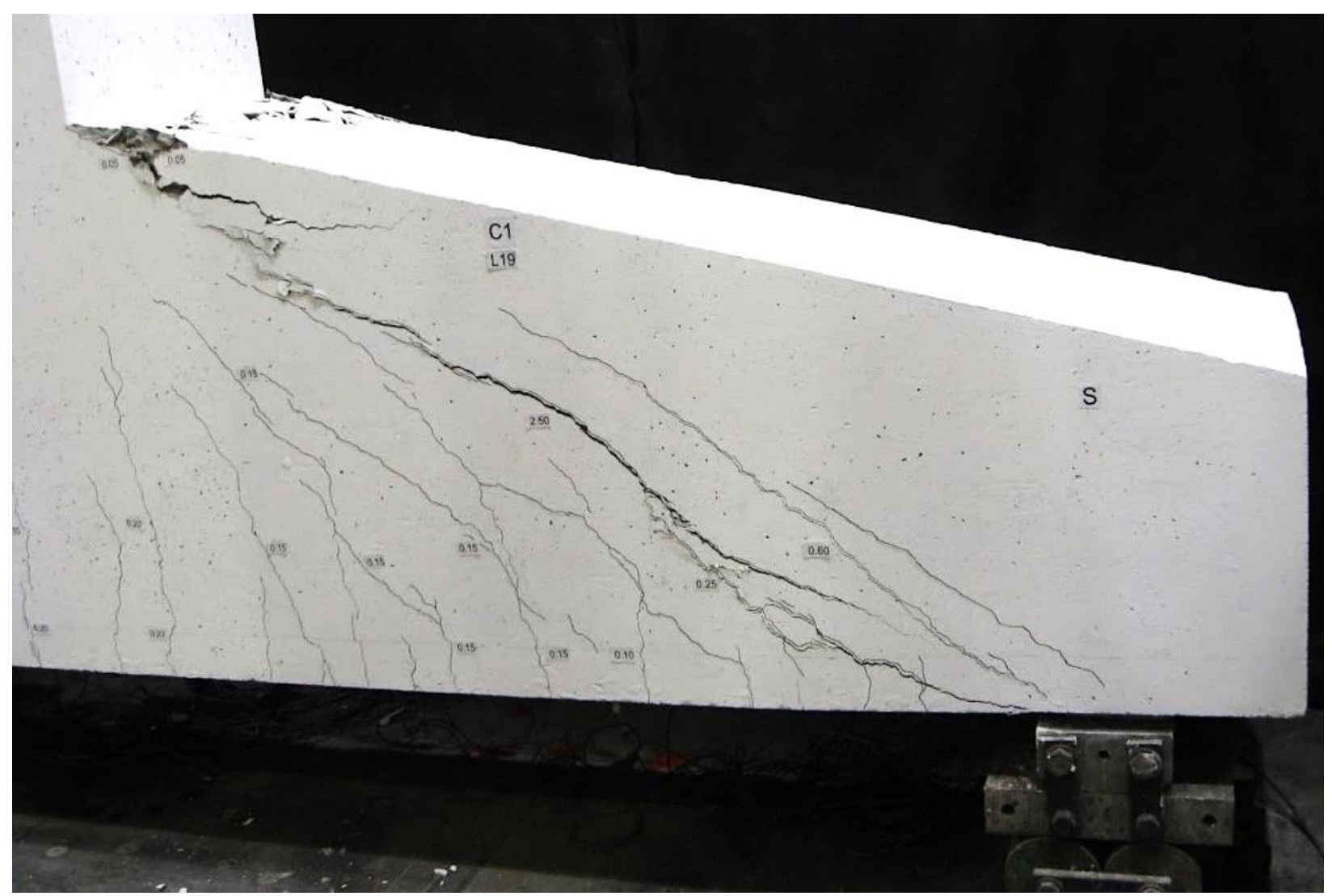

Figure 4.3: Shear failure of south cantilever of cap beam $\mathrm{C} 1$

\subsubsection{Crack Widths}

The maximum crack widths for the north and south cantilevers are shown in Figures 4.4 and 4.5, respectively. In these figures, flexure cracks are subdivided into two different types. "Flexure-Concentrated" represents flexure cracks observed in the region of the primary tension reinforcement and "Flexure-Web" represents flexure cracks observed in the web outside of the primary tension reinforcement zone.

At the service load level shear cracks were most critical, with maximum widths of 0.20 $\mathrm{mm}$ and $0.15 \mathrm{~mm}$ in the north and south sides respectively. Maximum flexural web crack widths 
were $0.15 \mathrm{~mm}$ and $0.10 \mathrm{~mm}$ for the north and south sides respectively, and maximum flexural cracks in the region of concentrated reinforcement were widths of $0.10 \mathrm{~mm}$ in both sides. Figures 4.6 and 4.7 show the crack patterns and measured crack widths for the north and south sides, respectively. Shear cracks and flexural web cracks were consistently smaller in the south side which had a higher amount of crack control reinforcement. Above the service load level the critical shear crack in the north cantilever propagated faster than the south cantilever.

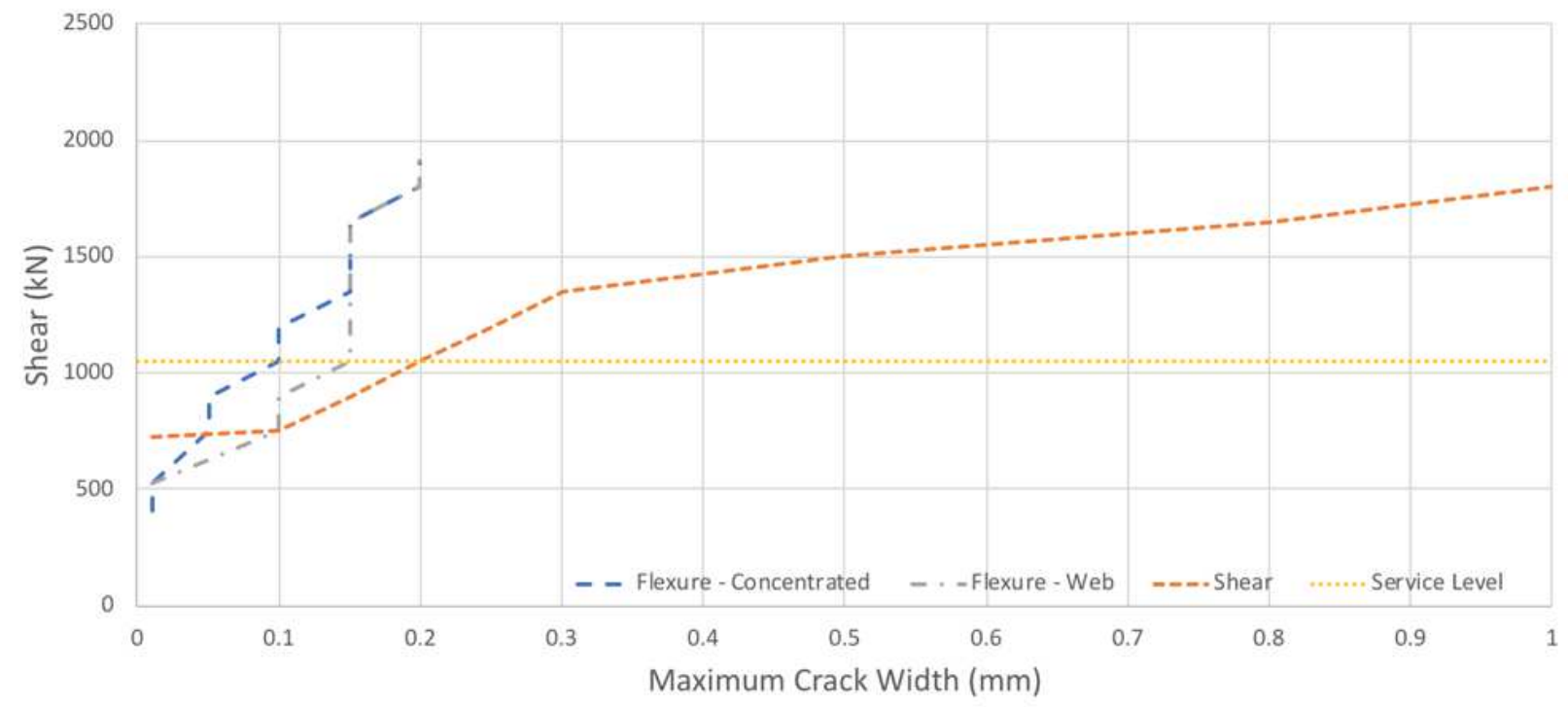

Figure 4.4: Shear versus maximum crack widths for north cantilever of cap beam C1

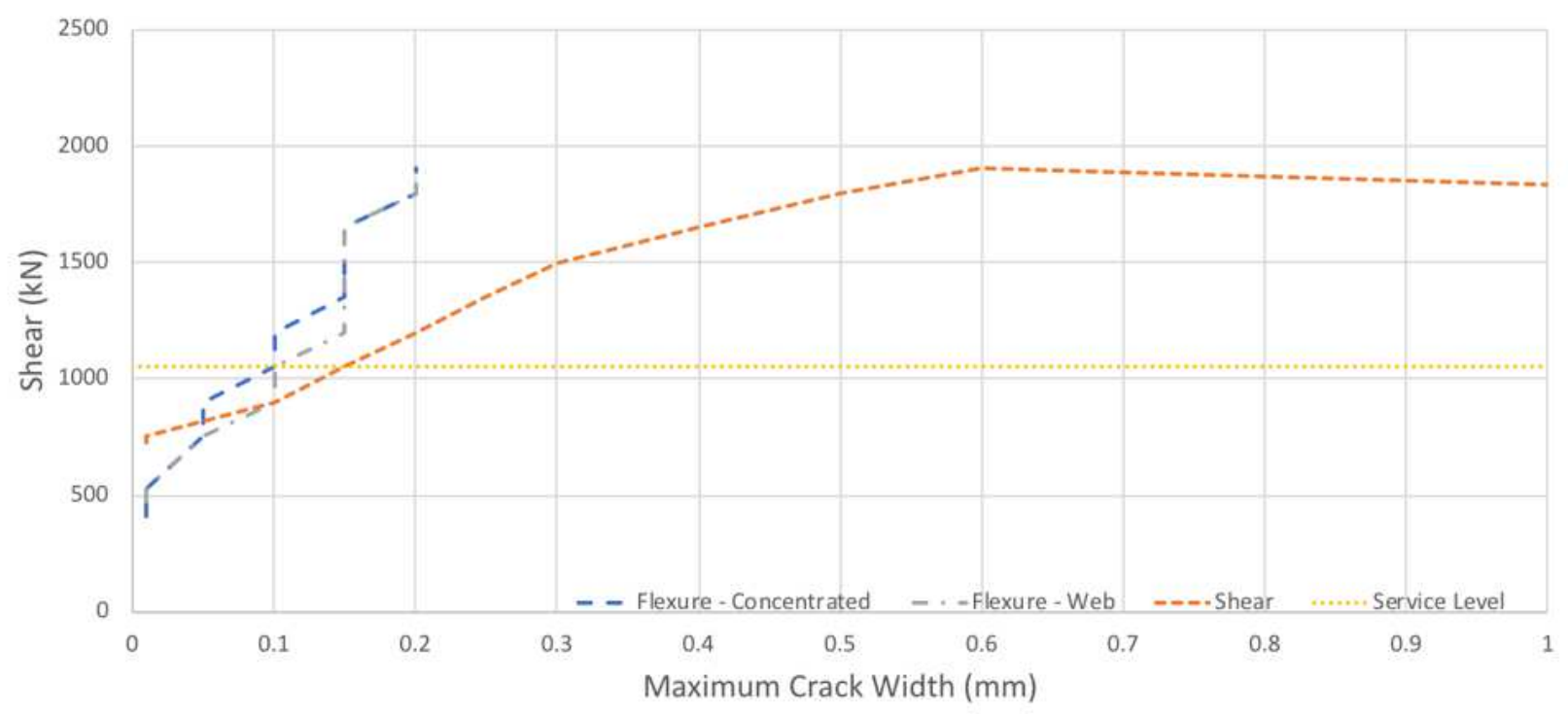

Figure 4.5: Shear versus maximum crack widths for south cantilever of cap beam C1 


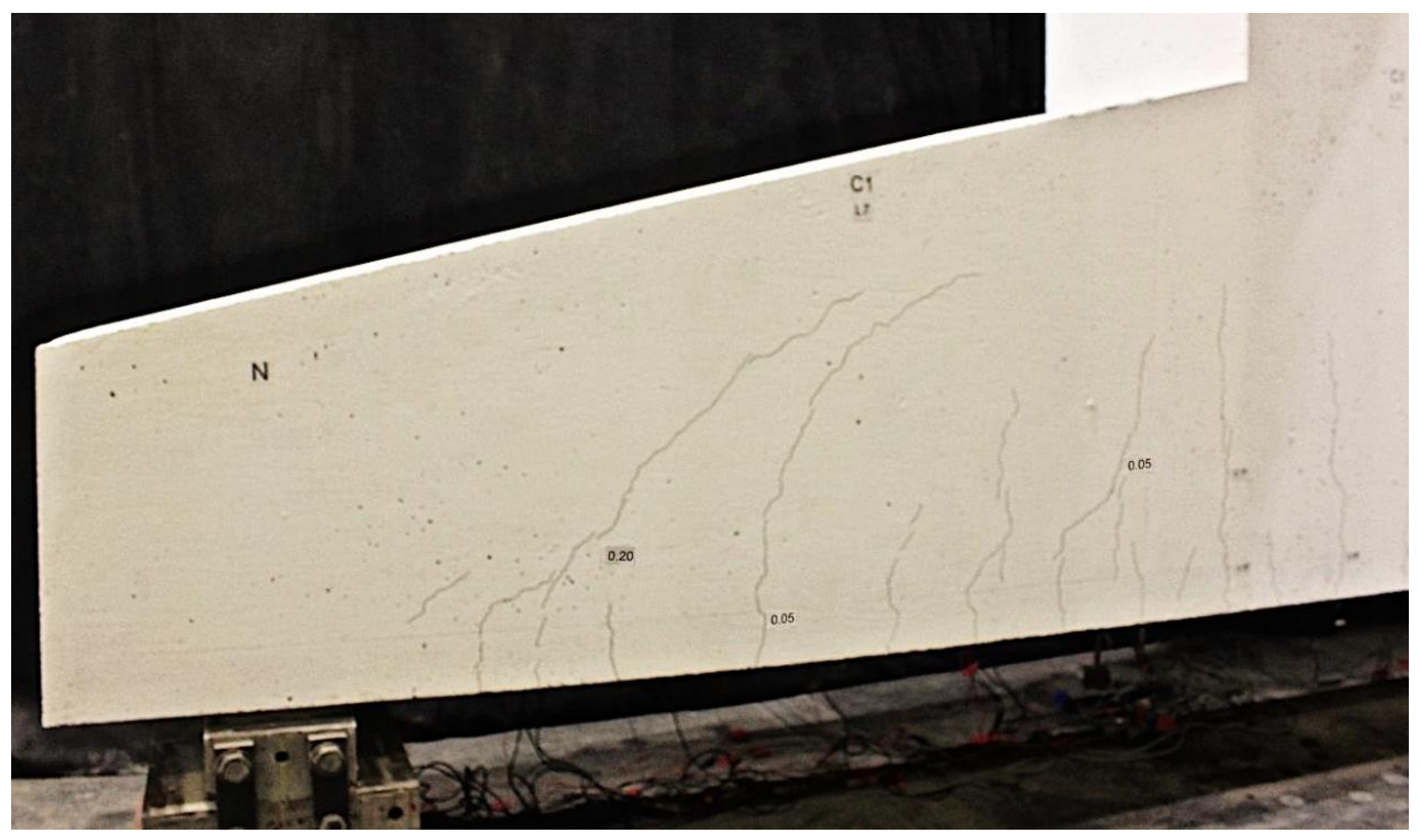

Figure 4.6: Crack pattern and widths at service loading for north cantilever of cap beam $\mathrm{C} 1$

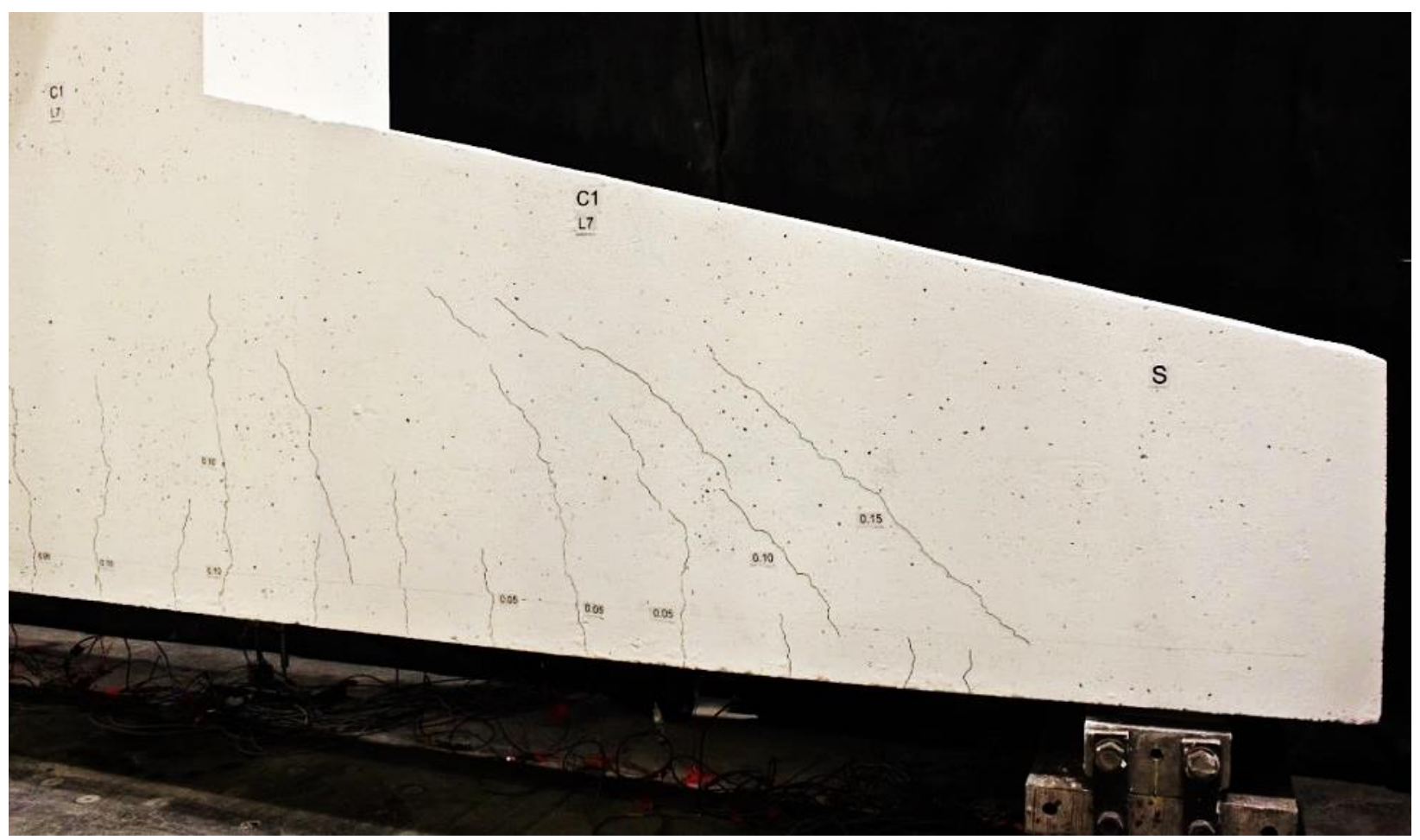

Figure 4.7: Crack pattern and widths at service loading for south cantilever of cap beam C1 


\subsubsection{Measured Strains}

The average tensile strains measured by LVDTs LV1-LV8 at the centroid of the $18-25 \mathrm{M}$ primary tension reinforcement are shown in Figure 4.8. The average strain was determined over a gage length of $525 \mathrm{~mm}$. The highest average strain at service loading was 0.00149 on the south cantilever near the column face. At failure four of the average strains were well above the yield strain of 0.00232 for the $25 \mathrm{M}$ bars, and one LVDT at the onset of yielding. Figures 4.9 and 4.10 show the shear versus average strain curves for each LVDT and indicate that for LV3-LV6 yielding of the primary tension steel had occurred before failure $(1908 \mathrm{kN})$. Specifically, LV3, LV4, LV5, and LV6 reached yielding at shears of $1630 \mathrm{kN}, 1597 \mathrm{kN}, 1900 \mathrm{kN}$, and $1744 \mathrm{kN}$, respectively

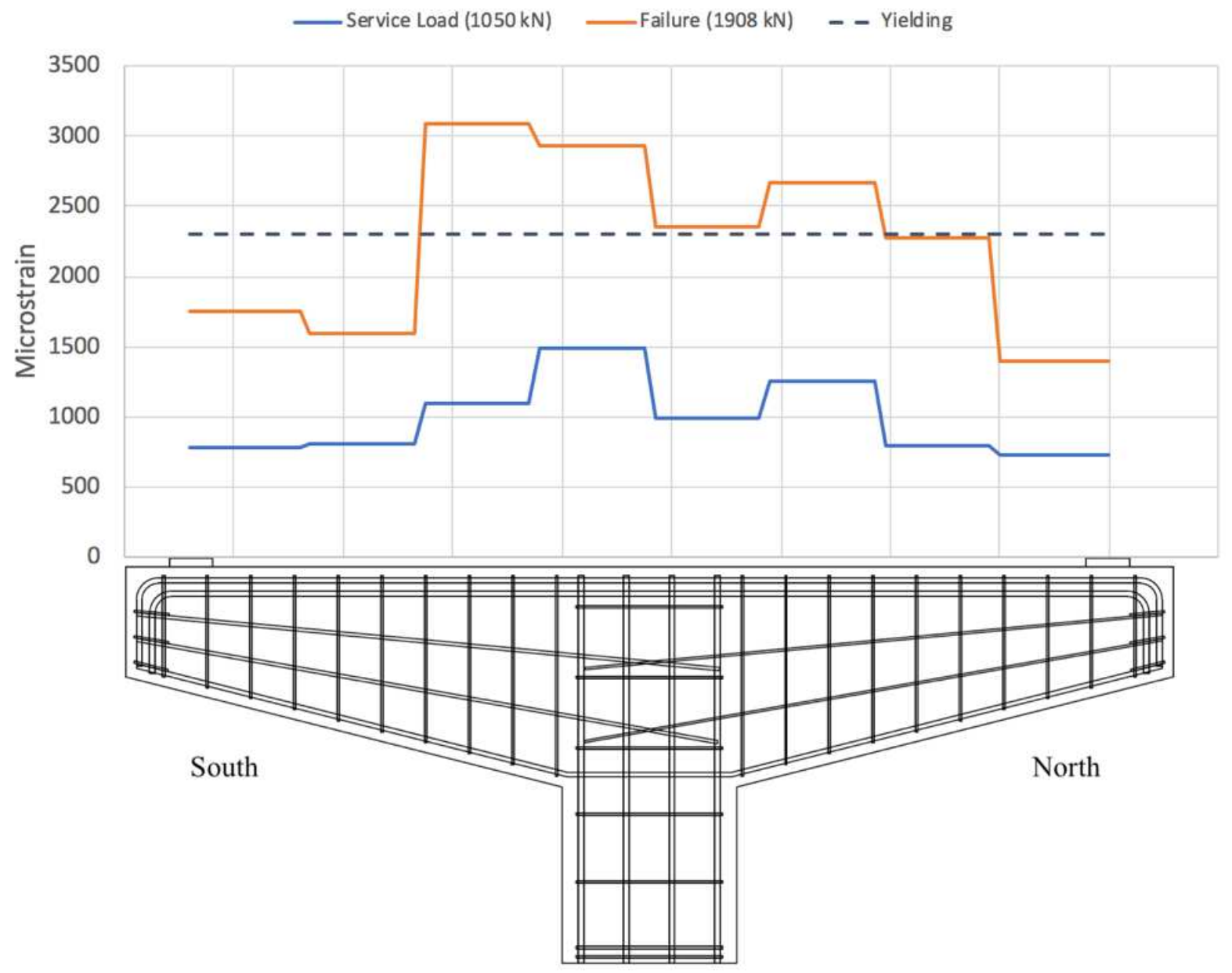

Figure 4.8: Average longitudinal strains measured along the centroid of the concentrated tension steel for cap beam $\mathrm{C} 1$ 


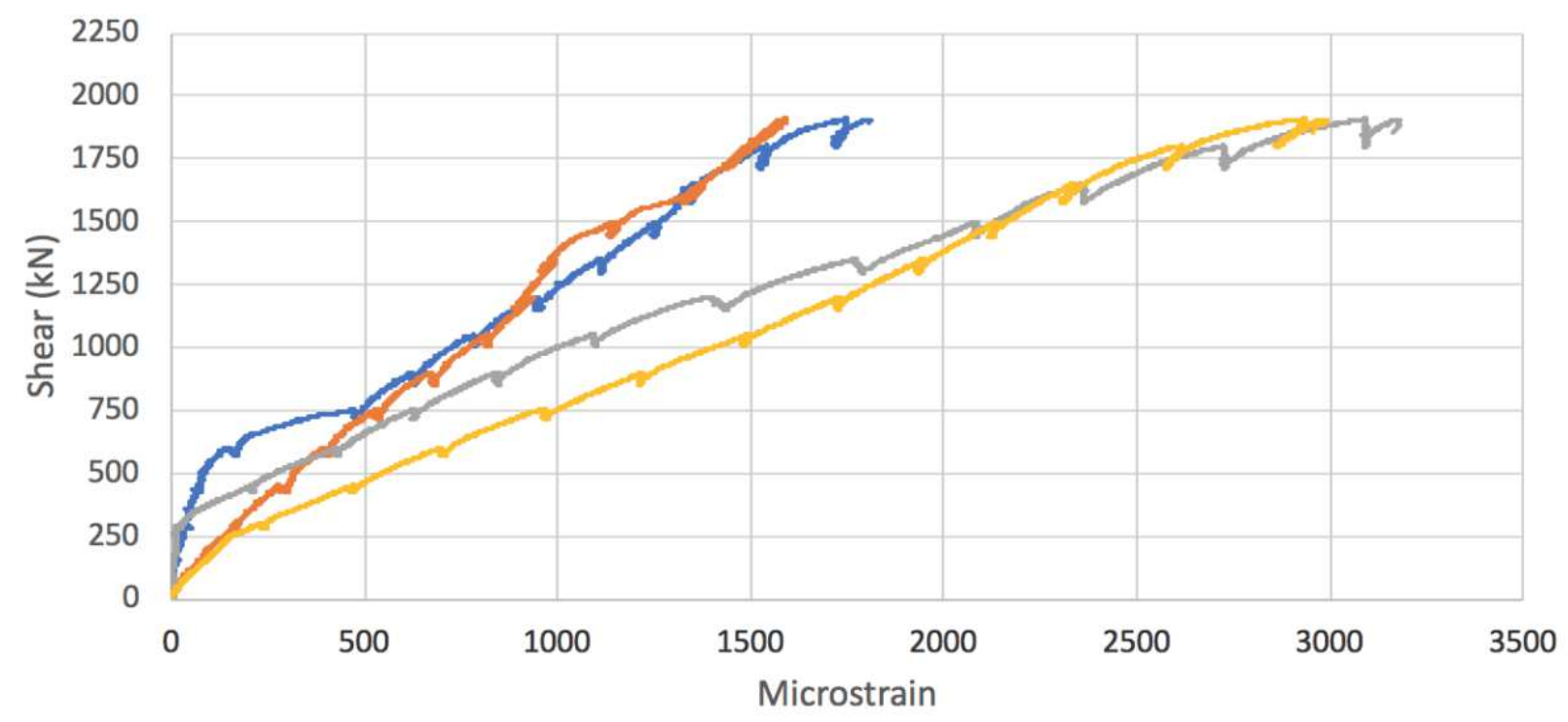

$-\mathrm{LV} 1-\mathrm{LV} 2-\mathrm{LV} 3-\mathrm{LV} 4$

Figure 4.9: Shear versus average longitudinal strain on the south cantilever of cap beam C1

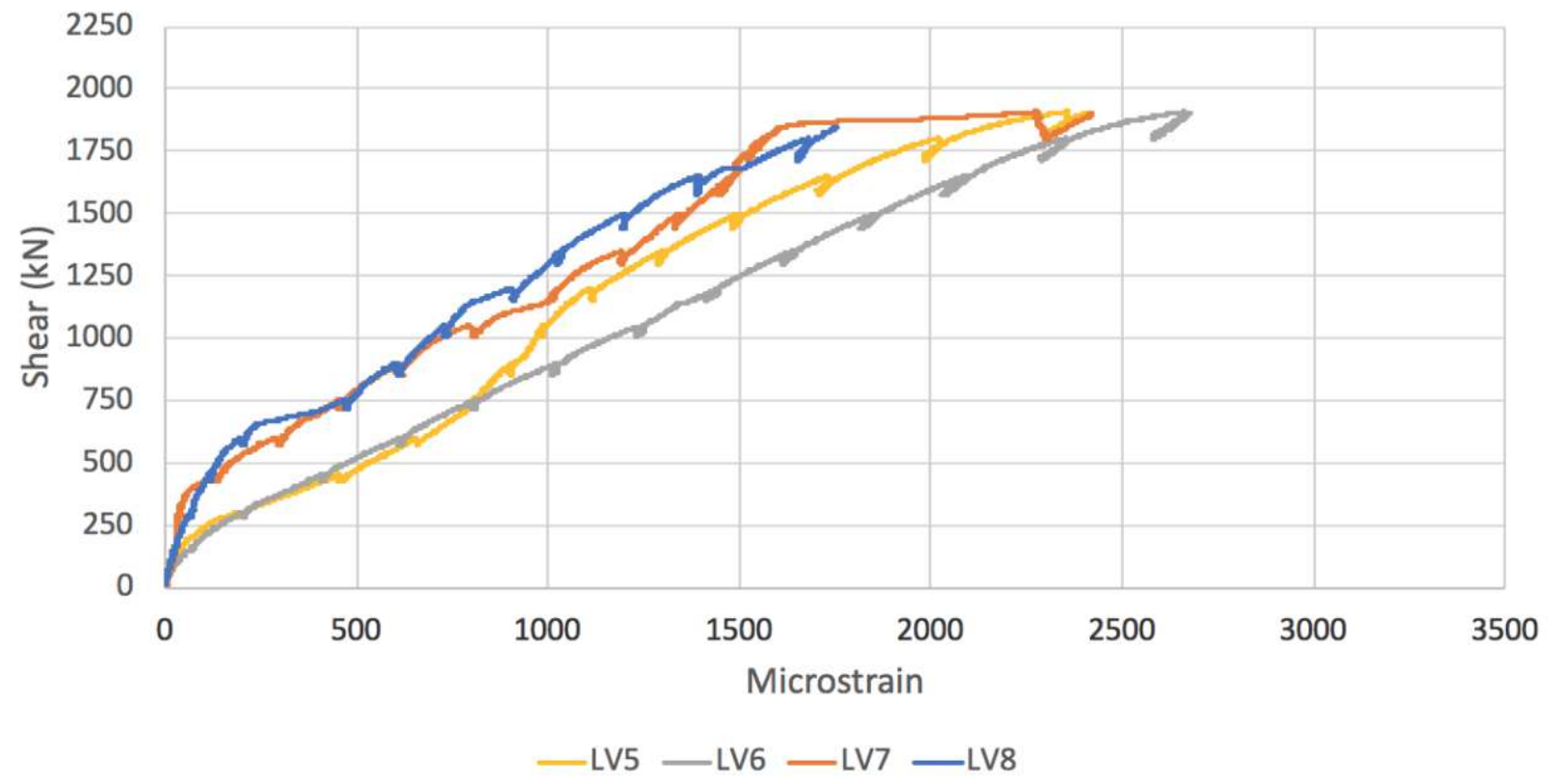

Figure 4.10: Shear versus average longitudinal strain on the north cantilever of cap beam C1 
The shear versus strain relationships for several stirrups in the north and south cantilevers are shown in Figures 4.11 and 4.12. On the north cantilever LS6 was the first strain gage to reach the yield strain of 0.00231 for $10 \mathrm{M}$ bars at a shear of $747 \mathrm{kN}$. It is noted that this is close to the observation of first shear cracking at $725 \mathrm{kN}$. Strain gages LS1, LS2, LS5, and LS7 each reached yielding at shears of $1820 \mathrm{kN}, 1822 \mathrm{kN}, 1880 \mathrm{kN}$, and $1678 \mathrm{kN}$, respectively. LS3 and LS4 had measured strains considerably below the yield strain and malfunctioned at shears of $1823 \mathrm{kN}$ and $1879 \mathrm{kN}$, respectively. Thus, significant stirrup yielding had occurred before failure of the north cantilever.

On the south cantilever, only RS3 definitively indicated stirrup yielding at a shear of $1586 \mathrm{kN}$. Stirrup RS6 started increasing in strain rapidly at $720 \mathrm{kN}$ similar to LS6 on the north cantilever but appeared to start malfunctioning upon reaching a strain of 0.00139 . RS5 and RS7 reached moderate peak strains of 0.00140 and 0.00142 , respectively. RS1, RS2, and RS4 did not reach significant strains, with RS4 appearing to malfunction after reaching a strain of 0.00102 near service loading.

Strain gages LLT and RLT measured compressive strains on the inclined face of the cantilevers next to the column interface on the north and south sides, respectively. The shear versus strain for these strain gages can be seen in Figure 4.13. LLT and RLT reached the yield strain of 0.00224 for $20 \mathrm{M}$ bars at shears of $1750 \mathrm{kN}$ and $1785 \mathrm{kN}$, respectively, indicating that the primary compressive reinforcement had buckled before failure. Two LVDTs were also placed at this reentrant corner. LV9 located on the south side reached a strain of 0.0035 at a shear of $1785 \mathrm{kN}$ (see Figure 4.13), while LV10 on the north side malfunctioned. 


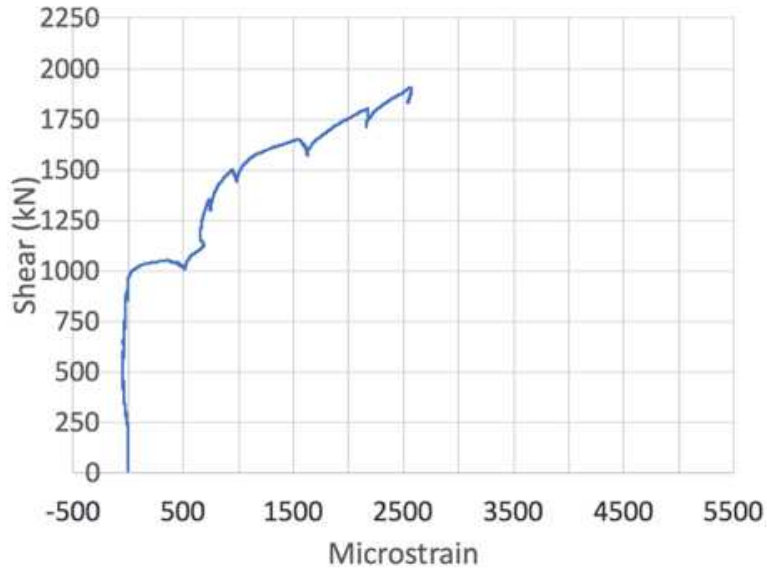

(a) LS1

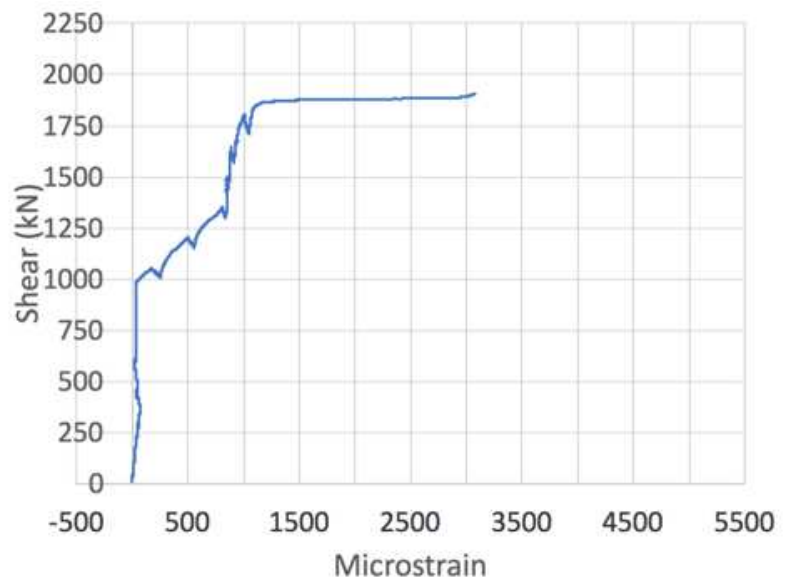

(c) LS5

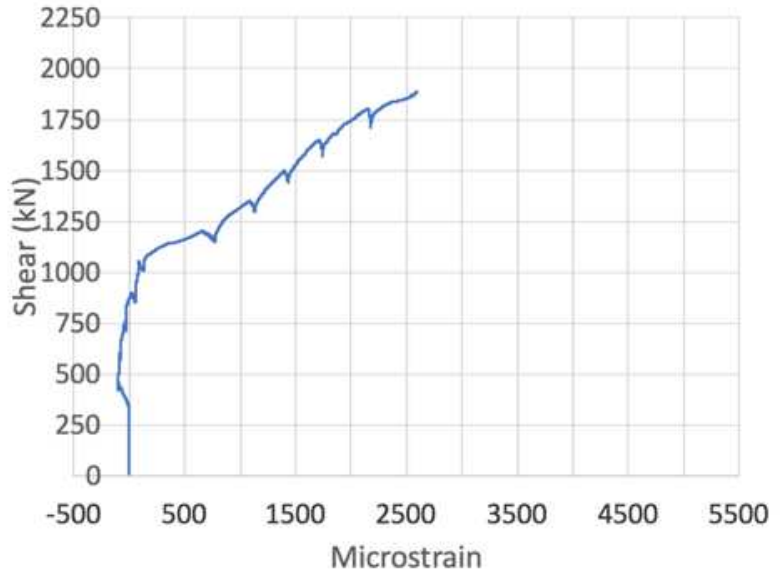

(b) LS2

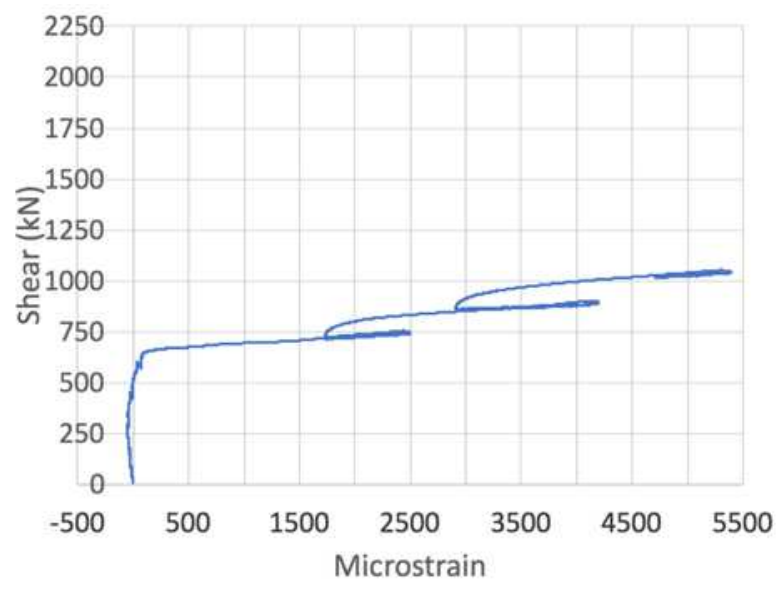

(d) LS6

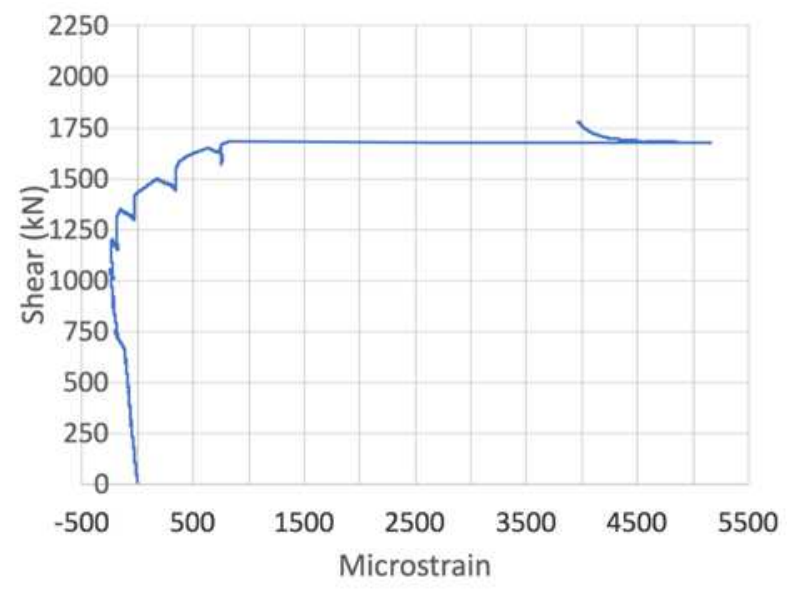

(e) LS7

Figure 4.11: Shear versus strain for stirrups in north cantilever of cap beam C1 


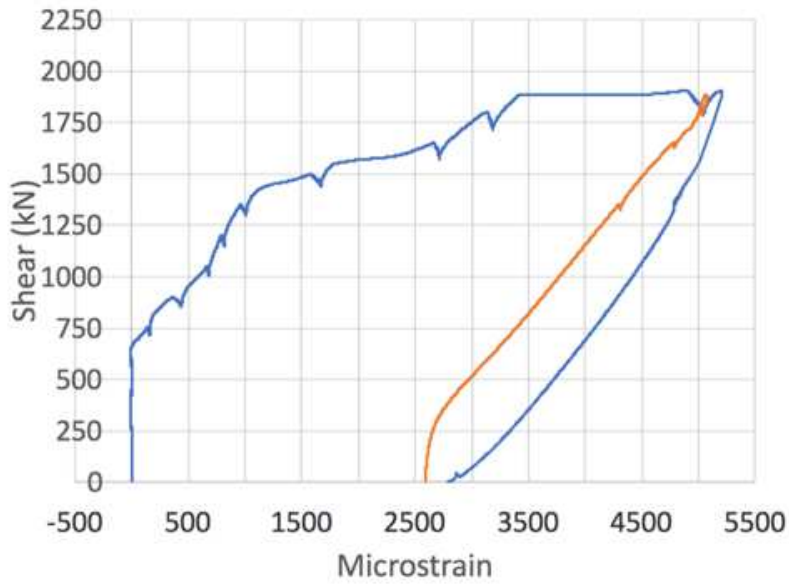

(a) RS3

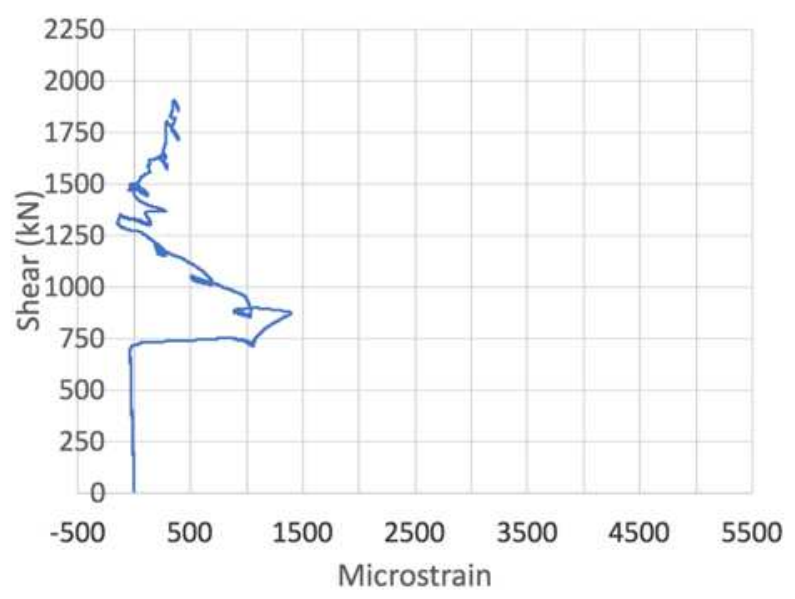

(c) RS6

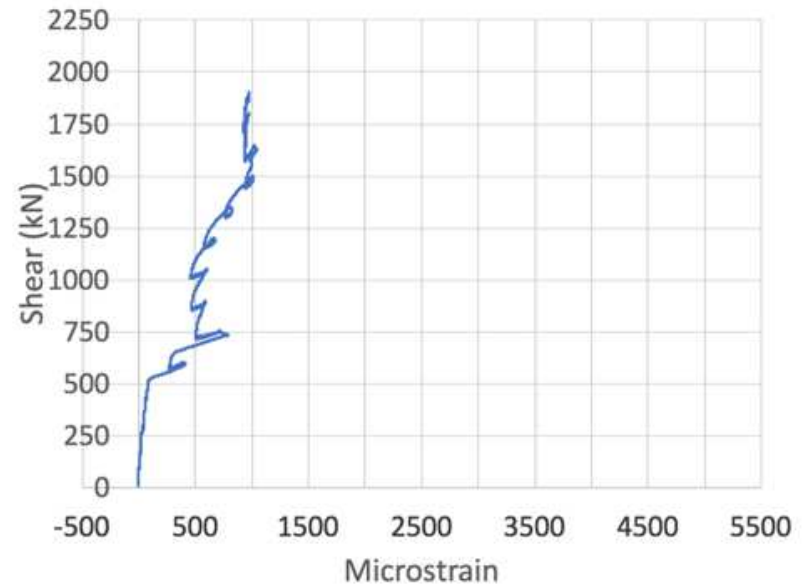

(b) RS5

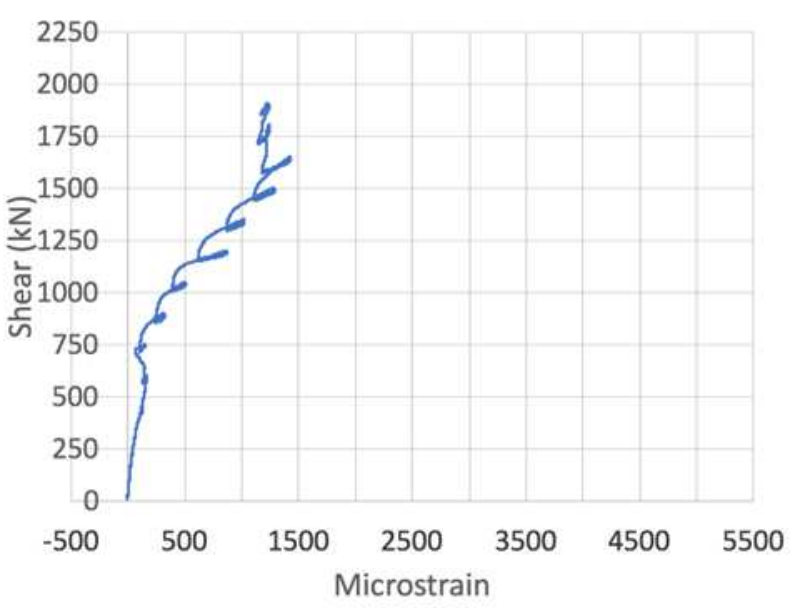

(d) RS7

\section{—Initital Loading -Post-Clamping Loading}

Figure 4.12: Shear versus strain for stirrups in south cantilever of cap beam $\mathrm{C} 1$ 


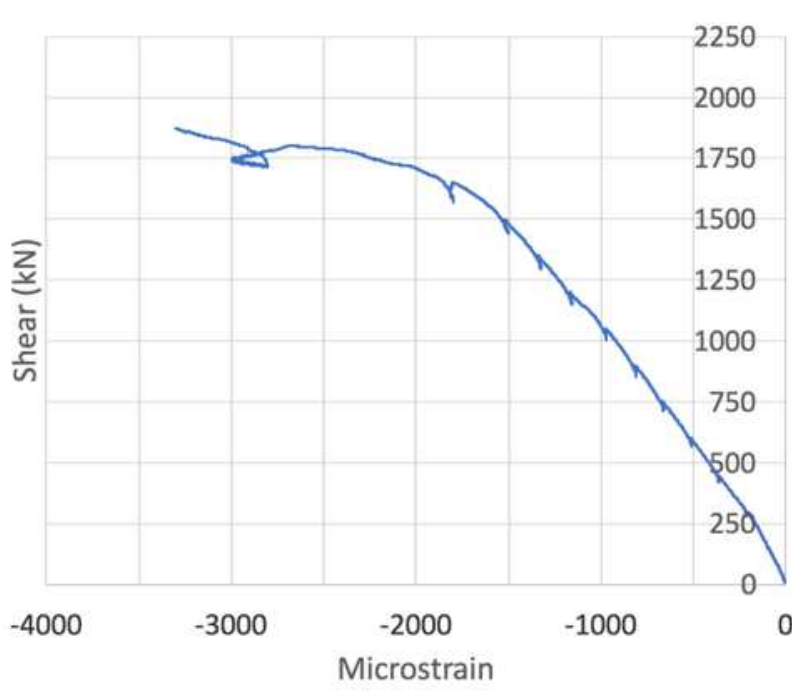

(a) LLT (north)

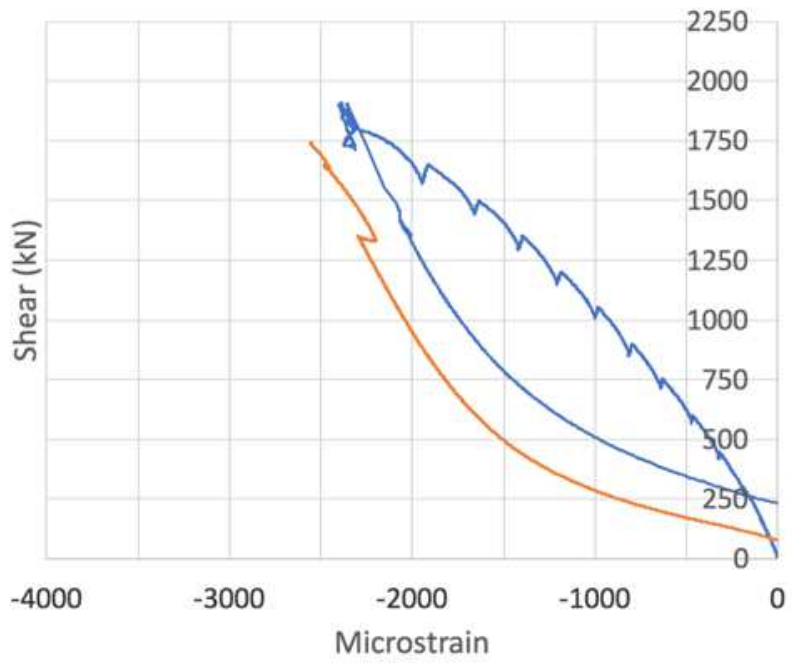

(b) RLT (south)

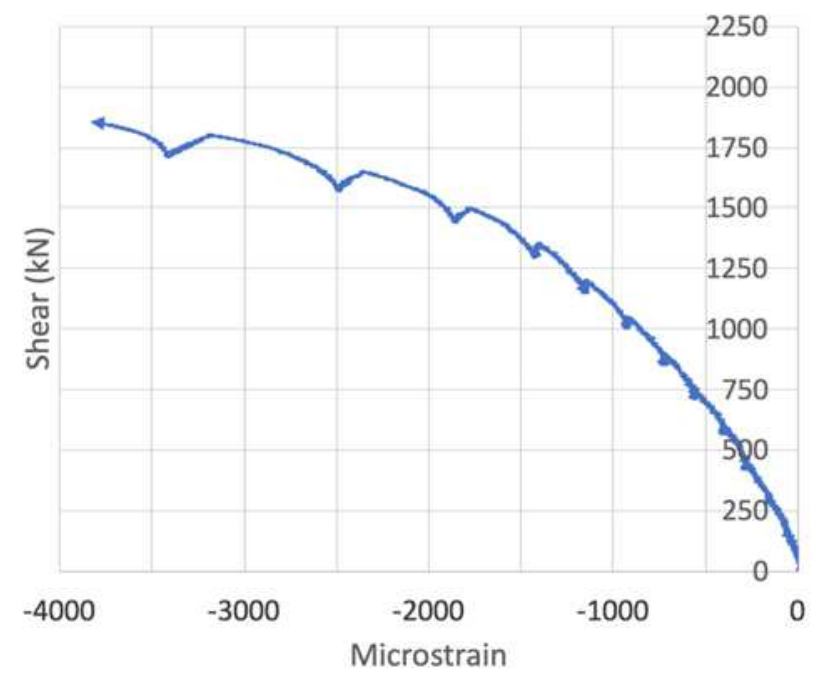

(c) LV9 (south)

—Initital Loading _Post-Clamping Loading

Figure 4.13: Shear versus compressive strain at re-entrant corners of cap beam C1 
Figure 4.14 shows the results from the LVDT rosettes on pier cap C1 for both the north and south cantilevers. "North-1" and "South-1" signify the response during the initial loading curve, and "South-2" represents the response during the post-clamping loading in the south cantilever. The horizontal strains $\left(\varepsilon_{\mathrm{x}}\right)$ were particularly low, reaching peak strains of only 0.000847 and 0.00152 for the north and south sides respectively. In terms of vertical strains $\left(\varepsilon_{\mathrm{y}}\right)$ the north side began developing strains at $725 \mathrm{kN}$ coinciding with the formation of the first shear crack and reached the yield strain of the $10 \mathrm{M}$ stirrups at $1530 \mathrm{kN}$. The south side had more crack control reinforcement and remained at very low strains until reaching a shear of $1520 \mathrm{kN}$. The vertical strains then increased quite rapidly, reaching the $10 \mathrm{M}$ yielding strain just before failure at $1885 \mathrm{kN}$. Both sides also exhibited similar ductility after reaching the peak shear. The maximum tensile strains $\left(\varepsilon_{1}\right)$ for both sides were similar, with the weaker north side reaching higher strains. At the initial failure the north side reached an $\varepsilon_{1}$ of $1.22 \%$ and the south side $0.67 \%$. After clamping the north side, the south side reached an $\varepsilon 1$ of $1.27 \%$ before failure. Shear strains $\left(\gamma_{\mathrm{xy}}\right)$ were also quite high, with the north side reaching $1.19 \%$ at initial failure, and the south side reaching shear strains of $0.80 \%$ and $1.17 \%$ at initial and post-clamping failures, respectively. The principal angle, $\theta_{\mathrm{p}}$, on each side during their respective failure was $28.1^{\circ}$ on the north side and $29.2^{\circ}$ on the south side. It was noted that the angle of the critical shear cracks near the rosettes at failure was $37.2^{\circ}$ on the north side and $31.7^{\circ}$ on the south side. 


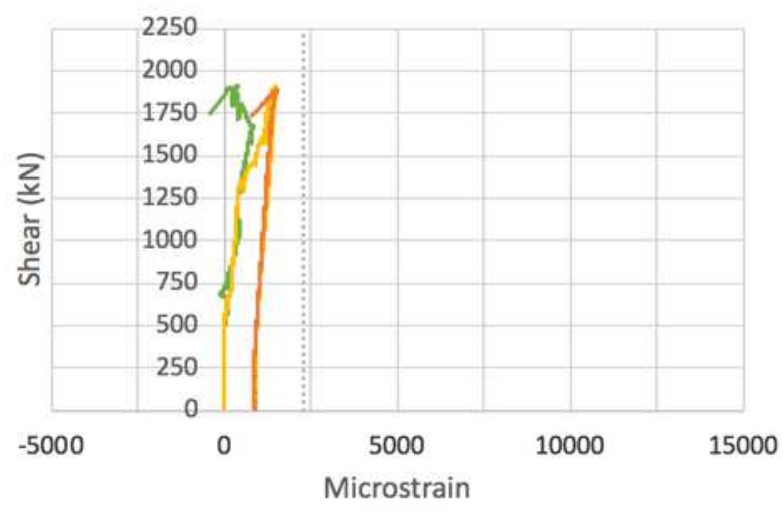

(a) horizontal strain, $\varepsilon_{x}$

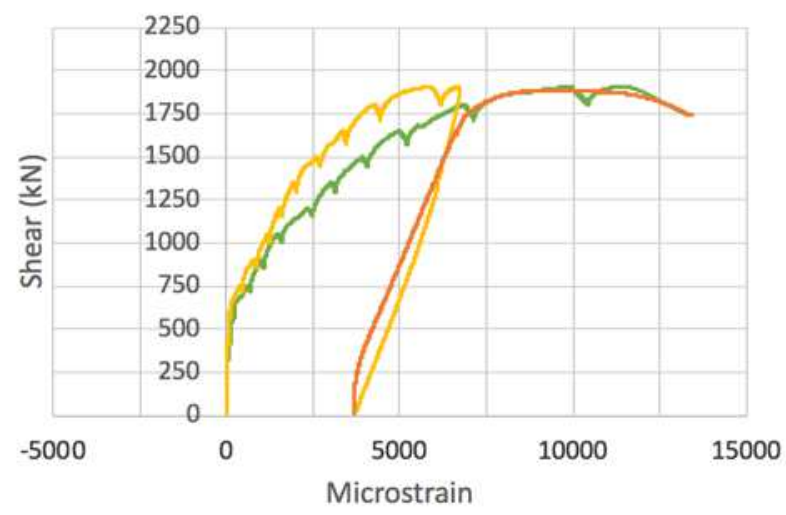

(c) principal tensile strain, $\varepsilon 1$

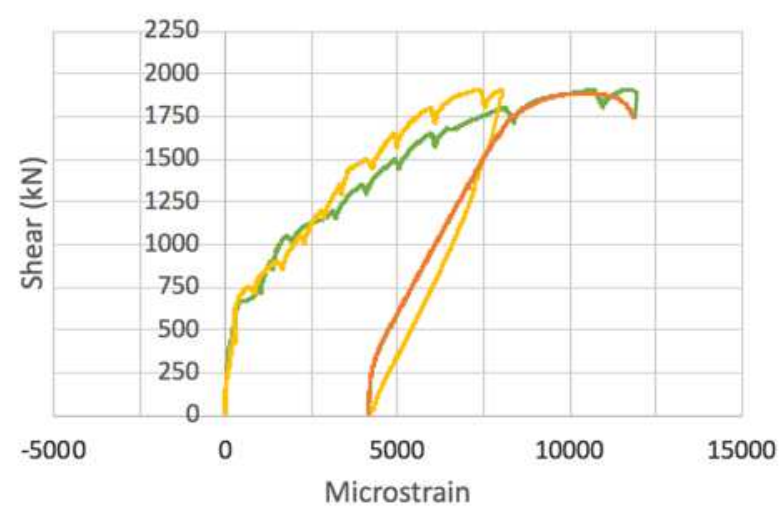

(e) shear strain, $\gamma_{x y}$

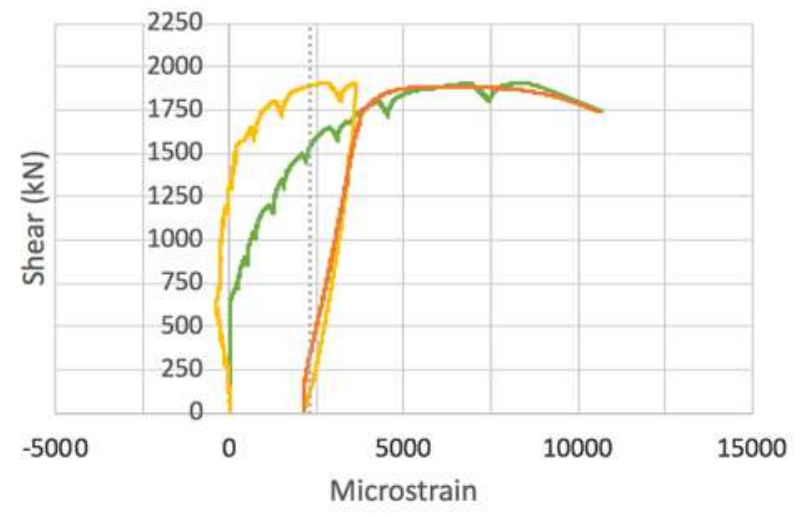

(b) vertical strain, $\varepsilon_{y}$

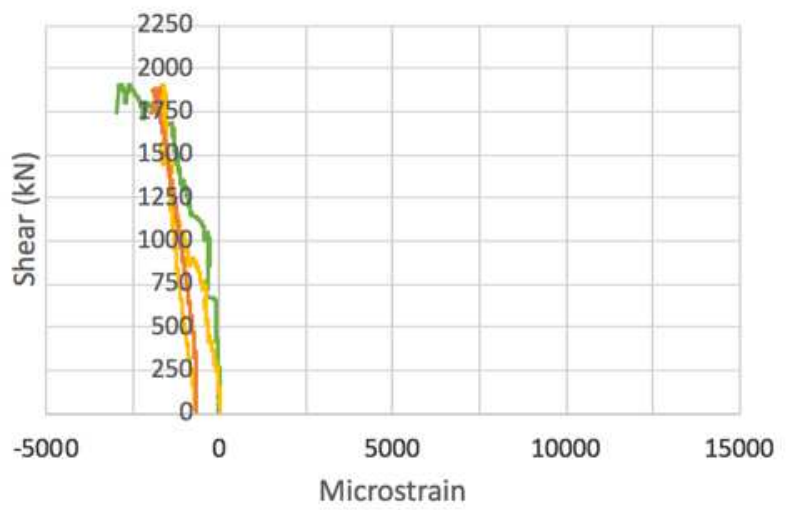

(d) principal compressive strain, $\varepsilon_{2}$

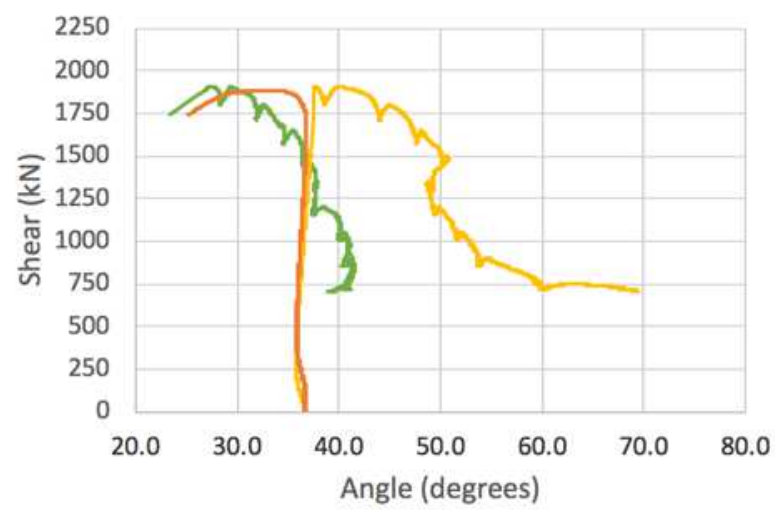

(f) principal angle, $\theta_{\mathrm{p}}$

North-1 $\longrightarrow$ South-1 $\longrightarrow$ South-2 ....... Yield

Figure 4.14: Principal strains and angles from cap beam C1 rosettes 


\subsection{Pier Cap C1R}

\subsubsection{Shear-Deflection Response}

The shear versus midspan deflection response for pier cap C1R is shown in Figure 4.15. The "To Service Load" curve indicates the initial loading of the pier cap to the service load level. Horizontal post-tensioning was then applied with the load held constant, and subsequently unloaded. On the "Initial Loading" curve the pier cap reached a shear of $1973 \mathrm{kN}$ and a midspan deflection of $14.7 \mathrm{~mm}$ before failing in shear in the south cantilever. After the installation of shear clamps on the south cantilever the pier cap reached a higher shear of $2017 \mathrm{kN}$ and a midspan deflection of $20.1 \mathrm{~mm}$ before failing in the north cantilever.

First flexural cracking was observed at a shear of $275 \mathrm{kN}$ near the column-cantilever interface on both sides, accompanied by a decrease in stiffness. The first shear cracks were observed at $575 \mathrm{kN}$ on the north cantilever and $725 \mathrm{kN}$ on the south cantilever.

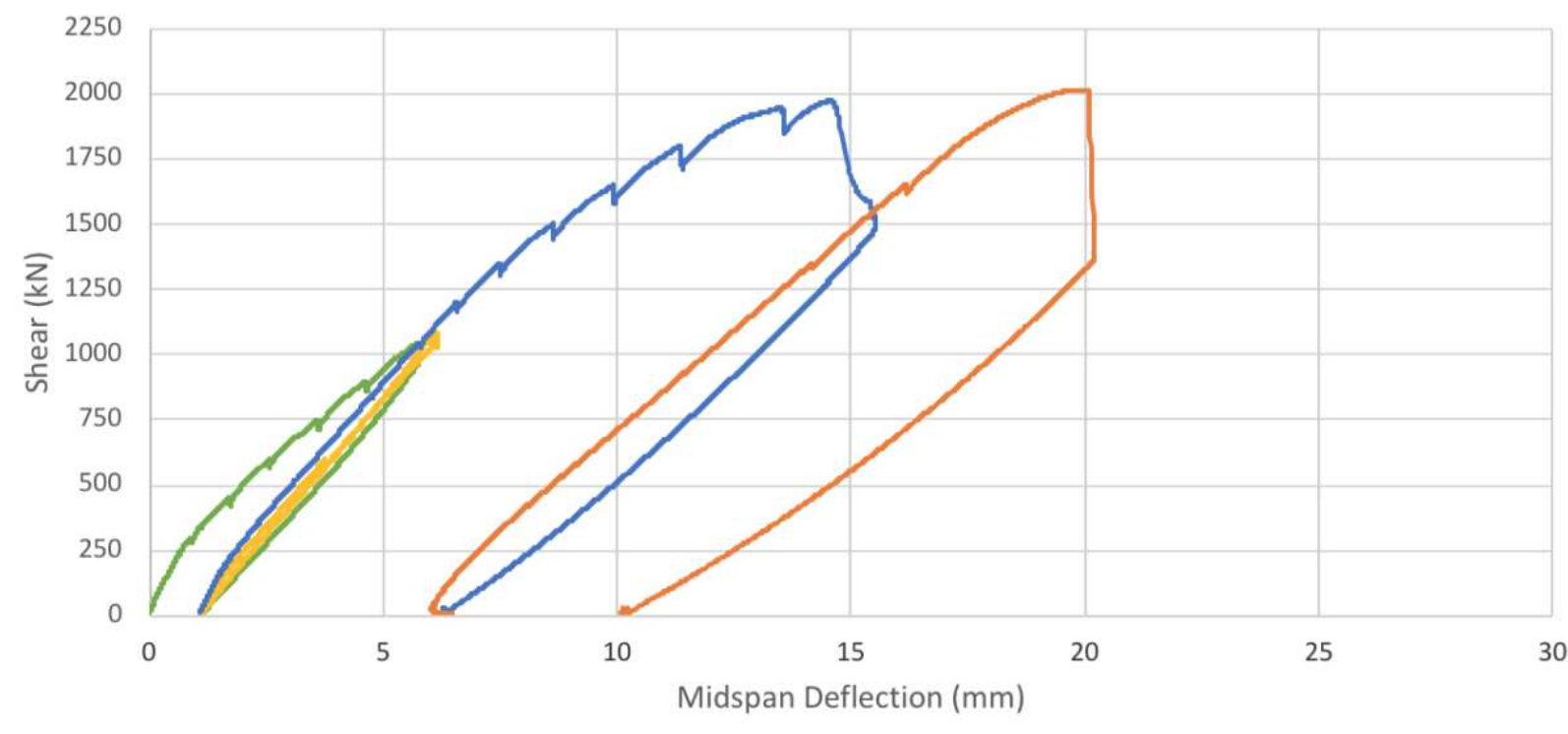

—To Service Load —Post-Tensioning at Service Load —Initial Loading —Post-Clamping Loading

Figure 4.15: Shear versus midspan deflection of cap beam C1R 


\subsubsection{Shear Failures}

Figure 4.16 shows the initial failure observed in the south cantilever. The specimen failed in shear with a $1.00 \mathrm{~mm}$ critical shear crack starting at the roller support face and ending $500 \mathrm{~mm}$ from the column face on the top surface. Concrete crushing on the inclined face and significant yielding of the stirrups were observed before shear failure.

The failure on the north cantilever can be seen in Figure 4.17. The specimen failed in crushing of the inclined face while the load was being held during a load stage. A $3.00 \mathrm{~mm}$ wide shear crack starting $50 \mathrm{~mm}$ from the roller support center and ending at the column face also contributed to the failure. Significant yielding of the stirrups occurred before shear failure.

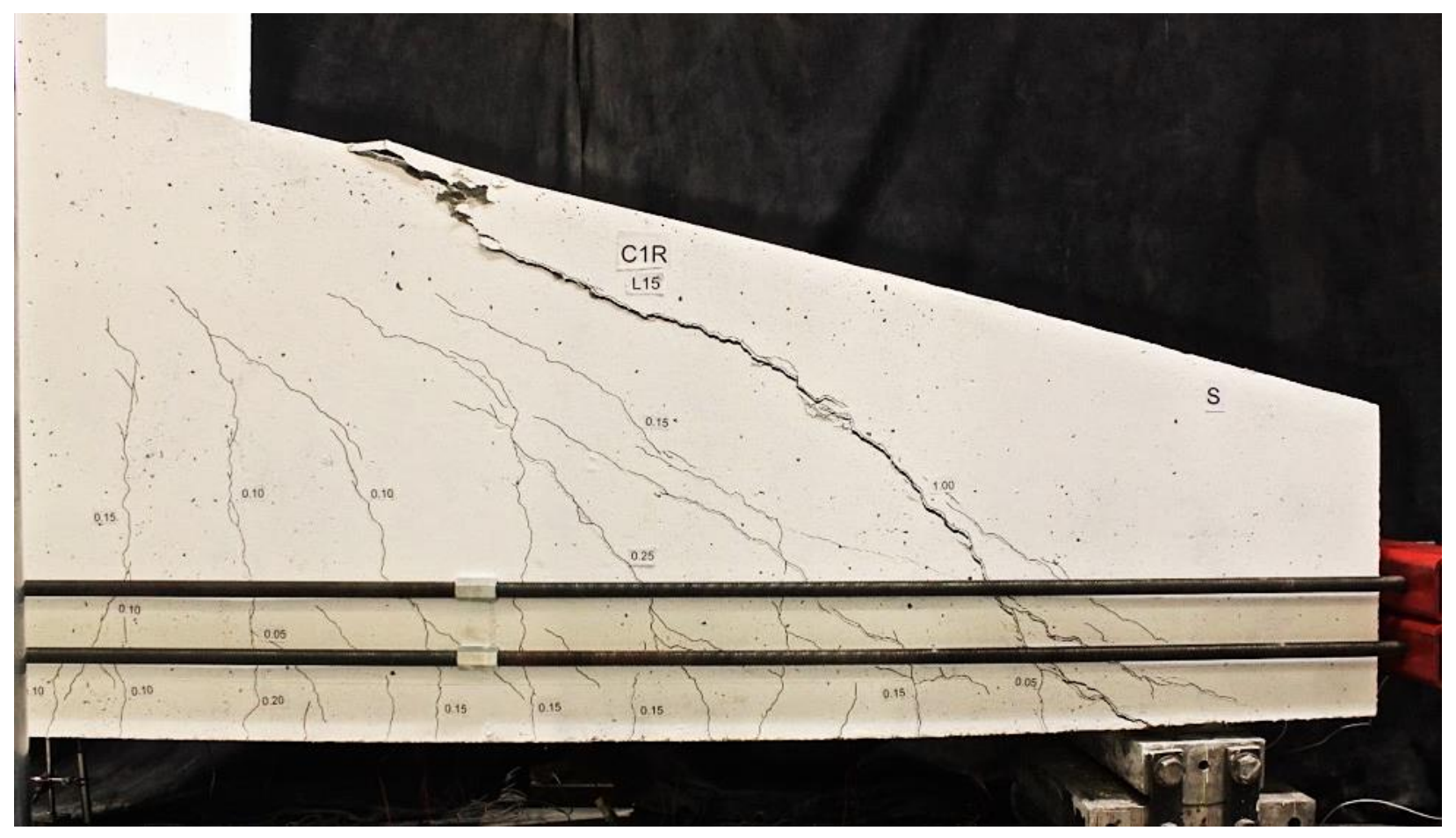

Figure 4.16: Shear failure of south cantilever of cap beam C1R 


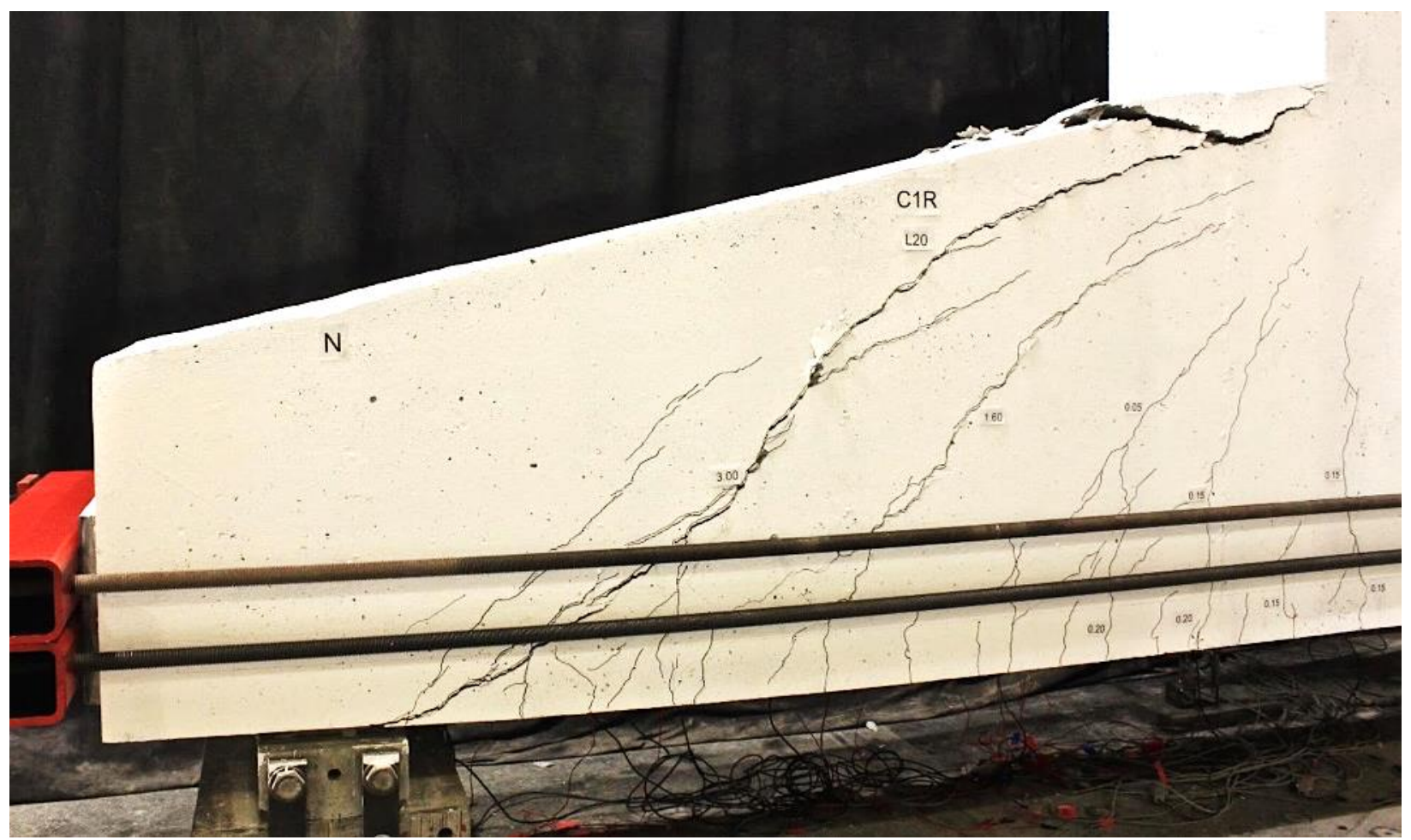

Figure 4.17: Shear failure of north cantilever of cap beam C1R

\subsubsection{Crack Widths}

The maximum crack widths for the north and south cantilevers are shown in Figures 4.18 and 4.19. At the service load level shear cracks were most critical, with widths of $0.20 \mathrm{~mm}$ and $0.15 \mathrm{~mm}$ in the north and south sides respectively. Flexure cracks were lower, with flexural web cracks being $0.15 \mathrm{~mm}$ and $0.10 \mathrm{~mm}$ for the north and south sides, respectively, and flexural cracks in the region of the concentrated tensile steel at $0.05 \mathrm{~mm}$ for both sides. Post-tensioning at the service load level decreased the shear crack widths by $0.05 \mathrm{~mm}$ and flexural crack widths by $0.05 \mathrm{~mm}$ on the north side. Figures 4.20 to 4.23 show the crack patterns and measured crack widths for the north and south sides, both before and after post-tensioning. Shear cracks and flexural web cracks were consistently smaller in the south side at the service load level and at higher loads due to its increased amount of crack control reinforcement. Despite this the south side failed before the north side. 


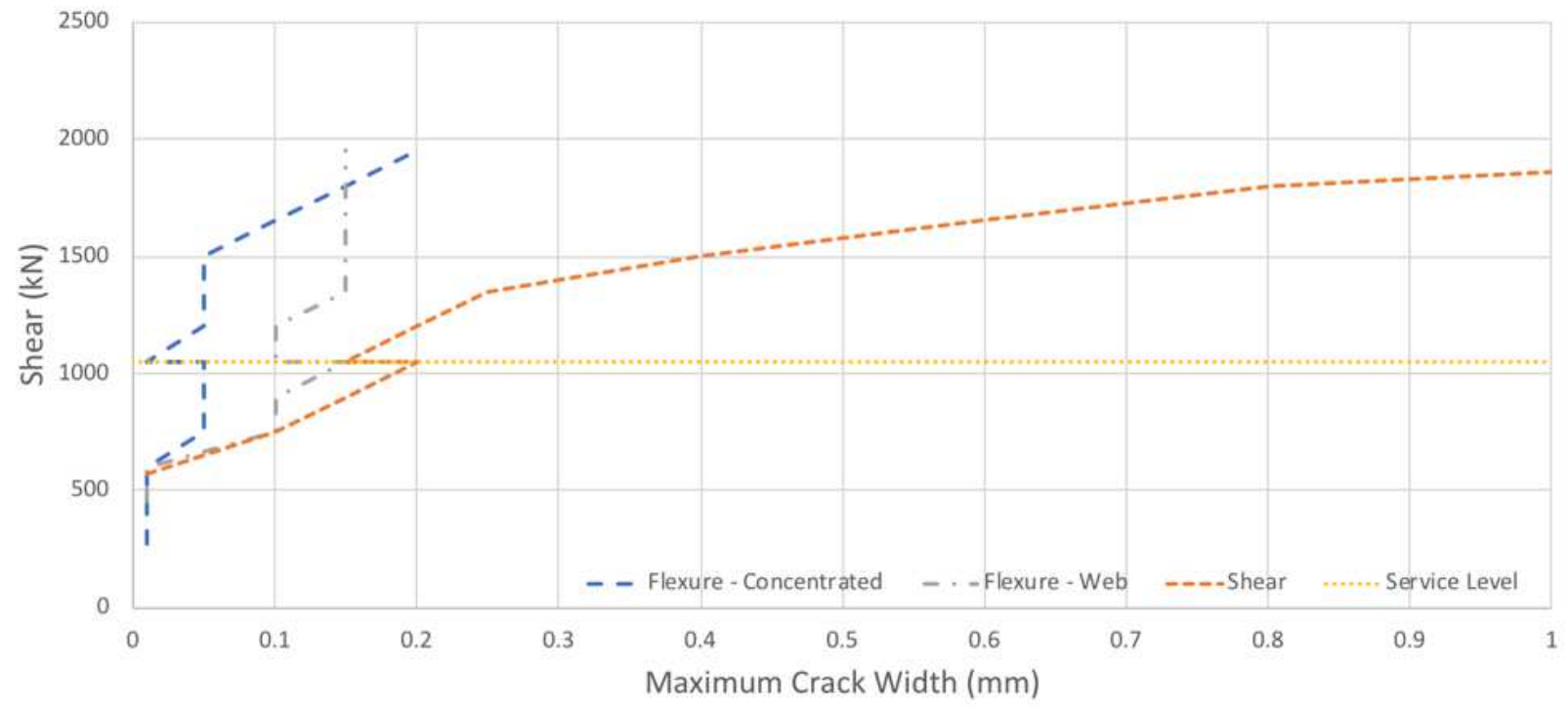

Figure 4.18: Shear versus maximum crack widths for north cantilever of cap beam C1R

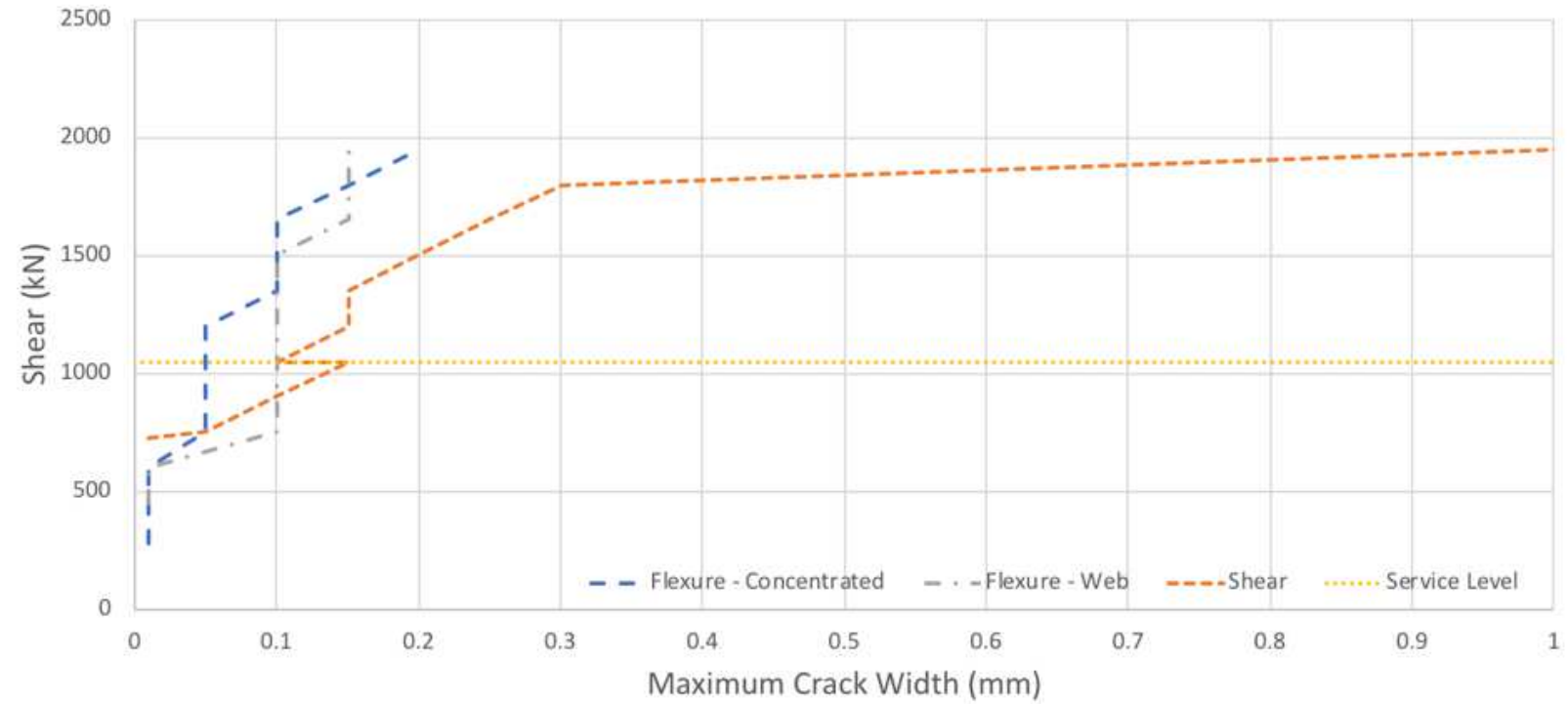

Figure 4.19: Shear versus maximum crack widths for south cantilever of cap beam C1R 


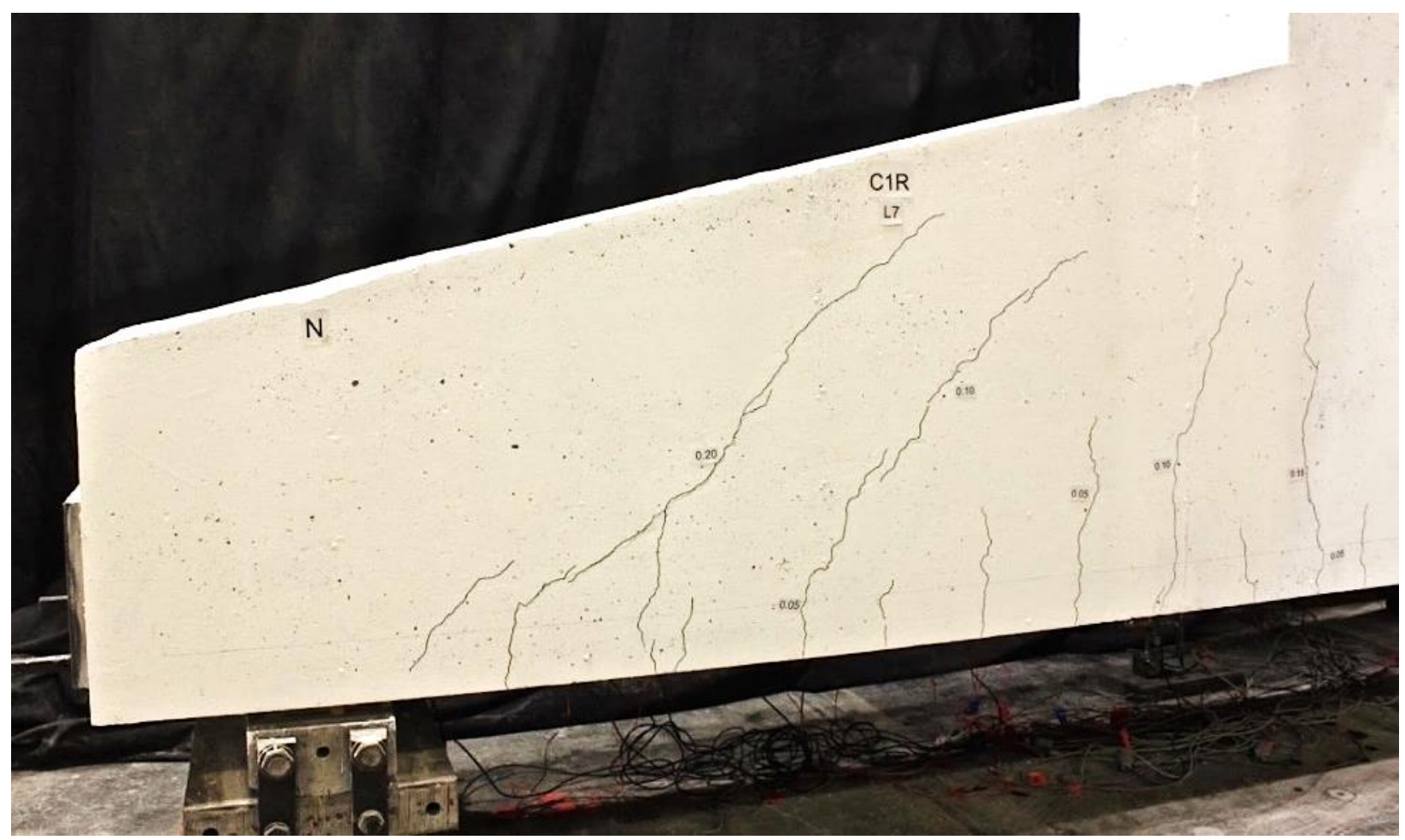

Figure 4.20: Crack pattern and widths at service loading for north cantilever of cap beam C1R

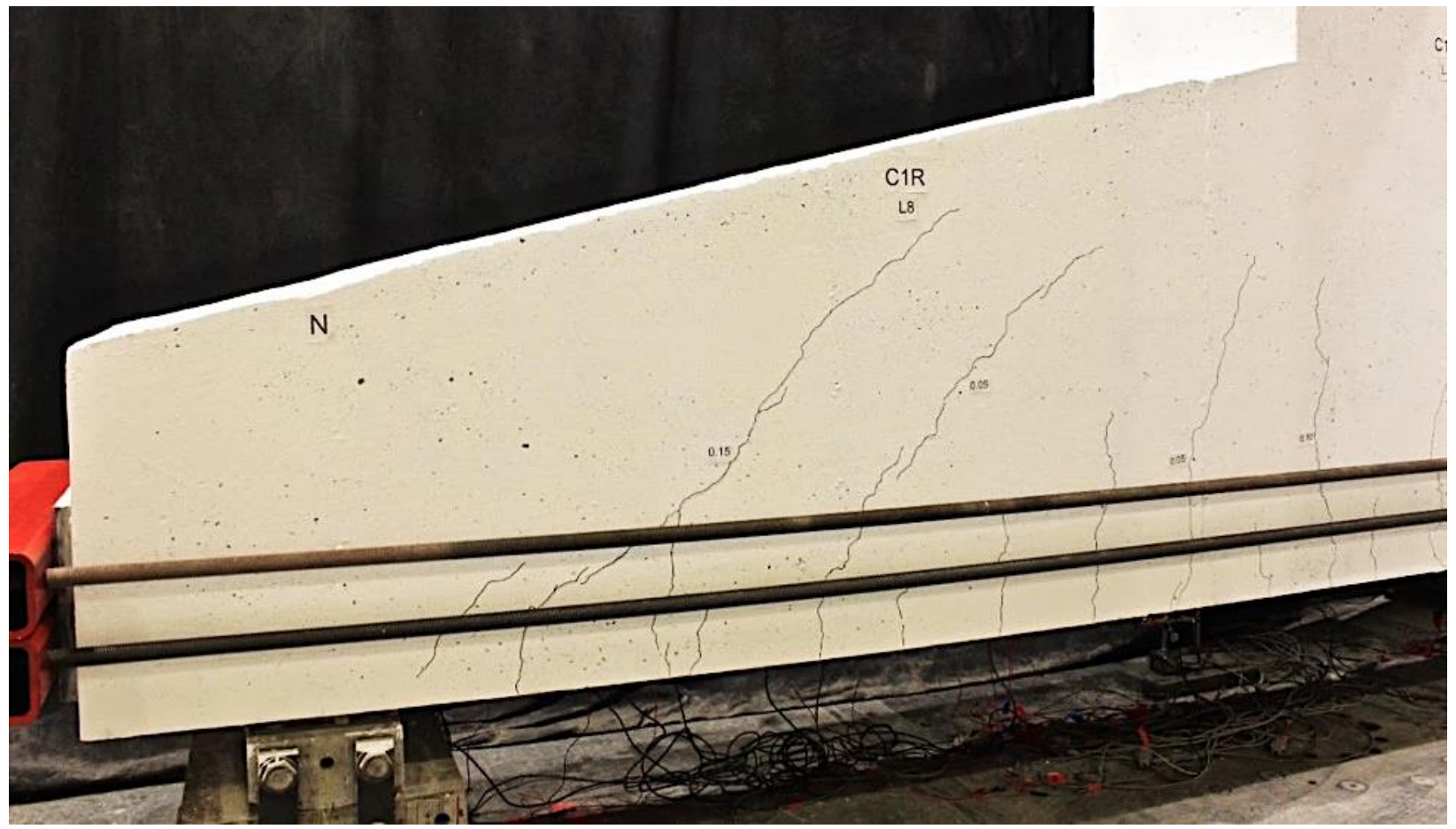

Figure 4.21: Cracks at service loading after post-tensioning for north cantilever of cap beam C1R 


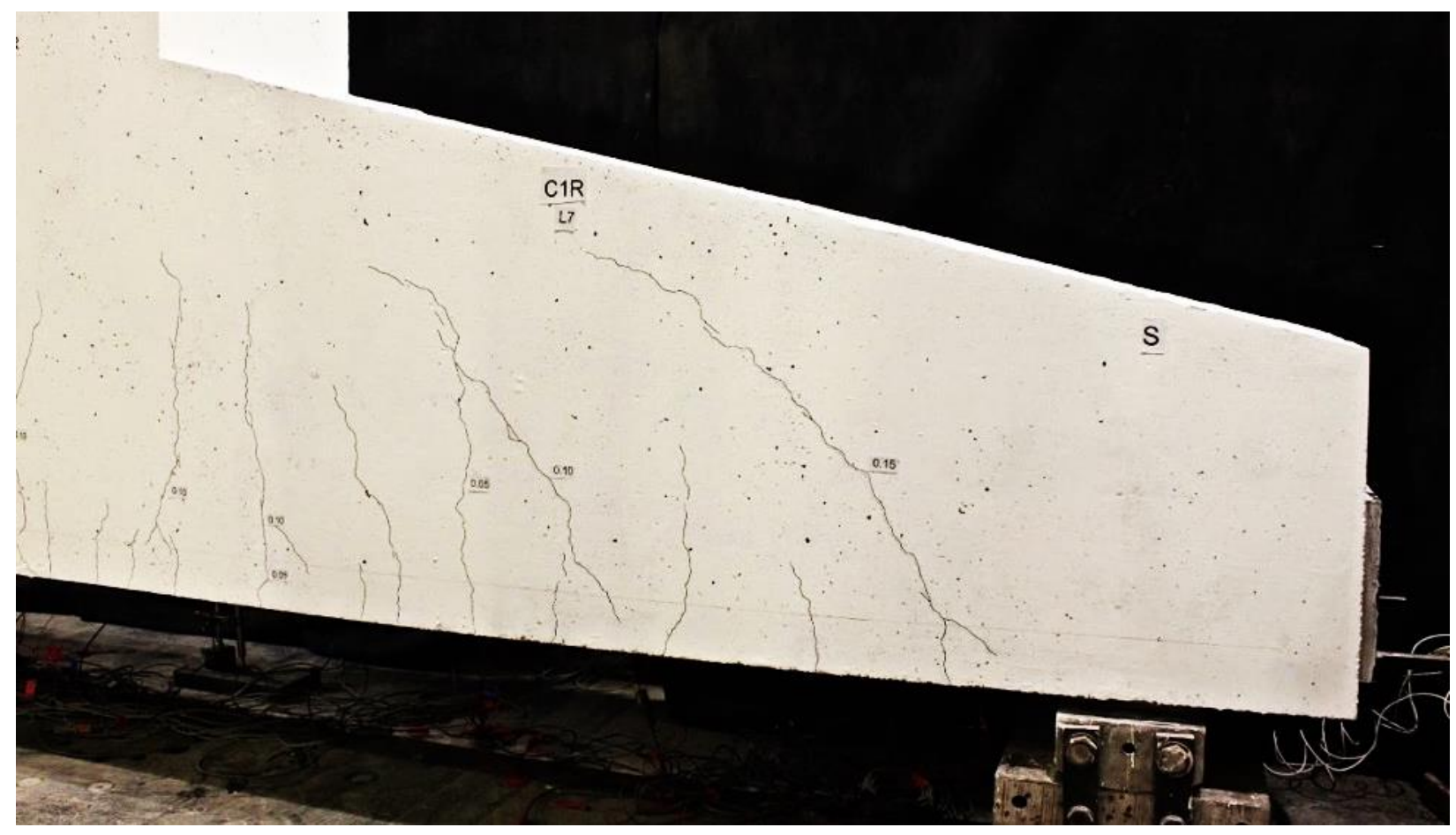

Figure 4.22: Crack pattern and widths at service loading for south cantilever of cap beam C1R

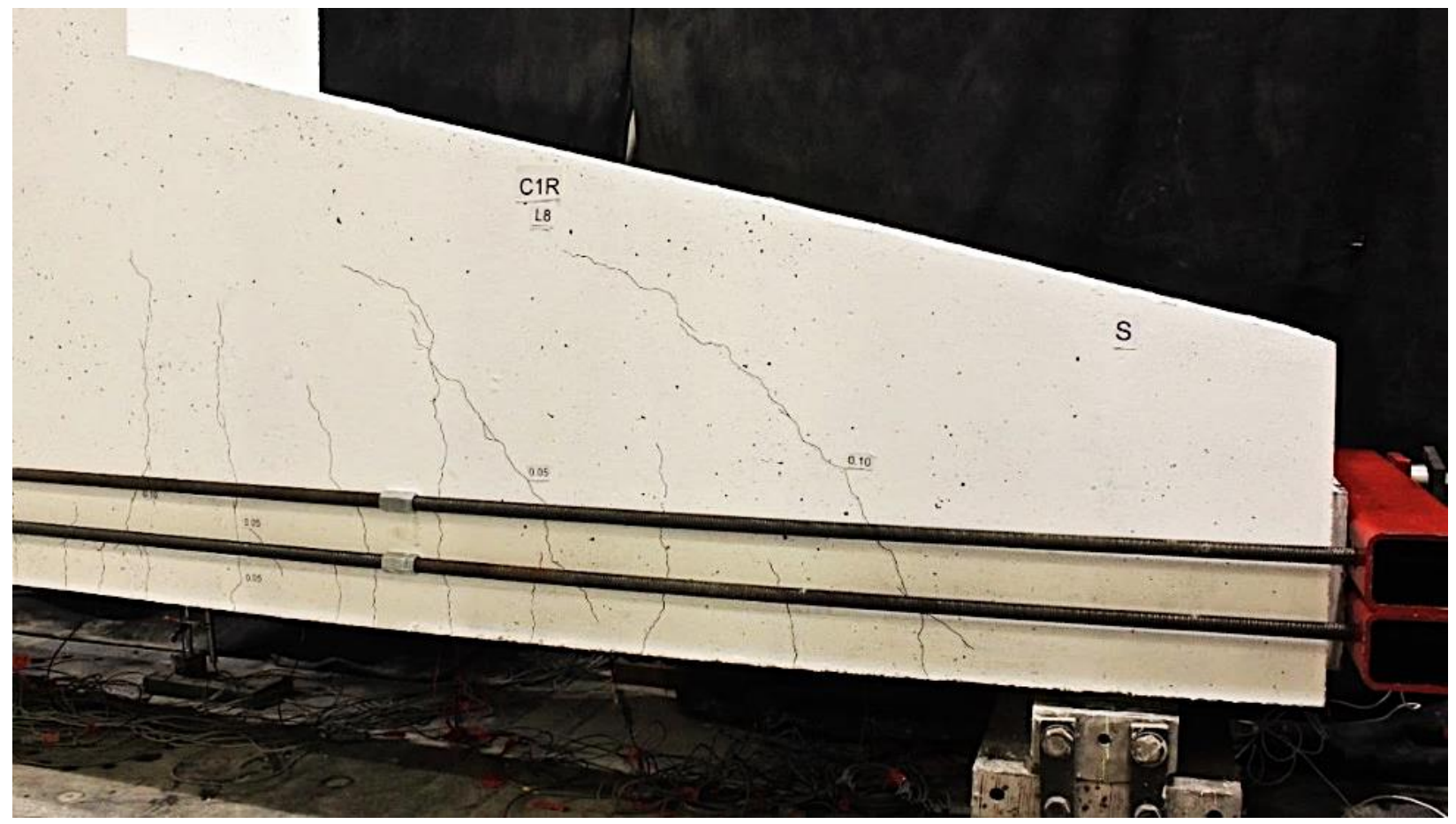

Figure 4.23: Cracks at service loading after post-tensioning for south cantilever of cap beam C1R 


\subsubsection{Measured Strains}

The average tensile strains measured by LVDTs LV1-LV8 at the centroid of the $18-25 \mathrm{M}$ primary tension reinforcement are shown in Figure 4.24. The highest average strain at the service load level before post-tensioning was 0.00166 at LV5 on the north cantilever near the column face. After post-tensioning all eight LVDTs recorded an appreciable decrease in strain, such as LV6, which decreased from a strain of $1171 \times 10^{-6}$ to $994 \times 10^{-6}$. At failure two of the average strains were well above the yield strain of 0.00232 for the $25 \mathrm{M}$ bars. Figures 4.25 and 4.26 show the shear versus average strain curves for each LVDT and indicate that for LV3 and LV5 yielding of the primary tension steel had occurred at shears of $1778 \mathrm{kN}$ and $1686 \mathrm{kN}$ respectively, both well before failure $(1973 \mathrm{kN})$.

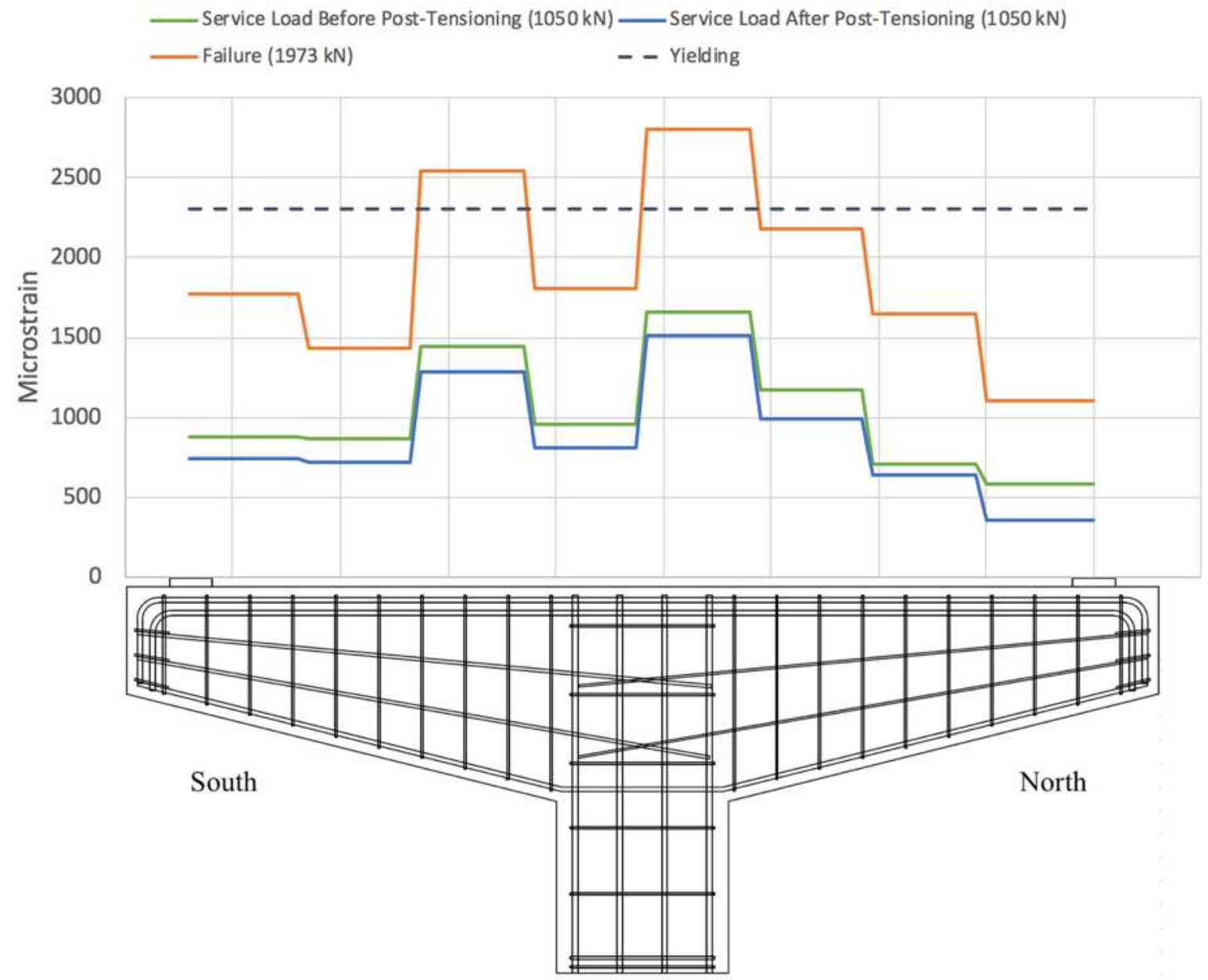

Figure 4.24: Average longitudinal strains measured along the centroid of the concentrated tension steel for cap beam C1R 


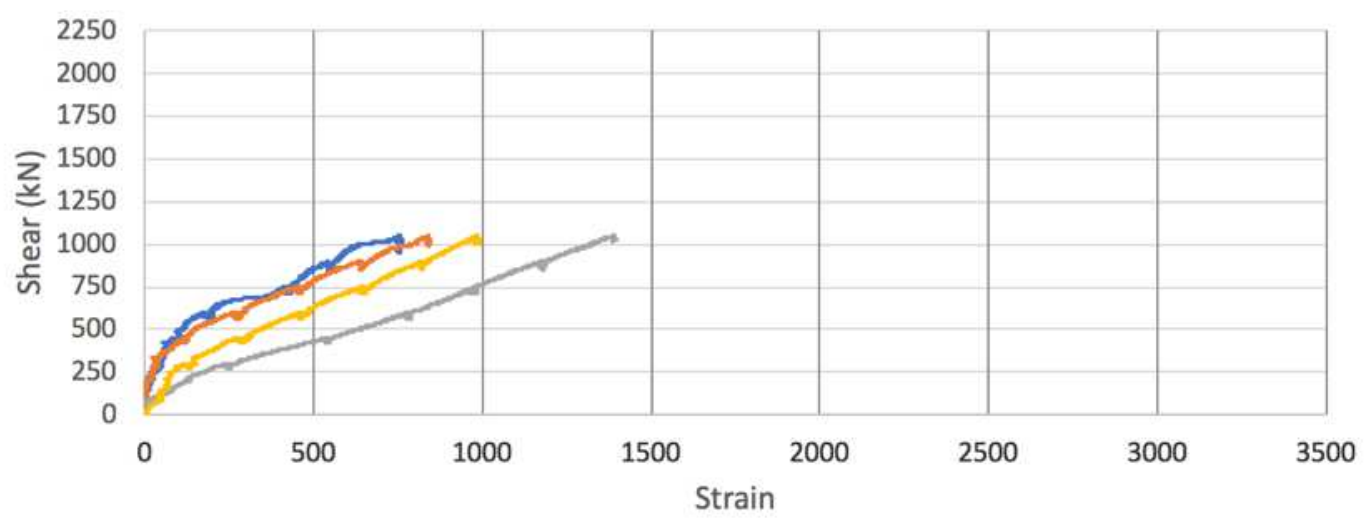

(a) to service load

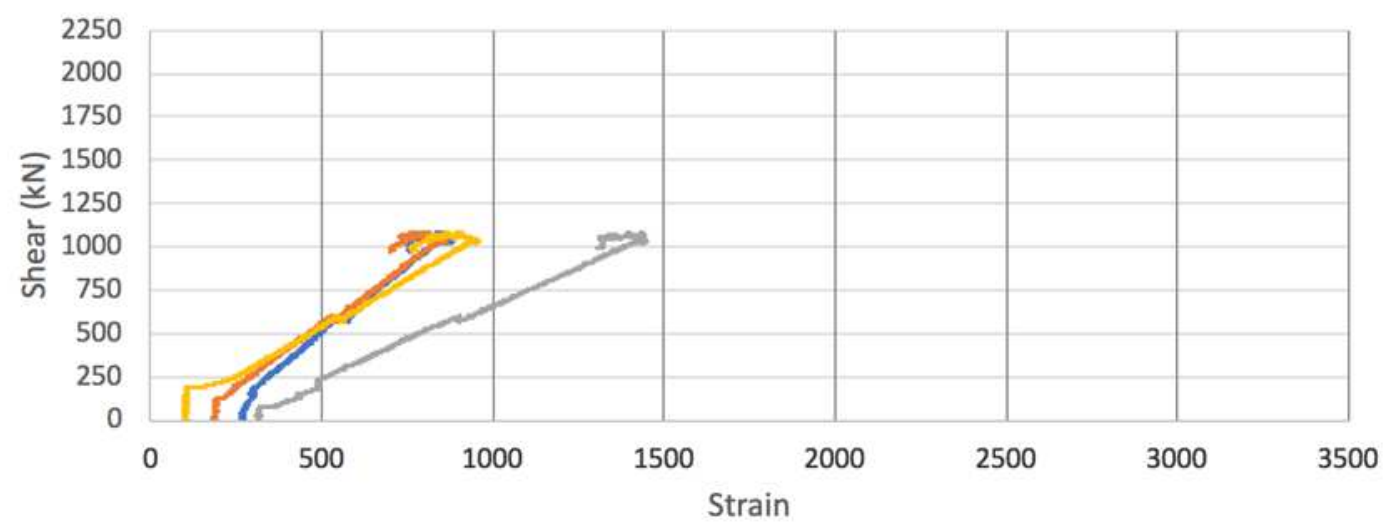

(b) post-tensioning at service load

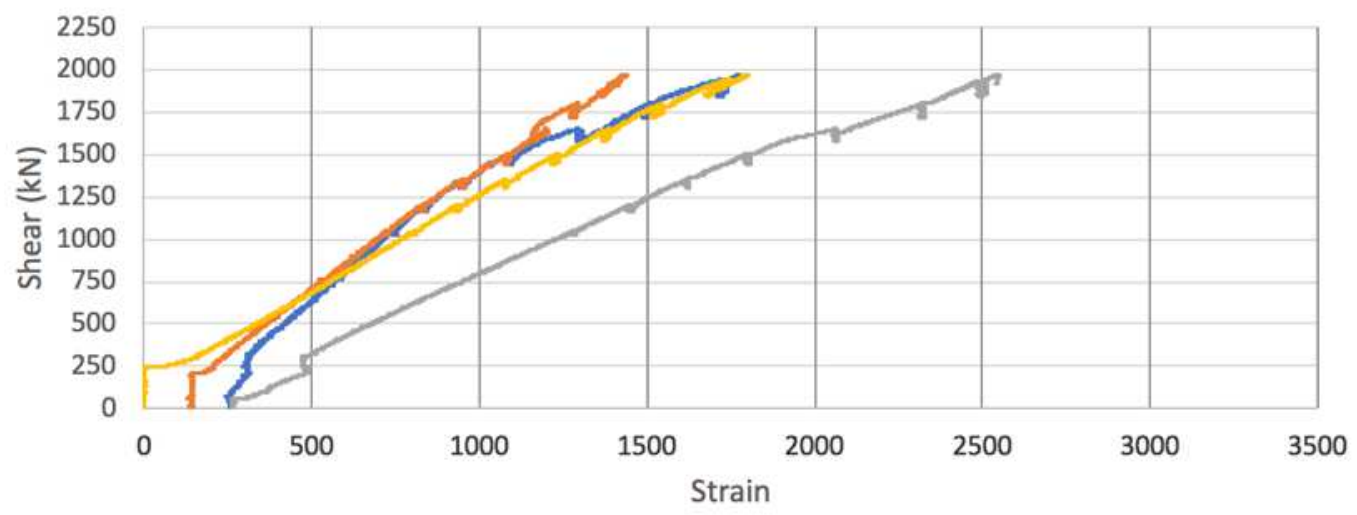

(c) initial loading

-LV1 -LV2 - LV3 - LV4

Figure 4.25: Shear versus average longitudinal strain in the south cantilever of cap beam C1R 


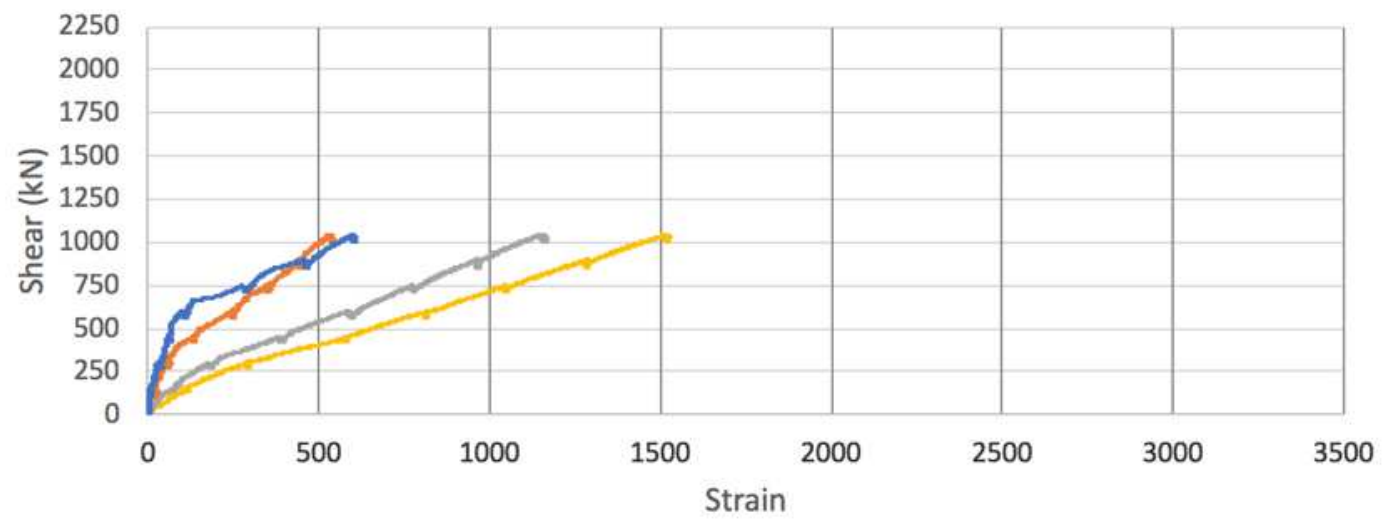

(a) to service load

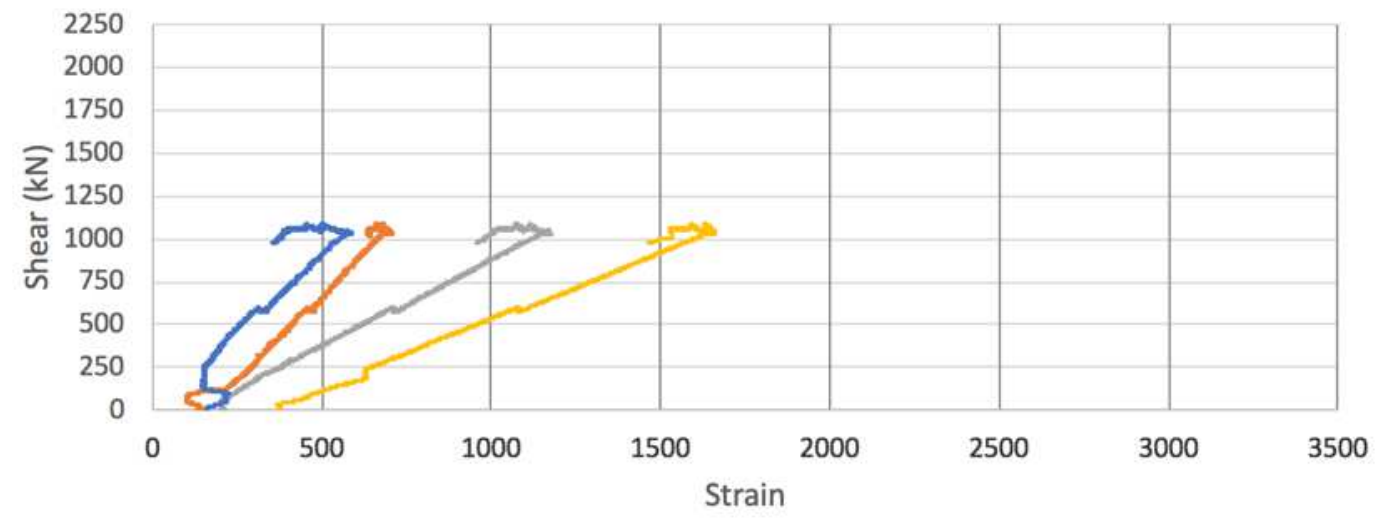

(b) post-tensioning at service load

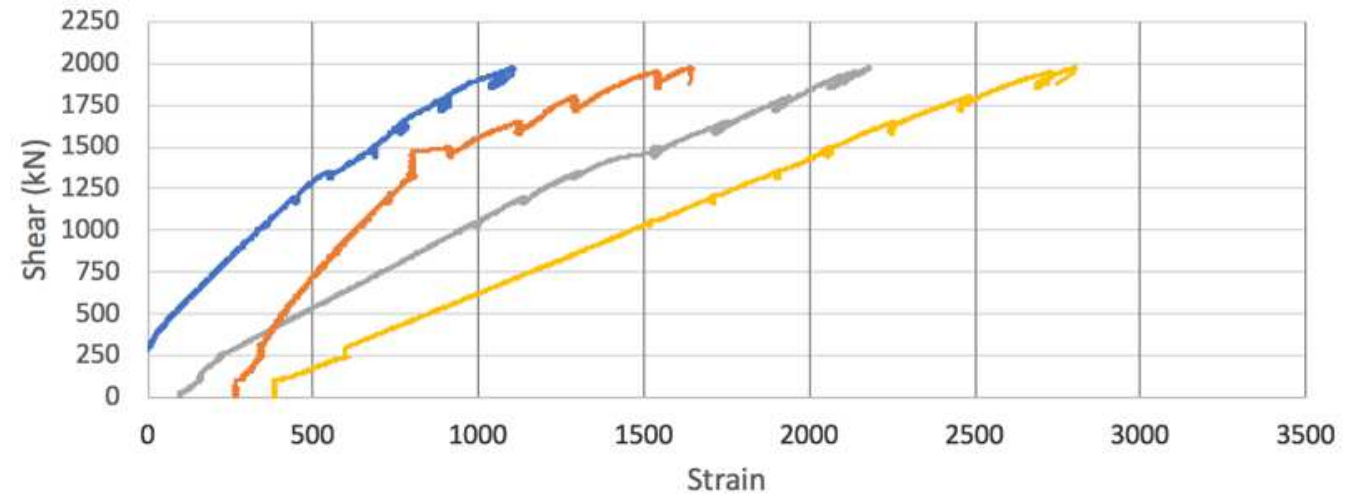

(c) initial loading

$-\operatorname{LV} 5-\operatorname{LV} 6-\operatorname{LV} 7-\operatorname{LV} 8$

Figure 4.26: Shear versus average longitudinal strain in the north cantilever of cap beam C1R 
The shear versus strain relationships for several stirrups in the north and south cantilevers are shown in Figures 4.27 and 4.28 Looking first at the north side, LS6 was the first stirrup to reach the yield strain of 0.00231 at a shear of $1357 \mathrm{kN}$, followed by LS2 at a shear of $1913 \mathrm{kN}$. LS1, LS5, and LS7 reached peak strains of 0.00106, 0.00161, and 0.00139, respectively. LS3 and LS4 were both well below yielding. As for the south cantilever stirrups RS6 and RS7 reached yielding at shears of $1920 \mathrm{kN}$ and $1730 \mathrm{kN}$, respectively. Stirrup RS3 was very close to yielding, reaching a peak strain of 0.00202 at failure. Stirrups RS1, RS2, and RS4 recorded low strain values, and strain gage RS5 malfunctioned. Overall these stirrup strain gages indicated that significant stirrup yielding had occurred before failure in both cantilevers.

Strain gages LLT and RLT measured compressive strains on the inclined face of the cantilevers next to the column interface on the north and south sides, respectively. The shear versus strain for these strain gages can be seen in Figure 4.29(a)-(b) below. Strain gage LLT reached a peak strain of 0.00187 , slightly below the 0.00224 yield strain for the $20 \mathrm{M}$ bars. Strain gage RLT reached a peak strain of 0.00218 , thus indicating the onset of concrete crushing and possible buckling of the primary compressive bars. Two LVDTs were also used at the reentrant corners. LV10 on the north side reached a strain of 0.0035 at a shear of $1755 \mathrm{kN}$, as shown in Figure 4.29(c). LV9 on the south side malfunctioned.

Unfortunately for pier cap C1R the rosette LVDTs LVV1 and LVV2 malfunctioned and gave no salvageable data. Thus, Figure 4.30 shows the horizontal strain $\varepsilon_{x}$ and the $45^{\circ}$ diagonal strain $\varepsilon_{x}$ ' measured by the two remaining LVDTs on either side. In the legend "PT" represents the loading before post-tensioning installation. On the north side the horizontal strains were approximately zero for the entire loading curve, and the $45^{\circ}$ diagonal strain reached a peak strain of 0.00245 . The diagonal strains started increasing at a shear of about $820 \mathrm{kN}$, noting the first signs of shear cracking were observed at $575 \mathrm{kN}$. The south side reached a peak horizontal strain of 0.00145 and a peak $45^{\circ}$ diagonal strain of 0.00942 at failure. The longitudinal strain started increasing at a shear of about $465 \mathrm{kN}$, coinciding with the first flexural web crack at $450 \mathrm{kN}$. The diagonal strain started increasing at a shear of about $700 \mathrm{kN}$, close to the first signs of shear cracking at $725 \mathrm{kN}$. Though the principal angles could not be determined, it was noted that the angle of the shear crack at failure near the rosettes was $38.1^{\circ}$ on the north side and $29.4^{\circ}$ on the south side. 


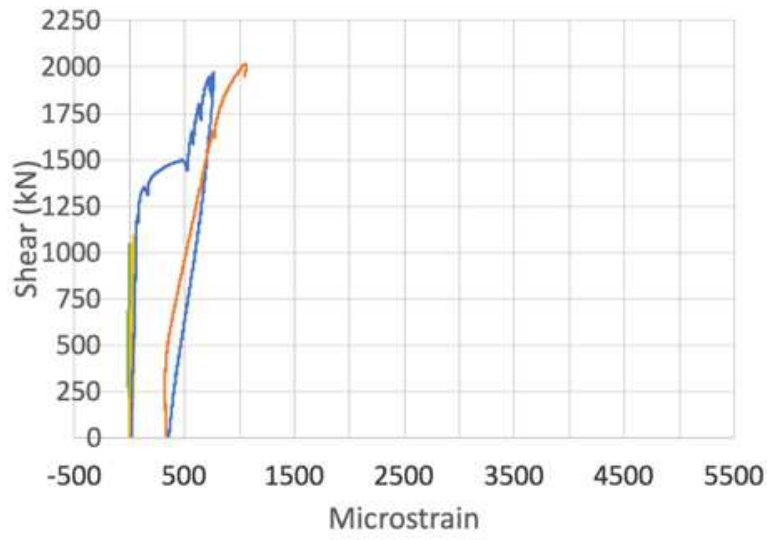

(a) LS1

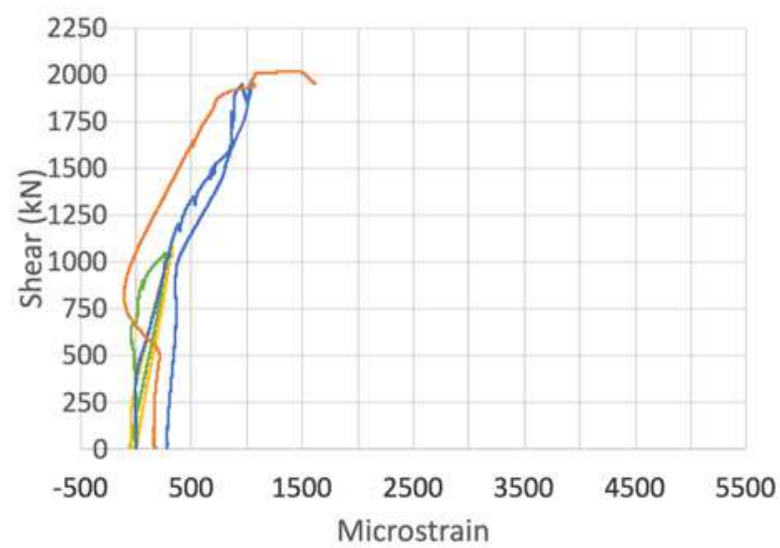

(c) LS5

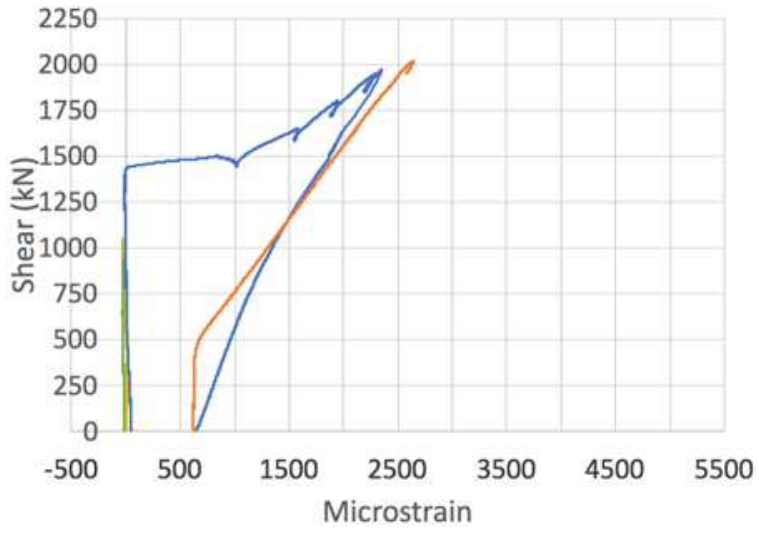

(b) LS2

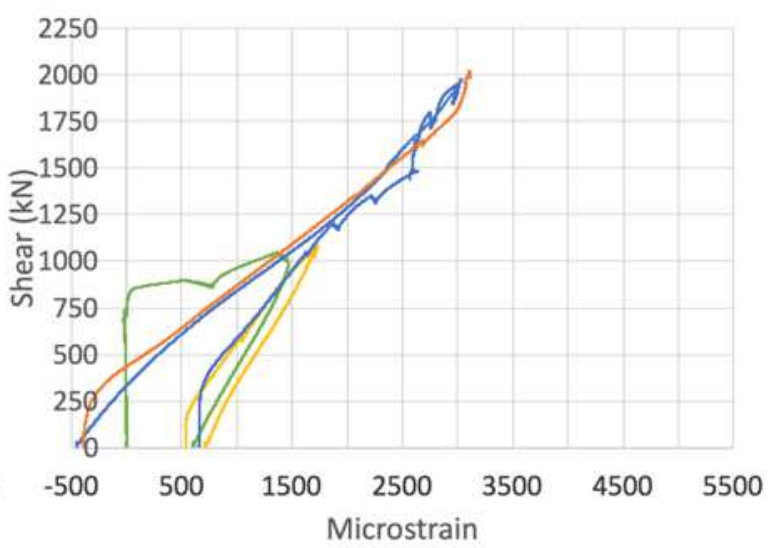

(d) LS6

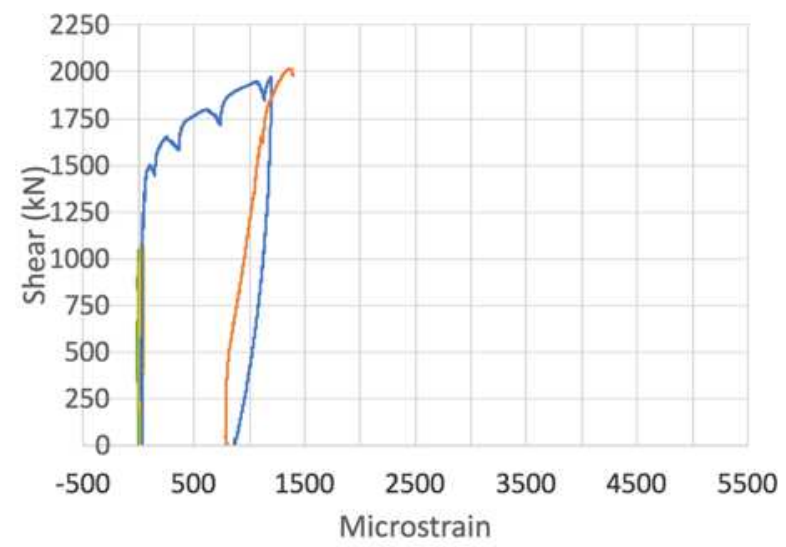

(e) LS7

—To Service Load __Post-Tensioning at Service Load _ Initial Loading —Post-Clamping Loading

Figure 4.27: Shear versus strain for stirrups in north cantilever of cap beam C1R 


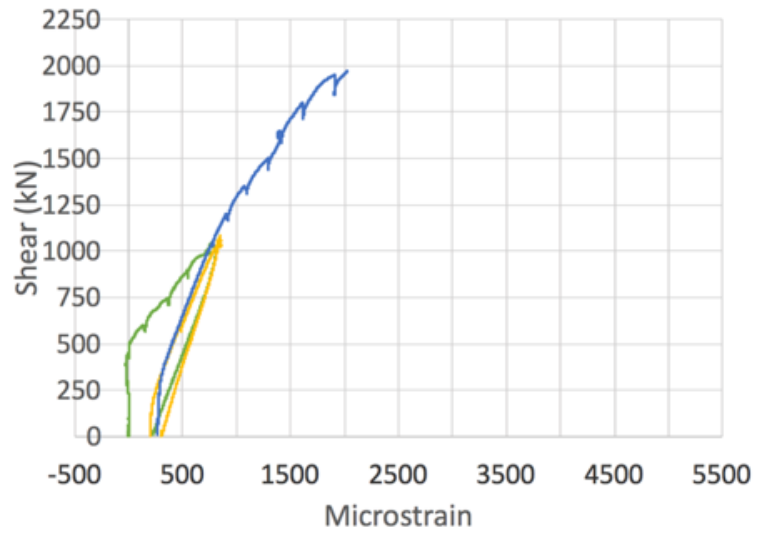

(a) RS3

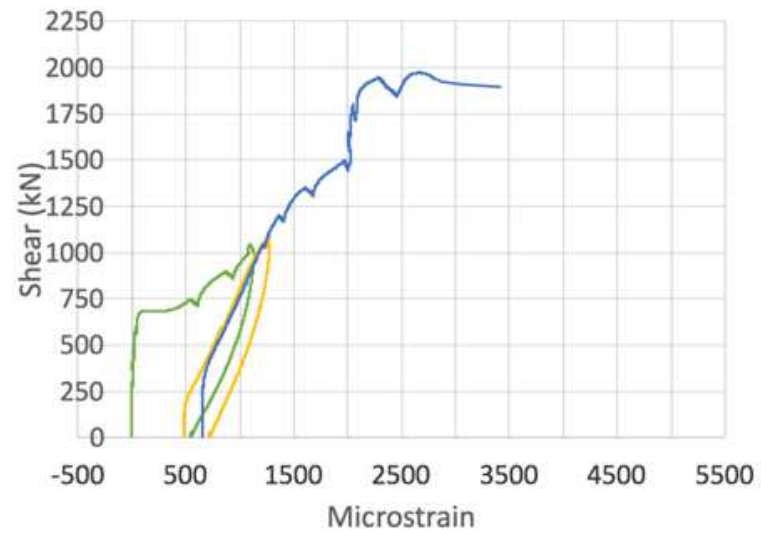

(b) RS6

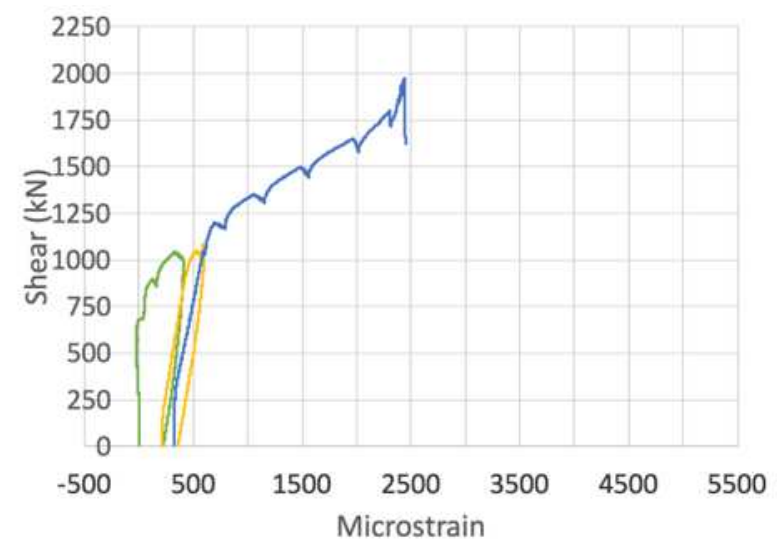

(c) RS7

— To Service Load _ _ Post-Tensioning at Service Load _ _Initial Loading

Figure 4.28: Shear versus strain for stirrups in south cantilever of cap beam C1R 


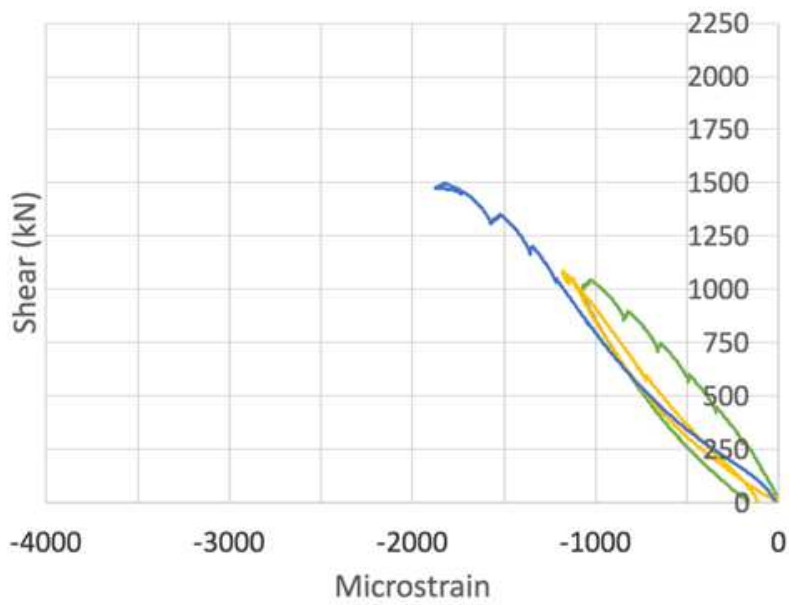

(a) LLT (north)

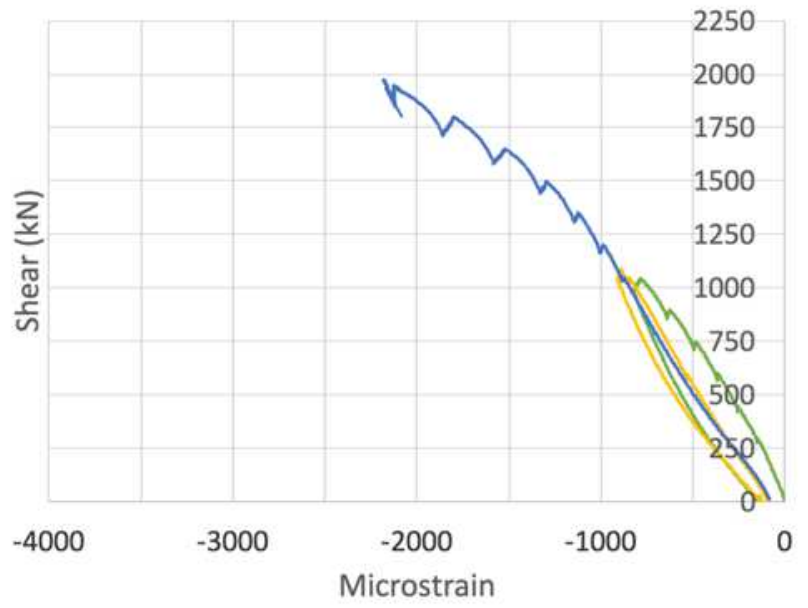

(b) RLT (south)

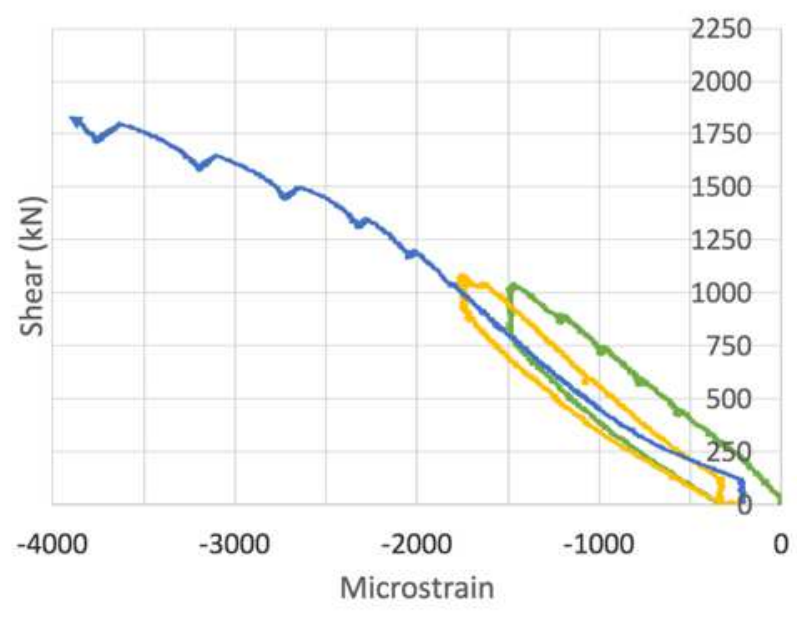

(c) LV10 (north)

—Initital Loading -Post-Clamping Loading

Figure 4.29: Shear versus compressive strain at re-entrant corners on cap beam C1R 


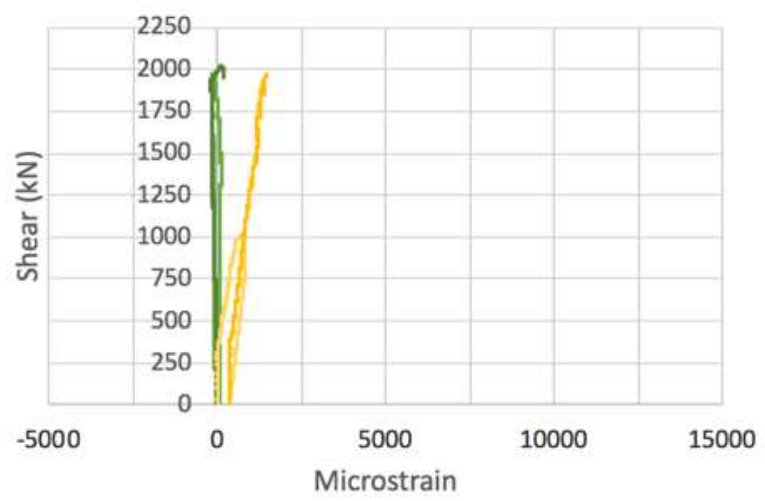

(a) horizontal strain, $\varepsilon_{\mathrm{x}}$

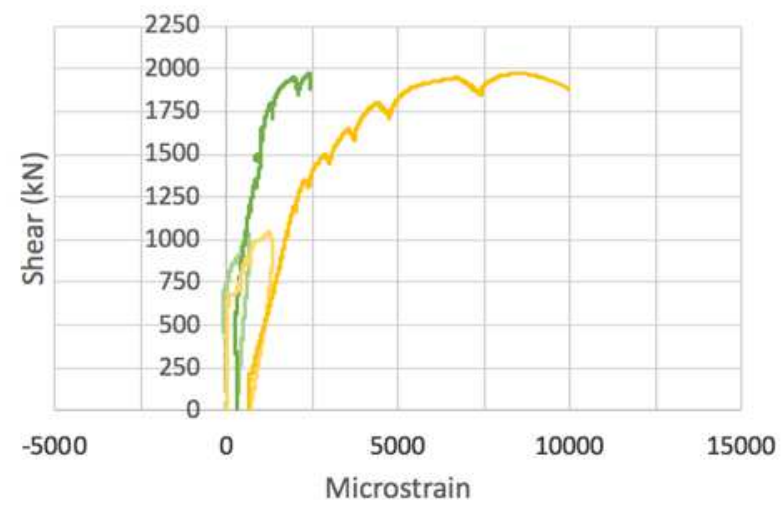

(b) $45^{\circ}$ diagonal strain, $\varepsilon_{x}^{\prime}$

- North-PT — North-1 - North-2 - South-PT —South-1

Figure 4.30: Shear versus strain from cap beam C1R rosettes

\subsubsection{Variation of Post-Tensioning Force}

Figure 4.31 demonstrates the post-tensioning force variation with increasing shear. The total force of post-tensioning at the service load level was approximately $600 \mathrm{kN}$. As the shear increased the post-tensioning force increased almost linearly to a peak of $748 \mathrm{kN}$ when the south cantilever failed. After external shear clamping the post-tensioning force again increased quite linearly to $740 \mathrm{kN}$ before failure of the north cantilever.

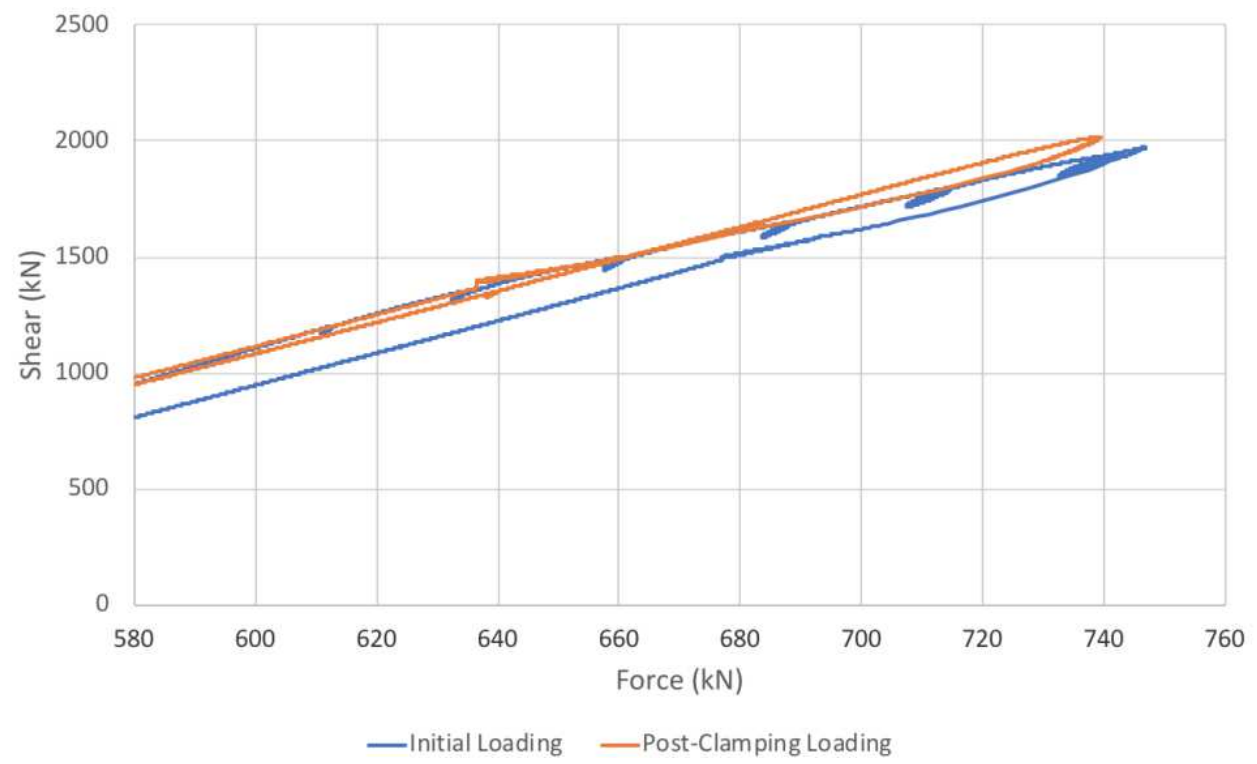

Figure 4.31: Shear versus total force in post-tensioning rods in cap beam C1R 


\subsection{Pier Cap C2}

\subsubsection{Shear-Deflection Response}

The shear versus midspan deflection response for pier cap C2 is shown in Figure 4.32. The pier cap reached a shear of $2075 \mathrm{kN}$ and a midspan deflection of $17.5 \mathrm{~mm}$ before failing in a combination of crushing and shear in the north cantilever. After the installation of shear clamps on the north cantilever the pier cap was loaded once again. However due to the extensive damage on the north cantilever it was not possible to fail the south cantilever. The shear clamps failed to prevent the north cantilever from failing again, with failure initiating at a shear of $2007 \mathrm{kN}$ and reaching a midspan deflection of $30.0 \mathrm{~mm}$. The north cantilever had reached a higher shear of $2075 \mathrm{kN}$ on the initial loading cycle.

First flexural cracking was observed at a shear of $250 \mathrm{kN}$ near the column-cantilever interface on both sides, accompanied by a decrease in stiffness in Figure 4.32. The first shear cracks were observed at $675 \mathrm{kN}$ in both cantilevers.

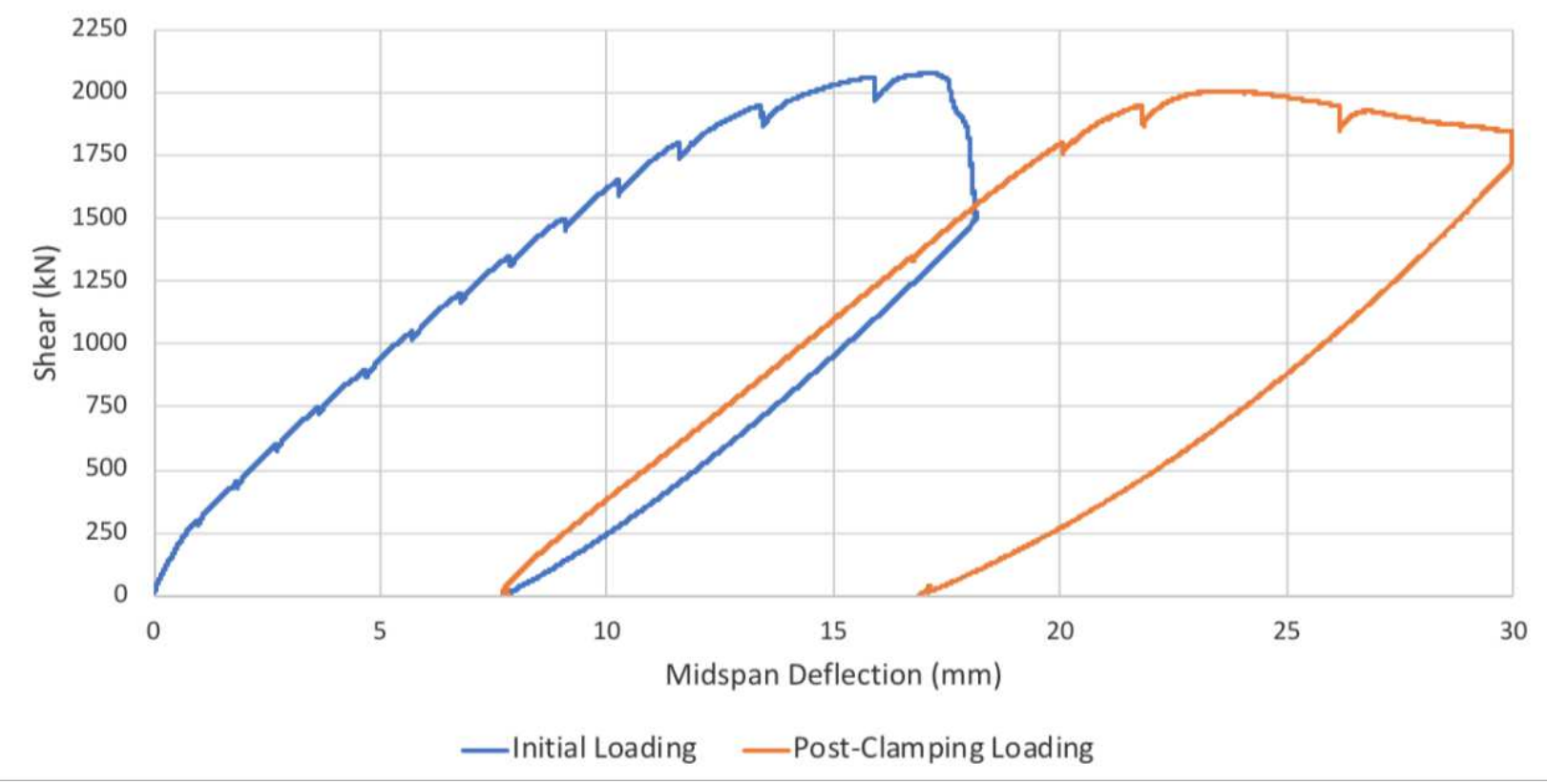

Figure 4.32: Shear versus midspan deflection of cap beam C2 


\subsubsection{Shear Failures}

Figure 4.33 shows the initial failure observed in the north cantilever. The specimen failed in a combination of crushing on the inclined face and shear with the $0.70 \mathrm{~mm}$ critical shear crack starting $50 \mathrm{~mm}$ from the center of the roller support on the bottom face and ending just before the column face on the top surface. Significant yielding of the stirrups and inclined reinforcement was observed before failure.

The crack pattern of the south cantilever at peak load after clamping is shown in Figure 4.34. The largest shear crack had a width of $1.30 \mathrm{~mm}$ and concrete cracking on the inclined surface had initiated. Despite not reaching failure, significant yielding of the stirrups and inclined reinforcement was observed in the south cantilever.

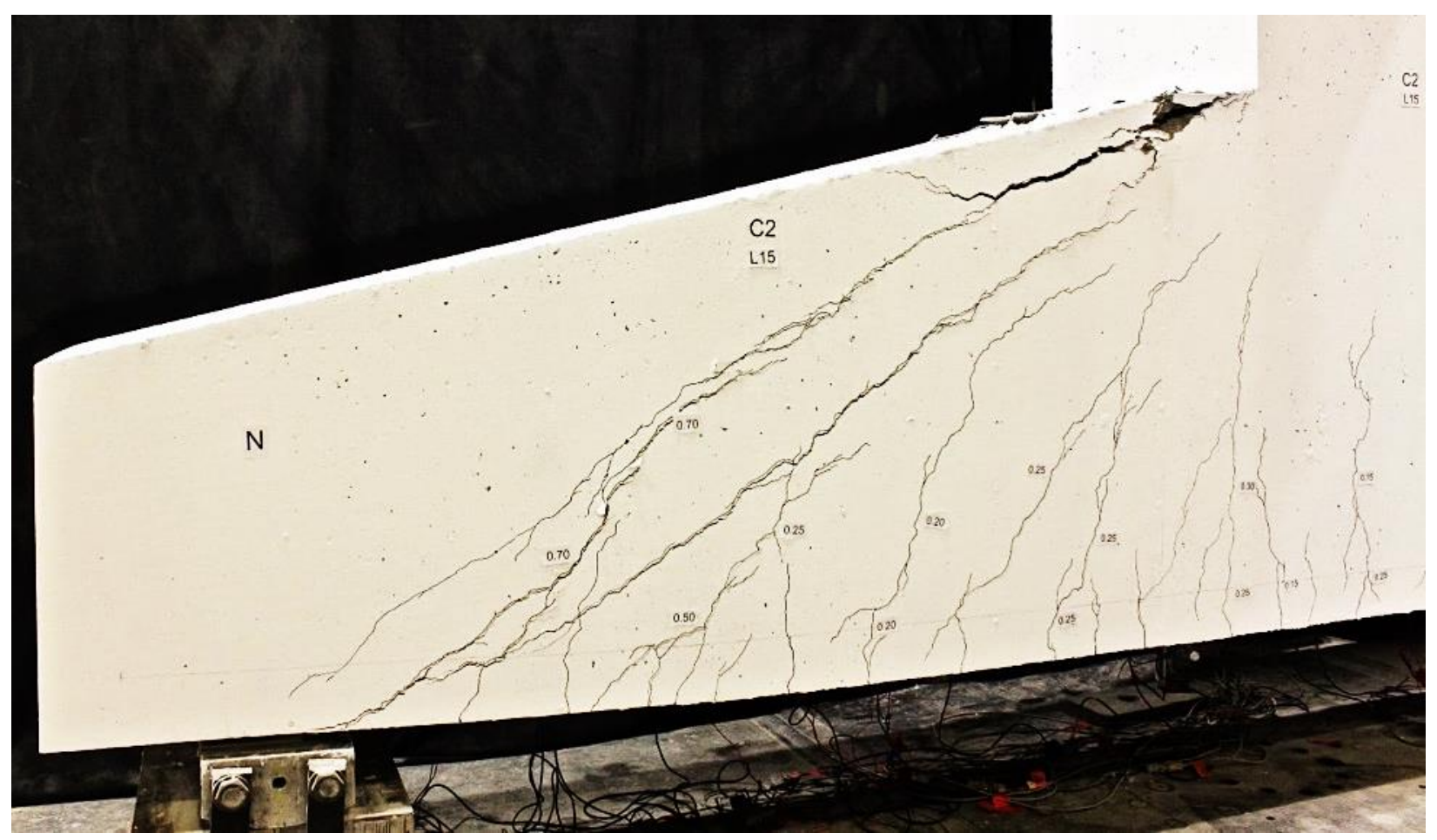

Figure 4.33: Shear failure of north cantilever of cap beam C2 


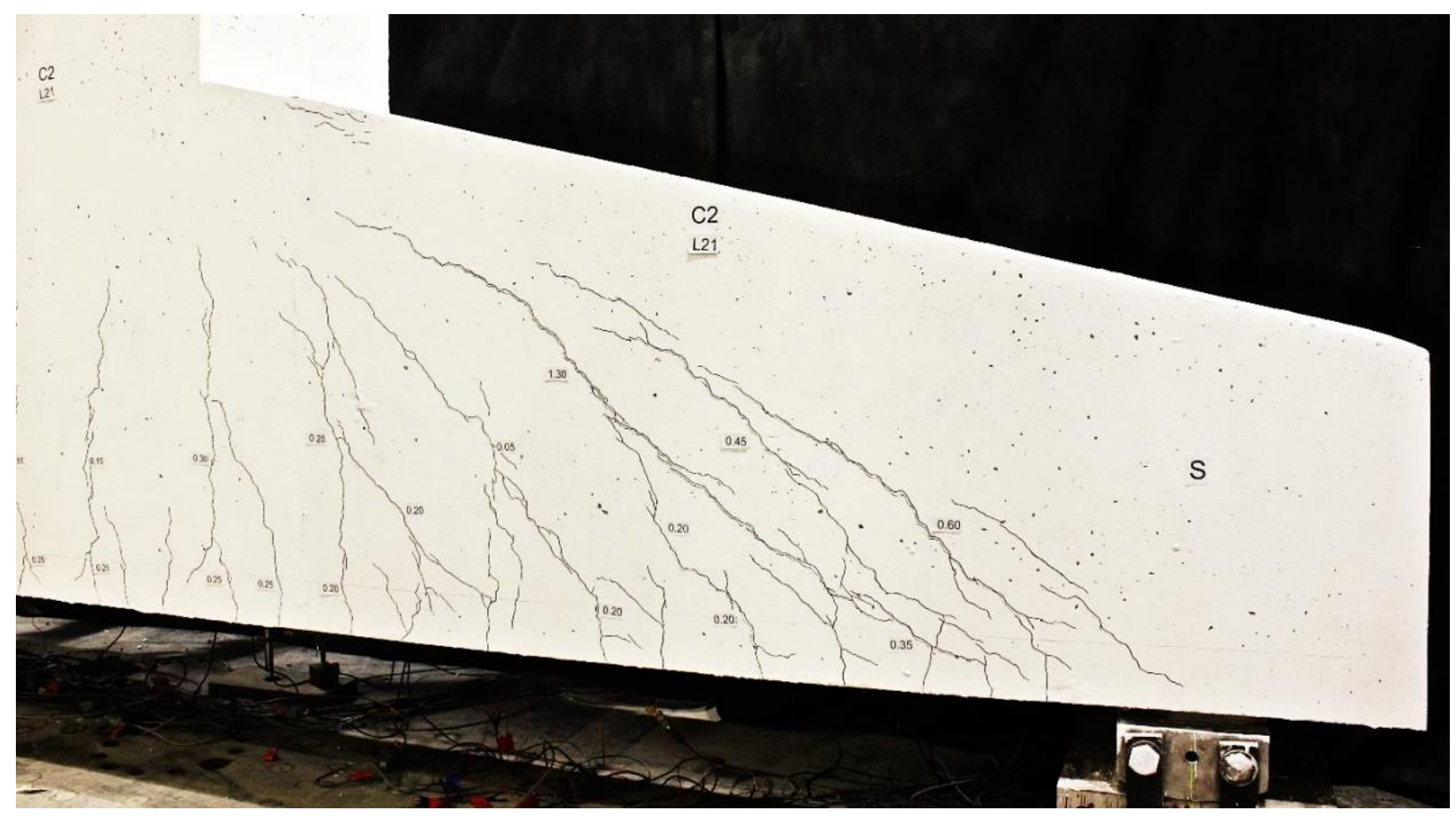

Figure 4.34: Shear distress and concrete crushing of south cantilever of cap beam C2

\subsubsection{Crack Widths}

The maximum crack widths for the north and south cantilevers can be seen in Figures 4.35 and 4.36. At service loading flexural cracks in the web were most critical, with widths of $0.15 \mathrm{~mm}$ and $0.10 \mathrm{~mm}$ in the north and south sides respectively. Flexure cracks in the region of the concentrated tensile steel were lower, at $0.10 \mathrm{~mm}$ and $0.05 \mathrm{~mm}$ for the north and south sides, respectively. Maximum shear cracks at the service load level were only $0.05 \mathrm{~mm}$ on both cantilevers due to the $45^{\circ}$ inclined reinforcement in the pier cap C2 design. Figures 4.37 and 4.38 show the crack patterns and measured crack widths at the service load level for the north and south sides respectively. Shear cracks and flexural web cracks were consistently smaller in the south side at the service load level and at higher loads due to the higher amount of crack control reinforcement. Despite the maximum shear cracks being smaller than the maximum flexural cracks at the service load level, at a shear of $1350 \mathrm{kN}$ in the north side and at $1650 \mathrm{kN}$ in the south side the maximum shear crack widths surpassed the maximum flexural crack widths.

For this cap beam horizontal splitting cracks of the hooks of the $45^{\circ}$ inclined reinforcing bars were also observed. These cracks were located along the hooked anchorages of the inclined 
bars that were spliced with the primary tension reinforcement layers. A horizontal splitting crack was first observed at a shear of $1650 \mathrm{kN}$ in the inclined bar closest to the end of the cantilever on the north side. This crack opened up to a width of $0.50 \mathrm{~mm}$ at failure, as observed in Figure 4.33. No horizontal splitting cracking was observed in the south cantilever.

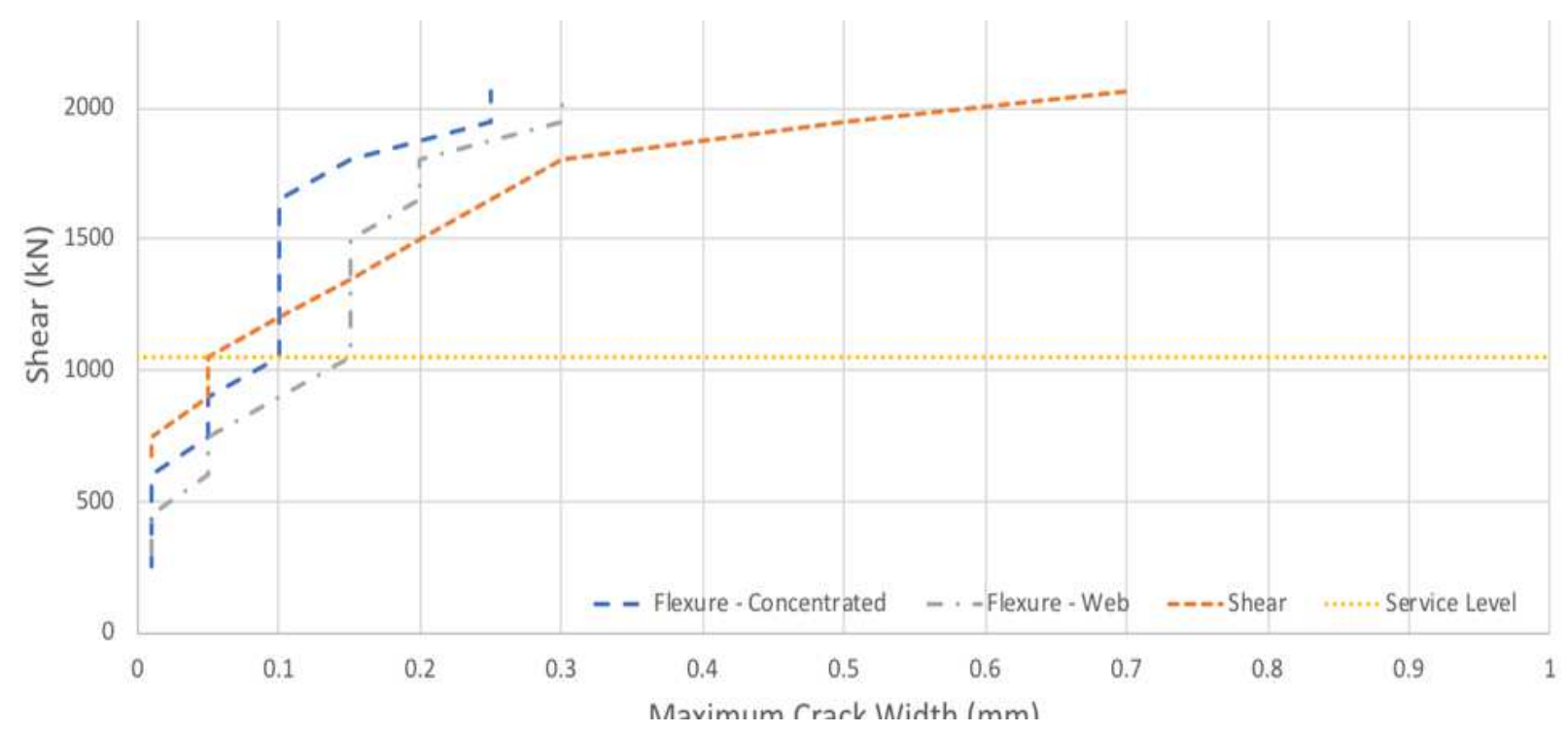

Figure 4.35: Shear versus maximum crack widths for north cantilever of cap beam C2

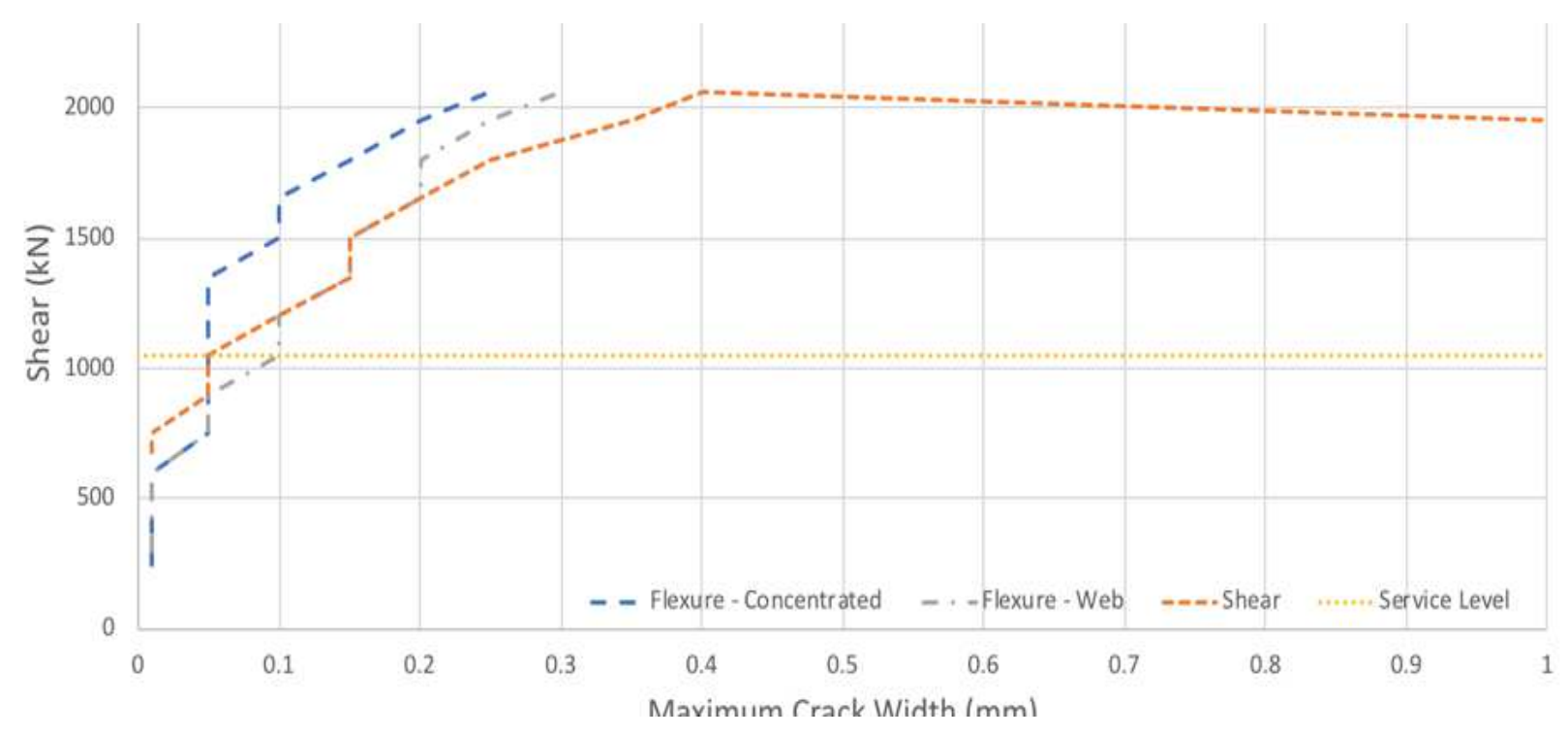

Figure 4.36: Shear versus maximum crack widths for south cantilever of cap beam C2 


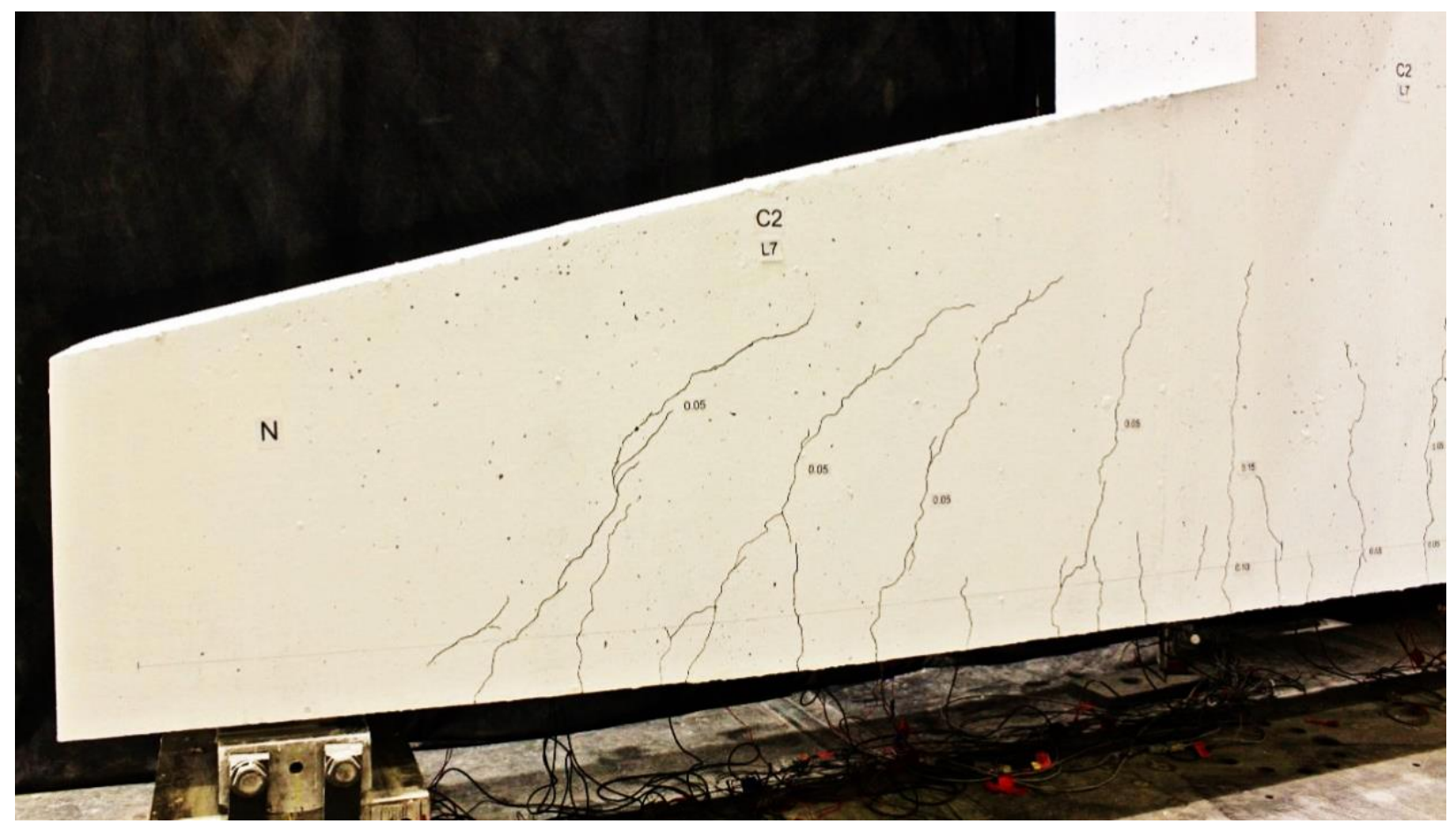

Figure 4.37: Crack pattern and widths at service loading for north cantilever of cap beam C2

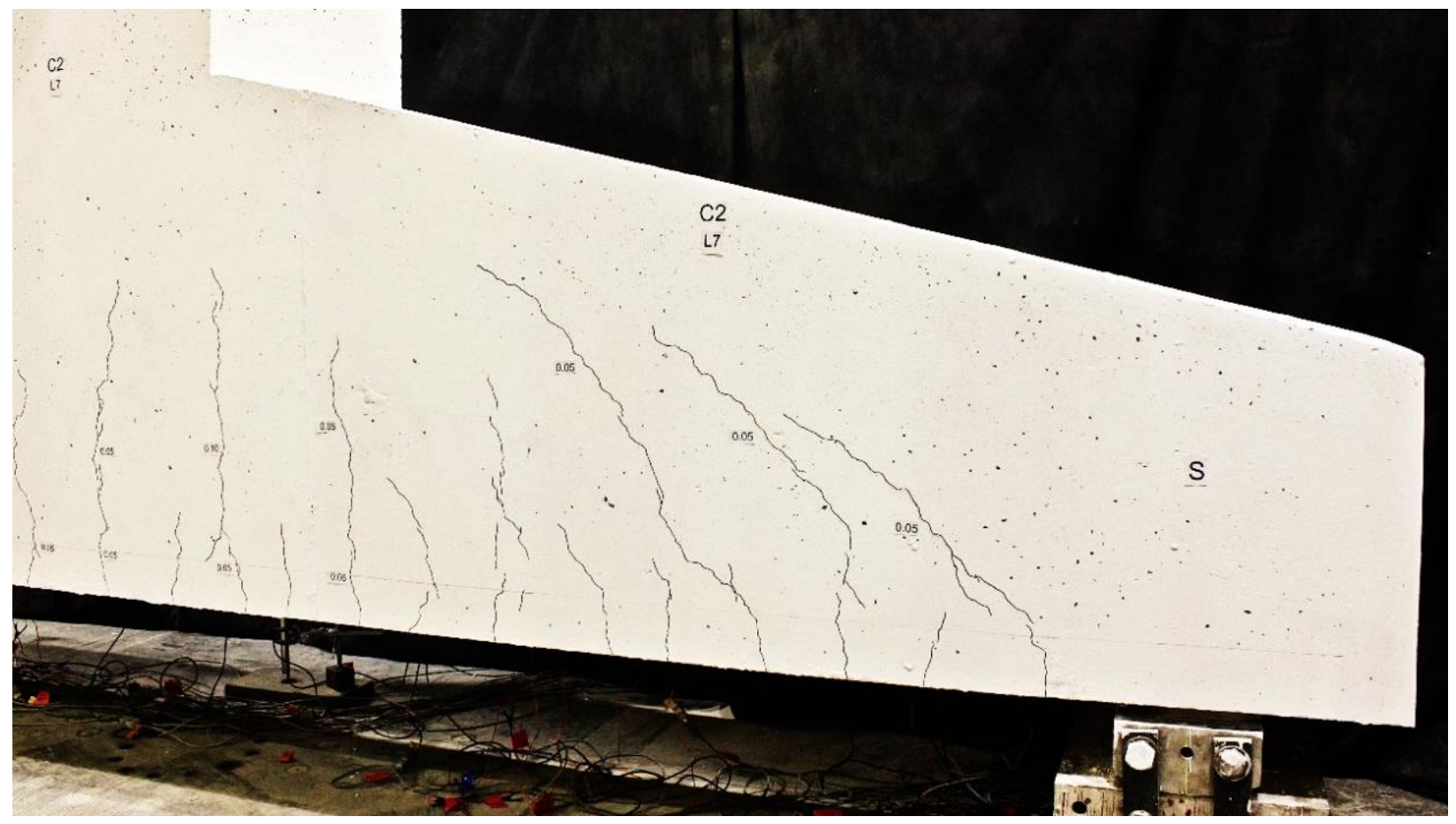

Figure 4.38: Crack pattern and widths at service loading for south cantilever of cap beam C2 


\subsubsection{Measured Strains}

The average tensile strains measured by LVDTs LV1-LV8 at the centroid of the $18-25 \mathrm{M}$ primary tension reinforcement are shown in Figure 4.39 below. The highest average strain at service loading was 0.00164 in the north cantilever about $300 \mathrm{~mm}$ from the column face. At failure four of the average strains were well above the yield strain of 0.00232 for the $25 \mathrm{M}$ bars. Figures 4.40 and 4.41 show the shear versus average strain curves for each LVDT and indicate that for LV3-LV6 yielding of the primary tension steel had occurred before failure $(2075 \mathrm{kN})$. Specifically, LV3, LV4, LV5, and LV6 indicated yielding at shears of $1650 \mathrm{kN}, 1690 \mathrm{kN}, 2035$ $\mathrm{kN}$, and $1475 \mathrm{kN}$, respectively.

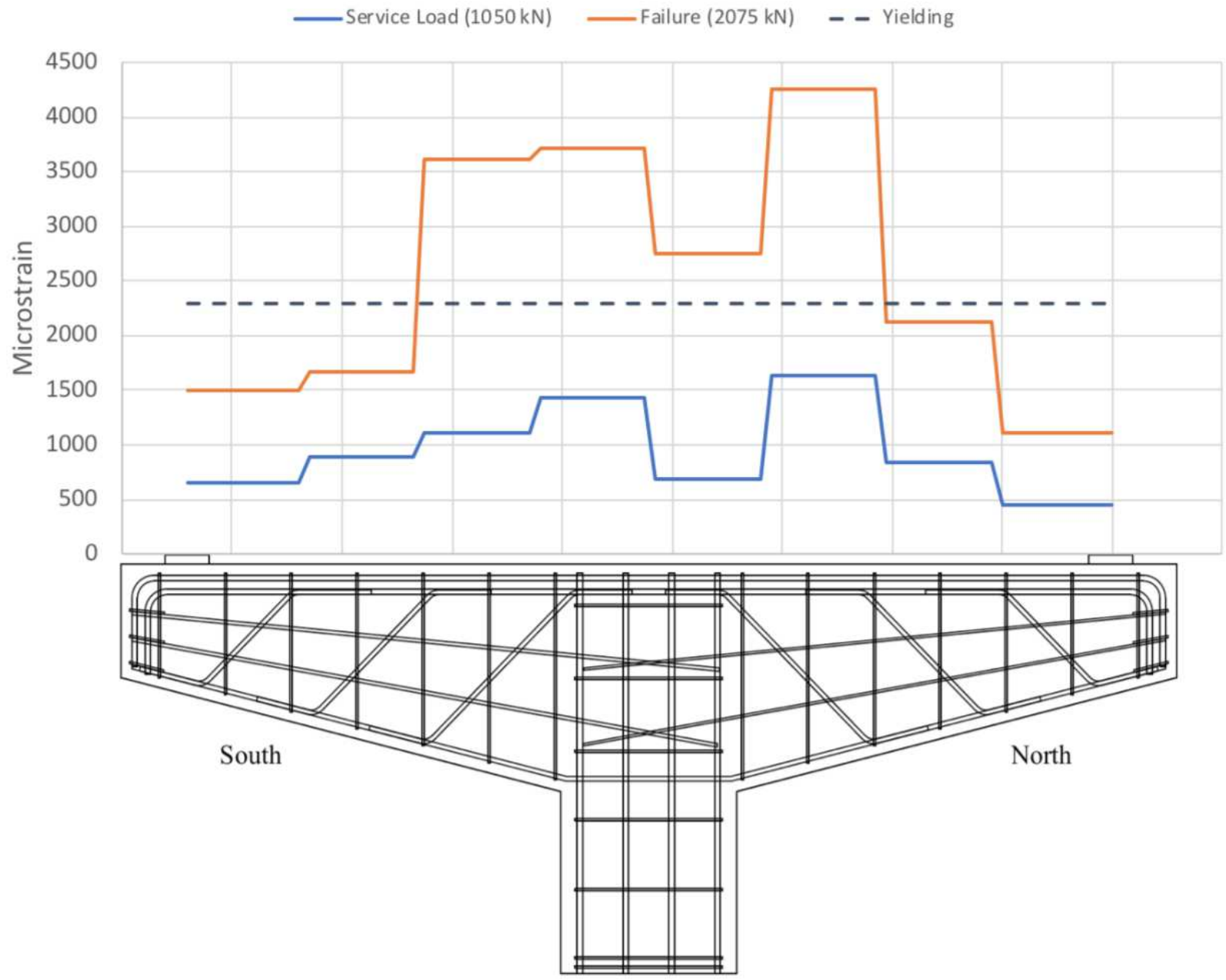

Figure 4.39: Average longitudinal strains measured along the centroid of the concentrated tension steel for cap beam C2 


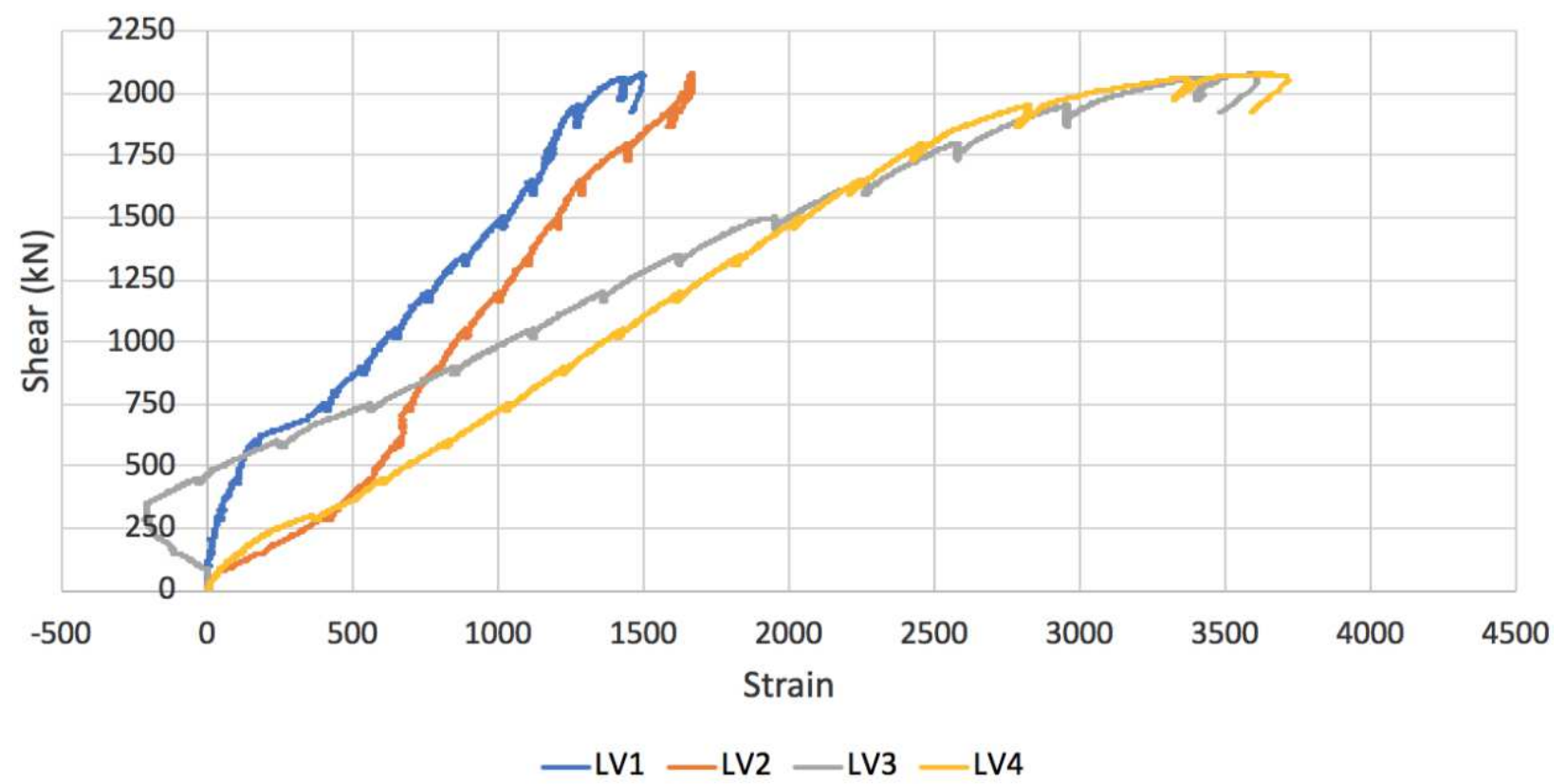

Figure 4.40: Shear versus average longitudinal strain in the south cantilever of cap beam C2

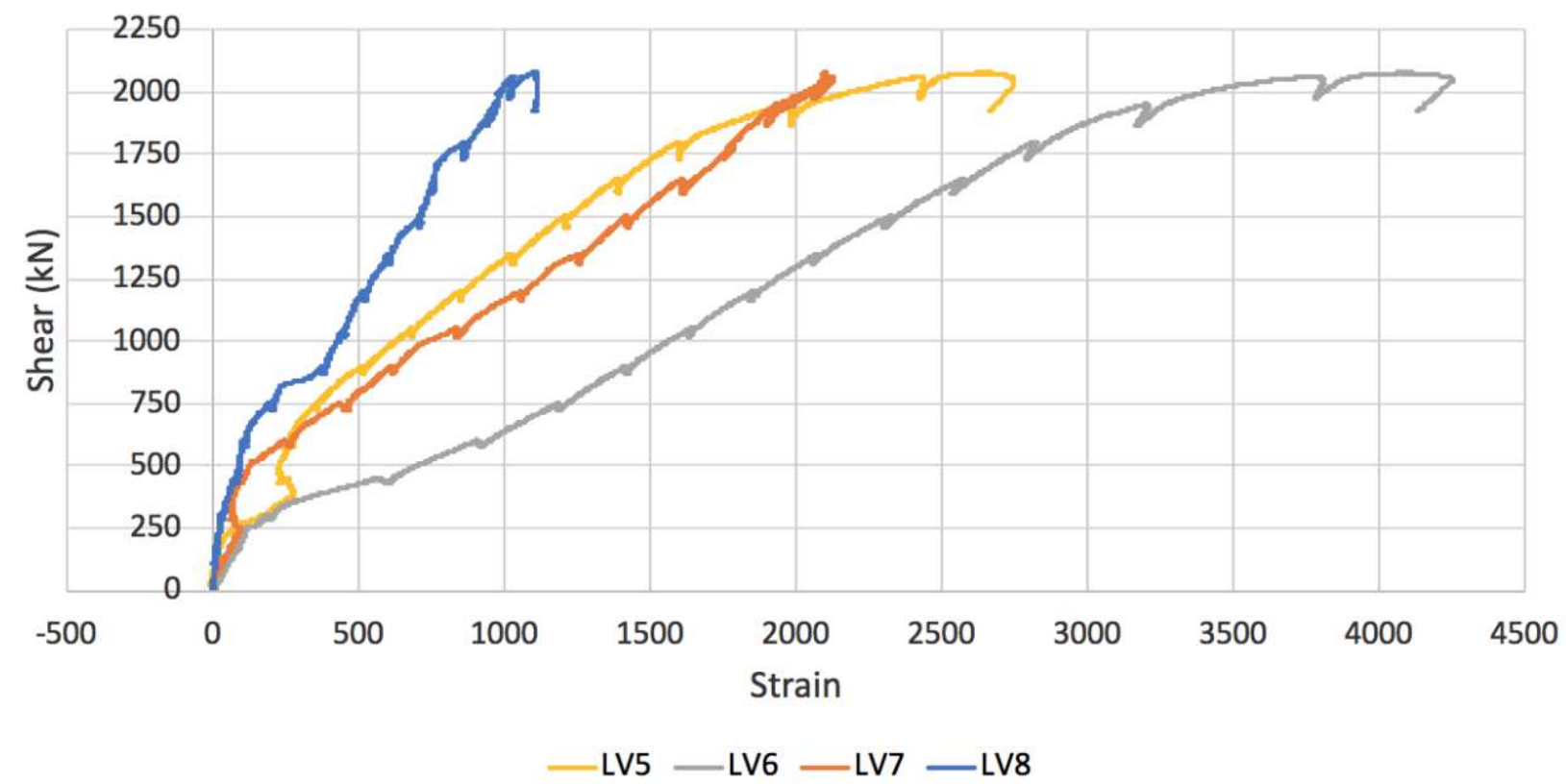

Figure 4.41: Shear versus average longitudinal strain in the north cantilever of cap beam C2 
The shear versus strain relationship for several stirrups and inclined reinforcing bars in the north and south cantilevers are shown in Figures 4.42 and 4.43. Looking first at the north side, stirrups LS1 and LS2 reached peak strains of 0.00130 and 0.00213 at failure, respectively, while stirrup LS3 reached the yield strain of 0.00231 for the $10 \mathrm{M}$ bars at a shear of $1884 \mathrm{kN}$. Strain gage LS4 malfunctioned. The strain gages for inclined bars LZ2 and LZ3 reached the yield strain of 0.00224 for $20 \mathrm{M}$ bars at shears of $1914 \mathrm{kN}$ and $1646 \mathrm{kN}$, while LZ1 malfunctioned. As for the south cantilever, strain gages RS2 and RS4 reached peak strains of 0.00197, and 0.00143 respectively, while stirrup RS3 reached yielding at a shear of $1785 \mathrm{kN}$. Strain gage RS1 only reached very low strain values. Inclined bar RZ3 reached yielding at 1905 kN while RZ1 and RZ2 malfunctioned. Overall this data indicates that several stirrups and inclined bars on both the north and south cantilevers experienced significant yielding before the initial north cantilever failure.

Strain gages LLT and RLT measured compressive strains on the inclined face of the cantilevers next to the column interface on the north and south sides, respectively. The shear versus strain for these strain gages can be seen in Figure 4.44. LLT and RLT reached the 20M yield strain of 0.00224 at shears of $2055 \mathrm{kN}$ and $2006 \mathrm{kN}$, respectively, both just before the specimen failure at $2075 \mathrm{kN}$ shear. This indicated the onset of concrete crushing and possible buckling of the primary compressive bars just before failure. Figure 4.44 also shows the compressive strains recorded by LVDTs LV9 and LV10. The LVDT on the south re-entrant corner, LV9, reached a strain of 0.0035 just before the north side failure at a shear of $2033 \mathrm{kN}$. LV10 on the north corner reaching a peak strain of 0.00228 at failure. After the testing of cap beam C2 was completed the concrete in front of the primary compressive steel on the north cantilever was chipped away, where the extent of steel buckling was clearly visible (see Figure 4.45). 


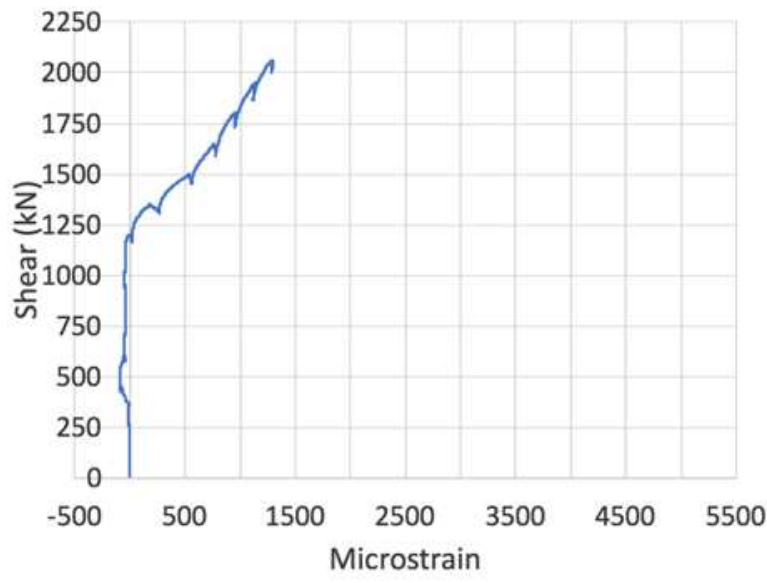

(a) LS1

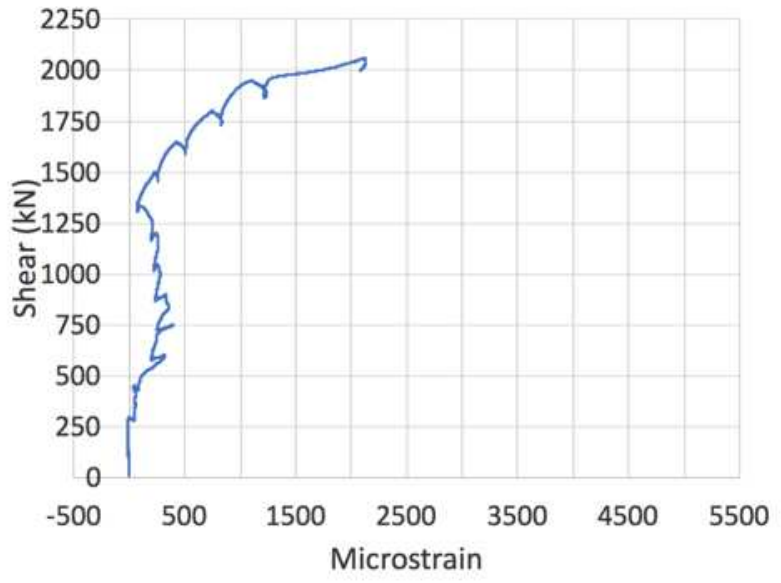

(b) LS2

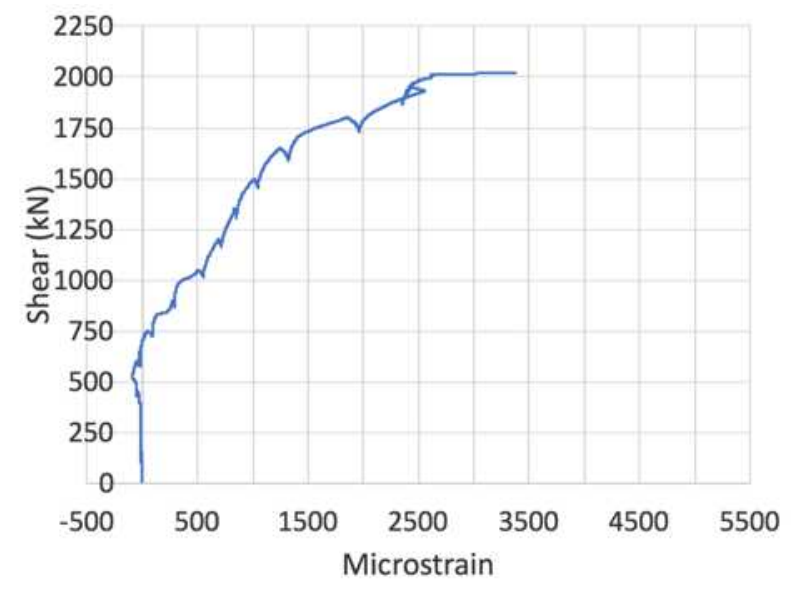

(c) LS3

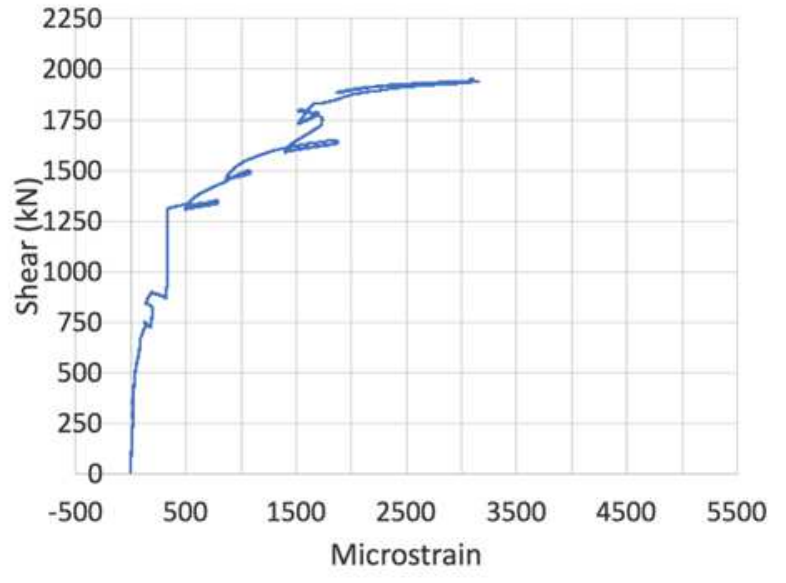

(d) LZ2

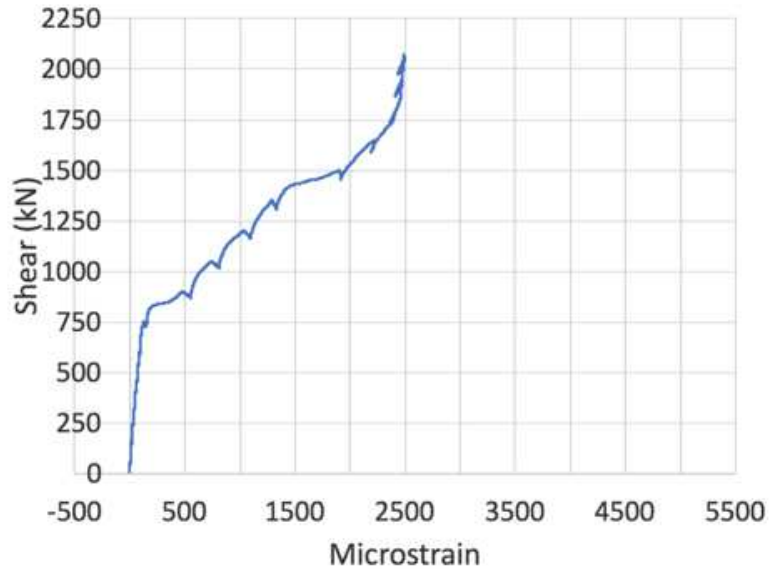

(e) LZ3

Figure 4.42: Shear versus strain for stirrups and inclined bars in north cantilever of cap beam C2 


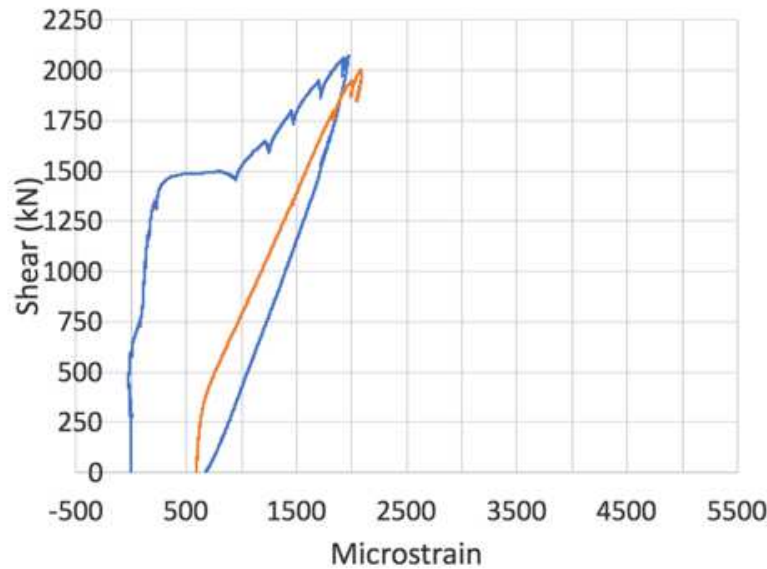

(a) RS2

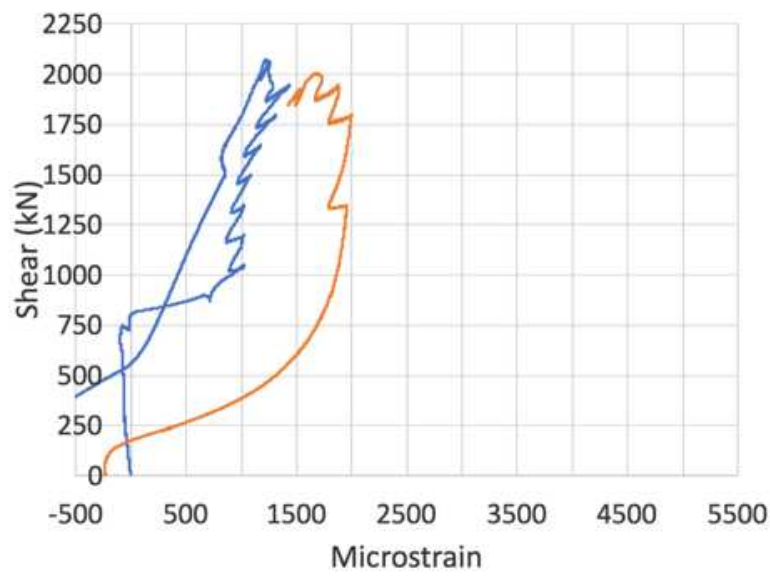

(c) RS4

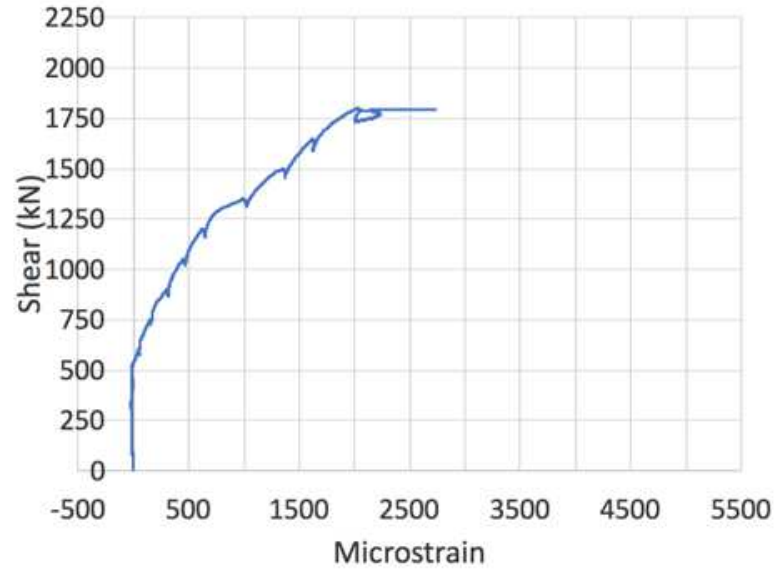

(b) RS3

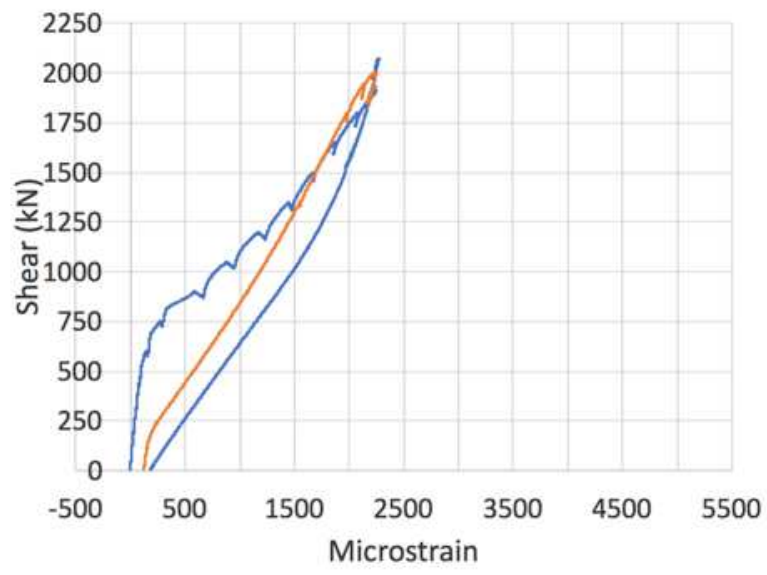

(d) RZ3

\section{—Initial Loading —Post-Clamping Loading}

Figure 4.43: Shear versus strain for stirrups and inclined bars in south cantilever of cap beam C2 


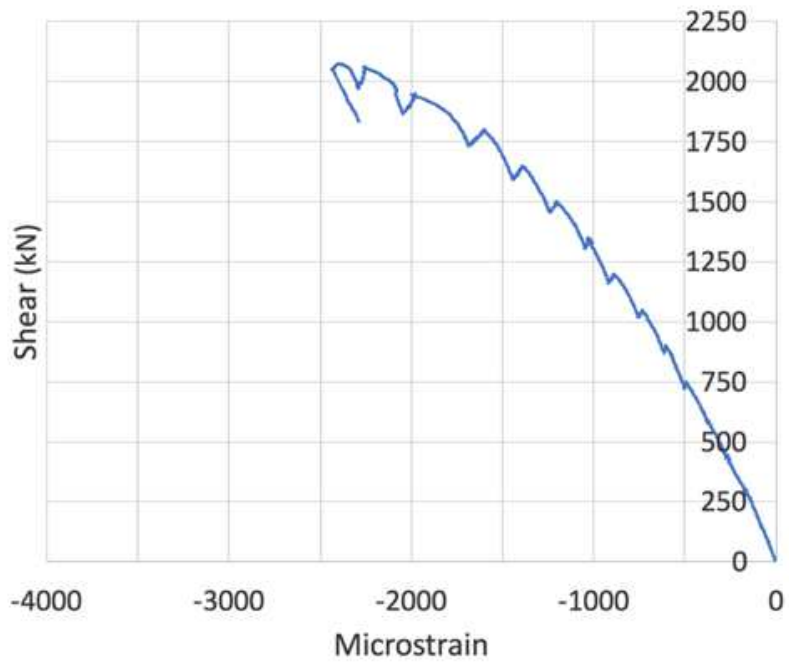

(a) LLT (north)

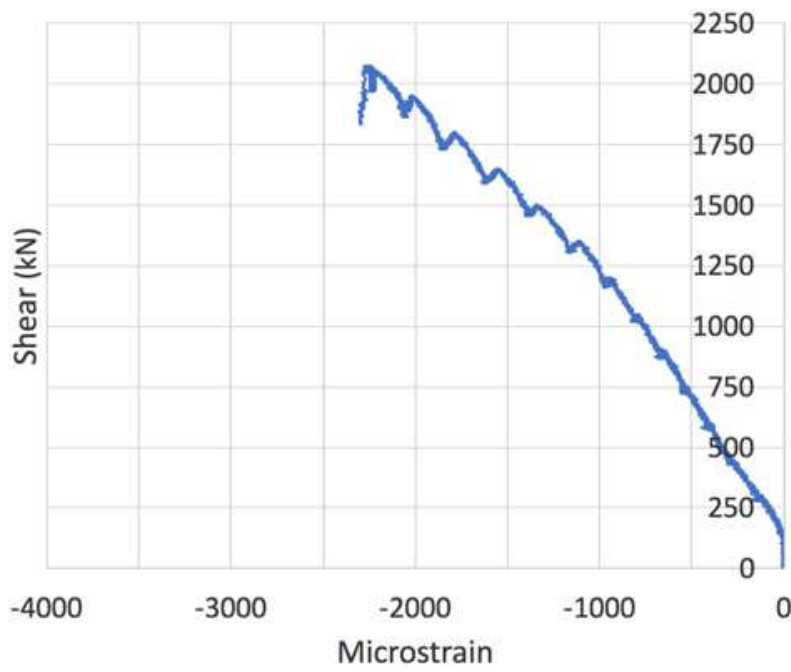

(c) LV10 (north)

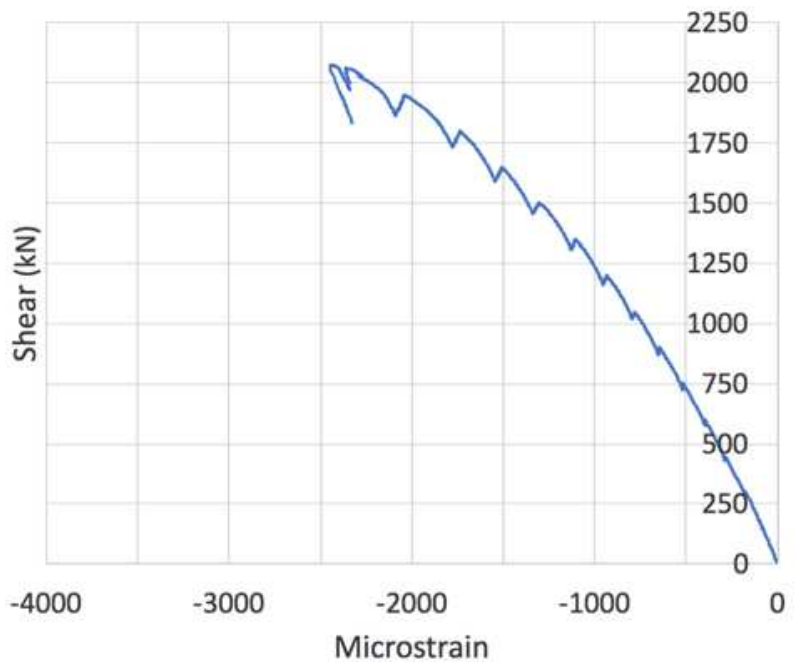

(b) RLT (south)

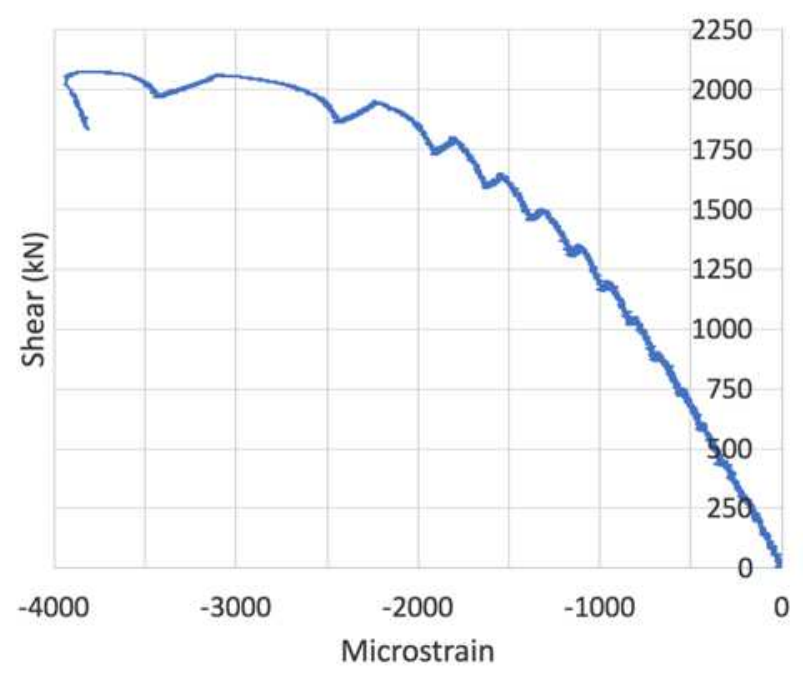

(d) LV9 (south)

Figure 4.44: Shear versus compressive strain at re-entrant corners on cap beam C2 


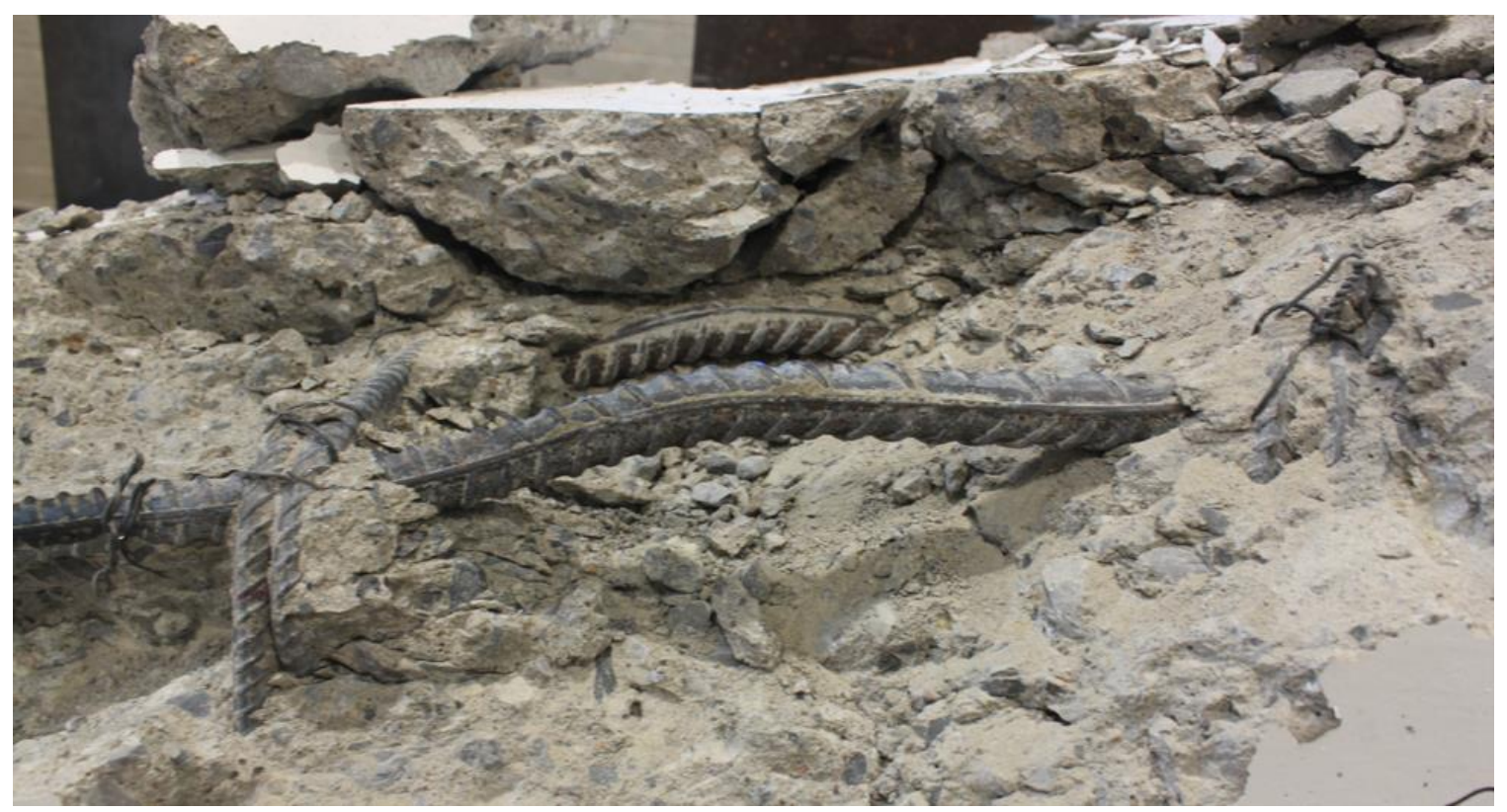

Figure 4.45: Buckling of primary compressive reinforcement on the north side of cap beam C2

Figure 4.46 shows the results from the LVDT rosettes on Pier Cap C2 for both the north and south cantilevers. The peak horizontal strains for the north and south sides were 0.00206 and 0.00293 respectively, with the south side reaching the yield strain of the $15 \mathrm{M}$ bars at a shear of $1735 \mathrm{kN}$. The horizontal strains started increasing at a shear of $590 \mathrm{kN}$, shortly before shear cracks were observed at $675 \mathrm{kN}$. The vertical strains were much higher, reaching the yield strain of the $10 \mathrm{M}$ stirrups at shears of $1930 \mathrm{kN}$ and $1927 \mathrm{kN}$ in the north and south sides, respectively. Nearby stirrups LS3 on the north side and RS3 on the south side reached yielding at similar shears of $1884 \mathrm{kN}$ and $1785 \mathrm{kN}$, respectively. Both vertical strain responses were almost identical up until the peak load, at which point the weaker north side developed higher strains and failed. Significant vertical strains started to develop at $950 \mathrm{kN}$ in the north side and $635 \mathrm{kN}$ in the south side. The maximum tensile strains for both sides were similar, with the weaker north side reaching slightly higher strains at the onset of failure. The north side reached a strain of $0.74 \%$ and the south side a strain of $0.58 \%$ at the initial failure. At this point the shear strains reached peak values of $0.52 \%$ and $0.44 \%$ on the north and south sides respectively. The principal angle of each side on the initial failure was $30.5^{\circ}$ on the north side and $37.3^{\circ}$ on the south side. It was noted that the angle of the shear cracks near the rosettes at failure was $38.7^{\circ}$ on the north side and $41.0^{\circ}$ on the south side. 


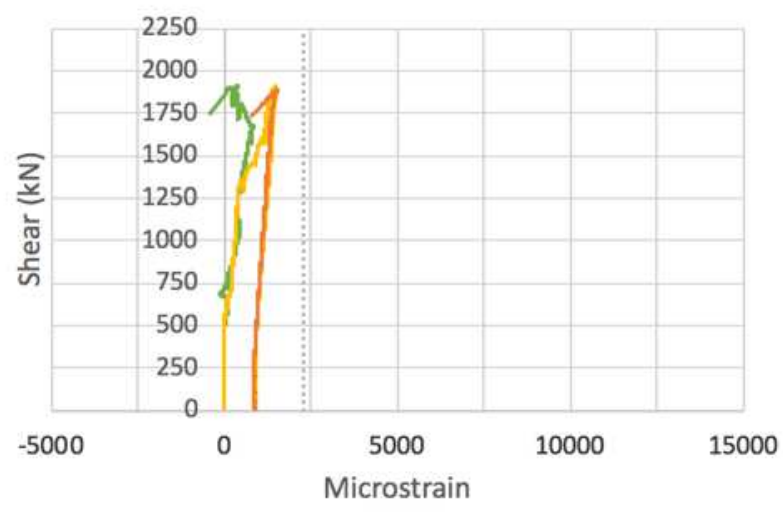

(a) horizontal strain, $\varepsilon_{\mathrm{x}}$

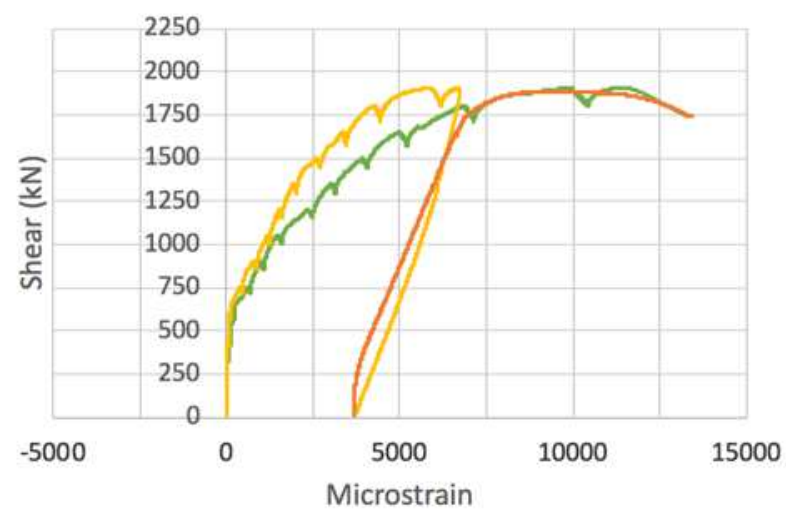

(c) principal tensile strain, $\varepsilon 1$

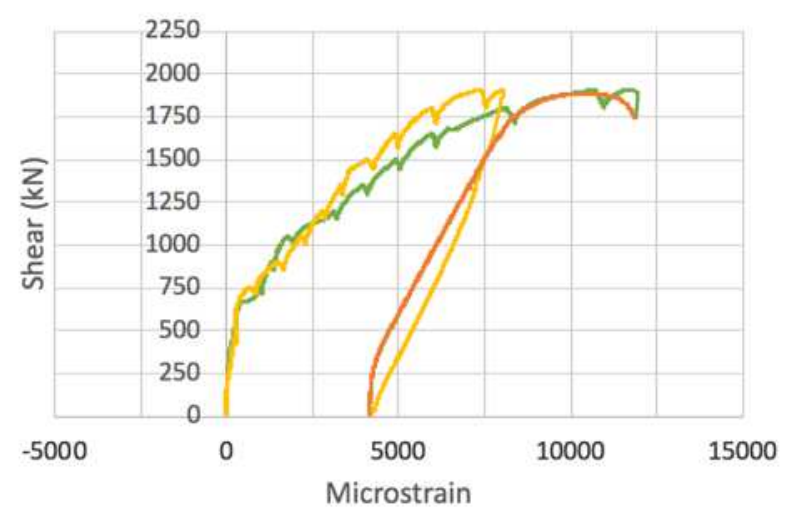

(e) shear strain, $\gamma_{x y}$

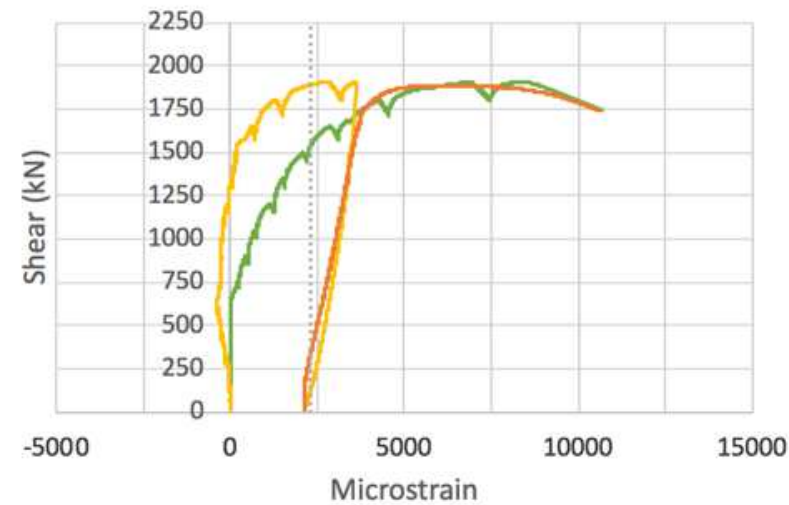

(b) vertical strain, $\varepsilon_{y}$

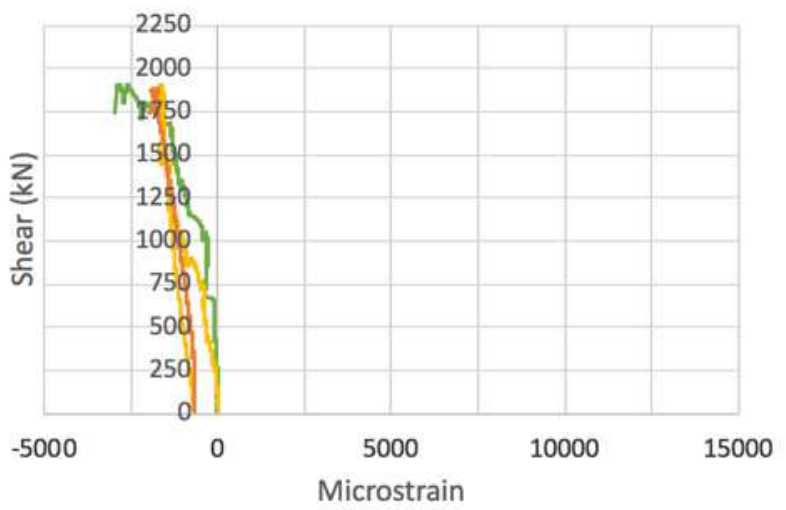

(d) principal compressive strain, $\varepsilon_{2}$

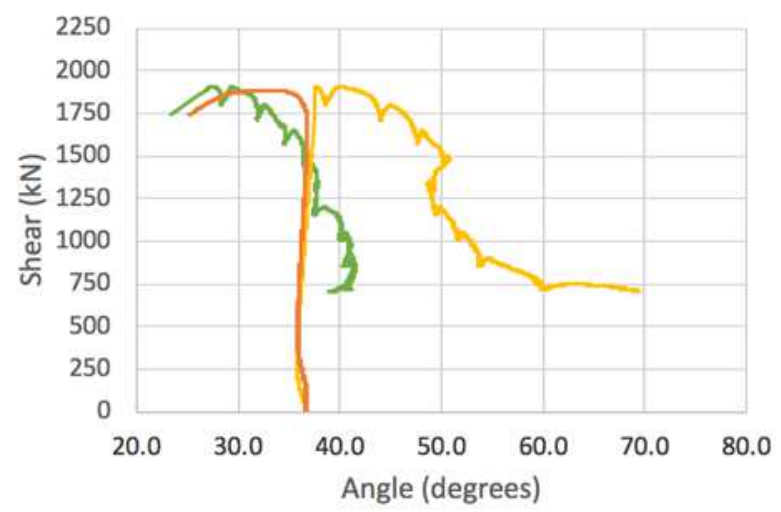

(f) principal angle, $\theta_{\mathrm{p}}$

-North-1 — South-1 — South-2 ....... Yield

Figure 4.46: Principal strains and angles from cap beam C2 rosettes 


\subsection{Pier Cap C2R}

\subsubsection{Shear-Deflection Response}

The shear versus midspan deflection response for pier cap C2R is shown in Figure 4.47. The "Post-Tensioning at Service Load" curve indicates the initial loading of the pier cap to the service load level and the subsequent horizontal post-tensioning operation was carried out at this service load level. On the "Initial Loading" curve the pier cap reached a shear of $2050 \mathrm{kN}$ and a midspan deflection of $12.6 \mathrm{~mm}$ before failing in a combination of flexural crushing and shear in the north cantilever. After the installation of shear clamps on the north cantilever the pier cap reached a higher shear of $2198 \mathrm{kN}$ and a midspan deflection of $26.9 \mathrm{~mm}$ before failing in the south cantilever.

First flexural cracking was observed at a shear of $250 \mathrm{kN}$ near the column-cantilever interface on both sides, accompanied by a decrease in stiffness in Figure 4.47. The first shear cracks were observed at $675 \mathrm{kN}$ in both cantilevers.

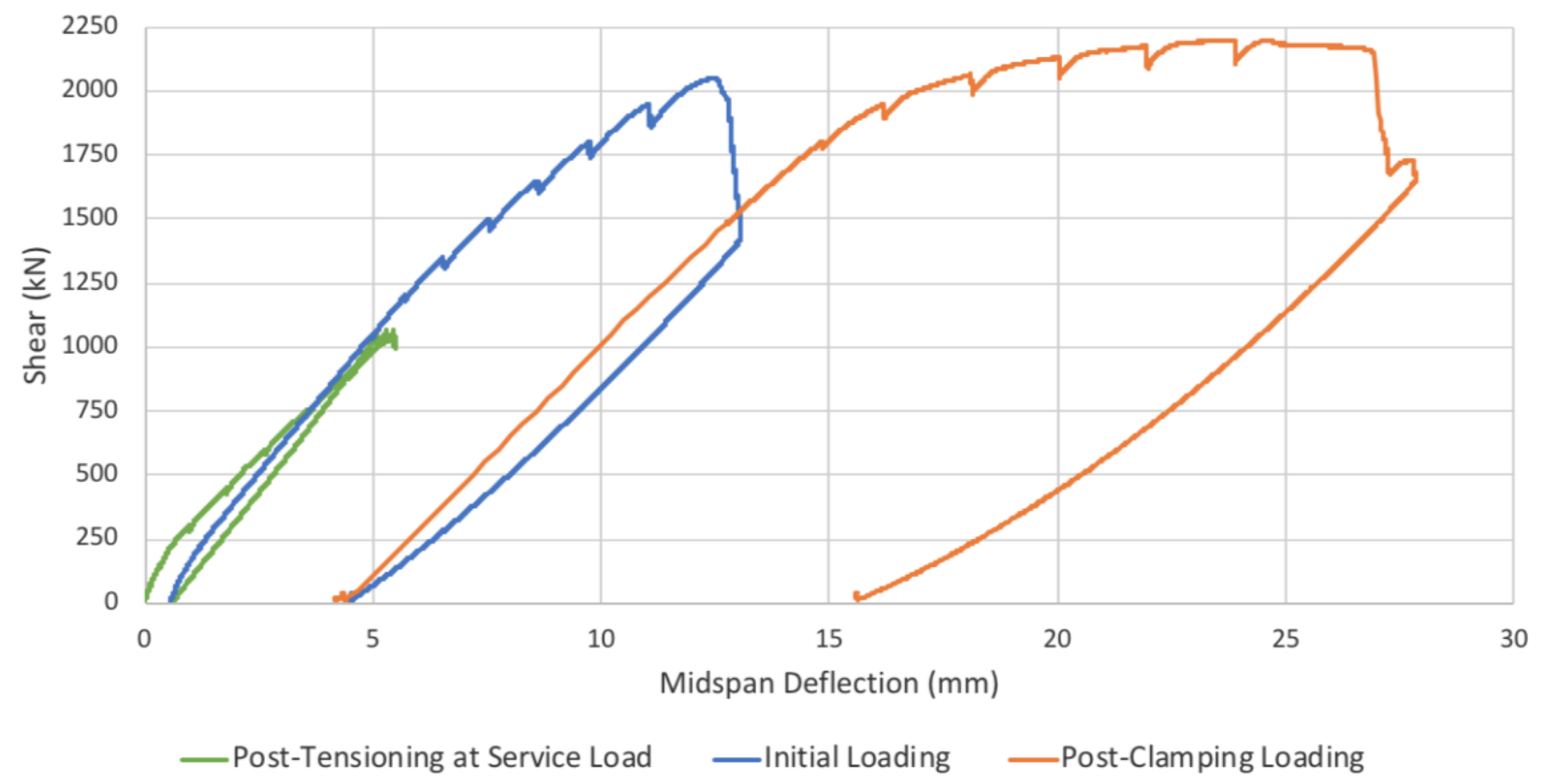

Figure 4.47: Shear versus midspan deflection of cap beam C2R 


\subsubsection{Shear Failures}

Figure 4.48 shows the initial failure observed in the north cantilever. The specimen failed in shear with a critical shear crack larger than $1.00 \mathrm{~mm}$ starting $150 \mathrm{~mm}$ from the column face on the top surface. Concrete crushing on the inclined face and significant yielding of the stirrups were also observed before failure.

The crack pattern of the south cantilever at failure can be seen in Figure 4.49. The specimen failed in shear with a $1.50 \mathrm{~mm}$ critical shear crack starting at the roller support center and ending $200 \mathrm{~mm}$ from the column face. Concrete crushing on the inclined face and significant yielding of the stirrups was observed before failure.

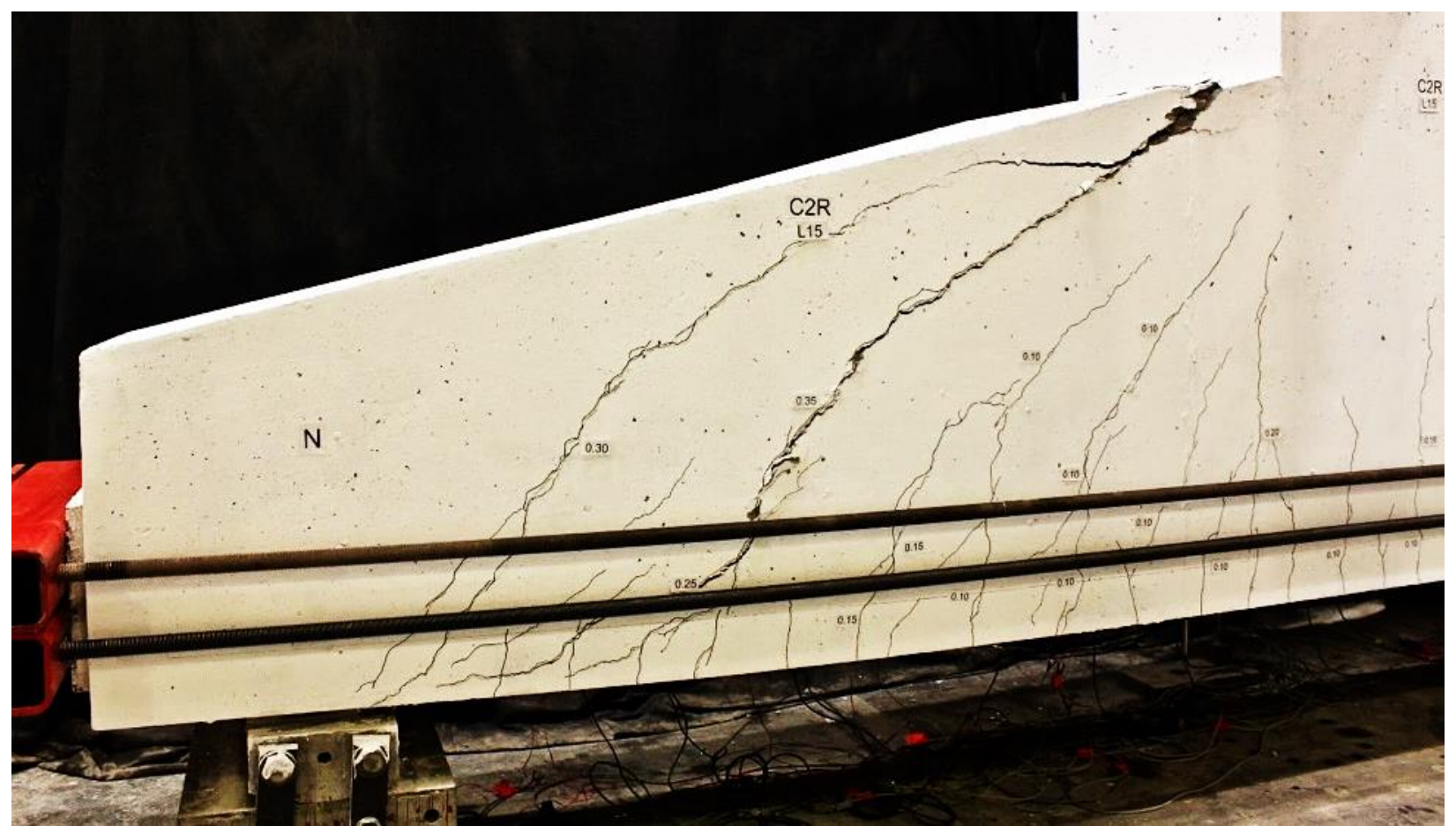

Figure 4.48: Shear failure of north cantilever of cap beam C2R 


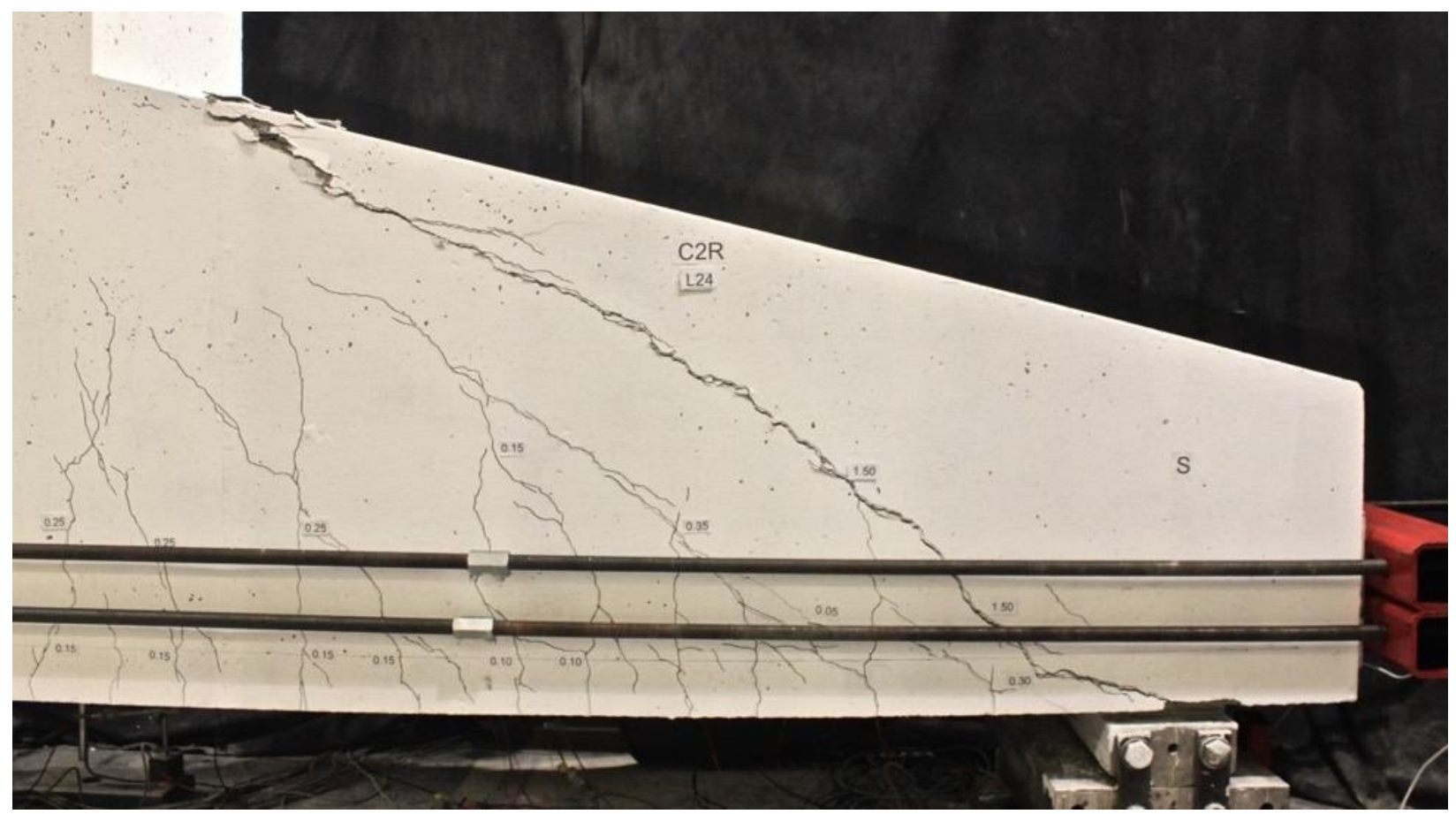

Figure 4.49: Shear failure of south cantilever of cap beam C2R

\subsubsection{Crack Widths}

The maximum crack widths for the north and south cantilevers can be seen in Figures 4.50 and 4.51. At the service load level flexural web cracks and shear cracks were equally critical, with widths of $0.15 \mathrm{~mm}$ and $0.10 \mathrm{~mm}$ in the north and south sides respectively. Posttensioning at service loading decreased the maximum shear crack widths by $0.05 \mathrm{~mm}$ in both cantilevers. Maximum flexural web crack widths decreased by $0.10 \mathrm{~mm}$ and $0.05 \mathrm{~mm}$ on the north and south sides respectively. Flexure cracks in the region of the concentrated tensile steel were lower, at a maximum of $0.05 \mathrm{~mm}$ for both cantilevers at the service load level with no significant change after post-tensioning. Figures 4.52 to 4.55 show the crack patterns and measured crack widths for the north and south sides respectively, both before and after posttensioning. Shear cracks and flexural web cracks were consistently smaller in the south side at service loading and at higher loads due to its higher amount of crack control reinforcement. Beyond the service load level, the flexural web cracks and shear cracks were equally critical until a shear of $1500 \mathrm{kN}$ was reached. Upon further loading the shear cracks became more critical on both cantilevers until failure. 
For this cap beam horizontal splitting cracks of the hooks of the $45^{\circ}$ inclined reinforcing bars were also observed. These cracks were located along the hooked anchorages of the inclined bars that were spliced with the primary tension reinforcement layers. A horizontal splitting crack was first observed at a shear of $900 \mathrm{kN}$ in the inclined bar closest to the end of the cantilever on the north side. This crack opened up to a width of $0.25 \mathrm{~mm}$ at failure, as observed in Figure 4.48. No horizontal splitting cracking was observed in the south cantilever until near the end of the post-clamping loading.

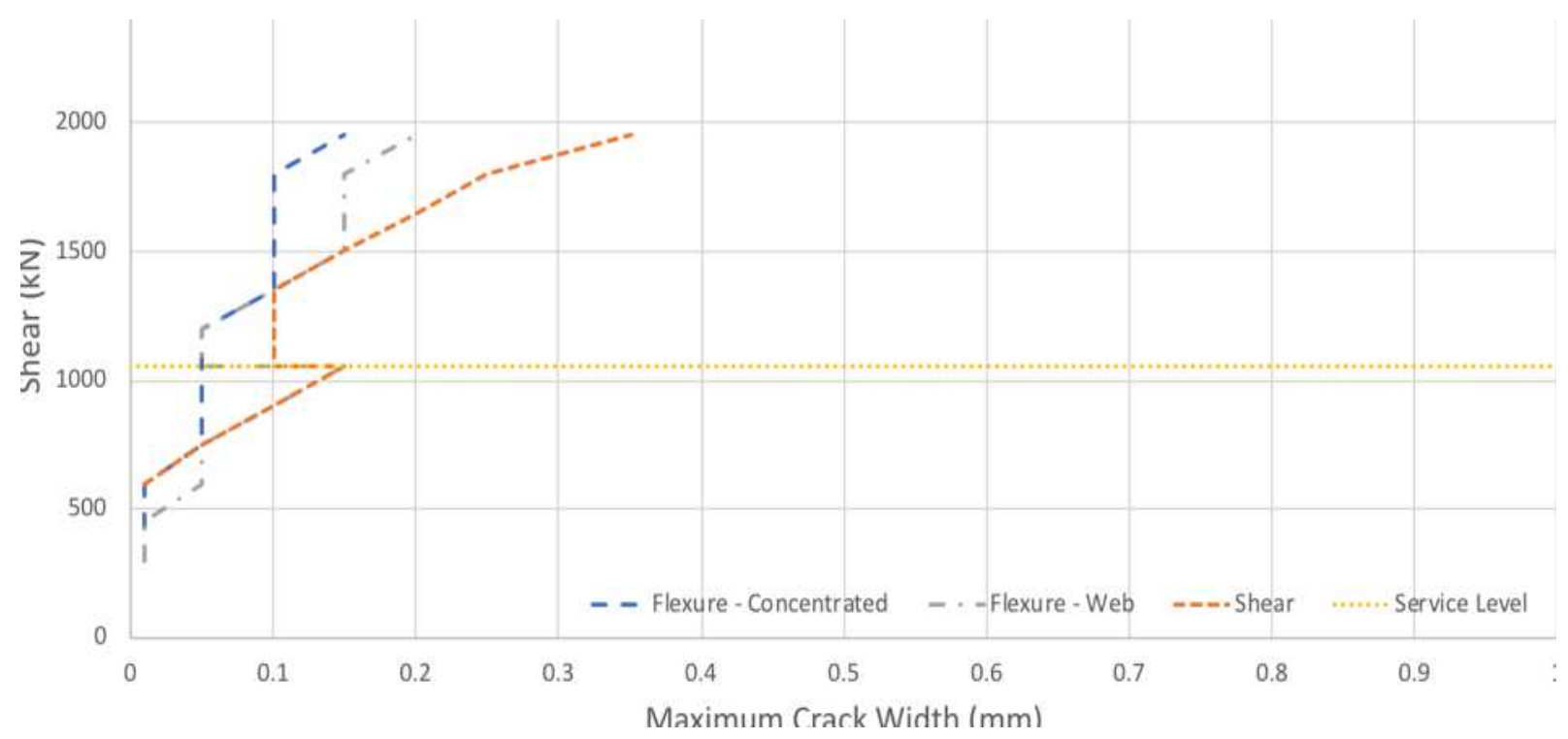

Figure 4.50: Shear versus maximum crack widths for north cantilever of cap beam C2R

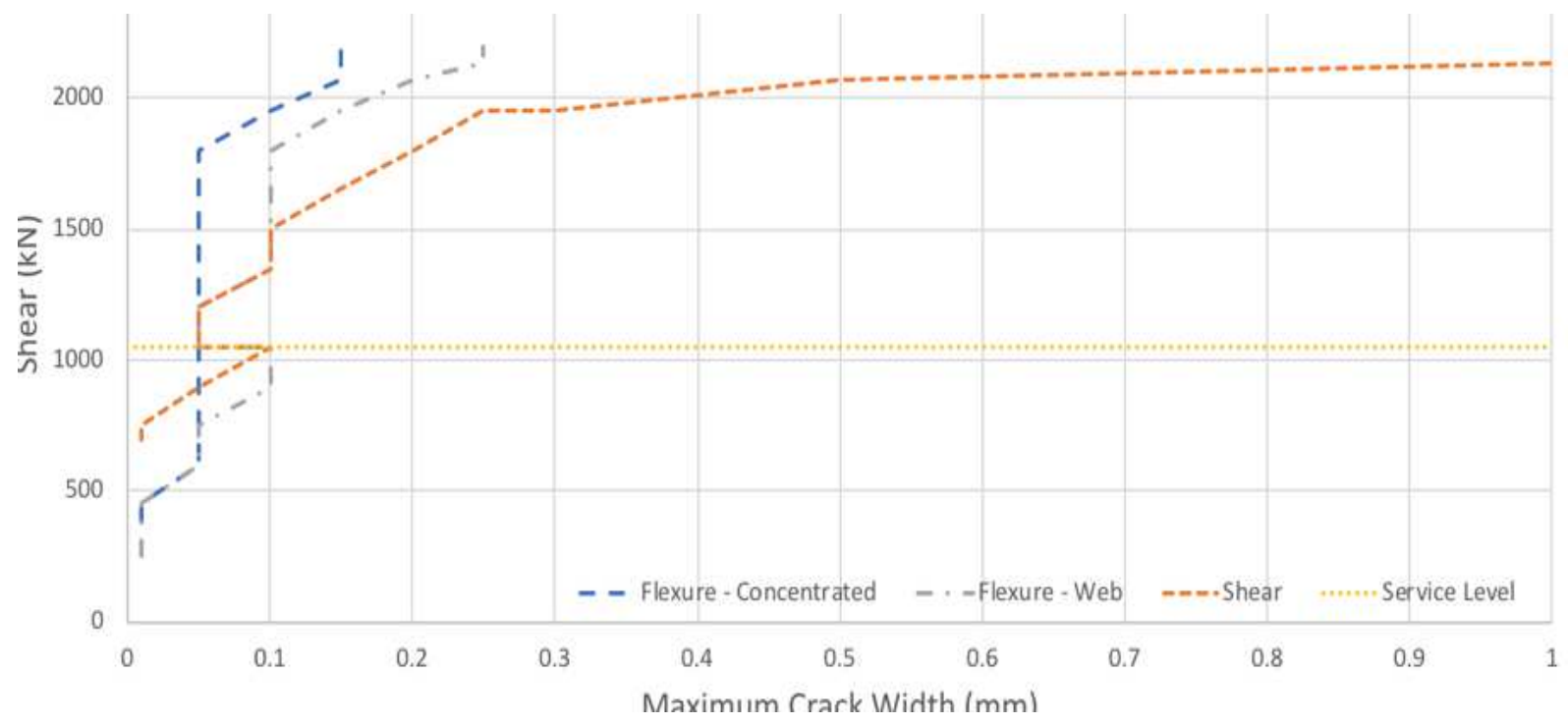

Figure 4.51: Shear versus maximum crack widths for south cantilever of cap beam C2R 


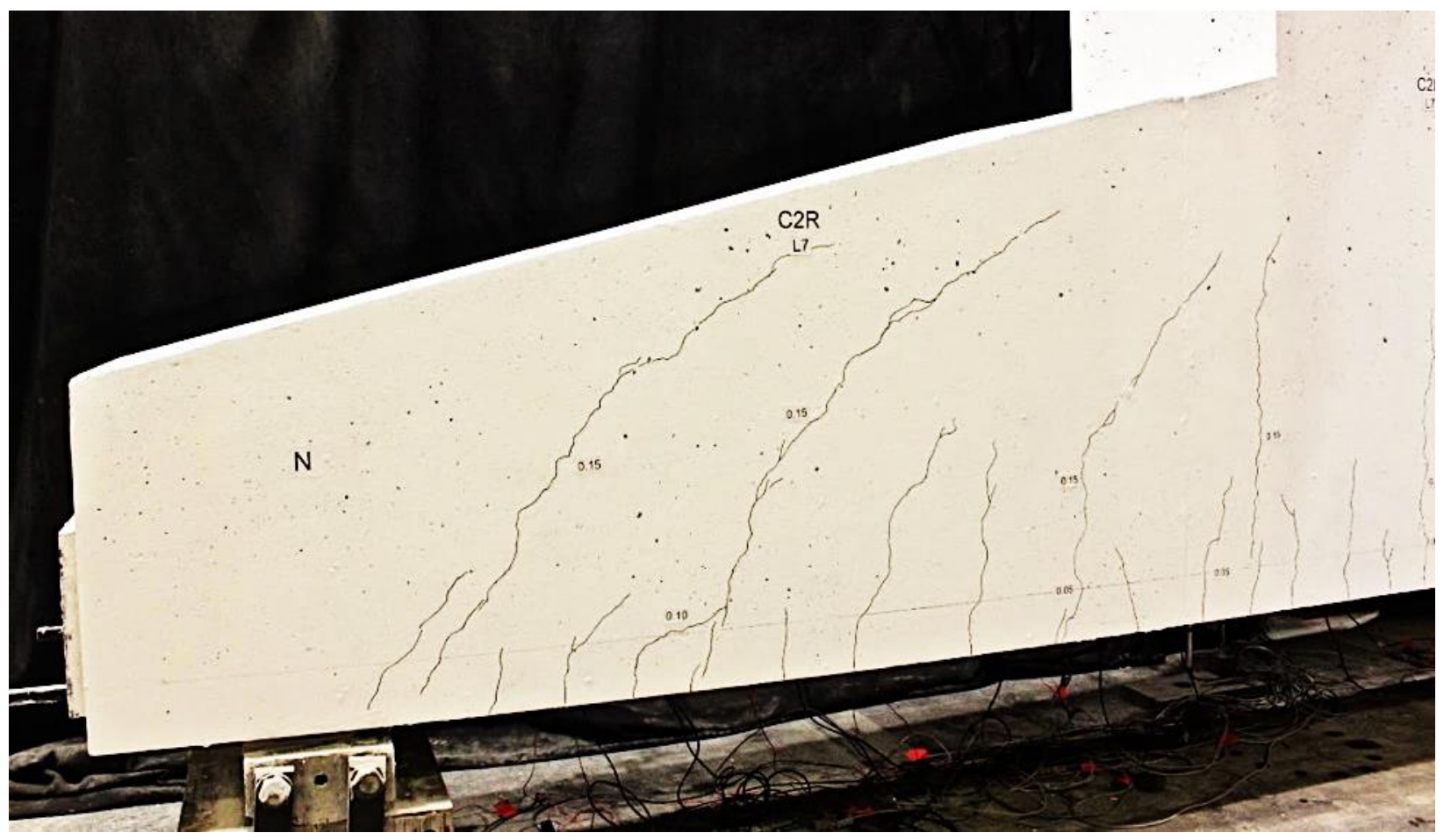

Figure 4.52: Crack pattern and widths at service loading for north cantilever of cap beam C2R

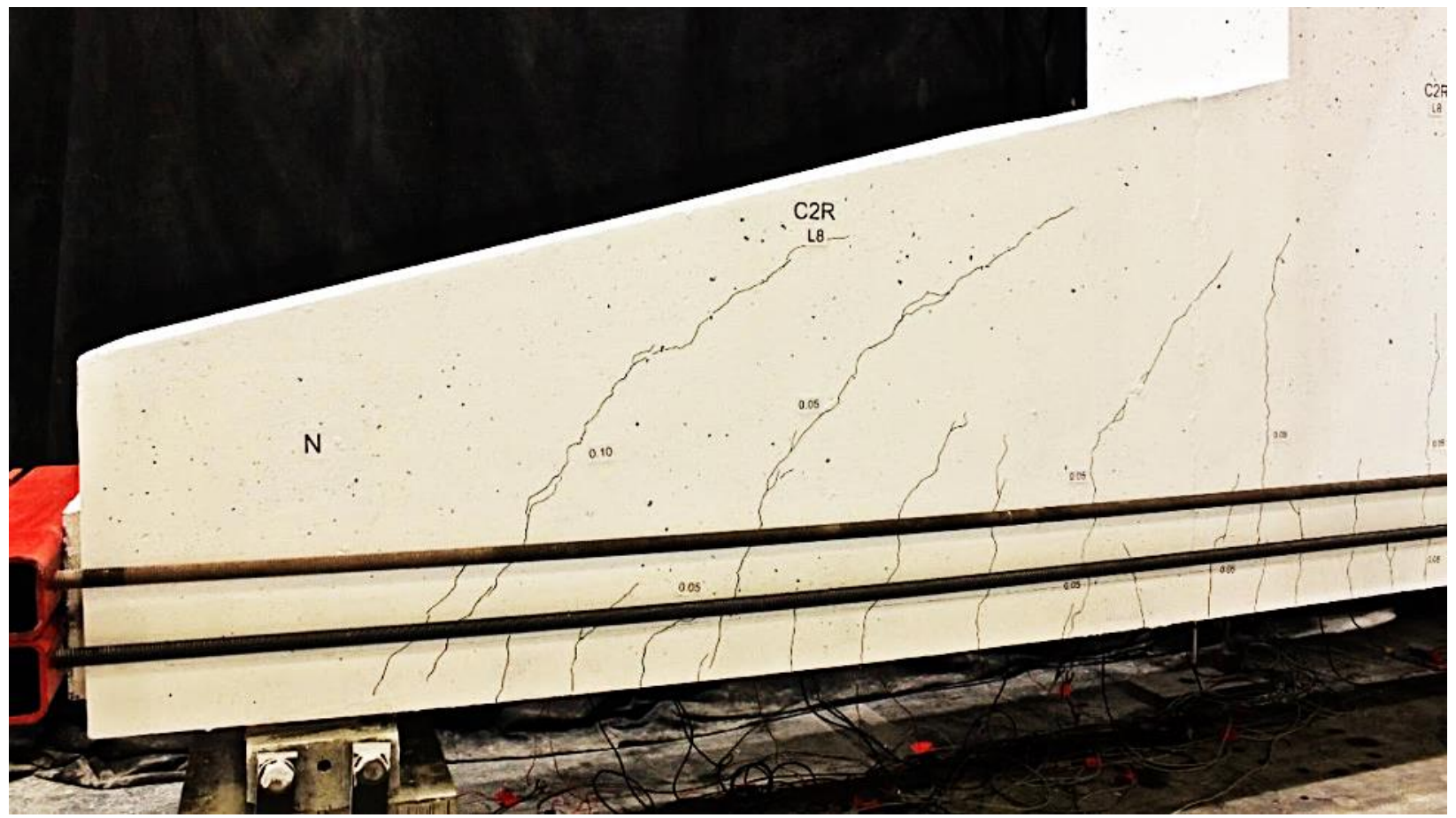

Figure 4.53: Cracks at service loading after post-tensioning for north cantilever of cap beam C2R 


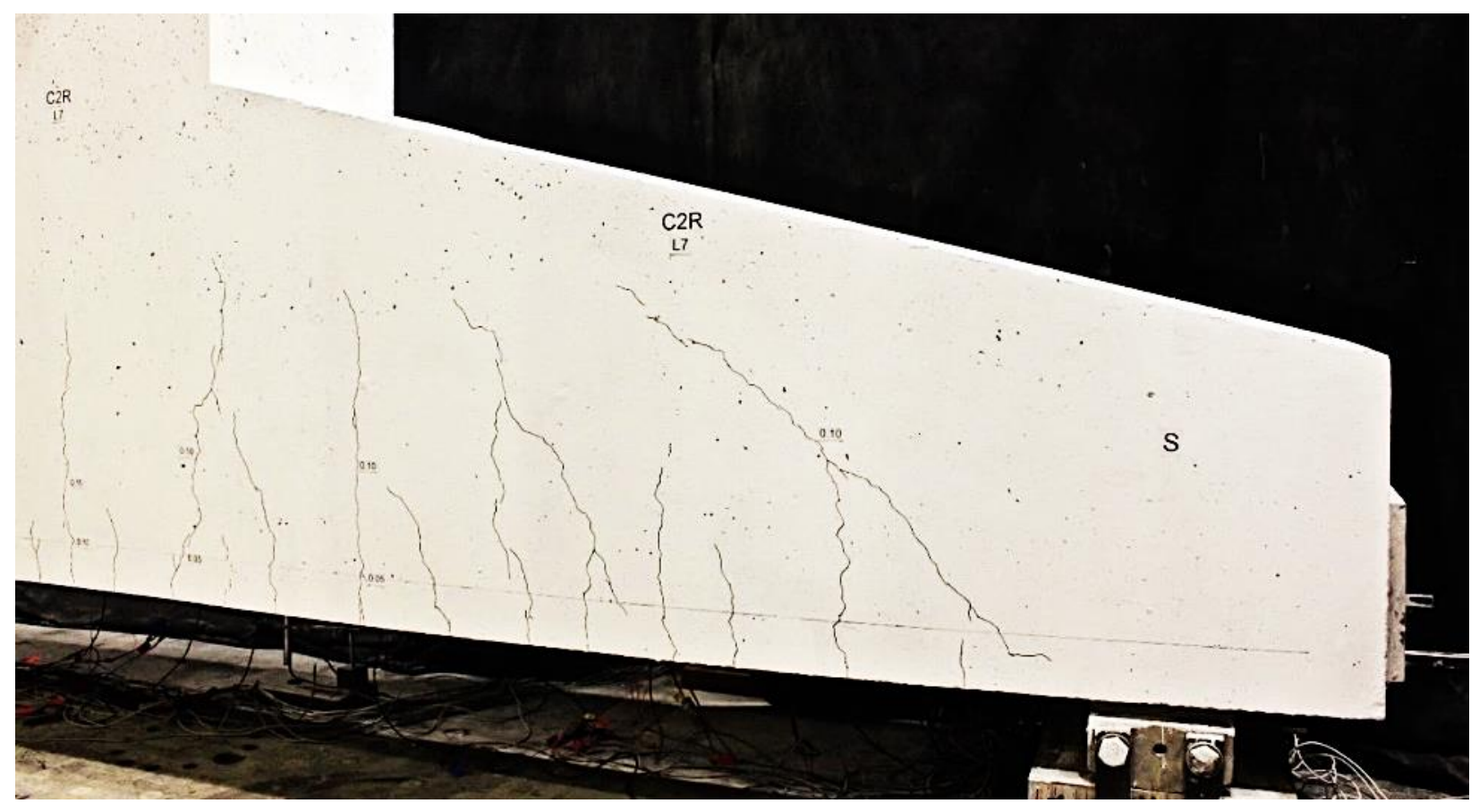

Figure 4.54: Crack pattern and widths at service loading for south cantilever of cap beam C2R

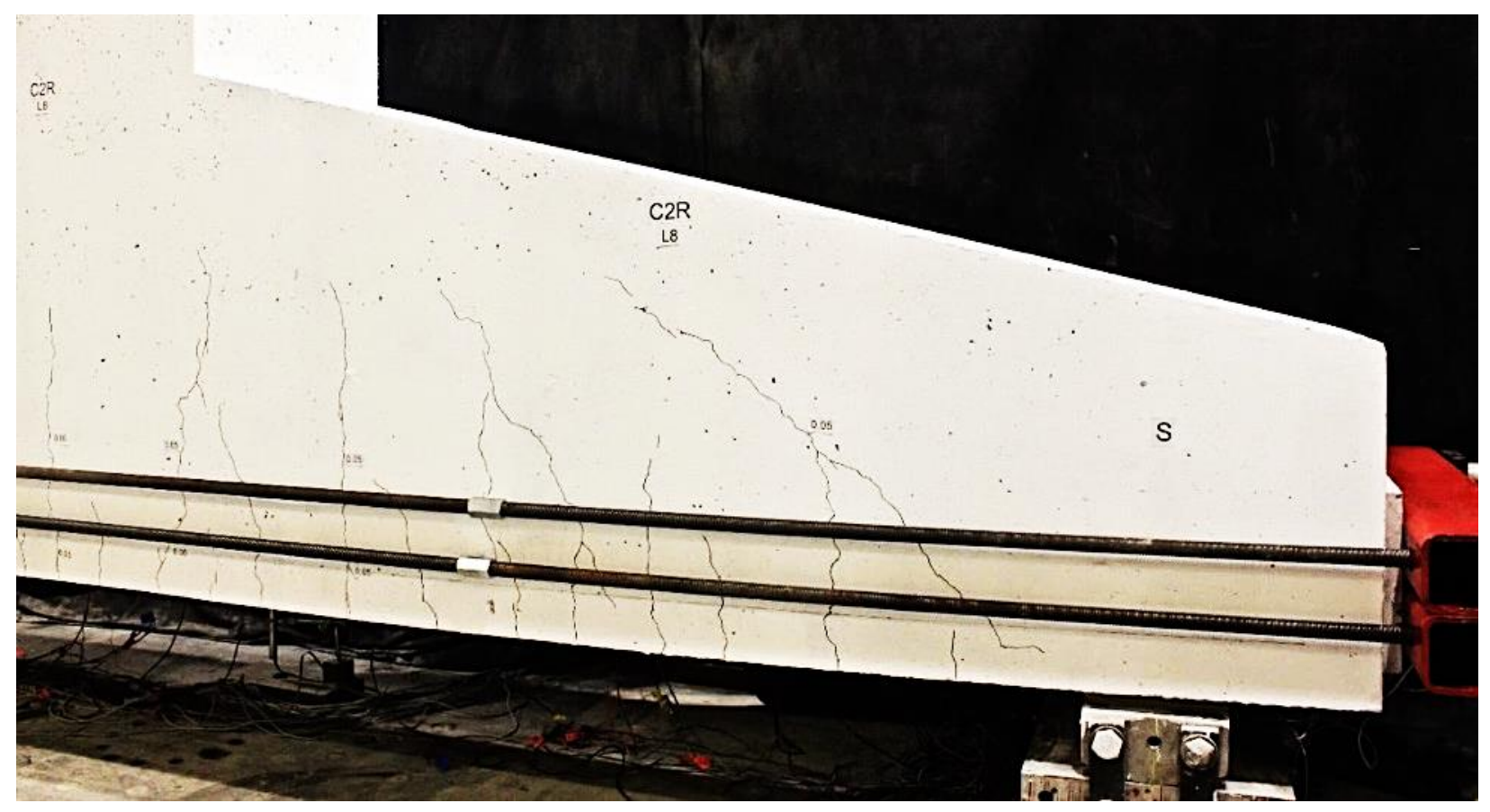

Figure 4.55: Cracks at service loading after post-tensioning for south cantilever of cap beam C2R 


\subsubsection{Measured Strains}

The average tensile strains measured by LVDTs LV1-LV8 at the centroid of the $18-25 \mathrm{M}$ primary tension reinforcement are shown in Figure 4.56. The highest average strain at service loading before post-tensioning was 0.00246 at LV5 on the north cantilever near the column face. This is above the yield strain of 0.00232 for the $25 \mathrm{M}$ bars, indicating that some yielded had occurred before post-tensioning. After post-tensioning all eight LVDTs recorded decreases in strain. The peak strain LV5 dropped to 0.00225 , a reduction of $8.5 \%$. At failure two of the average strains were well above yielding strain. Figures 4.57 and 4.58 show the shear versus average strain curves for each LVDT and indicate that LV3 and LV5 reached yielding at shears of $1442 \mathrm{kN}$ and $1098 \mathrm{kN}$. LV7 was at the onset of yielding at failure, as it reached a strain of 0.00230 or $99.1 \%$ of the yield strain.

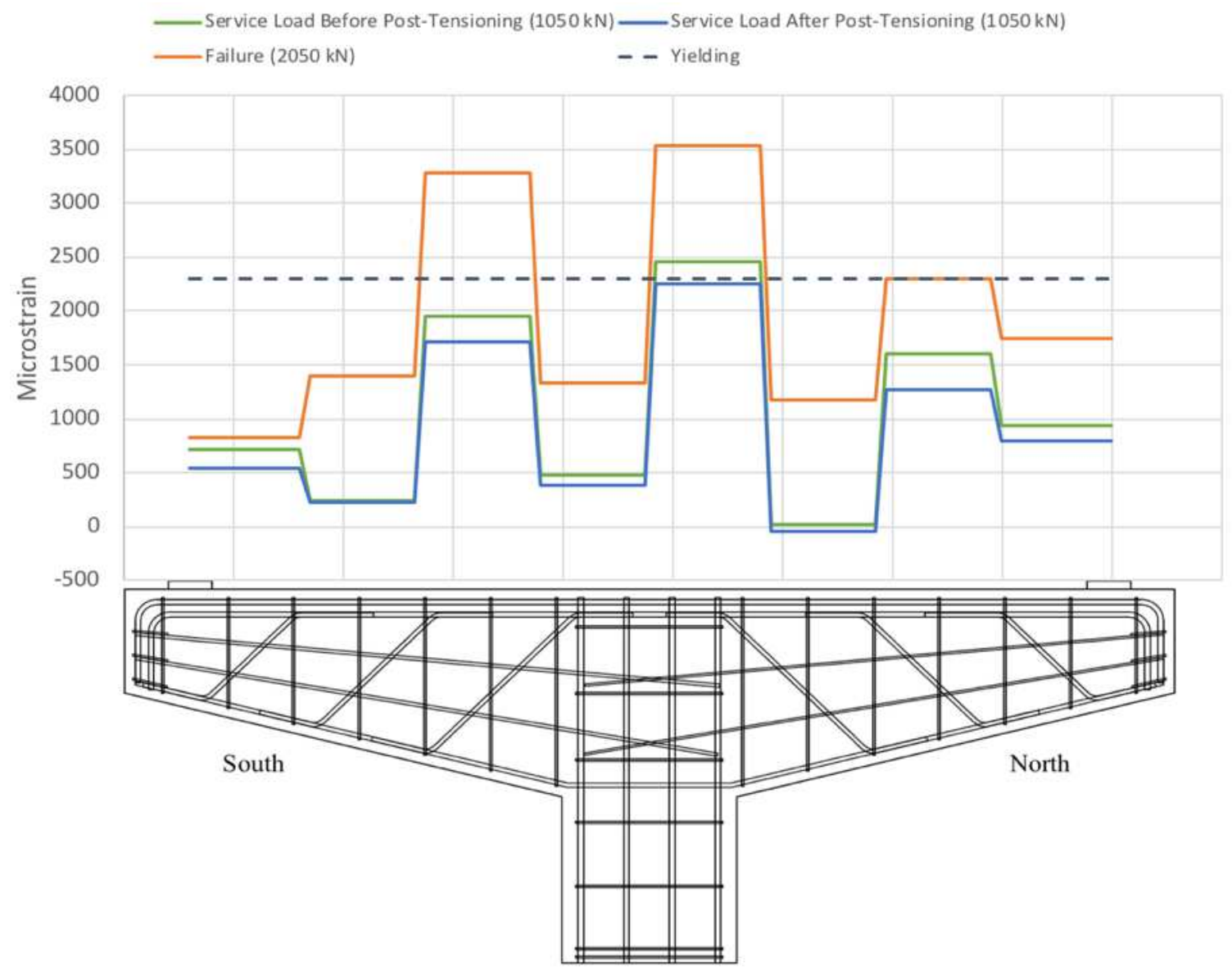

Figure 4.56: Average longitudinal strains measured along the centroid of the concentrated tension steel for cap beam C2R 


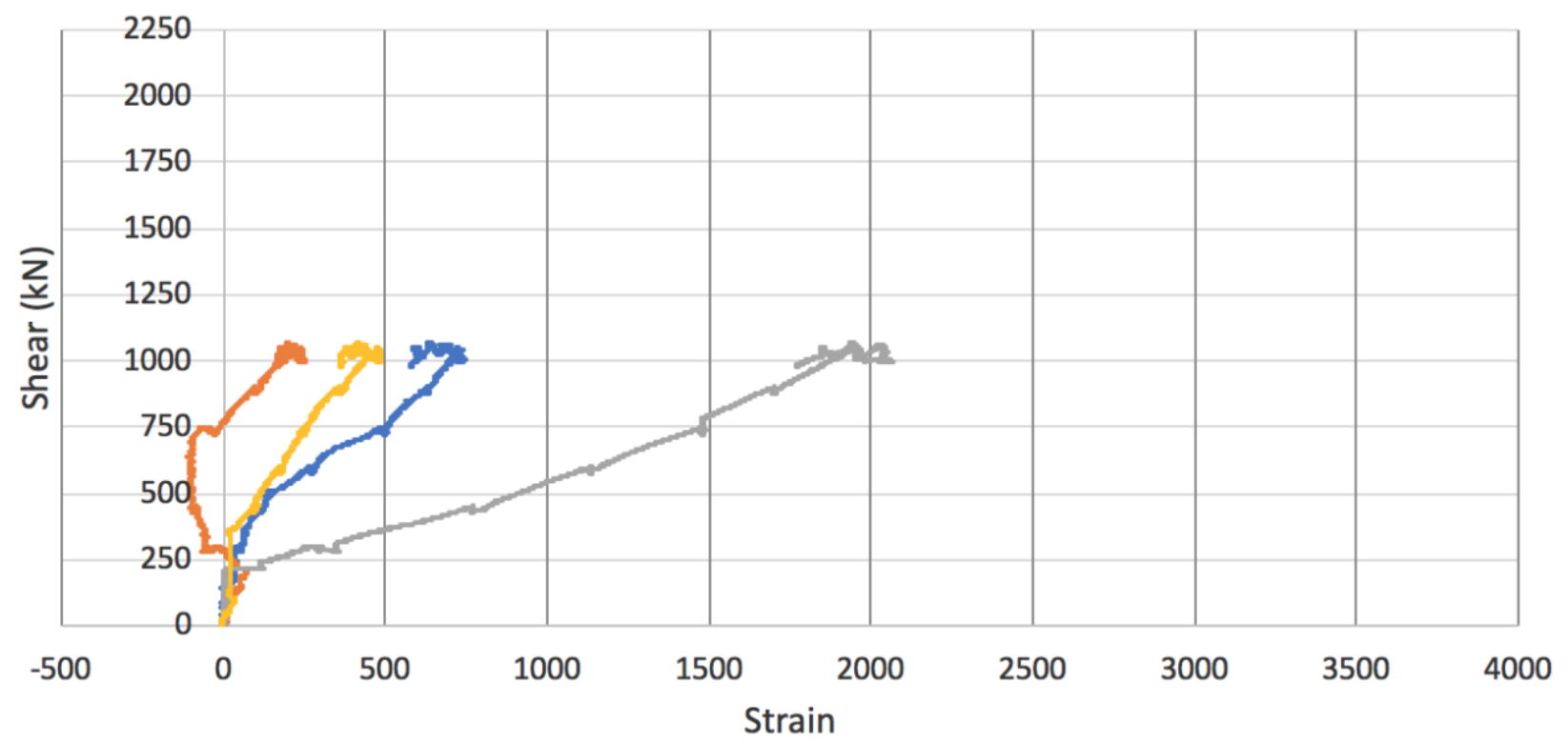

(a) post-tensioning at service load

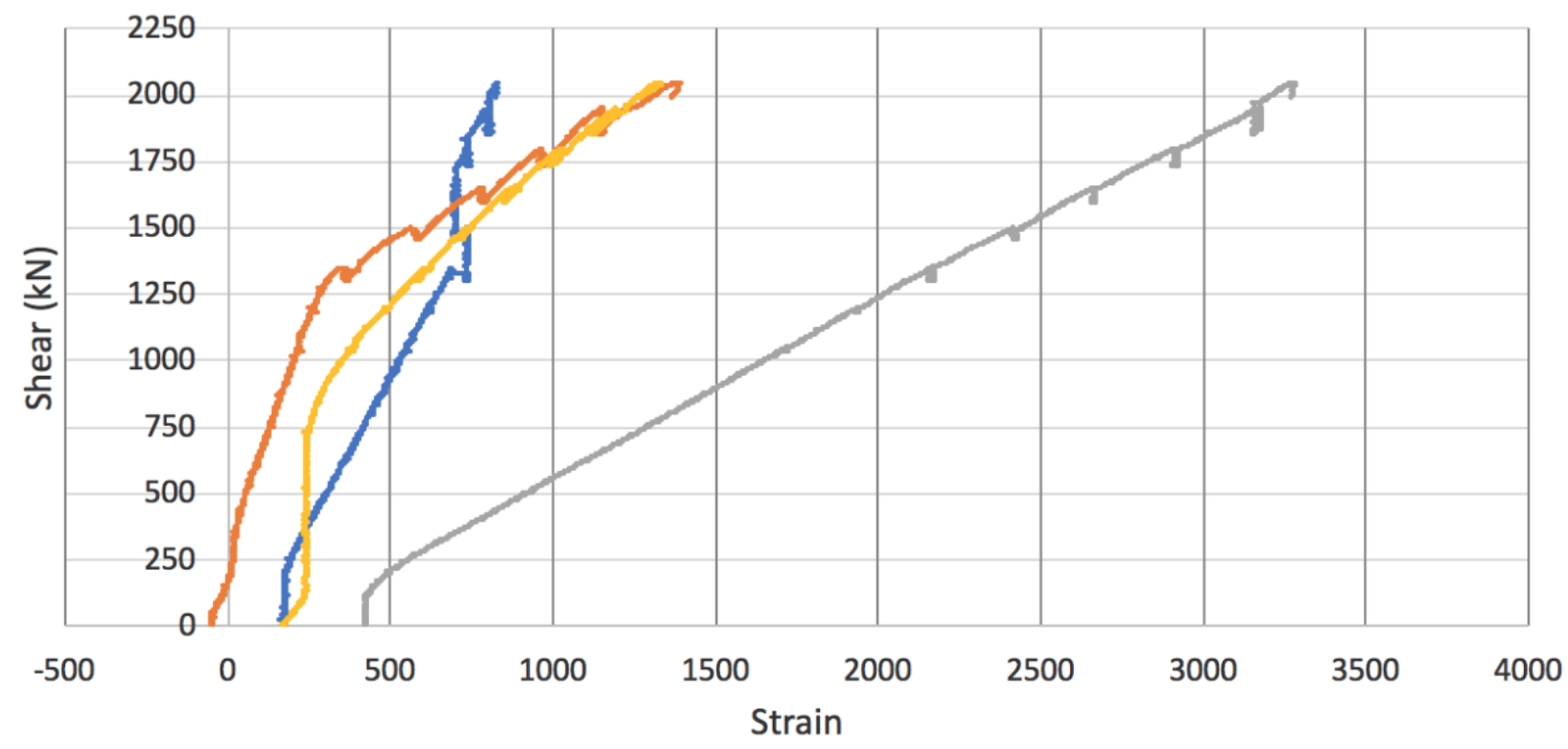

(b) initial loading

$$
-\mathrm{LV} 1-\mathrm{LV} 2-\mathrm{LV} 3-\mathrm{LV} 4
$$

Figure 4.57: Shear versus average longitudinal strain in the south cantilever of cap beam C2R 


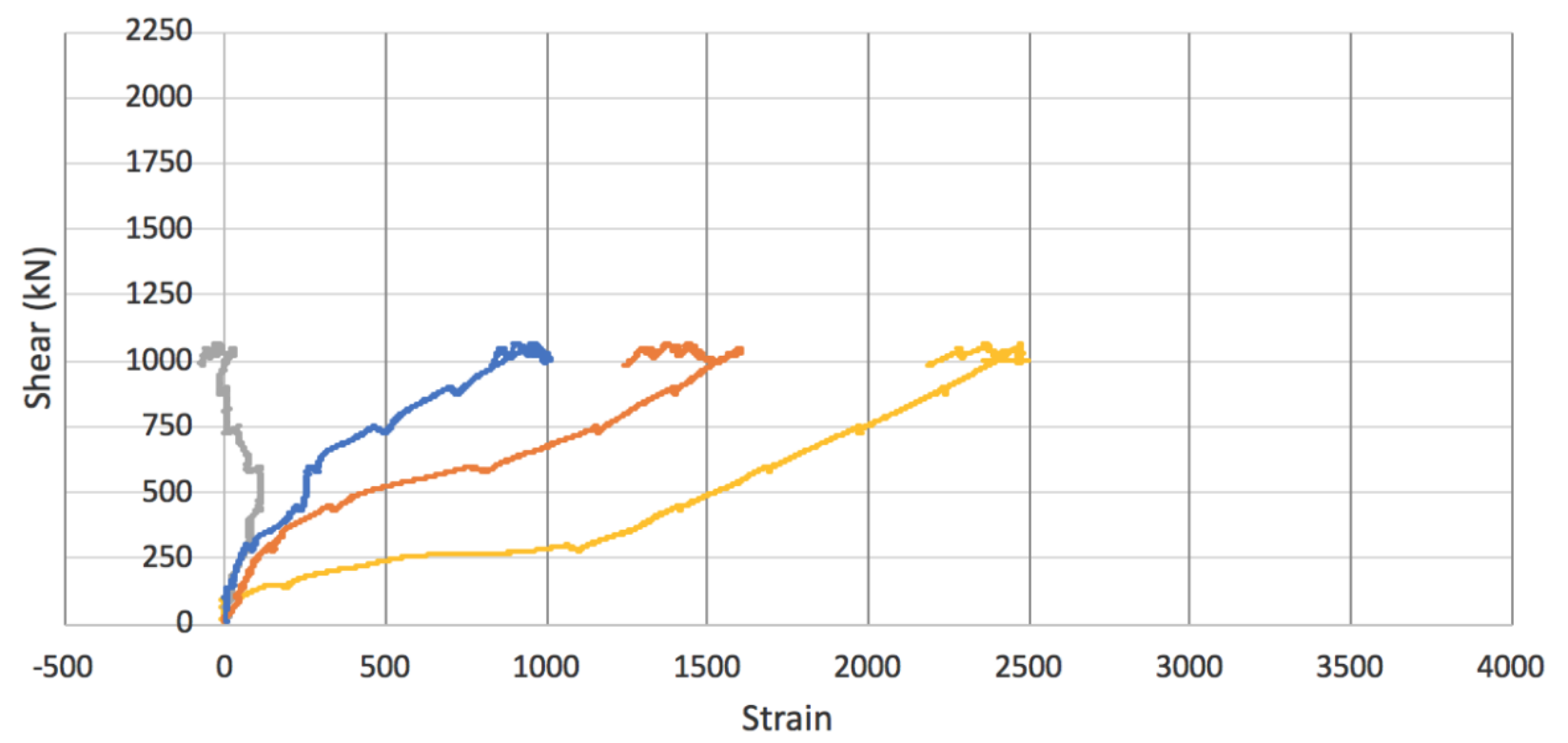

(a) post-tensioning at service load

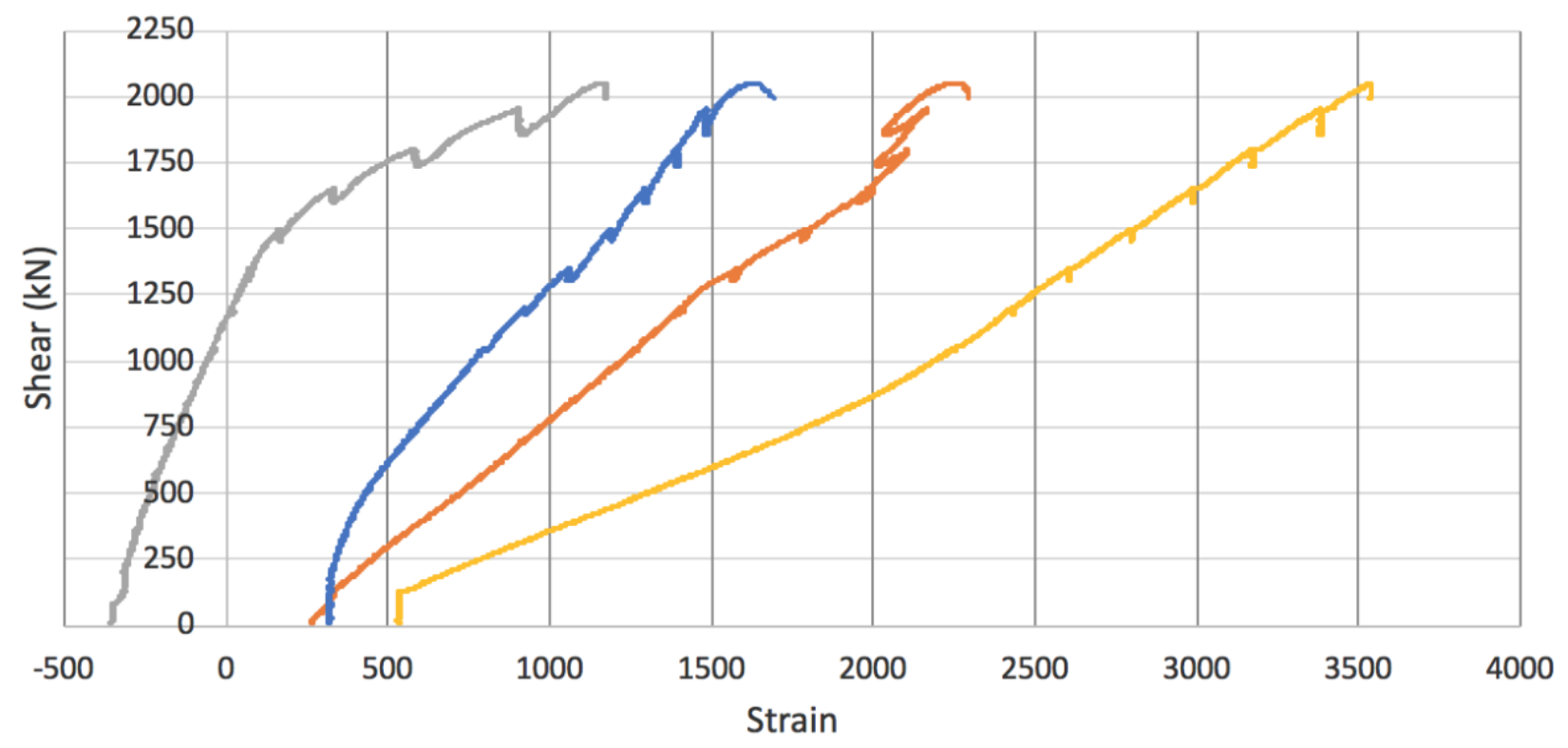

(b) initial loading

$-\operatorname{LV} 5-\operatorname{LV} 6-\operatorname{LV} 7-\operatorname{LV} 8$

Figure 4.58: Shear versus average longitudinal strain in the north cantilever of cap beam C2R 
The shear versus strain relationships for several stirrups and inclined reinforcing bars in the north and south cantilevers are shown in Figures 4.59 and 4.60. Looking first at the north side, strain gage LS2 started malfunctioning after reaching a strain of 0.00138 at a shear of 1497 $\mathrm{kN}$. This was likely due to the shear crack widening to $0.15 \mathrm{~mm}$ at a shear of $1500 \mathrm{kN}$. Strain gages LS3 and LZ2 indicated that both the stirrups and inclined bars were close to yielding at failure with peak strains of 0.00209 and 0.00219. LS1, LS4, LZ1, and LZ3 were well below yielding, reaching peak strains of $0.00105,0.00116,0.00165$ and 0.000841 , respectively. Although none of the strain gages definitively indicated stirrup or inclined bar yielding in the north cantilever, the shear crack at failure previously shown in Figure 4.48 clearly shows that considerable stirrup yielding had occurred.

As for the south cantilever, strain gages RS1, RS3, and RZ1 reached yielding at shears of $2115 \mathrm{kN}, 2140 \mathrm{kN}$, and $2163 \mathrm{kN}$, respectively, all of which occurring on the loading curve after external shear clamping. Inclined bar RZ3 was slightly below yielding at a peak strain of 0.00198 , and the strain gage for inclined bar RZ2 malfunctioned at a shear of $1345 \mathrm{kN}$ possibly due to the widening of the shear cracks. Strain gages on stirrups RS2 and RS4 reached peak strains of 0.00112 and 0.00125 , respectively, both well below yielding. Overall the strain gages on the south cantilever indicate that both stirrup and inclined bar yielding had occurred before the post-clamping failure.

Strain gages LLT and RLT measured compressive strains on the inclined face of the cantilevers next to the column interface on the north and south sides, respectively. The shear versus strain for these strain gages can be seen in Figure 4.61. LLT and RLT reached the 20M yield strain of 0.00224 at shear values of $1900 \mathrm{kN}$ and $1920 \mathrm{kN}$, respectively, indicating that the primary compressive reinforcement had buckled before the initial failure at $2050 \mathrm{kN}$. Figure 4.61 also shows the shear versus strain for LVDT LV9 located at the south reentrant corner. LV9 only reached a peak strain of 0.000447 during the first loading cycle, however after installing external shear clamps to the north side LV9 reached a strain of 0.0035 at $2185 \mathrm{kN}$, just before failure (2198 kN). LV10 experienced malfunctioning. 


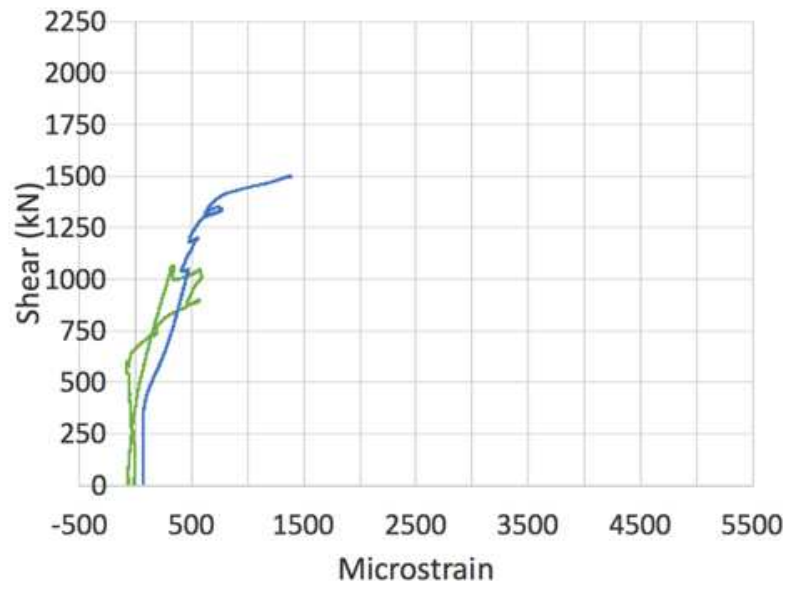

(a) LS2

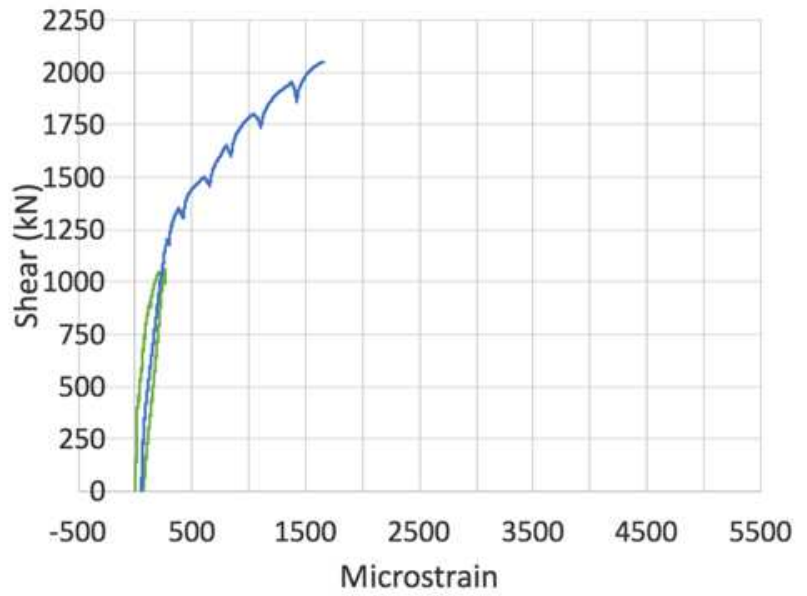

(c) LZ1

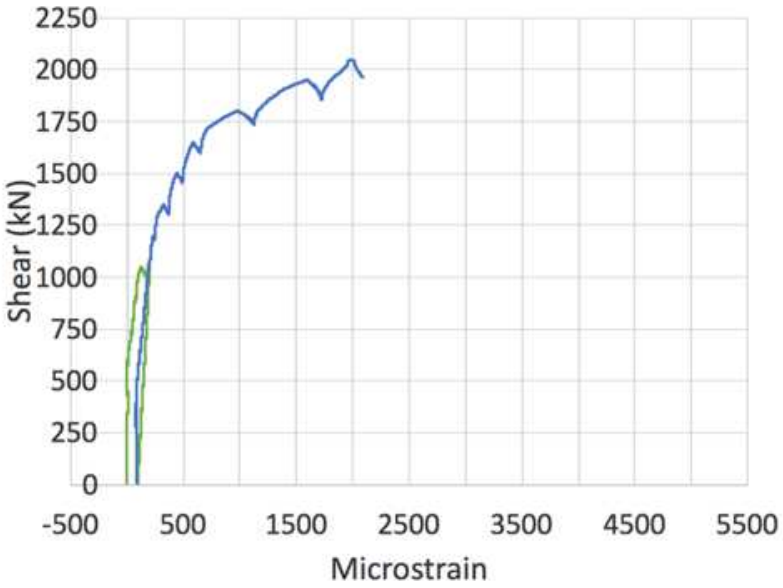

(b) LS3

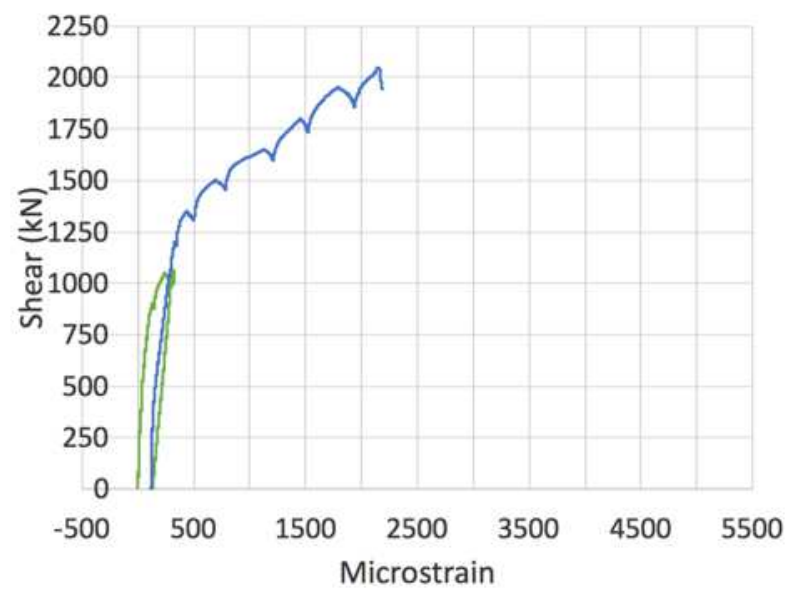

(d) LZ2

— Post-Tensioning at Service Load _ _ Initial Loading

Figure 4.59: Shear versus strain for stirrups and inclined bars in north cantilever of cap beam C2R 


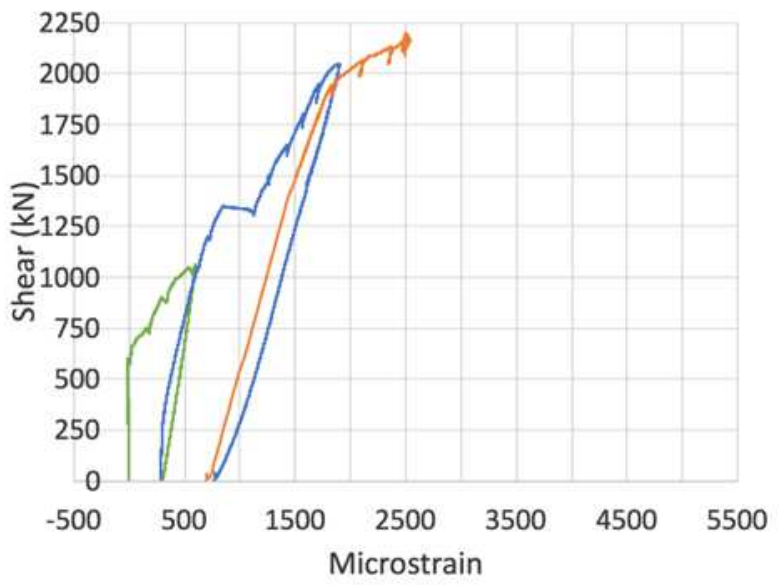

(a) RS1

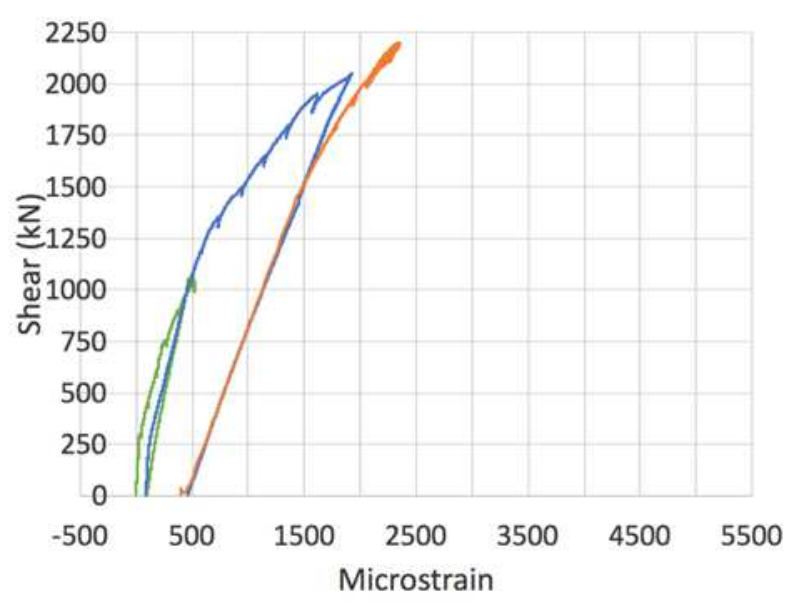

(c) RZ1

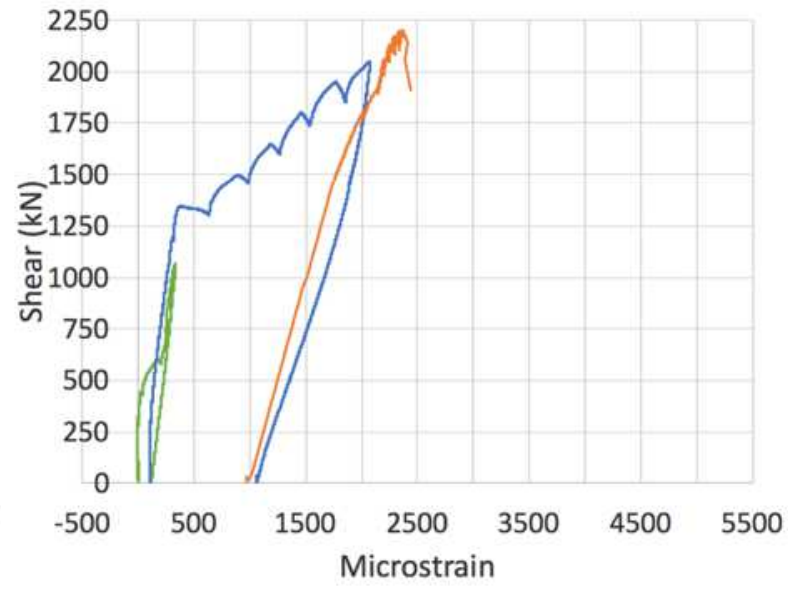

(b) RS3

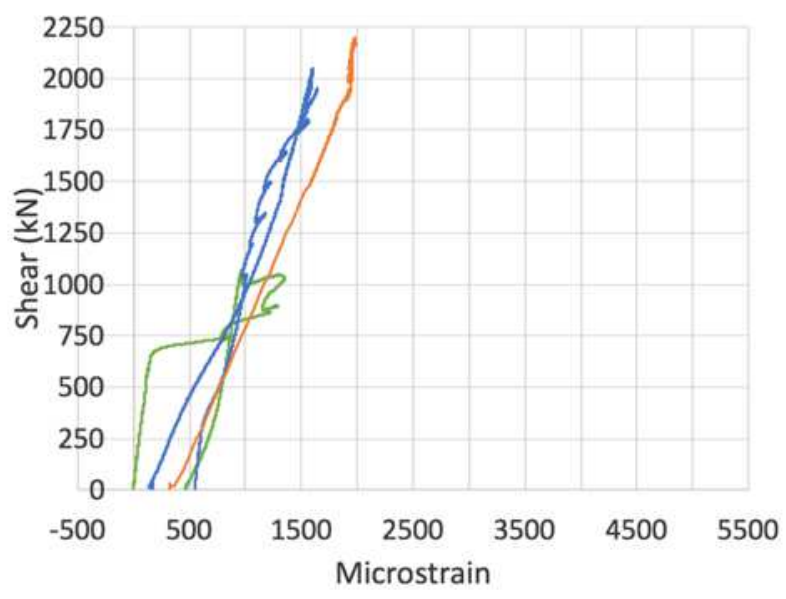

(d) RZ3

\section{—Post-Tensioning at Service Load —Initial Loading _Post-Clamping Loading}

Figure 4.60: Shear versus strain for stirrups and inclined bars in south cantilever of cap beam $\mathrm{C} 2 \mathrm{R}$ 


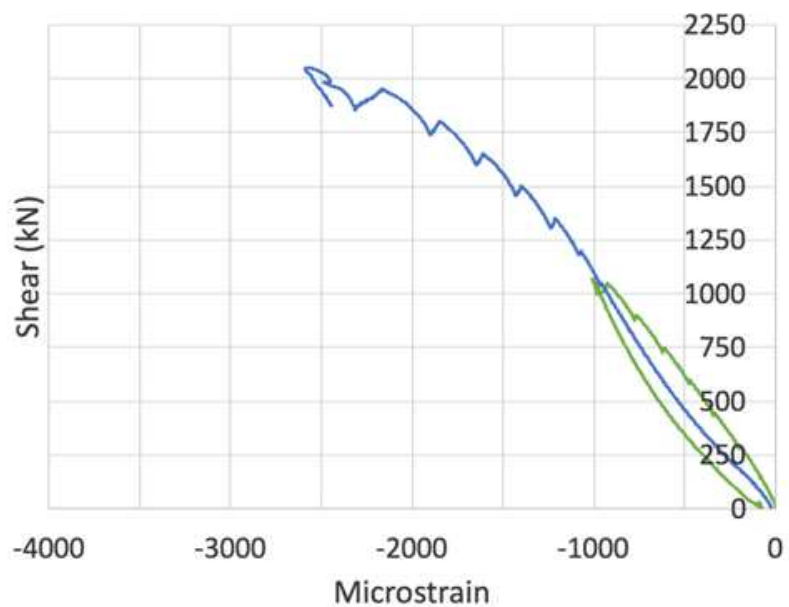

(a) LLT (north)

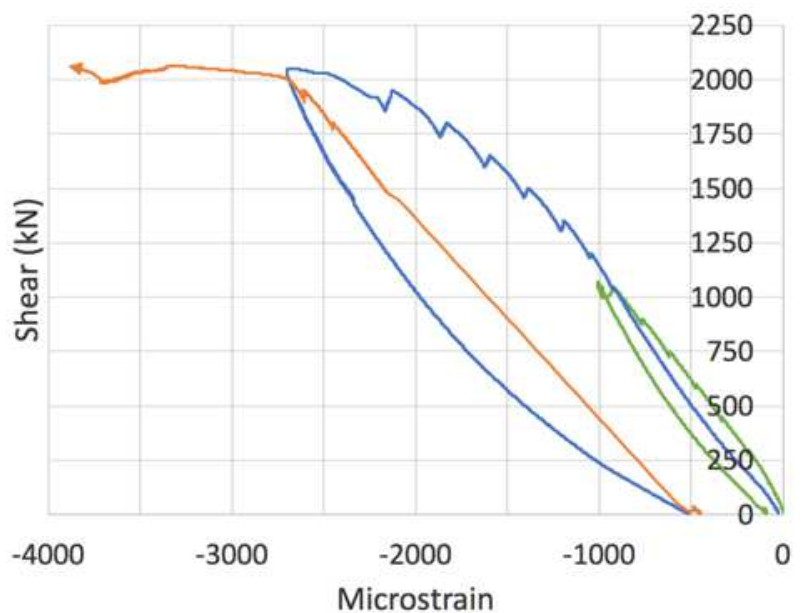

(b) RLT (south)

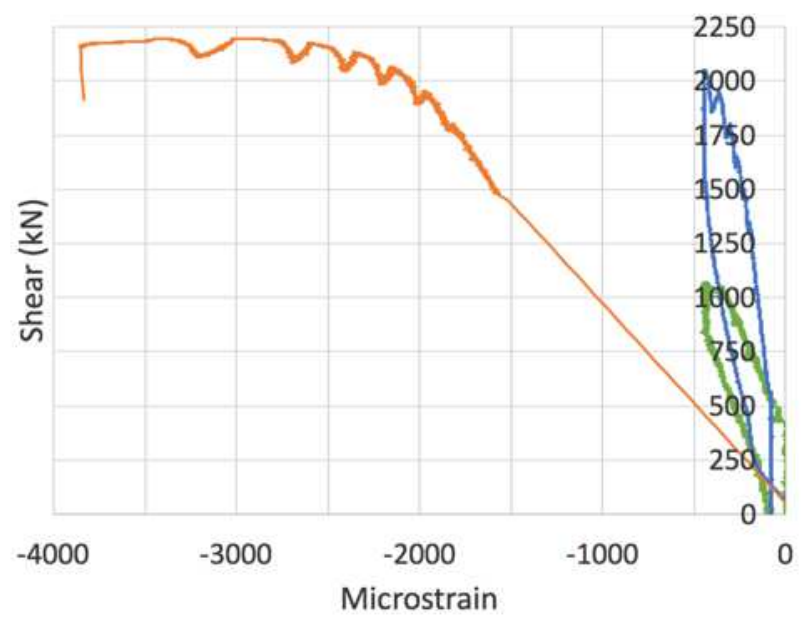

(c) LV9 (south)

—Post-Tensioning at Service Load —Initial Loading —Post-Clamping Loading

Figure 4.61: Shear versus compressive strain at re-entrant corners on cap beam C2R 
Figure 4.62 shows the results from the LVDT rosettes on pier cap C2R for both the north and south cantilevers. The peak horizontal strains were 0.00111 on the north side and 0.000752 on the south side for the initial loading curve. After clamping the south side reached a peak horizontal strain of 0.00106 before failure. As for the vertical strains, the north and south sides reached peak vertical strains of 0.00177 and 0.00035 at initial failure, both well below the stirrup yielding strain. A nearby stirrup LS3 on the north side reached a similar strain of 0.00209 at failure. After clamping the south side reached stirrup yielding shortly before failure, at a shear of $2170 \mathrm{kN}$. Nearby stirrup RS3 recorded yielding after clamping at $2140 \mathrm{kN}$. The maximum tensile strains reached were $0.37 \%$ and $0.28 \%$ at the initial failure on the north and south sides respectively. After clamping the south cantilever reached a peak tensile strain of $0.50 \%$ at failure. The shear strains on both cantilevers were very similar at the initial failure, with both reaching peak strains of $0.44 \%$. After clamping the shear strain in the south cantilever increased to $0.64 \%$. The principal angle of each side at their respective failures was $41.0^{\circ}$ on the north side and $39.0^{\circ}$ on the south side. It was noted that the angle of the shear cracks near the rosettes at failure was $42.8^{\circ}$ on the north side and $30.5^{\circ}$ on the south side.

\subsubsection{Variation of Post-Tensioning Force}

Figure 4.63 demonstrates the post-tensioning force variation with increasing shear. The total force of post-tensioning at the service load level was approximately $600 \mathrm{kN}$. As the shear increased the post-tensioning force increased almost linearly to a peak of $752 \mathrm{kN}$ when the north cantilever failed. After external shear clamping the post-tensioning force again increased quite linearly to $743 \mathrm{kN}$ before failure of the south cantilever. 


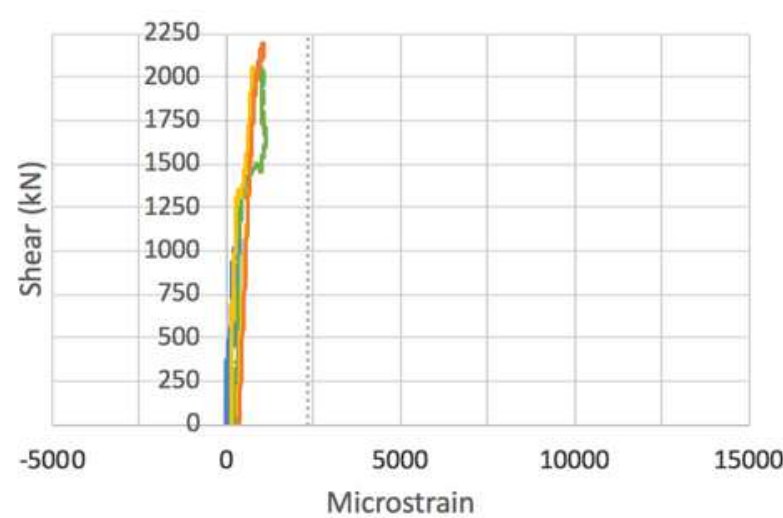

(a) horizontal strain, $\varepsilon_{\mathrm{x}}$

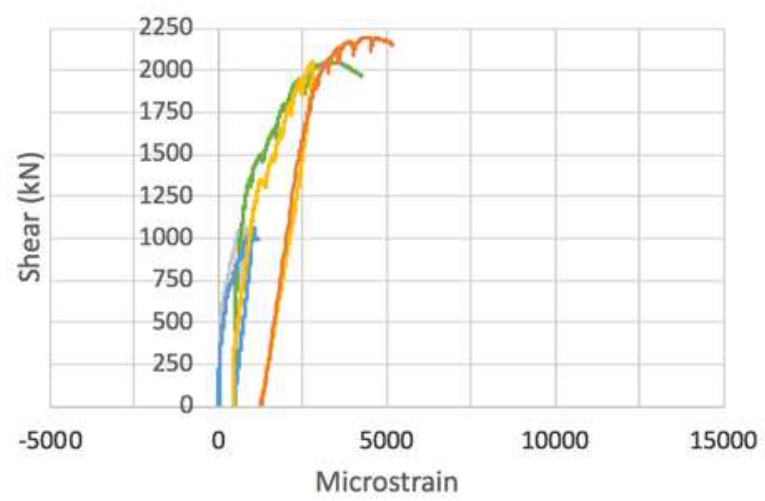

(c) principal tensile strain, $\varepsilon 1$

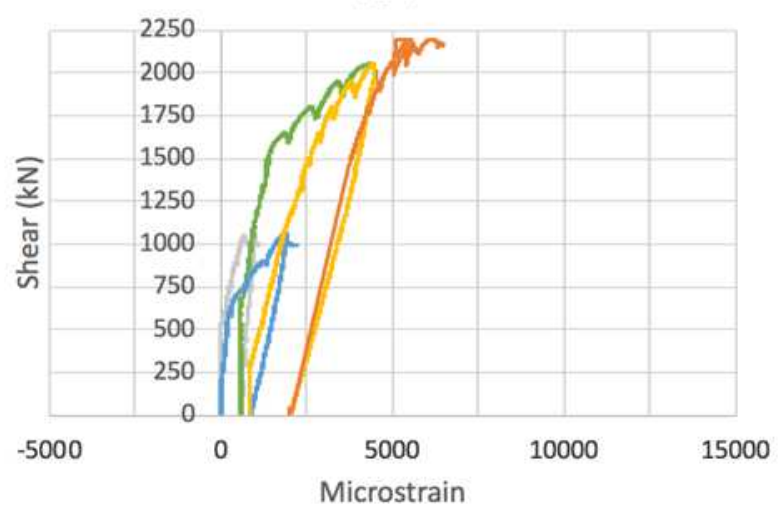

(e) shear strain, $\gamma_{x y}$

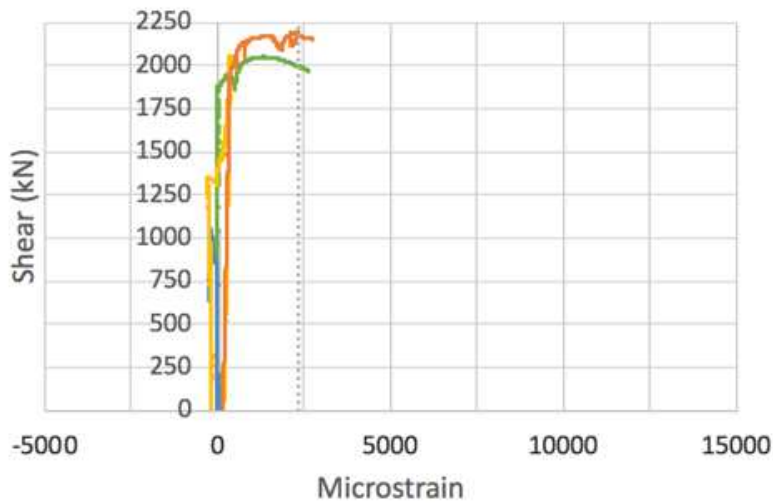

(b) vertical strain, $\varepsilon_{y}$

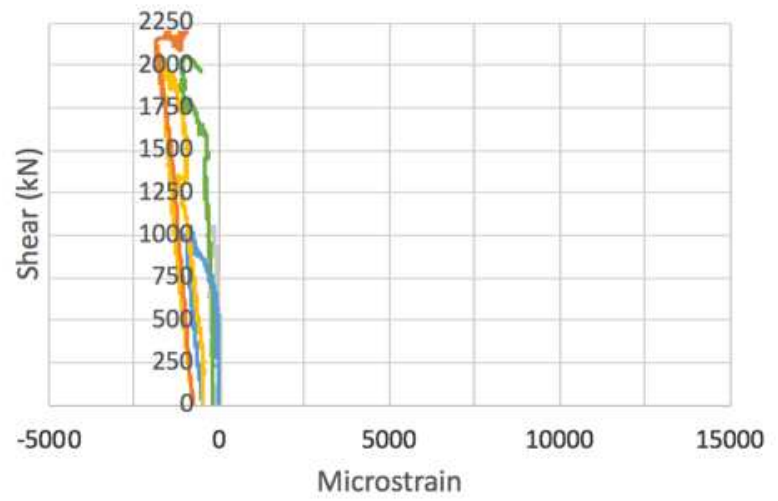

(d) principal compressive strain, $\varepsilon_{2}$

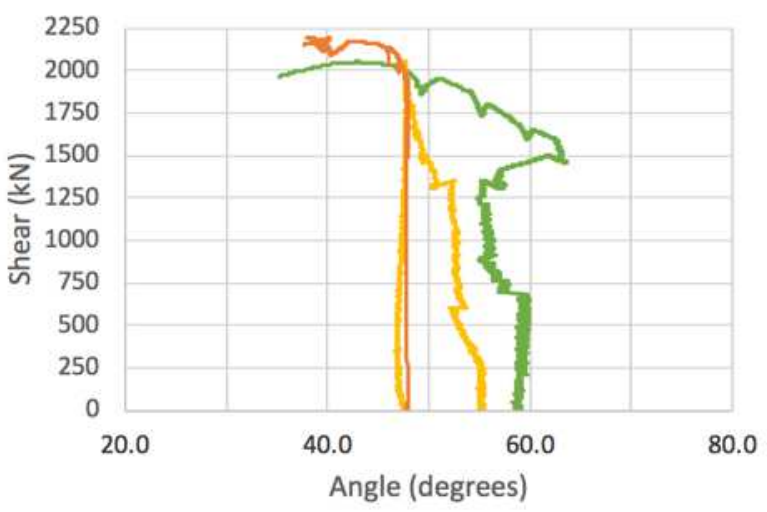

(f) principal angle, $\theta_{\mathrm{p}}$

North-PT $\longrightarrow$ North-1 $\longrightarrow$ South-PT $\longrightarrow$ South-1 $\longrightarrow$ South-2 ....... Yield

Figure 4.62: Principal strains and angles from cap beam C2R rosettes 


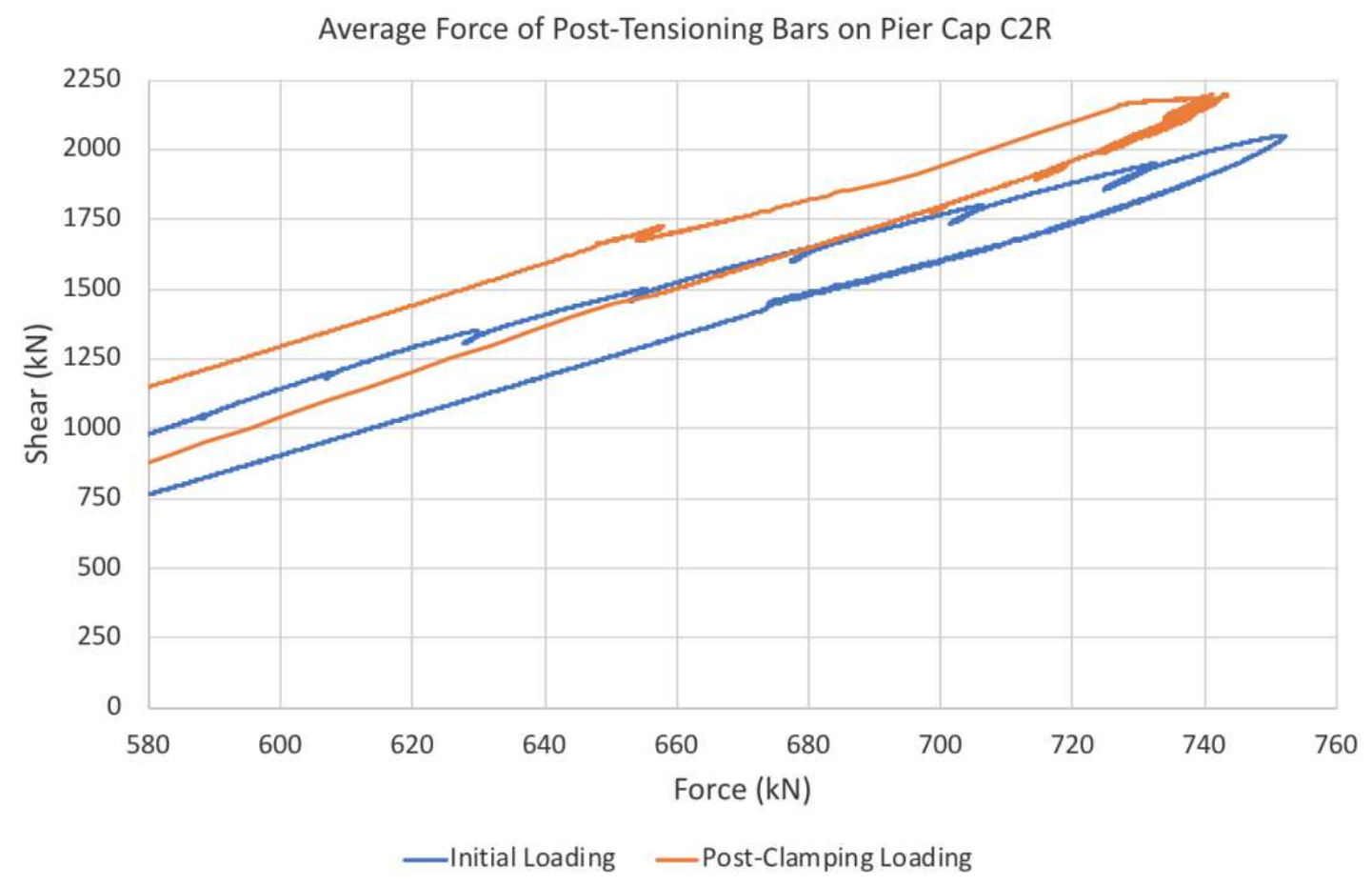

Figure 4.63: Shear versus total force in post-tensioning rods in cap beam C2R 


\section{CHAPTER 5}

\section{ANALYSIS OF RESULTS}

\subsection{Discussion and Comparison of Experimental Results}

\subsubsection{Shear-Deflection Response}

A comparison of the shear-deflection responses of the initial loading for the four pier caps is shown in Figure 5.1. Pier cap C1 reached the lowest peak shear at $1908 \mathrm{kN}$, and it can be observed that it also had the lowest stiffness. Pier cap C1R reached a higher peak shear of 1973 $\mathrm{kN}$ and had a much stiffer response when compared to C1. Cap beam C2 had a stiffness similar to that of specimen $\mathrm{C} 1 \mathrm{R}$ but the inclined reinforcement in $\mathrm{C} 2$ allowed it to reach a significantly higher shear of $2075 \mathrm{kN}$. Pier cap C2R had the greatest stiffness of the four cap beams and reached a shear of $2050 \mathrm{kN}$, just below that reached by $\mathrm{C} 2$.

The post-tensioning caused a significant increase in the stiffness of the pier caps while not gaining much additional capacity. As shown in Table 5.1, for the initial loading response pier cap C1R reached a 3.4\% higher shear at a 15\% smaller deflection than $\mathrm{C} 1$. Pier cap C2R reached a $1.2 \%$ smaller shear at a $28 \%$ smaller deflection than $\mathrm{C} 2$.

It is also noted that cap beams C1, C2, and C2R failed on the north side first which had less crack control reinforcement than the south side. However, for C1R the south side failed first. In this initial south failure the critical shear crack in the south cantilever before failure was smaller than the critical shear crack in the north cantilever, demonstrating that the increased horizontal crack control reinforcement was still more effective in controlling crack widths. However the area of horizontal crack control reinforcement was very low when compared to the area of primary tension steel, thus giving very little additional strength to the pier cap. The strength of the south side was thus only slightly higher than the north side, and with the variability of concrete an initial failure in the south cantilever was within reason. 


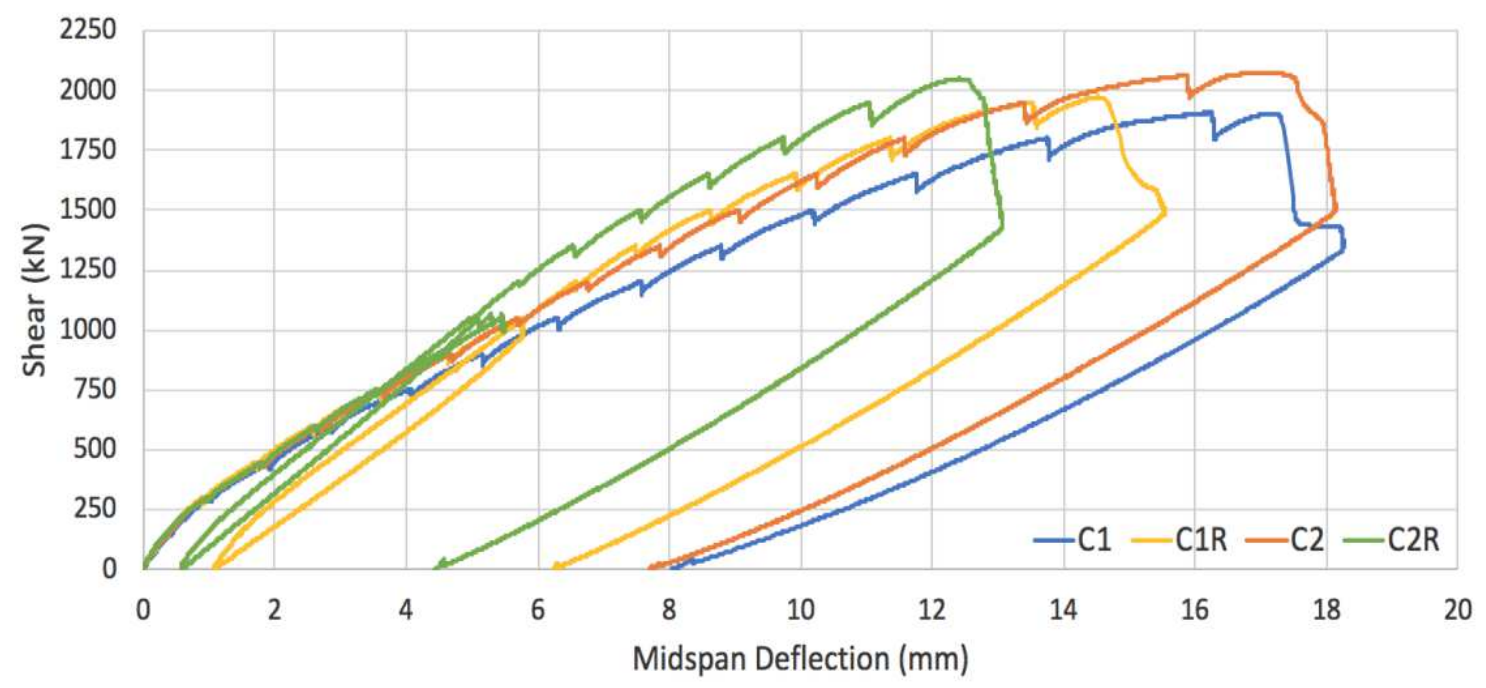

Figure 5.1: Shear-deflection response of cap beams

Table 5.1: Comparison of peak shear and deflections between cap beams

\begin{tabular}{|c||c|c|c||c|c|c|}
\hline & $\mathrm{C} 1$ & $\mathrm{C} 1 \mathrm{R}$ & $\%$ change & $\mathrm{C} 2$ & $\mathrm{C} 2 \mathrm{R}$ & $\%$ change \\
\hline \hline Peak Shear (kN) & 1908 & 1973 & $3.4 \%$ & 2075 & 2050 & $-1.2 \%$ \\
\cline { 2 - 6 } & 17.3 & 14.7 & $-15.0 \%$ & 17.5 & 12.6 & $-28.0 \%$ \\
\hline $\begin{array}{c}\text { Peak Deflection } \\
(\mathrm{mm})\end{array}$ & & & & & \\
\hline
\end{tabular}

\subsubsection{Crack Widths}

Figures 5.2 to 5.4 compare the flexural and shear cracks on the north and south sides for all four specimens. The shear cracking behavior can be seen in Figure 5.2. At service load level the shear crack widths in $\mathrm{C} 1$ and $\mathrm{C} 1 \mathrm{R}$ were $0.20 \mathrm{~mm}$ and $0.15 \mathrm{~mm}$ in the north and south ends respectively. These were consistently larger than the shear crack widths in pier caps $\mathrm{C} 2$ and $\mathrm{C} 2 \mathrm{R}$. Cap beam $\mathrm{C} 2$ had crack widths of $0.05 \mathrm{~mm}$ in both cantilevers, and C2R had crack widths of $0.15 \mathrm{~mm}$ and $0.10 \mathrm{~mm}$ in the north and south ends, respectively. Post-tensioning was effective in reducing the shear cracks by $0.05 \mathrm{~mm}$. Beyond service loading $\mathrm{C} 1$ and $\mathrm{C} 1 \mathrm{R}$ had significantly 
larger shear cracks than $\mathrm{C} 2$ and C2R. The weaker north cantilever typically had larger shear crack widths than the south cantilever.

Looking next at flexural web cracks in Figure 5.3, up until service loading all four specimens exhibited similar cracking, reaching crack widths of $0.15 \mathrm{~mm}$ and $0.10 \mathrm{~mm}$ in the north and south side respectively. The added crack control reinforcement in the south side resulted in slightly smaller crack widths. The post-tensioning applied to pier caps C1R and C2R was effective in reducing these flexural web crack widths. Pier cap C1R saw a crack width decrease of $0.05 \mathrm{~mm}$ in the north side, and pier cap C2R saw a crack width decrease of $0.1 \mathrm{~mm}$ and $0.05 \mathrm{~mm}$ in the north and south cantilevers respectively. Beyond the service load level cap beams $\mathrm{C} 1$ and $\mathrm{C} 2$ had the largest flexural web cracks, with $\mathrm{C} 1 \mathrm{R}$ and $\mathrm{C} 2 \mathrm{R}$ having smaller crack widths due to the post-tensioning. Pier caps $\mathrm{C} 2$ and $\mathrm{C} 2 \mathrm{R}$ generally had larger flexural crack widths at failure, likely due to reaching higher loads by having additional resistance to shear cracking.

Flexural cracking behavior in the concentrated tensile steel region is shown in Figure 5.4. At service loading pier cap C1 had the largest crack widths at $0.10 \mathrm{~mm}$ on both sides. Pier cap C1R had lower crack widths at $0.05 \mathrm{~mm}$ on both sides. Pier cap C2 had crack widths of $0.10 \mathrm{~mm}$ and $0.05 \mathrm{~mm}$ on the north and south sides respectively, and $\mathrm{C} 2 \mathrm{R}$ had crack widths of $0.05 \mathrm{~mm}$ on either side. In general, up until the service load level the four pier caps had similar flexural cracking behavior in the concentrated tensile steel region. The post-tensioning was not very effective in reducing these crack widths, with only $\mathrm{C} 1 \mathrm{R}$ in the north side seeing a notable reduction of $0.05 \mathrm{~mm}$. Beyond service loading cap beam $\mathrm{C} 1$ consistently had the largest flexural cracks in the region of the concentrated steel. Pier caps C1R and C2 had similar crack widths, and $\mathrm{C} 2 \mathrm{R}$ generally had the highest resistance to this type of flexural cracking. There was no significant difference observed in these flexural cracks between the north and south side, as the amount of primary flexural steel remained the same for the span of the pier cap. 


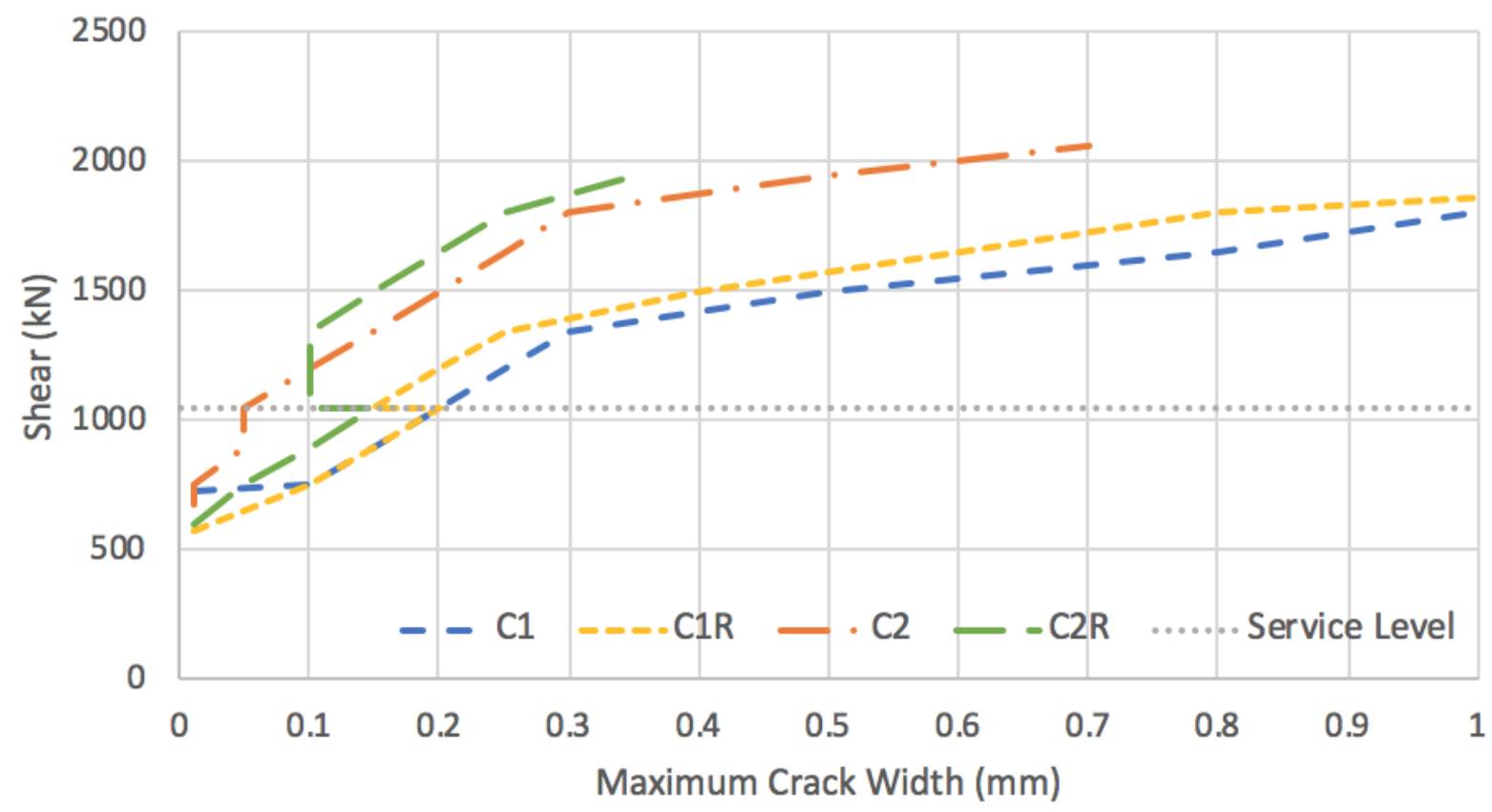

(a) North cantilever

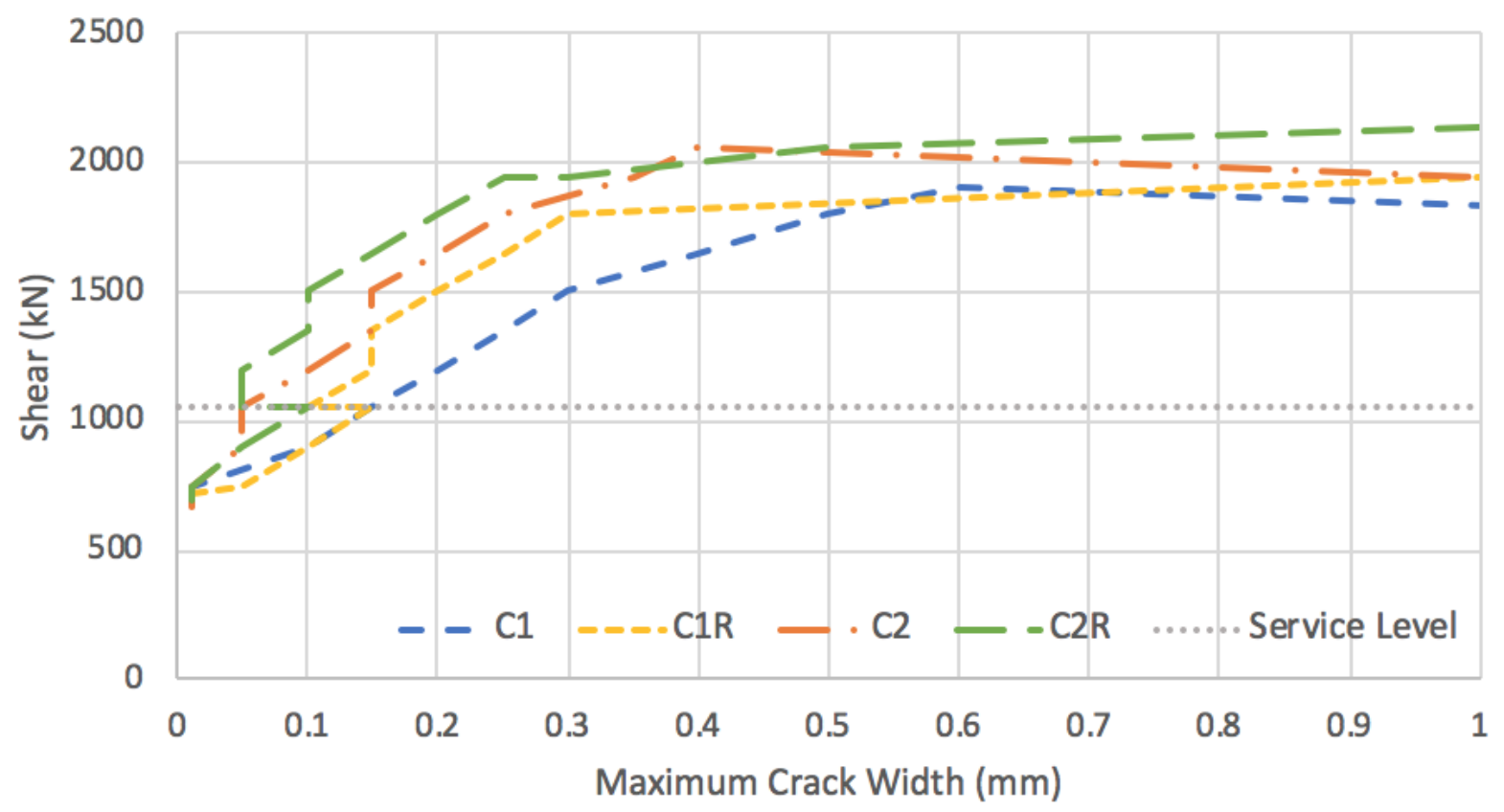

(b) South cantilever

Figure 5.2: Maximum shear crack widths 


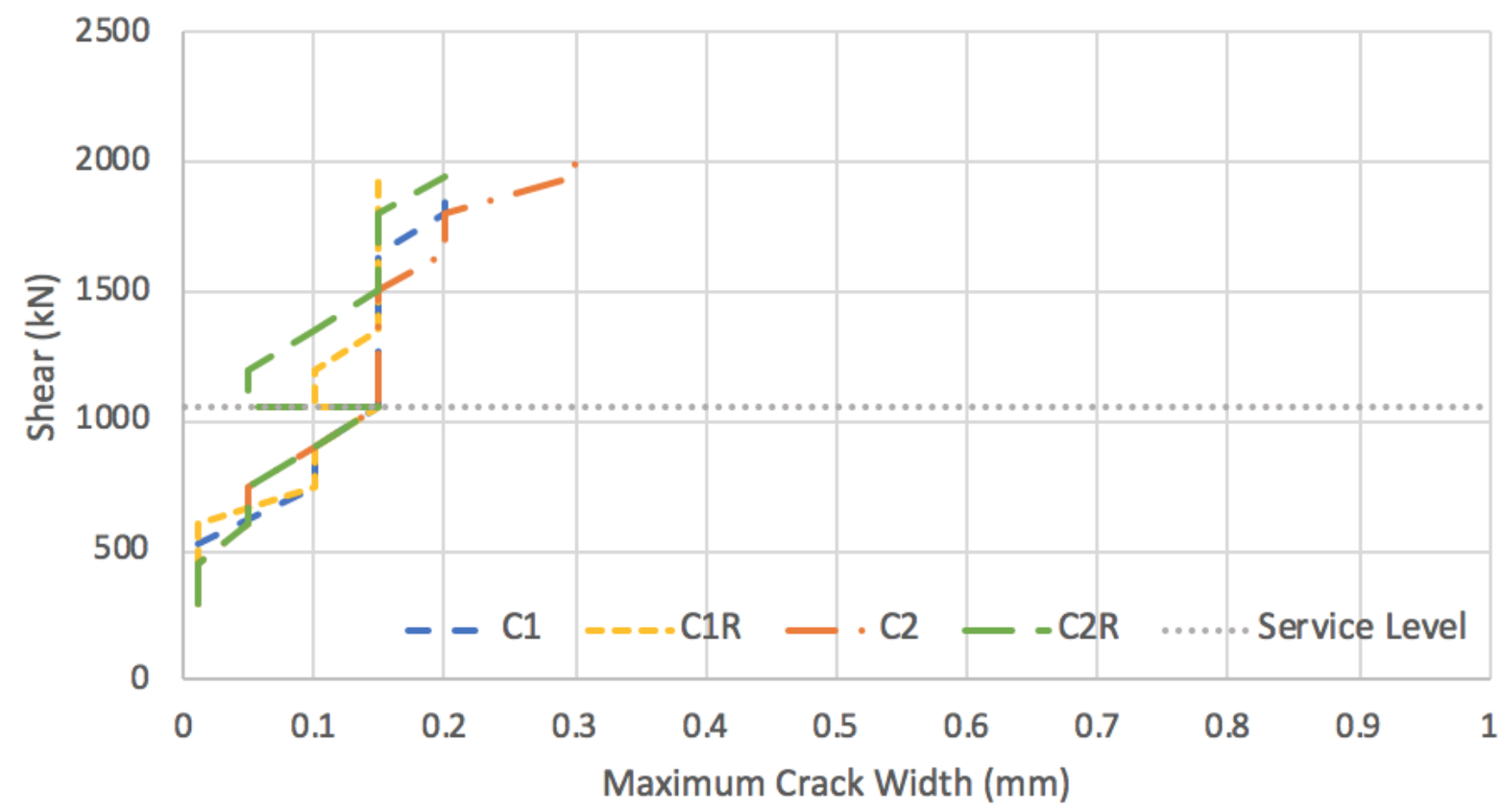

(a) North cantilever

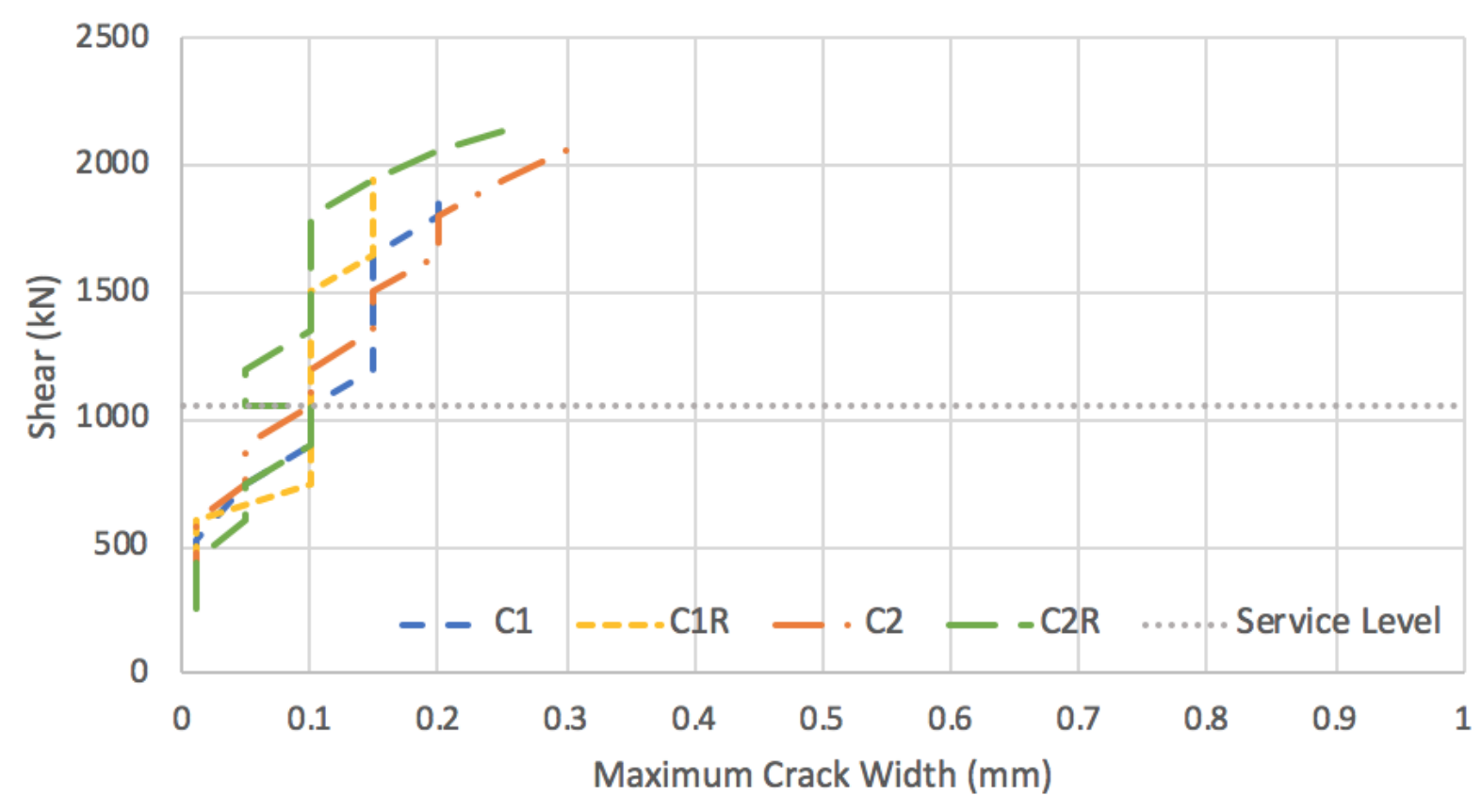

(b) South cantilever

Figure 5.3: Maximum flexural crack widths in the web 


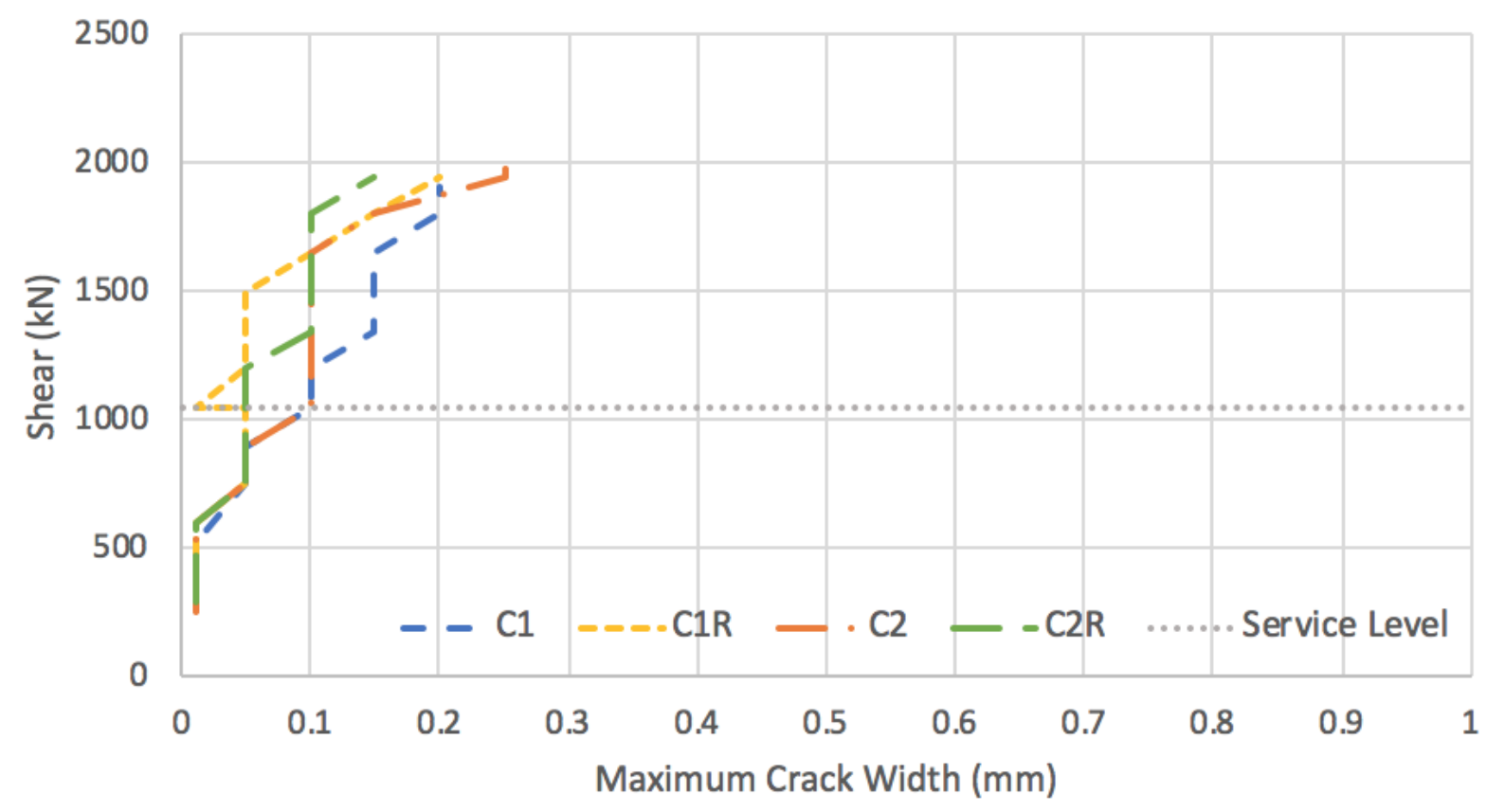

(a) North cantilever

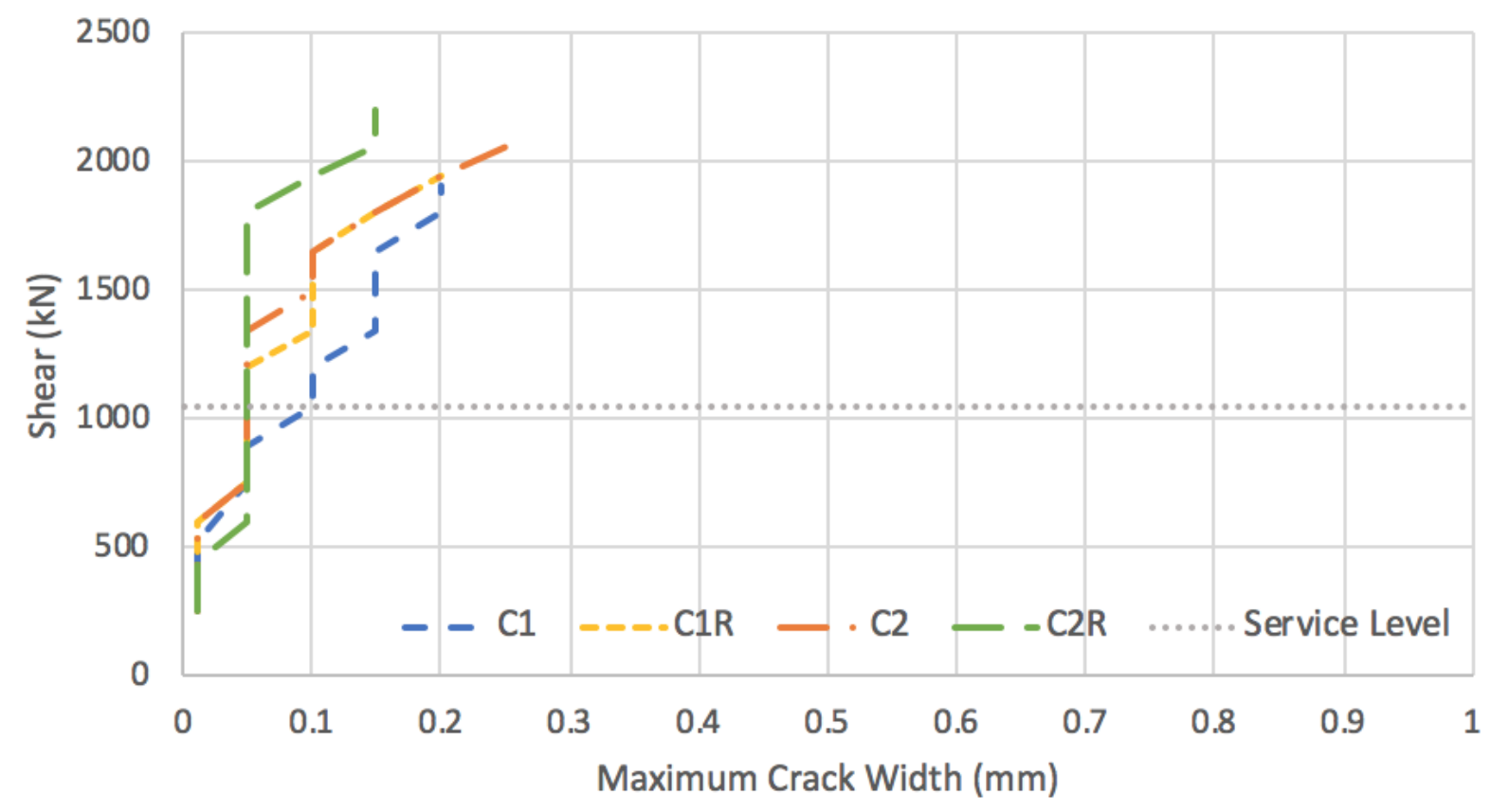

(b) South cantilever

Figure 5.4: Maximum flexural crack widths in the primary tension reinforcement 
Maximum horizontal splitting crack widths at the hook locations of the $45^{\circ}$ inclined reinforcing bars in the primary tension steel is shown in Figure 5.5. Both cap beams C2 and C2R had significant splitting cracks in the north cantilevers, reaching values of $0.50 \mathrm{~mm}$ and $0.25 \mathrm{~mm}$ at their respective failures. In the south cantilevers no horizontal splitting cracking was observed for $\mathrm{C} 2$, and splitting cracking only initiated near the second, post-clamping failure of specimen $\mathrm{C} 2 \mathrm{R}$. These results seem to indicate that the higher amount of crack control reinforcement in the south cantilever for both cap beams was effective in controlling the formation of the horizontal splitting cracking. It is also noted that the post-tensioned cap beam C2R had a significantly smaller splitting crack than cap beam C2. After testing of cap beam C2 the concrete in front of the inclined reinforcement on the north cantilever was chipped away. Figures 5.6 and 5.7 indicate that there was no slip of the inclined reinforcement hooks at the top and bottom primary steel layers at the locations closest to the critical shear crack.

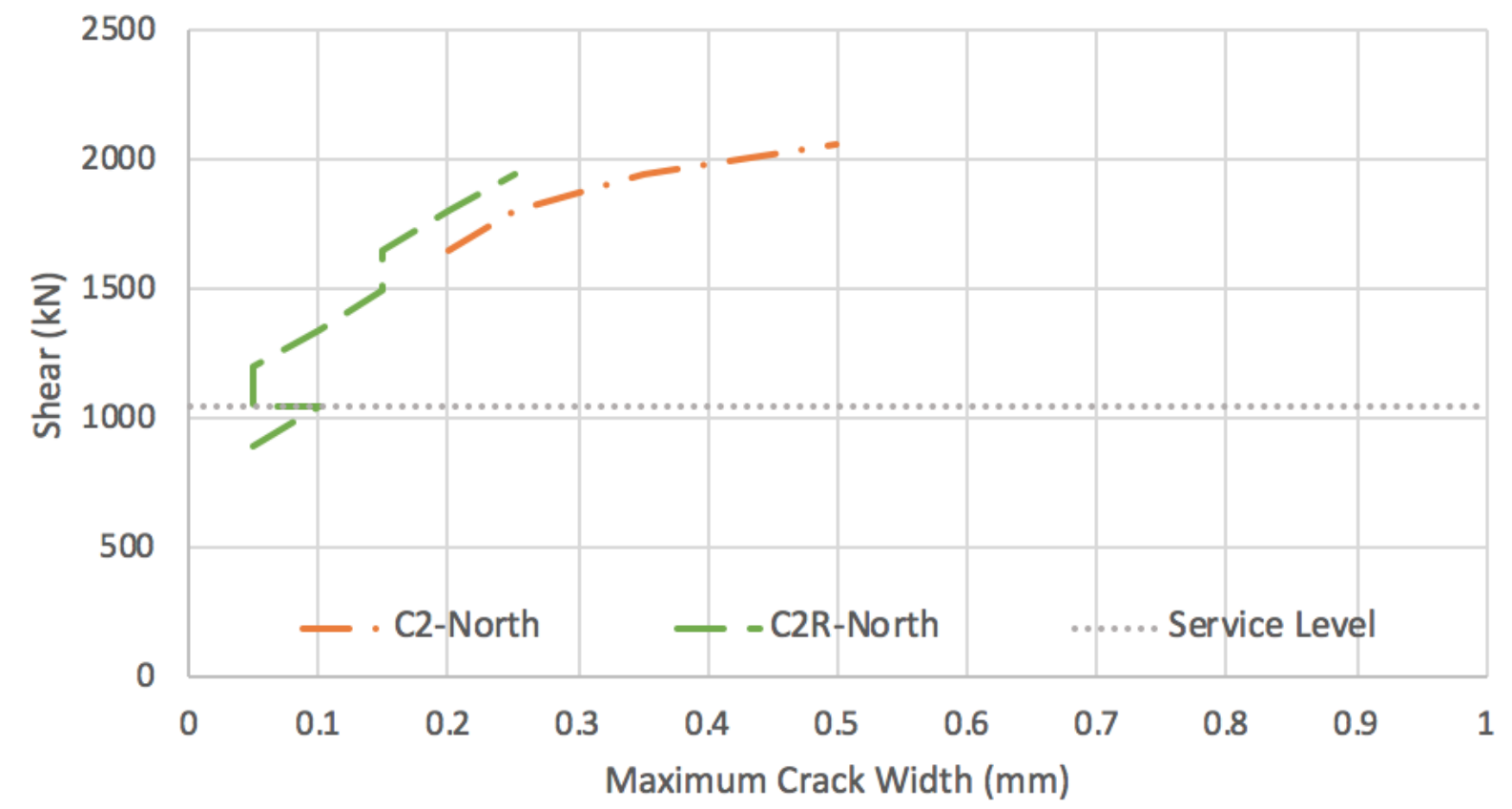

Figure 5.5: Maximum horizontal splitting crack widths for $45^{\circ}$ inclined reinforcing bars in cap beams $\mathrm{C} 2$ and $\mathrm{C} 2 \mathrm{R}$ 


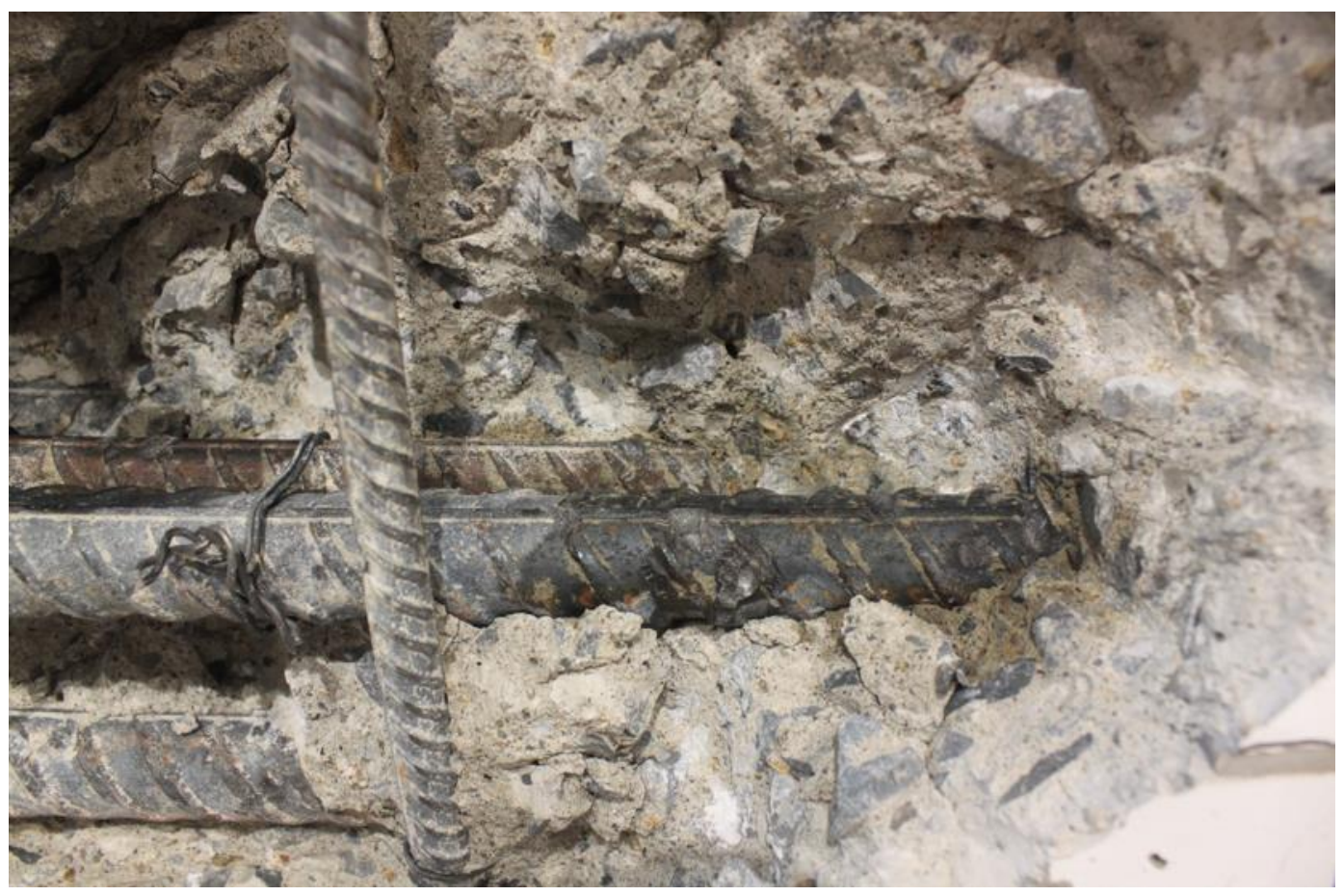

Figure 5.6: Inclined reinforcement hook at primary tension steel layer on north side of C2

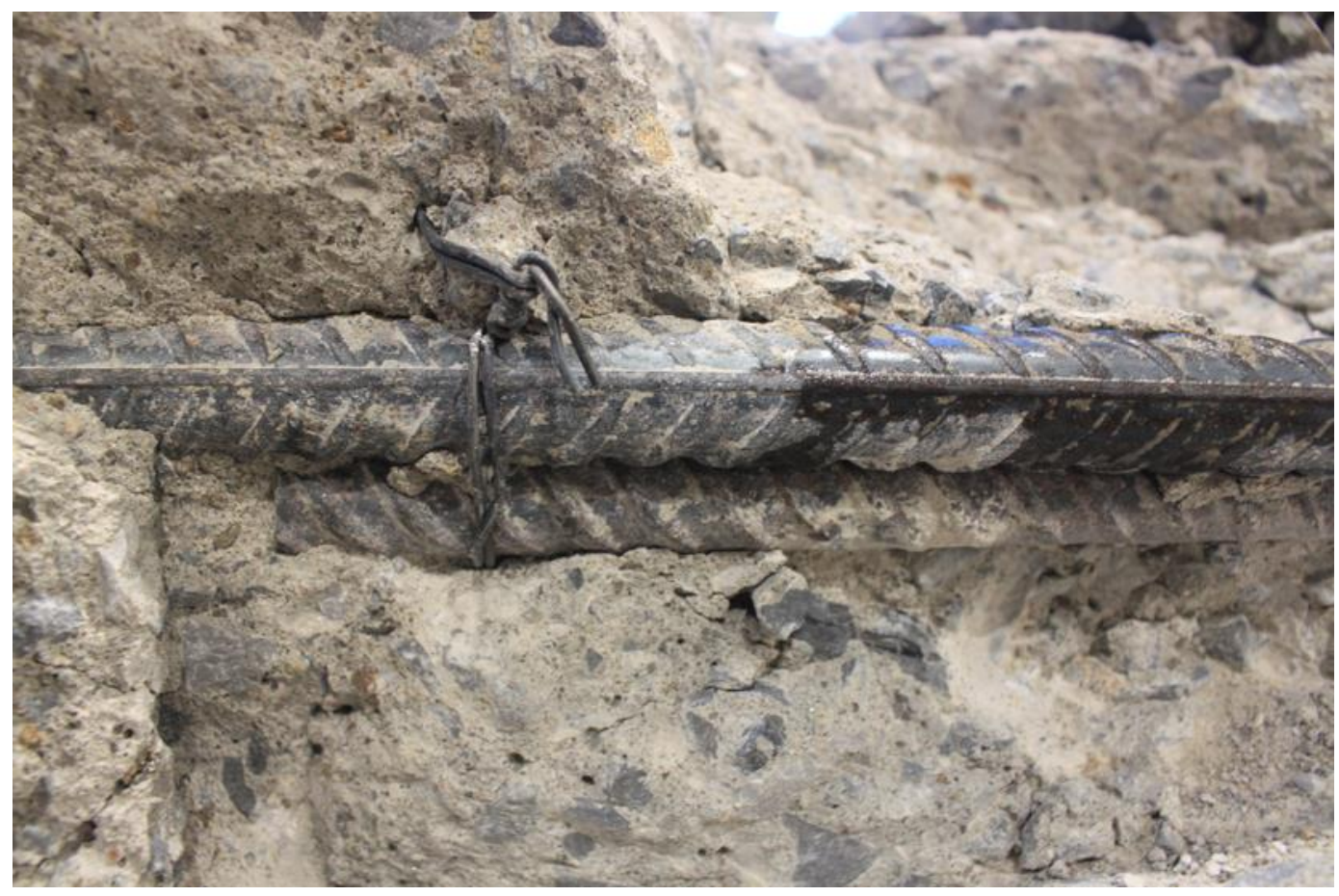

Figure 5.7: Inclined reinforcement hook at primary compression steel layer on north side of C2 


\subsection{Predicted Behavior from Sectional Analysis}

\subsubsection{Determining Locations of Critical Sections}

In order to perform a sectional analysis, the locations of the critical sections must first be determined. A critical section is located a distance $d_{v}$ away from the face of supports or loading areas. This is shown in Figure 5.8, where for these pier caps there will be two critical sections to be checked: one a distance $d_{v}$ away from the inner edge of the bearing (Section 1), and another a distance $d_{v}$ from the column face (Section 2). The effective shear depth $d_{v}$ is typically taken as,

$$
d_{v}=0.9 d
$$

where $d$ is the effective depth at the critical section. However due to the 1:4 sloped bottom face the $d_{v}$ at the critical section is different than the $d_{v}$ at the face of the loading point.

Looking first at Section 1, the compression forces flow in a fanning pattern from the support to the inclined bottom face. As such the effective shear depth will be larger due to the critical section location being further away from the support. Using the 1:4 slope, $d_{v}$ for Section 1 was calculated as,

$$
d_{v}=0.9 d_{1}=0.9(d+0.25 d)
$$

where $d_{1}$ is the effective depth at the critical section.

For Section 2, the compression forces instead fan from the edge of the column up to the top horizontal surface. Therefore, the distance to Section 2 from the column face was taken as Equation 5.1, where $d$ is the effective depth at the column face. At the section the $d_{v}$ was then determined from Equation 5.1, where $d$ is equal to $d_{2}$, the effective depth at Section 2.

Using Equations 5.1 and 5.2 the effective depth at Section 1, $d_{1}$, and Section $2, d_{2}$, were calculated as 650.2 and $703.3 \mathrm{~mm}$, respectively. The effective shear depth, $d_{v}$, was then calculated as 585.2 and $633.0 \mathrm{~mm}$ for Sections 1 and 2, respectively. 


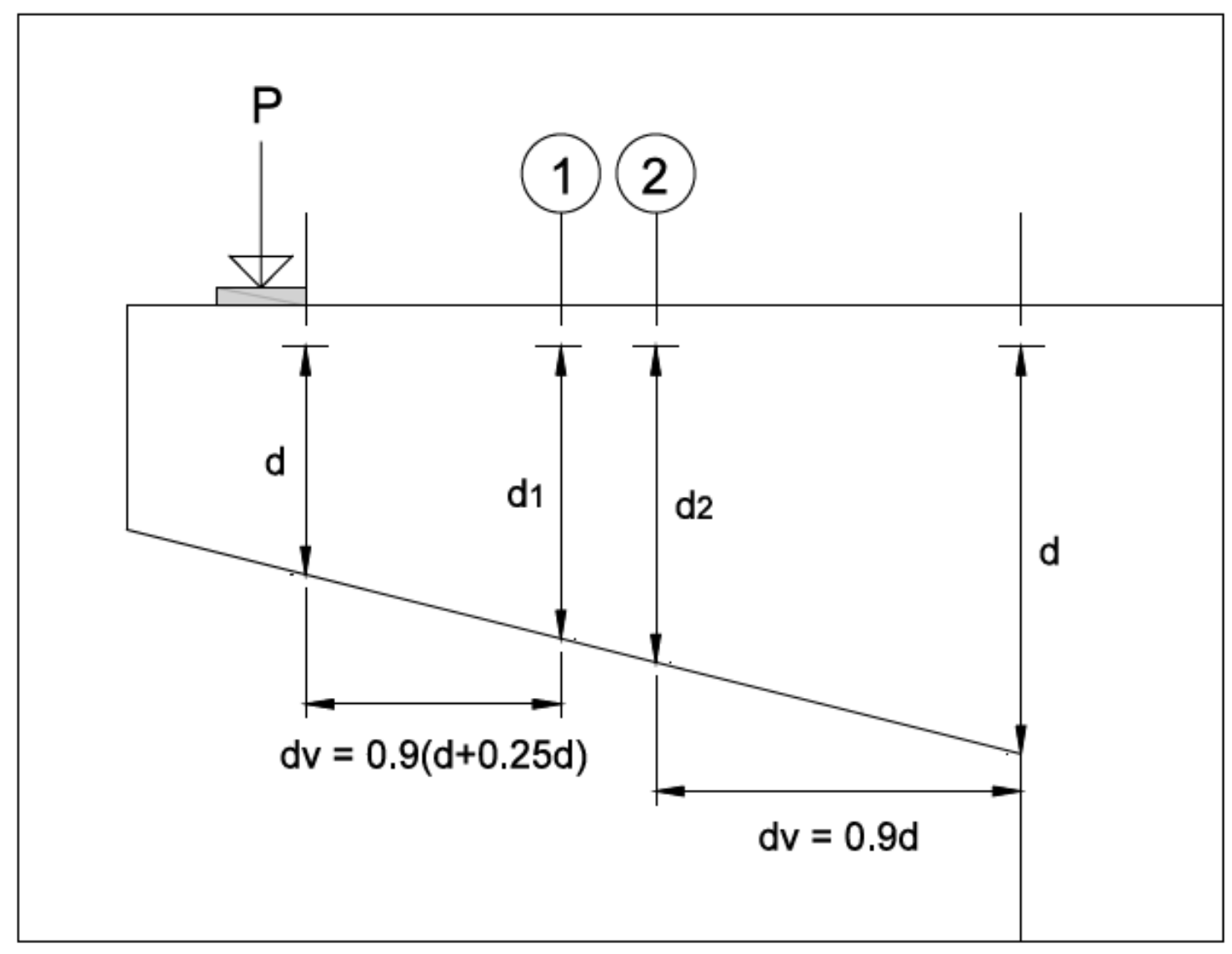

Figure 5.8: Critical sections for sectional analysis

\subsubsection{Sectional Design Methodology}

The general method outlined in the CSA S6-14 Canadian Highway Bridge Design Code (CSA 2014) was used for the analysis of the pier caps. This general method was discussed earlier in Section 2.1 and was performed at the critical sections 1 and 2 in Figure 5.8. The primary objective of this analysis was to determine the nominal shear resistance, $V$, of the pier caps. As such, material resistance factors $\left(\phi_{\mathrm{s}}, \phi_{\mathrm{c}}, \phi_{\mathrm{p}}\right)$ were taken as 1.0 for this analysis. An iterative general method was used in order to determine $V$ at the critical sections, the steps of which are described below:

Step 1: A value for the nominal shear resistance, $V$, was assumed

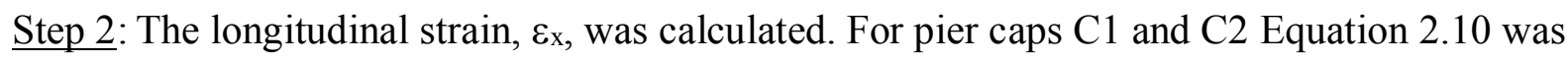
simplified as: 


$$
\varepsilon_{x}=\frac{M / d_{v}+V-V_{p}}{2\left(E_{S} A_{s}\right)}
$$

In this equation $M$ is the nominal moment corresponding to the shear $V$, with the lever arm from the critical section to the center of the bearing. $A_{s}$ and $E_{s}$ are the cross-sectional area and modulus of elasticity of the flexural tension reinforcement, respectively. $V_{p}$ was taken as the vertical component of flexural compression parallel to the 1:4 inclined face. For pier caps $\mathrm{C} 1$ and $\mathrm{C} 2$ this was calculated as:

$$
V_{p}=0.25 \times M / d_{v}
$$

For pier caps C1R and C2R Equations 5.3 and 5.4 were adjusted to take into consideration the external unbonded post-tensioning force, $P$, applied at an eccentricity, $e$. This post-tensioning force acts as both an applied moment and axial load. In the longitudinal strain equation, the moment was reduced by $P \times e$, and the post-tensioning force treated as an externally applied compressive force. That is, $N_{f}$ in Equation 2.10 was substituted by $P$, with the sign changed for compression. Thus, for pier caps $\mathrm{C} 1 \mathrm{R}$ and $\mathrm{C} 2 \mathrm{R}$ the longitudinal strain equation becomes:

$$
\varepsilon_{x}=\frac{(M-P \times e) / d_{v}+V-V_{p}-P / 2}{2\left(E_{S} A_{s}\right)}
$$

where $V_{p}$ was also modified to become:

$$
V_{p}=0.25 \times(M-P \times e) / d_{v}
$$

Note that in these equations the post-tensioning force was assumed to remain constant over the loading cycle.

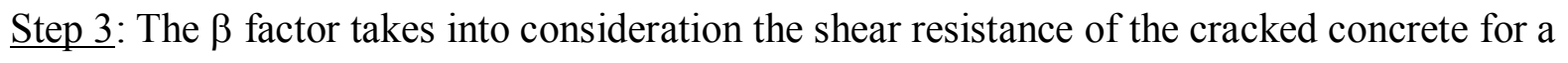
member with shear reinforcement. This was calculated with Equation 2.15, where $s_{z e}$ was assumed to be the typical value of $300 \mathrm{~mm}$ for members with at least minimum web reinforcement.

Step 4: The angle of principal compression, $\theta$, was calculated from Equation 2.16. 
Step 5: The nominal shear resistance provided by the cracked concrete, $V_{c}$, was calculated as per Equation 2.8. The measured concrete strength from material testing was used for $f_{c}$ '.

Step 6: The nominal shear resistance provided by the vertical stirrups, $V_{s}$, was calculated as per Equation 2.7 for pier caps $\mathrm{C} 1$ and $\mathrm{C} 1 \mathrm{R}$. Pier caps $\mathrm{C} 2$ and $\mathrm{C} 2 \mathrm{R}$ have additional inclined reinforcement, the transverse component of which must be added to Equation 2.7. Thus, this becomes,

$$
V_{s}=\frac{f_{y} A_{v} d_{v} \cot \theta}{s}+\frac{f_{y} A_{v i} d_{v}(\cot \theta+\cot \alpha) \sin \alpha}{s_{i}}
$$

where $s i$ is the spacing of the inclined reinforcement, $A_{v i}$ is the cross-sectional area of the inclined reinforcement within the spacing $s i$, and $\alpha$ is $45^{\circ}$, the angle of the inclined reinforcement. The measured yield strength for the $10 \mathrm{M}$ bars was used for $f_{y}$.

Step 7: The nominal shear resistance, $V$, was calculated as:

$$
V=V_{c}+V_{s}+V_{p}
$$

Step 8: The nominal shear resistance $V$ calculated in Step 7 was compared with the assumed value in Step 1. The assumed value was changed, and procedure repeated until the solution converged.

\subsubsection{Sectional Design Results}

The predicted nominal shear resistances, $V_{\text {predicted, }}$ by the general method described above are shown in Table 5.2. The reported values are the predicted shear resistances at Section 1 in Figure 5.8, as for all four pier caps this location had a lower and hence more critical shear resistance than at Section 2. Comparing the predictions to the experimental shear resistances, $V_{\text {test }}$, it is clear that the general shear design method of the 2014 CHBDC consistently gave conservative shear predictions. The $V_{\text {test }} / V_{\text {predicted }}$ ranged from 1.10 to 1.22 , with pier caps $\mathrm{C} 1$ and $\mathrm{C} 1 \mathrm{R}$ being predicted slightly more conservatively than pier caps $\mathrm{C} 2$ and $\mathrm{C} 2 \mathrm{R}$. 
Table 5.2: Comparison of predicted shear capacities from the sectional analysis with shear capacities achieved during testing

\begin{tabular}{|c|c|c|c|c|c|c|c|c|}
\hline & $\mathrm{C} 1$ & $\mathrm{C} 1$ & $\mathrm{C} 1 \mathrm{R}$ & $\mathrm{C} 1 \mathrm{R}$ & $\mathrm{C} 2$ & $\mathrm{C} 2$ & $\mathrm{C} 2 \mathrm{R}$ & $\mathrm{C} 2 \mathrm{R}$ \\
$\mathrm{N}$ & $\mathrm{S}$ & $\mathrm{N}$ & $\mathrm{S}$ & $\mathrm{N}$ & $\mathrm{S}$ & $\mathrm{N}$ & $\mathrm{S}$ \\
\hline $\begin{array}{c}\mathrm{V}_{\text {predicted }} \\
\mathrm{kN}\end{array}$ & 1567 & 1583 & 1661 & 1675 & 1774 & 1791 & 1865 & 1881 \\
\hline $\begin{array}{c}\mathrm{V}_{\text {test }} \\
\mathrm{kN}\end{array}$ & 1908 & 1908 & 2017 & 1973 & 2075 & $2075^{+}$ & 2050 & 2198 \\
\hline $\begin{array}{c}\mathrm{V}_{\text {test }} \\
\mathrm{V}_{\text {predicted }}\end{array}$ & 1.22 & 1.21 & 1.21 & 1.18 & 1.17 & 1.16 & 1.10 & 1.17 \\
\hline
\end{tabular}

\subsection{Predicted Behavior using Strut-and-Tie Analysis}

\subsubsection{Strut-and-Tie Methodology}

The methodology used for performing the strut-and-tie analysis was primarily based on the steps given by Mitchell et al. (2004). Stress limits were based on those in the Canadian Highway Bridge Design Code (2014), though all material resistance factors were taken as 1.0. The concrete strength, $f_{c}$, and yield strength of the reinforcing bars, $f_{y}$, were based on values from material testing. The primary steps are listed below:

Step 1: The flow of stresses through the structure were visualized.

Step 2: An idealized strut-and-tie model was drawn. The primary compressive and tensile reinforcement layers were represented as longitudinal ties located at the centroids of their respective steel layers. Vertical ties representative of the stirrups were added to the model, and concrete compressive struts added to complete the model.

Step 3: The area of the ties was determined. For the stirrup ties this area was determined by the number of stirrups in the band width for each stirrup tie.

Step 4: An applied load, $P$, was assumed at the support, and the forces in the struts and ties calculated by statics. 
Step 5: The strength of the ties was checked to ensure that the applied nominal tensile force, $T$, was less than the nominal tensile resistance, $T_{n}$, calculated as:

$$
T_{n}=A_{s} f_{y}
$$

Step 6: The stresses in the nodal zones were calculated to ensure that the nodal zone stress limits were not exceeded. For the CSA S6-14 code (2014) these stress limits are:

1. $0.85 f_{c}^{\prime}$ for CCC nodes

2. $0.75 f_{c}^{\prime}$ for CCT nodes

3. $0.65 f_{c}^{\prime}$ for CTT nodes

Step 7: The strength of the struts was checked to ensure that the nominal compressive force, $C$, was less than the nominal compressive resistance, $C_{n}$, calculated as:

$$
C_{n}=A_{c s} f_{c u}
$$

The determination of the crushing strength of concrete when cracked, $f_{c u}$, required several steps discussed previously in Chapter 2. Equation 2.21 was first used to determine the principal strain $\varepsilon 1$, where the 0.002 term, representing an assumed $\varepsilon_{c}^{\prime}$ for the strain at peak compressive strength, was instead taken based on material testing. Subsequently Equation 2.19 was used to determine $f_{2, \max }$, equal to $f_{c u}$, and the nodal zone stress limits in Step 6 above were checked for compliance. The nominal compressive strength was then determined by Equation 5.10, and compared with the nominal compressive force $C$.

Step 8: Based on the Step 5-Step 7 checks, the applied load $P$ or stirrup configuration was varied until these checks were adequate at stirrup yielding.

\subsubsection{Strut-and-Tie Model}

The strut-and-tie model representative of cap beam $\mathrm{C} 1$ can be seen in Figure 5.9. In this figure the solid lines are tension ties, and the dashed lines compressive struts. One horizontal tension tie is located at the top of the cap beam at the centroid of the two layers of primary tension reinforcement. Similarly, a compressive strut is located at the centroid of the primary compression steel layer at the bottom face. Each cantilever has a vertical tension tie 
representative of the stirrups located within its effective tributary length. This vertical tie was located at a distance of $850 \mathrm{~mm}$ from the loading point, that is halfway along the $1700 \mathrm{~mm}$ shear span. An effective tributary length of $950 \mathrm{~mm}$ was chosen to represent the band of stirrups over a length of one half of the distance from the loading point to the reaction (See Figure 5.9). It was assumed that the number of stirrup sets in this tie was $950 \mathrm{~mm} / 200 \mathrm{~mm}=4.75$. Hence the yield force in the tie was $876 \mathrm{kN}$.

By varying the load, $P$, at the bearings, it was found that stirrup yielding occurred at an applied force of $1317 \mathrm{kN}$, with the inclined compression in the bottom strut contributing to the shear strength. The stresses in the nodal zone at the bearing and in the strut below the bearing were both found to be below the limit of $0.75 f_{c}{ }^{\prime}$ for CCT nodes. The width of the strut was taken as $600 \mathrm{~mm}$, that is the full width of the cap beam, due to spreading of the compressive stresses from the bearing interface down to the centroid of the top tension reinforcement. The observed failure shears for pier cap C1 were $1908 \mathrm{kN}$ for both the north and south cantilevers. Thus, the observed shear failure was 1.45 times the predicted shear failure from the strut-and-tie model, making it a very conservative prediction.

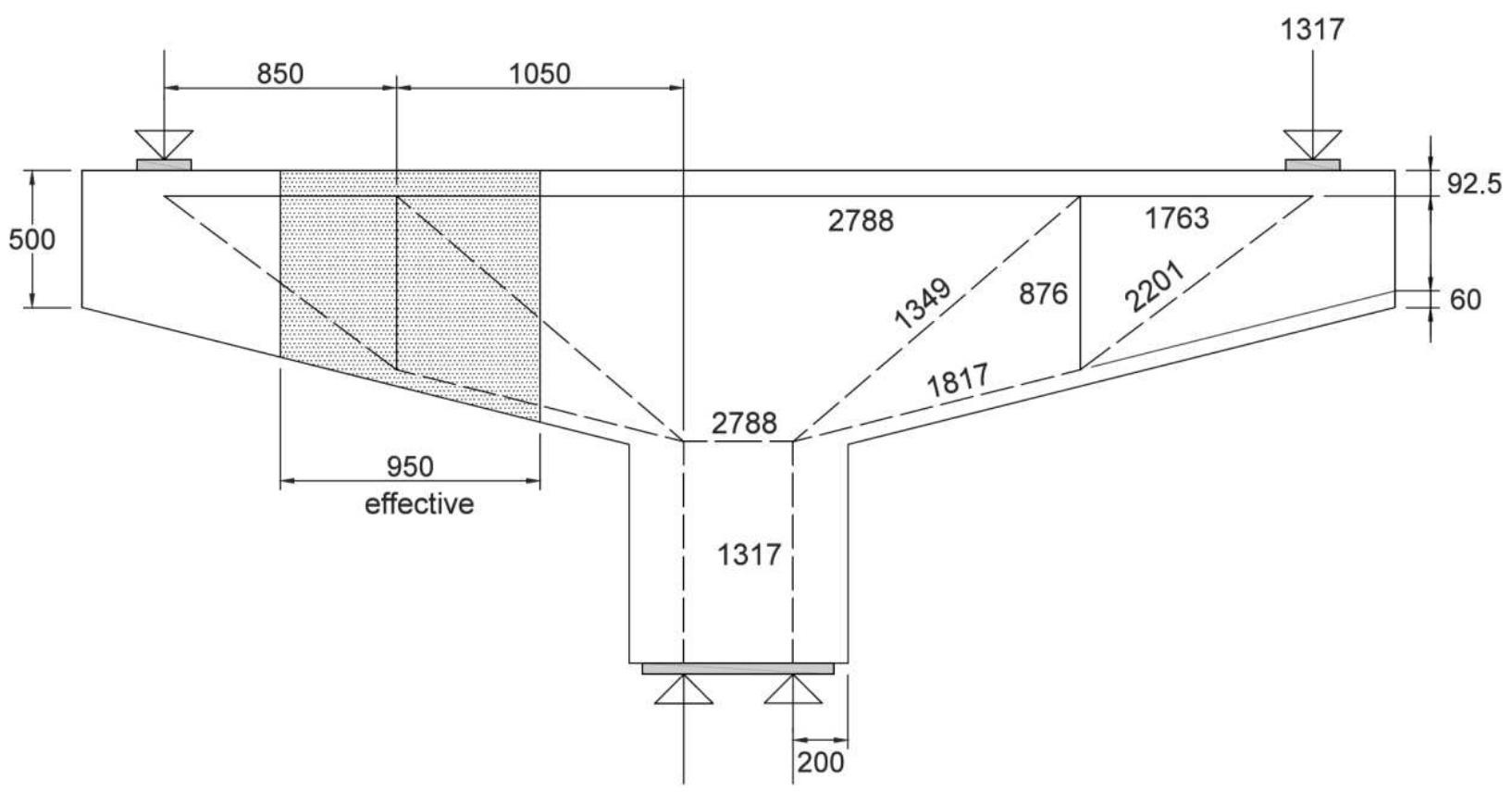

Figure 5.9: Strut-and-tie model of cap beam $\mathrm{C} 1$, with forces in $\mathrm{kN}$ and dimensions in $\mathrm{mm}$ 


\subsection{Predicted Behavior by Non-Linear Finite Element Analysis}

\subsubsection{Pier Cap C1}

The non-linear finite element software used for analysis was VecTor2 (Vecchio, 2018), previously introduced in Chapter 2.3. Before the analyses could be carried out, a finite element model for each pier cap was made using the pre-processor FormWorks (Wong, 2002). Figure 5.10 demonstrates the finite element model for pier cap $\mathrm{C} 1$, which was modeled as a planemembrane structure. A combination of truss and quadrilateral elements were used, with a maximum width and height of $100 \mathrm{~mm}$. The longitudinal reinforcement was modelled as truss elements assumed to be perfectly bonded with the concrete, indicated by thin horizontal regions. The vertical stirrups in the cantilevers were modelled as smeared reinforcement layers in the concrete, that is, the steel was assumed to be uniformly distributed in these elements. The column region had smeared reinforcement layers in both the horizontal and vertical directions to take into account the vertical 25M column bars and the horizontal 10M column ties. Figure 5.10 also shows the concentrated loading points for the pier cap. The concentrated loads are assumed to be distributed over each 200-mm bearing plate with half of the applied load in the center of the plate and a quarter of the applied load on either edge of the plate, where the applied loads were incremented from zero loading to failure with a load step of $25 \mathrm{kN}$. The self-weight of the structure was also taken into account. After the VecTor2 analysis was complete the postprocessor Augustus (Bentz, 2003) was used to visualize the results.

The concrete and reinforcing steel material properties used in VecTor 2 were those obtained from material testing. The modulus of elasticity of the reinforcement was assumed to be 200,000 MPa, and the maximum horizontal and vertical concrete crack spacing assumed to be $200 \mathrm{~mm}$. The models used in the VecTor 2 analysis are summarized in Table 5.3. Information on these models can be found in the VecTor2 \& FormWorks User's Manual, Second Edition (Wong et al., 2013). 
Table 5.3: Models used in VecTor2

\begin{tabular}{|c|c|c|}
\hline & Description & Model \\
\hline \multirow[t]{12}{*}{ Concrete } & Compression Pre-Peak Response & Popovics (Normal Strength Concrete) \\
\hline & Compression Post-Peak Response & Modified Park-Kent \\
\hline & Compression Softening & Vecchio 1992-A (e1/e2-Form) \\
\hline & Tension Stiffening & Modified Bentz 2003 \\
\hline & Tension Softening & Bilinear \\
\hline & Confined Strength & Kupfer/Richart \\
\hline & Dilation & Variable - Isotropic \\
\hline & Cracking Criterion & Mohr-Coulomb (Stress) \\
\hline & Crack Stress Calculation & Basic (DSFM/MCFT) \\
\hline & Crack Width Check & $\mathrm{Agg} / 2.5 \mathrm{Max}$ Crack Width \\
\hline & Crack Slip Calculation & Walraven \\
\hline & Hysteretic Response & Nonlinear with Plastic Offsets \\
\hline \multirow[t]{3}{*}{ Reinforcement } & Dowel Action & Tassios (Crack Slip) \\
\hline & Buckling & Akkaya 2012 \\
\hline & Hysteretic Response & Bauschinger Effect (Seckin) \\
\hline Bond & Concrete Bond & Eigenhausen \\
\hline Analysis & Cracking Spacing & CEB-FIP 1978 - Deformed \\
\hline
\end{tabular}

Figure 5.11 shows the predicted cracking pattern of pier cap C1 at the service load level (1050 kN per bearing plate). Flexural cracks in the concentrated steel region were predicted along the entire span between the bearing plates, flexural web cracks were predicted inside and 
close to the column interface, and shear cracks in the cantilevers were also predicted. Figure 5.12 demonstrates the predicted crack widths at service loading. These were $0.35 \mathrm{~mm}$ for shear cracks in both cantilevers, $0.52 \mathrm{~mm}$ and $0.26 \mathrm{~mm}$ for flexural web cracks located just outside the column face in the north and south sides respectively, and $0.24 \mathrm{~mm}$ for flexural cracking of the region containing concentrated reinforcement in both cantilevers.

Figure 5.13 shows the predicting cracking pattern of pier cap $\mathrm{C} 1$ at a predicted failure shear of $1750 \mathrm{kN}$. Figure 5.14 shows the predicted crack widths at failure. The largest crack widths were due to shear cracking in the north cantilever, predicted as $1.19 \mathrm{~mm}$. Maximum flexural web cracks were predicted to be $0.80 \mathrm{~mm}$ at the column-cantilever interface. Thus, the analysis predicted a failure due to shear combined with flexure. Figure 5.15 shows the predicted principal compressive stresses, $f_{2}$, in the concrete at failure. The largest principal compressive stresses were at the re-entrant corners, reaching a maximum value of 30.7 to $32.0 \mathrm{MPa}$, with concrete cracking predicted at these locations. Although these stresses exceed the cylinder compressive strength of the concrete, VecTor 2 considers the beneficial effects of biaxial confinement from the reinforcement on the peak compressive strength and strain in its analysis.

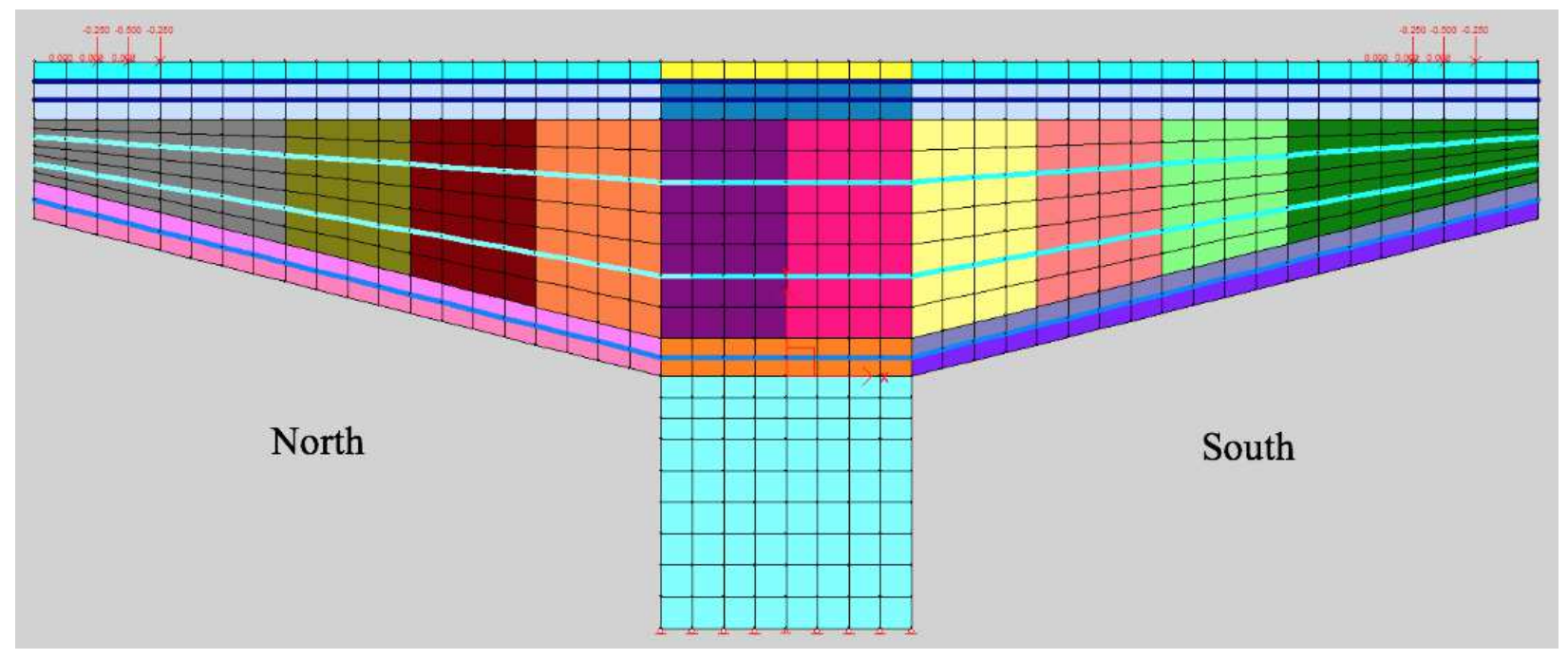

Figure 5.10: Finite element model for cap beam $\mathrm{C} 1$ 


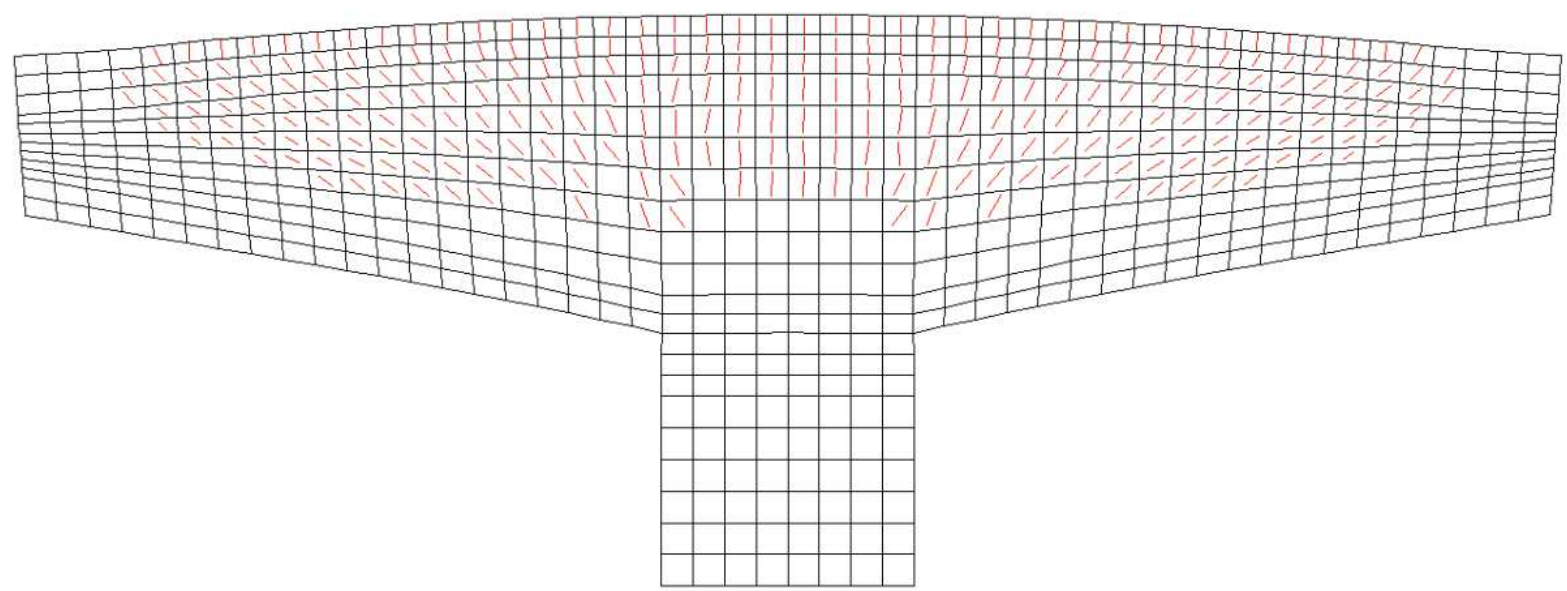

Figure 5.11: Predicted cracking pattern for cap beam $\mathrm{C} 1$ at service loading
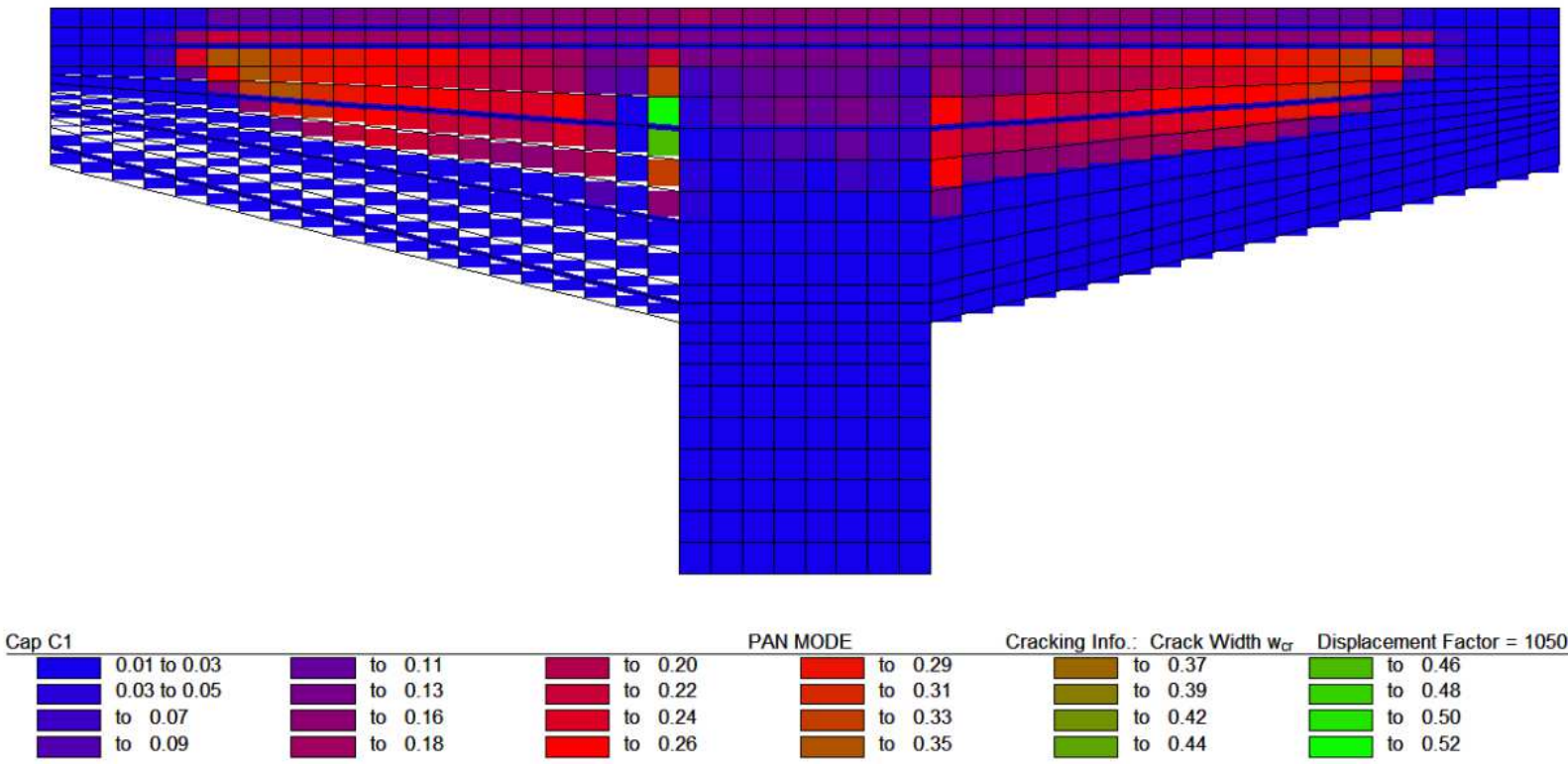

to 0.11
to 0.13
to 0.16
to 0.18

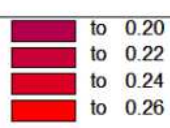

PAN MODE

\begin{tabular}{|r|r|}
\hline to & 0.29 \\
to & 0.31 \\
to & 0.33 \\
to & 0.35
\end{tabular}

Cracking Info: Crack Width $w_{c r}$ Displacement Factor $=1050.00$

Figure 5.12: Predicted crack widths for cap beam $\mathrm{C} 1$ at service loading 


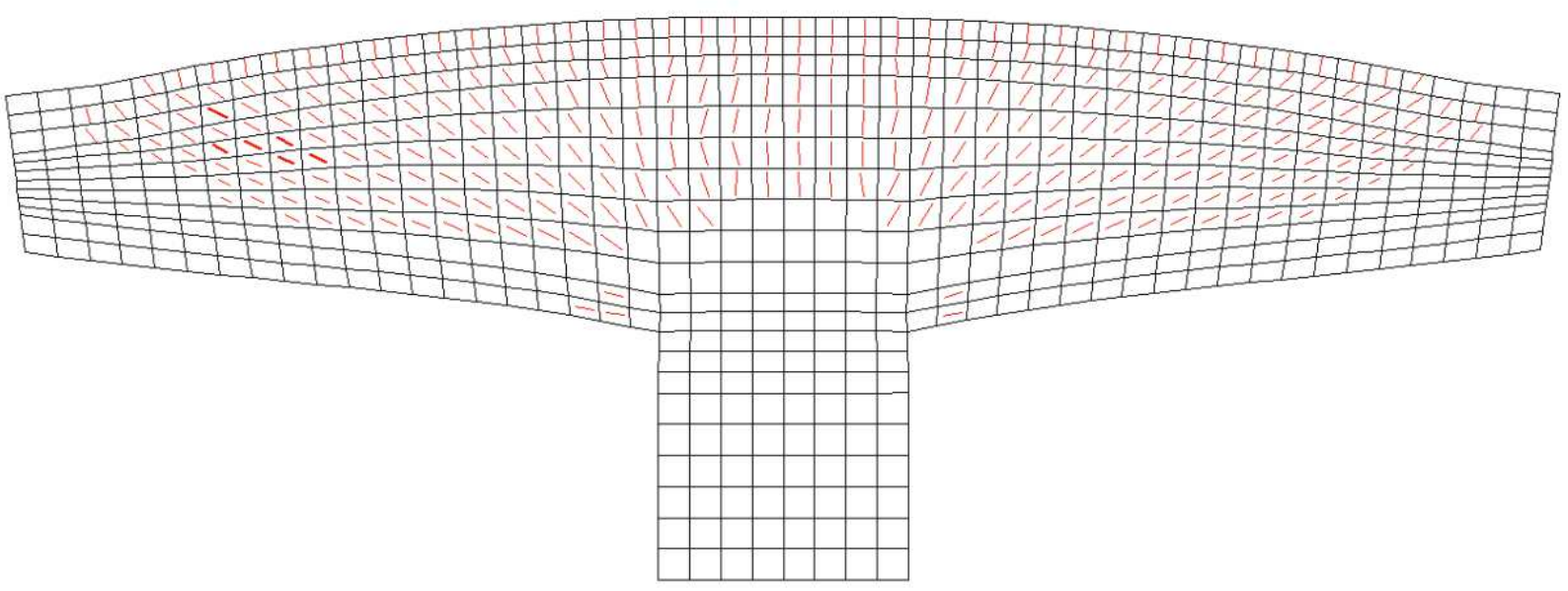

Figure 5.13: Predicted cracking pattern for cap beam $\mathrm{C} 1$ at failure
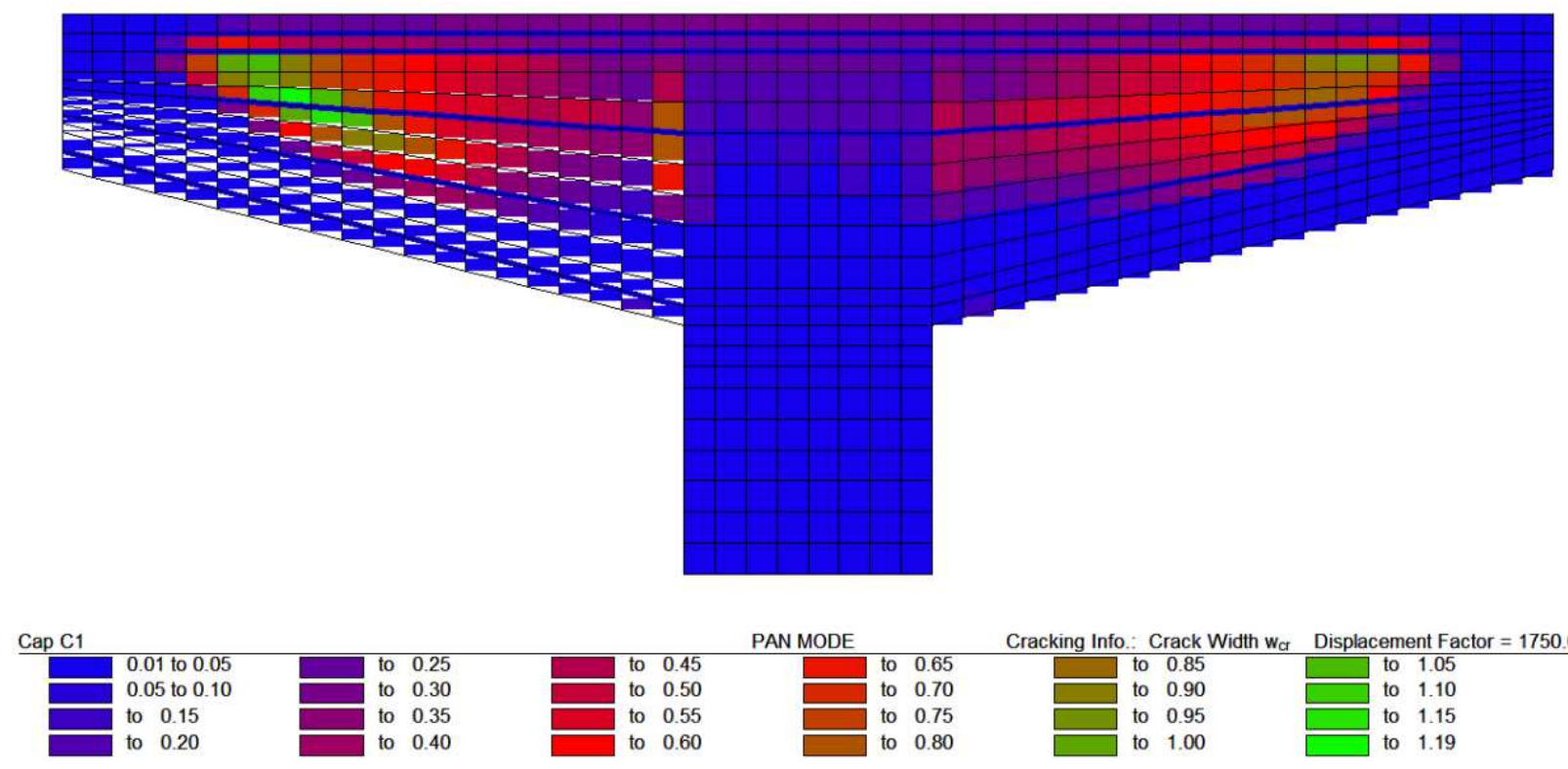

PAN MODE

\begin{tabular}{l} 
MODE \\
\hline$\square$ to 0.65 \\
\hline \\
to 0.70 \\
to 0.75
\end{tabular}

Cracking Info:: Crack Width $w_{\text {Cr }}$ Displacement Factor $=1750.00$ to 0.15

to 0.60

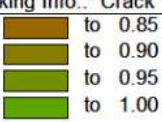

\begin{tabular}{|l} 
Displacement Factor $=1750.00$ \\
\hline to 1.05 \\
to 1.10 \\
to 1.15 \\
to 1.19
\end{tabular}

Figure 5.14: Predicted crack widths for cap beam $\mathrm{Cl}$ at failure 

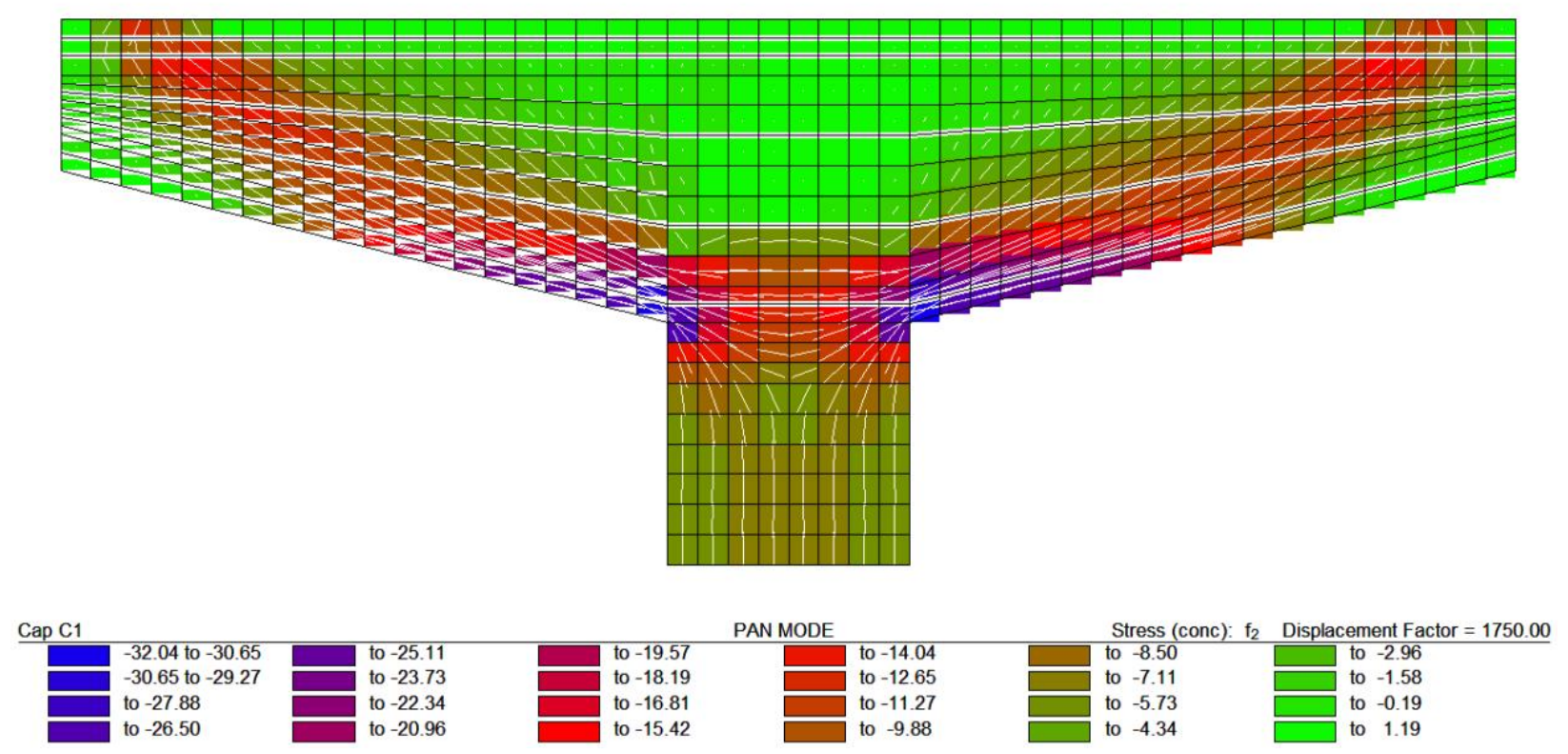

Figure 5.15: Predicted principal compressive stress for cap beam $\mathrm{C} 1$ at failure

\subsubsection{Pier Cap C1R}

The finite element model used for pier cap C1 was also used for pier cap C1R. The only difference is the external post-tensioning force of $600 \mathrm{kN}$, applied as horizontal compressive forces distributed over the loading plate height as shown in Figure 5.16. Figure 5.17 shows the predicted cracking pattern of pier cap C1R at service loading after post-tensioning. The cracking pattern was similar to pier cap C1 but with noticeably smaller flexural and shear cracks. Figure 5.18 demonstrates the predicted crack widths after post-tensioning. These were $0.25 \mathrm{~mm}$ for shear cracks on both cantilevers, $0.35 \mathrm{~mm}$ and $0.19 \mathrm{~mm}$ for flexural web cracks located just outside the column face on the north and south sides respectively, and $0.15 \mathrm{~mm}$ for flexural cracking in the region of concentrated tensile reinforcement on both cantilevers.

Figure 5.19 shows the predicting cracking pattern of pier cap C1R at a predicted failure shear of $1900 \mathrm{kN}$. Figure 5.20 shows the predicted crack widths at failure. The largest crack widths were due to shear cracking in the north cantilever, predicted as $1.10 \mathrm{~mm}$. Maximum flexural web cracks were predicted to be $0.55 \mathrm{~mm}$ at the column-cantilever interface. Thus, the analysis predicted a failure due to shear combined with flexure. Figure 5.21 shows the predicted principal compressive stresses, $f_{2}$, in the concrete at failure. The largest principal compressive 
stresses were at the re-entrant corners, reaching a maximum value of 30.9 to $32.3 \mathrm{MPa}$, with concrete cracking predicted at these locations.

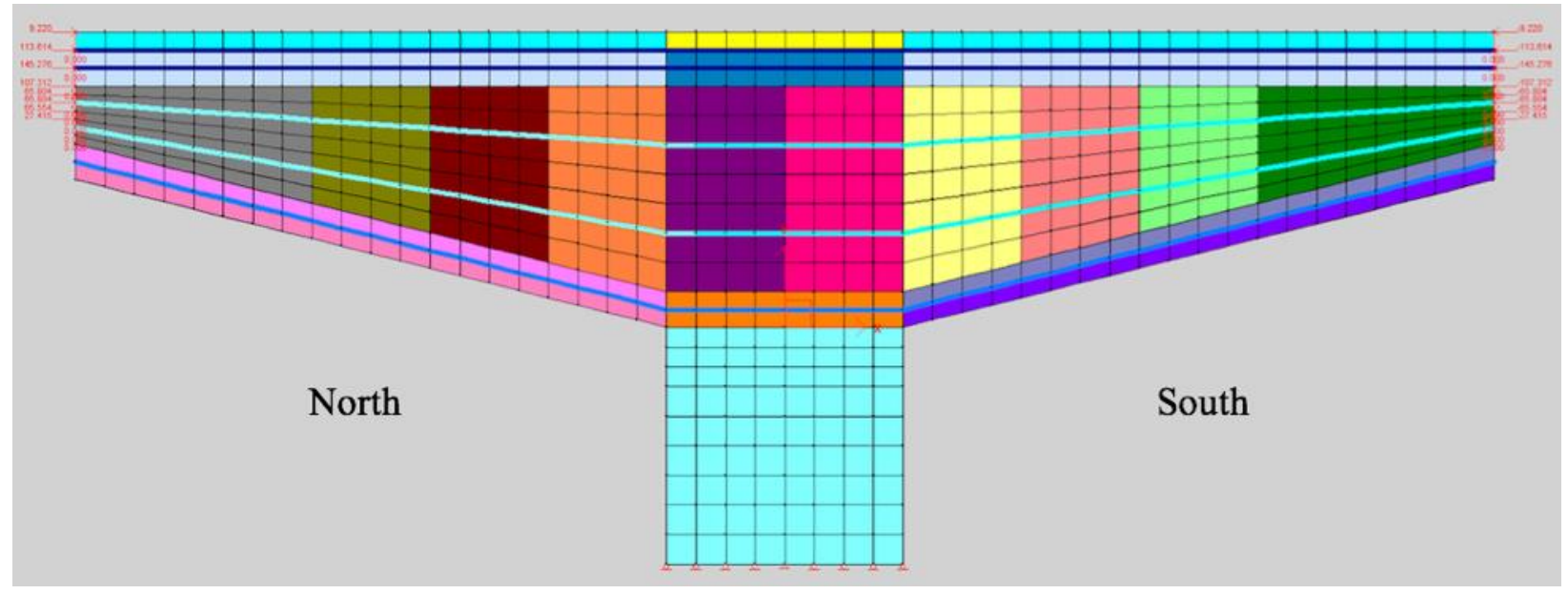

Figure 5.16: Finite element model for cap beam C1R indicating applied post-tensioning force (bearing loads not shown)

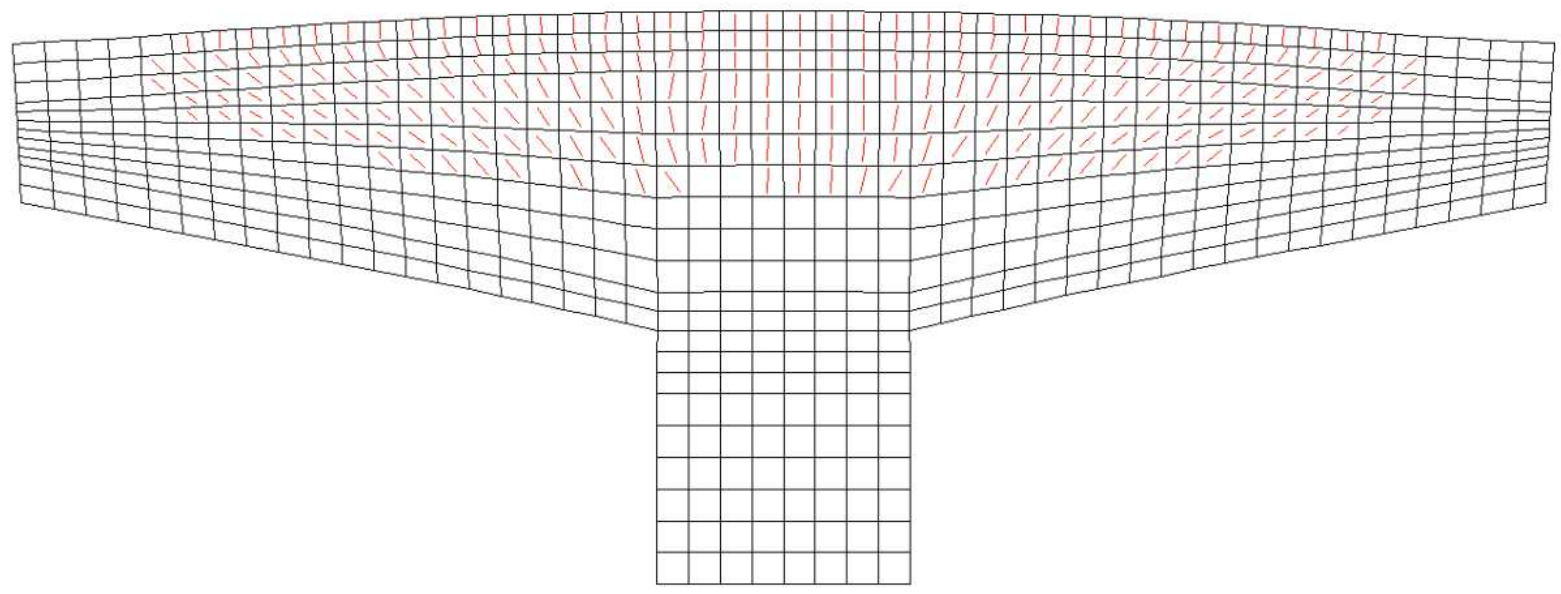

Cap C1R

PAN MODE

Displace/Cracks: Combined View Displacement Factor $=1050.00$

Figure 5.17: Predicted cracking pattern for cap beam C1R at service loading after post-tensioning 


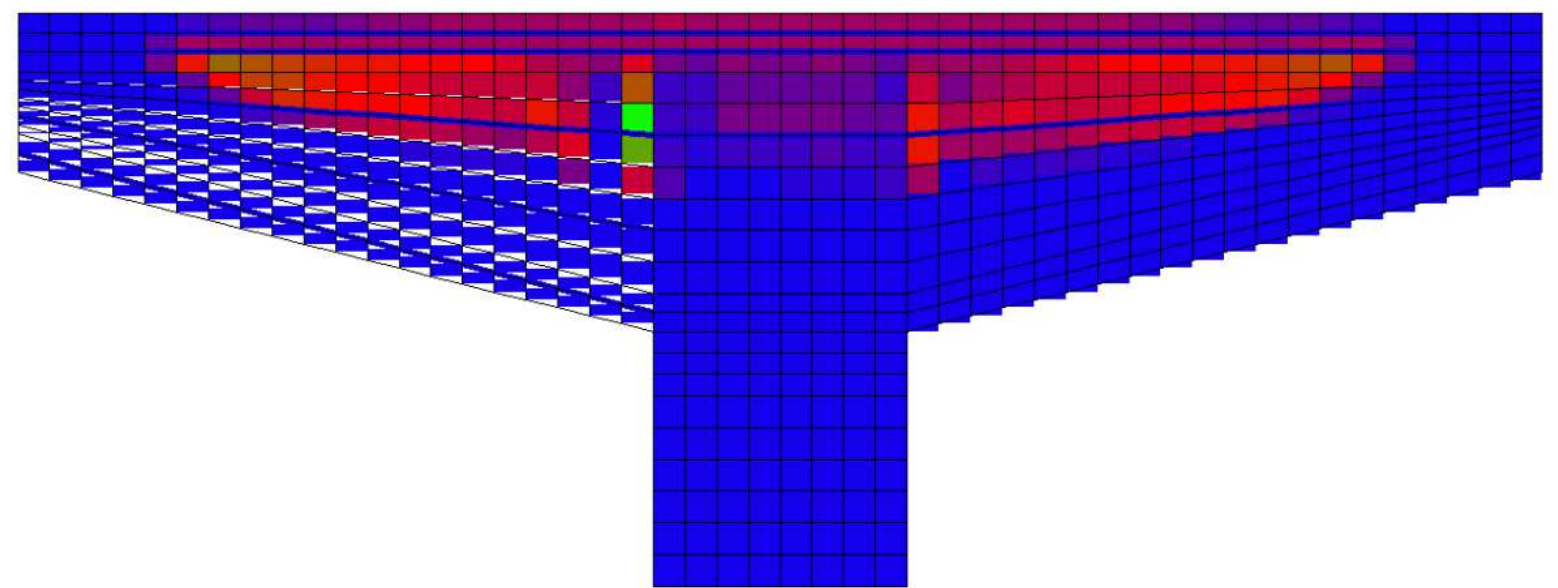

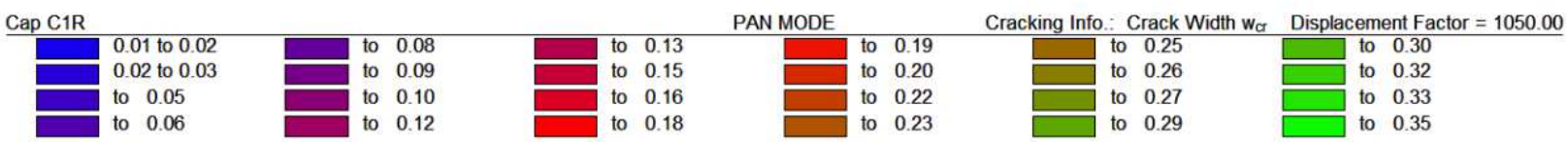

Figure 5.18: Predicted crack widths for cap beam C1R at service loading after post-tensioning

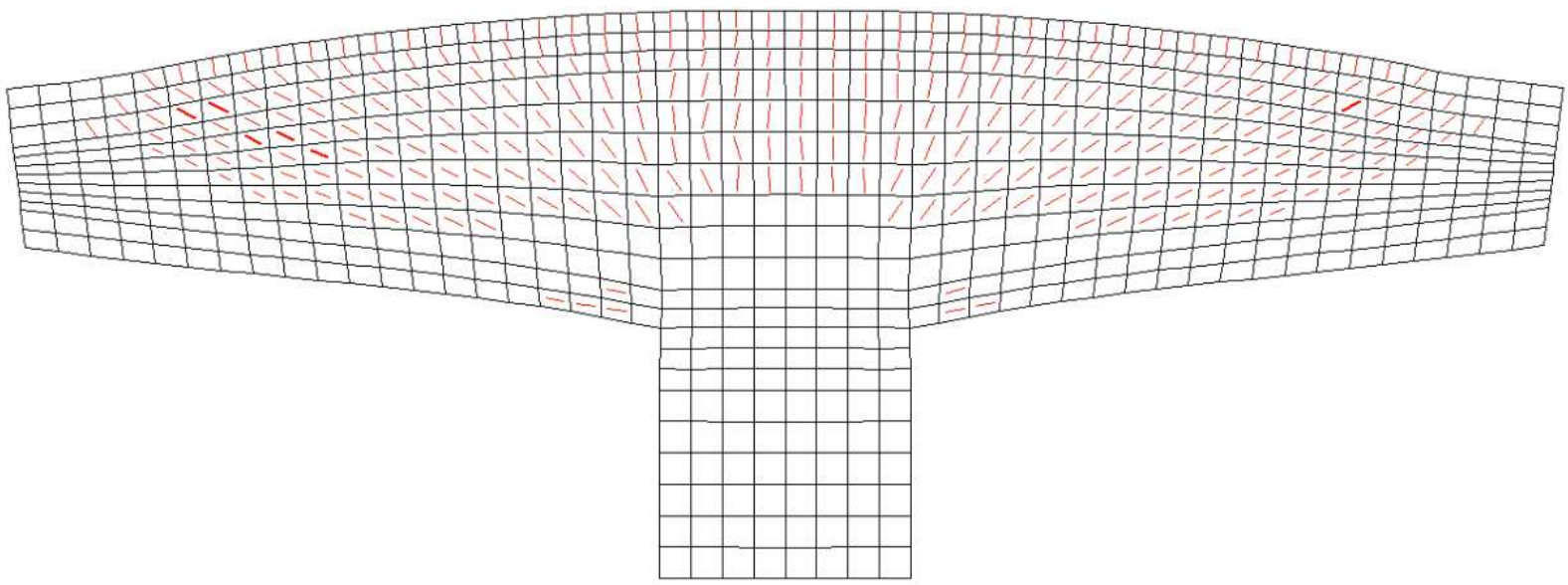

Cap C1R

PAN MODE

Displace/Cracks: Combined View Displacement Factor $=1900.00$

Figure 5.19: Predicted cracking pattern for cap beam C1R at failure 

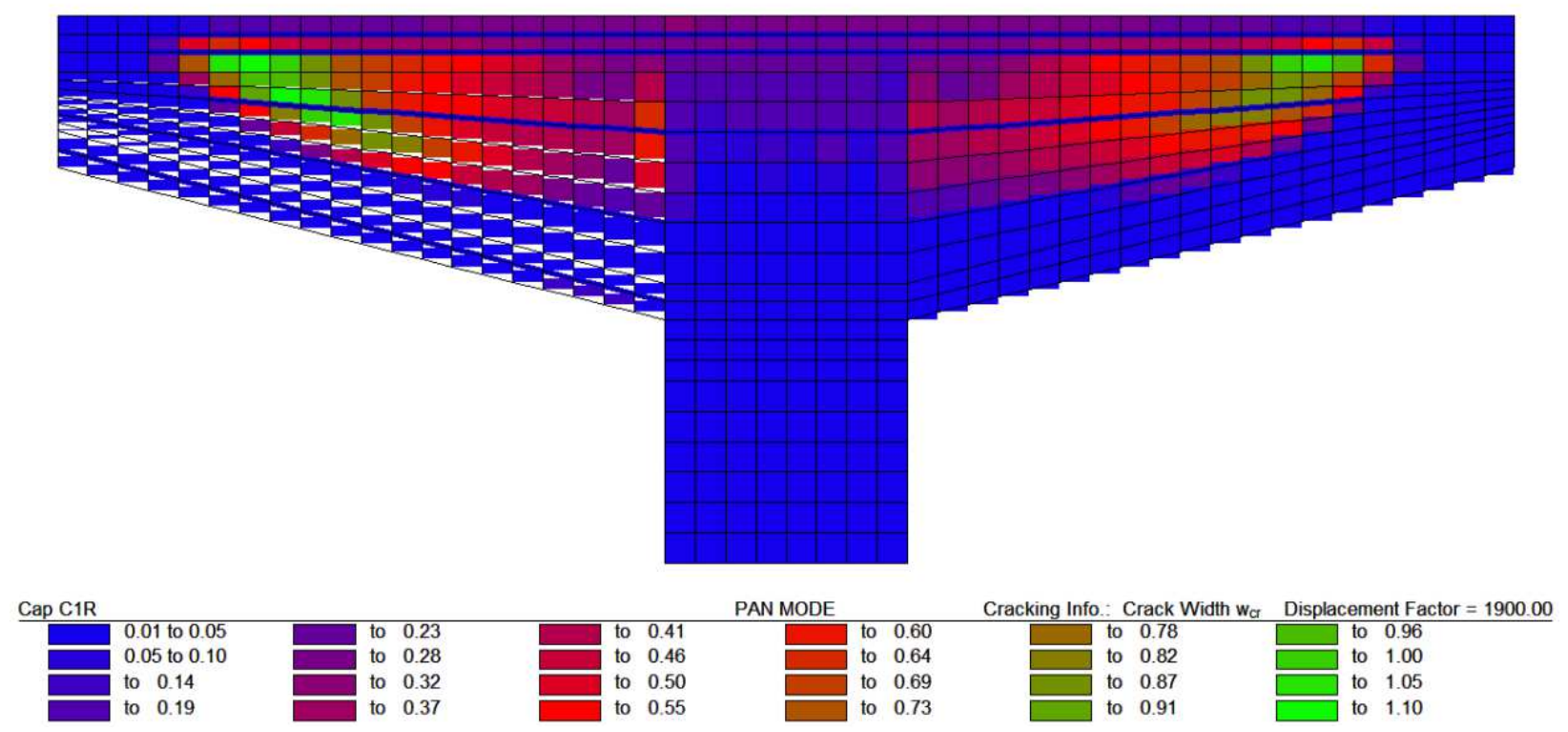

Figure 5.20: Predicted crack widths for cap beam C1R at failure

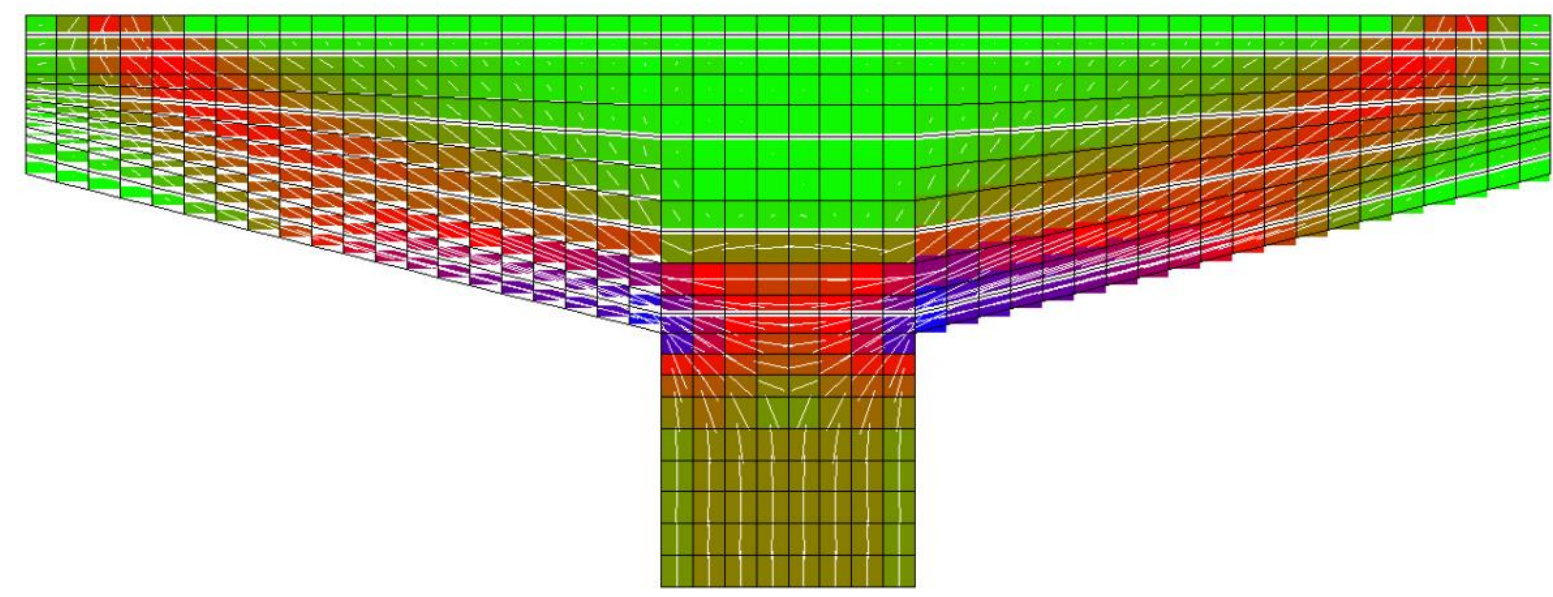

\begin{tabular}{l|l|l|l|l|l|l|l|} 
Stress (conc): $f_{2}$ Displacement Factor = 1900.00 \\
Cap C1R
\end{tabular}

Figure 5.21: Predicted principal compressive stress for cap beam C1R at failure

\subsubsection{Pier Cap C2}

Figure 5.22 shows the finite element model used for pier cap C2. This was similar to the pier cap C1 model with several key differences. The vertical stirrups were modelled again as a smeared reinforcement layer attached to the concrete, but with a lower reinforcement ratio due to 
the larger stirrup spacing for pier cap C2. The inclined reinforcement was added as a smeared reinforcement layer at a $45^{\circ}$ angle, and the concrete properties adjusted because of the different concrete batch properties for pier caps $\mathrm{C} 2$ and $\mathrm{C} 2 \mathrm{R}$.

Figure 5.23 shows the predicted cracking pattern of pier cap C2 at service loading. Flexural cracks were predicted along the span in the concentrated steel region and near the column-cantilever interfaces. Shear cracks were predicted in the cantilevers. Figure 5.24 shows the predicted crack widths at service loading. These were $0.23 \mathrm{~mm}$ for shear cracks in both cantilevers, $0.34 \mathrm{~mm}$ and $0.21 \mathrm{~mm}$ for flexural web cracks located just outside the column face in the north and south sides respectively, and $0.17 \mathrm{~mm}$ for flexural cracking in the region of concentrated tensile reinforcement in both cantilevers.

Figure 5.25 shows the predicting cracking pattern of pier cap C2 at a predicted failure shear of $2075 \mathrm{kN}$. Figure 5.26 shows the predicted crack widths at failure. The largest crack widths were due to shear cracking in the north cantilever, predicted as $0.97 \mathrm{~mm}$. Maximum flexural web cracks were predicted to be $0.73 \mathrm{~mm}$ at the column-cantilever interface. Thus, the analysis predicted a failure due to shear combined with flexure. Figure 5.27 shows the predicted principal compressive stresses, $f_{2}$, in the concrete at failure. The largest principal compressive stresses were at the re-entrant corners, reaching maximum values of 34.8 to $36.3 \mathrm{MPa}$, with concrete cracking predicted at these locations.

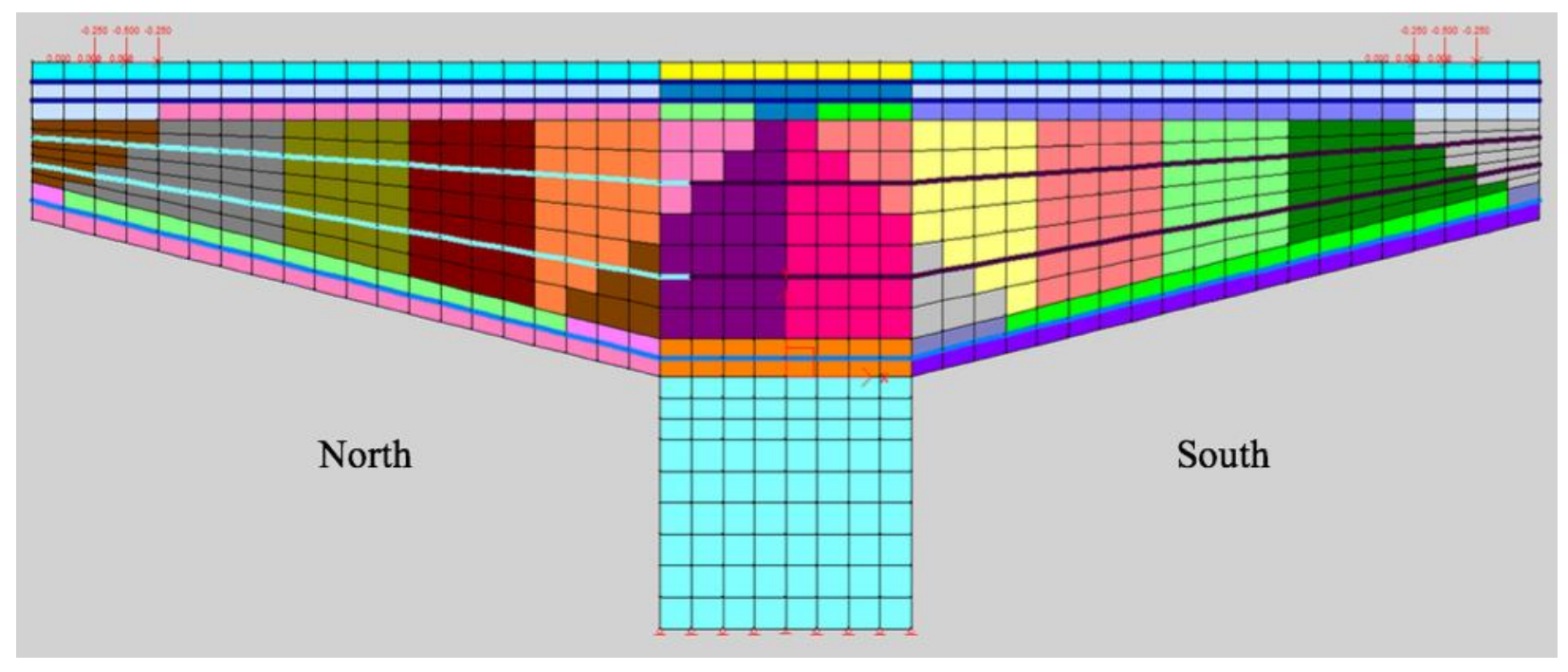

Figure 5.22: Finite element model for cap beam C2 


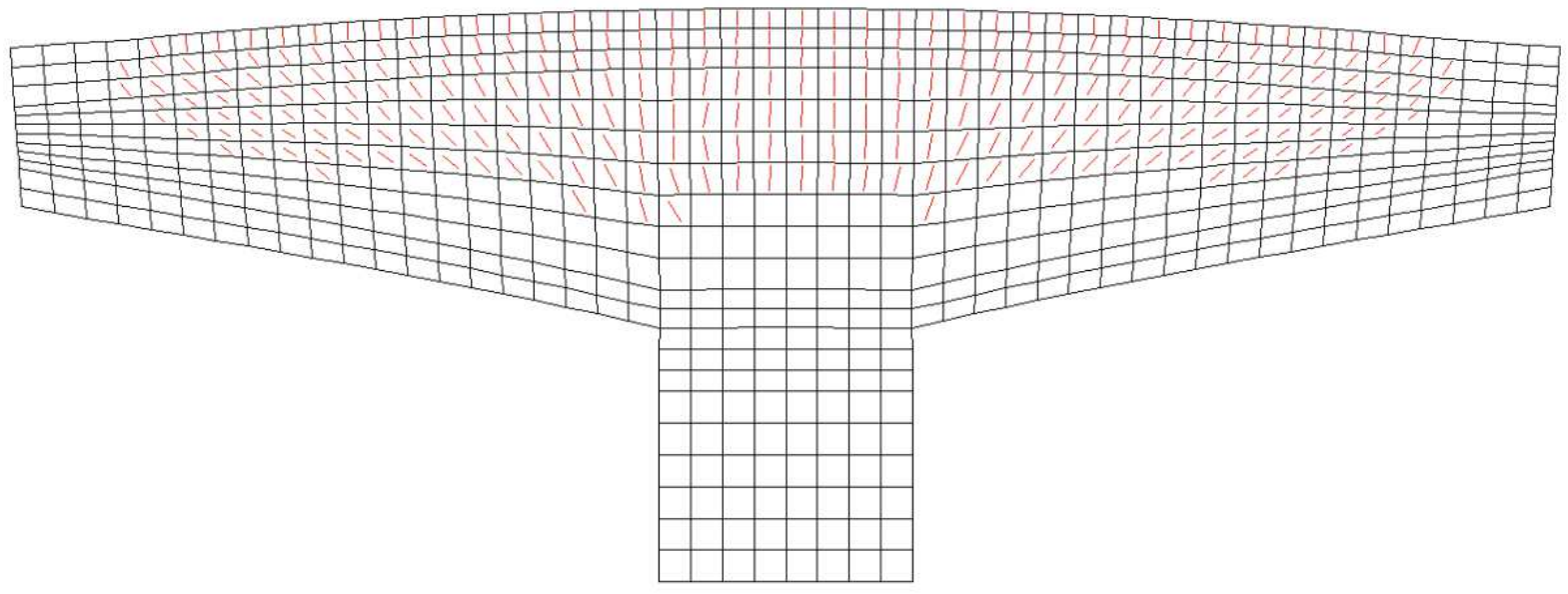

Figure 5.23: Predicted cracking pattern for cap beam C2 at service loading
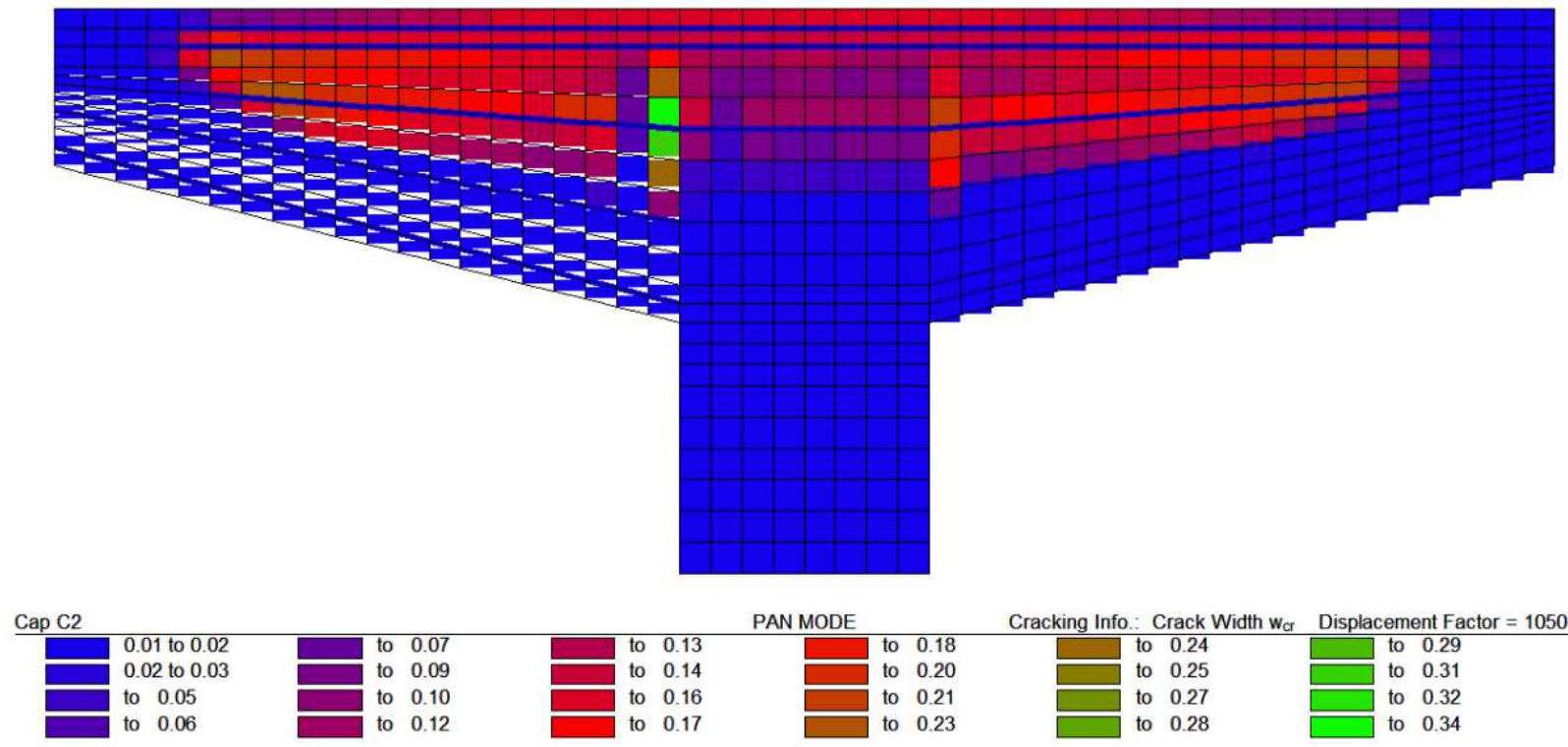

PAN MODE

Cracking Info: Crack Width $w_{C r} \quad$ Displacement Factor $=1050.00$ to 0.05

Figure 5.24: Predicted crack widths for cap beam C2 at service loading 


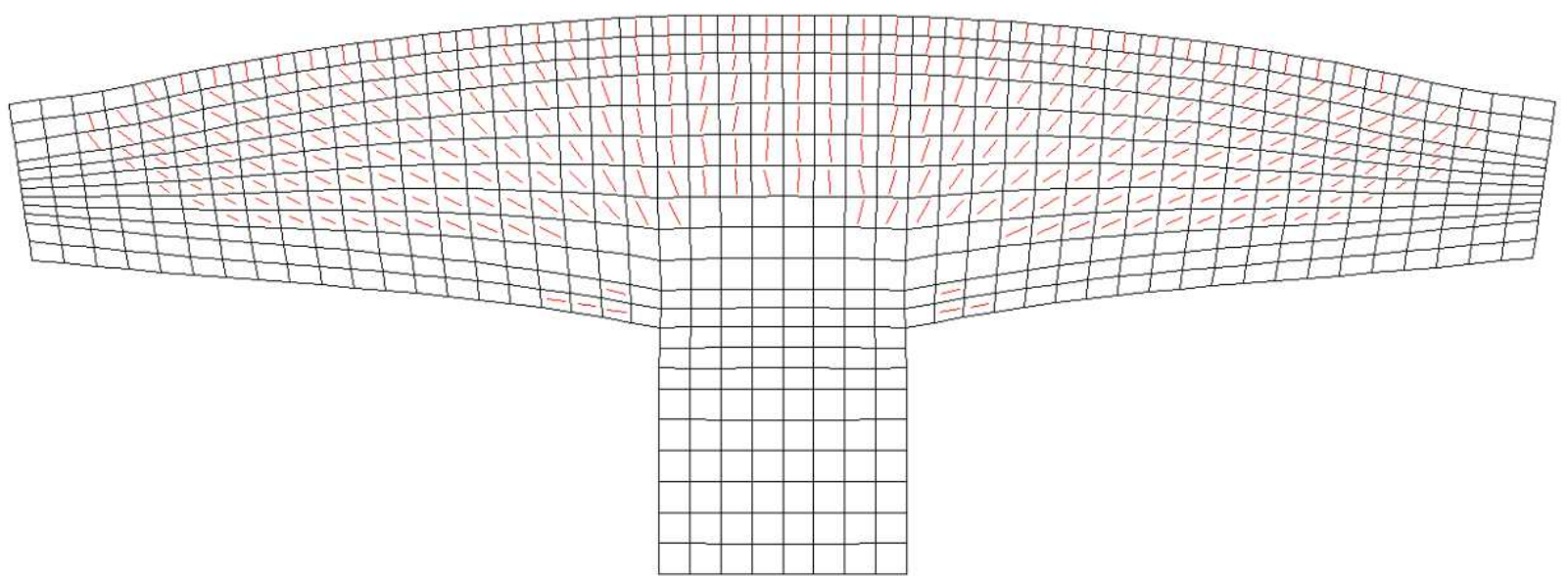

Figure 5.25: Predicted cracking pattern for cap beam C2 at failure

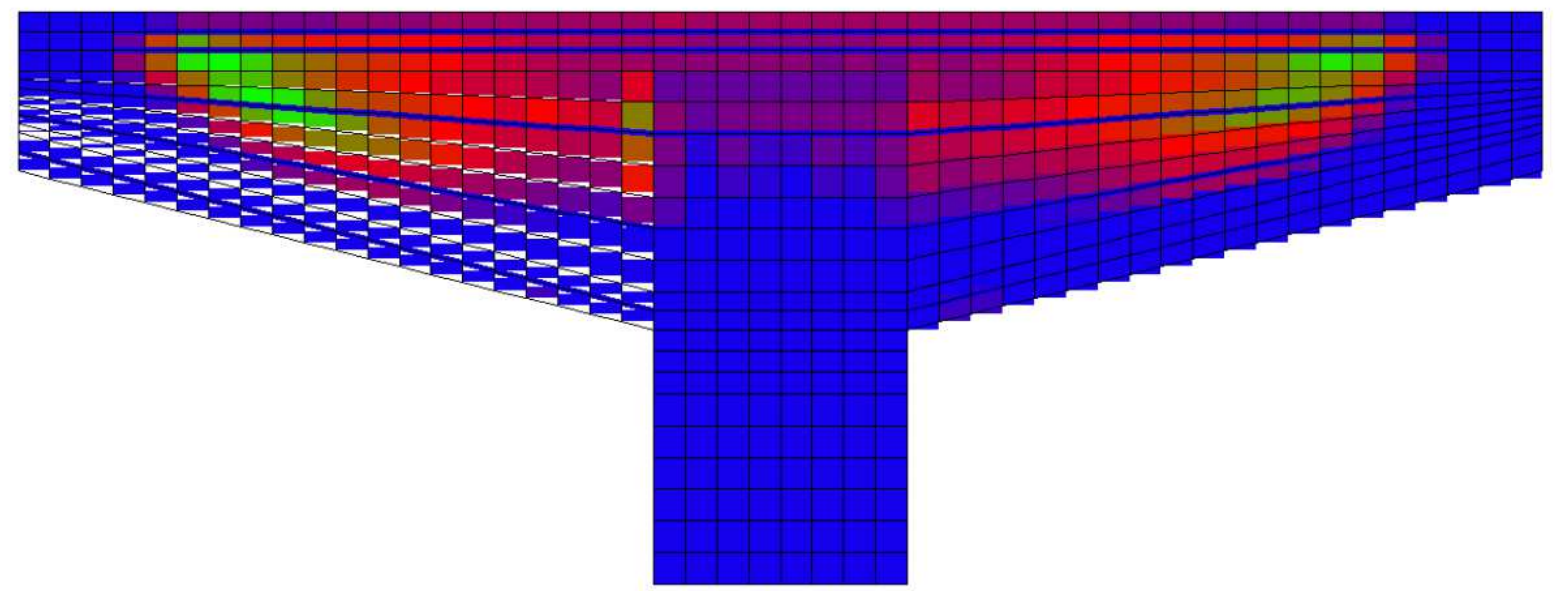

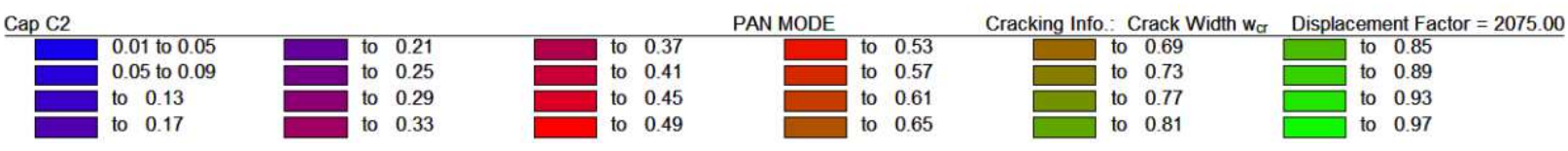

Figure 5.26: Predicted crack widths for cap beam C2 at failure 


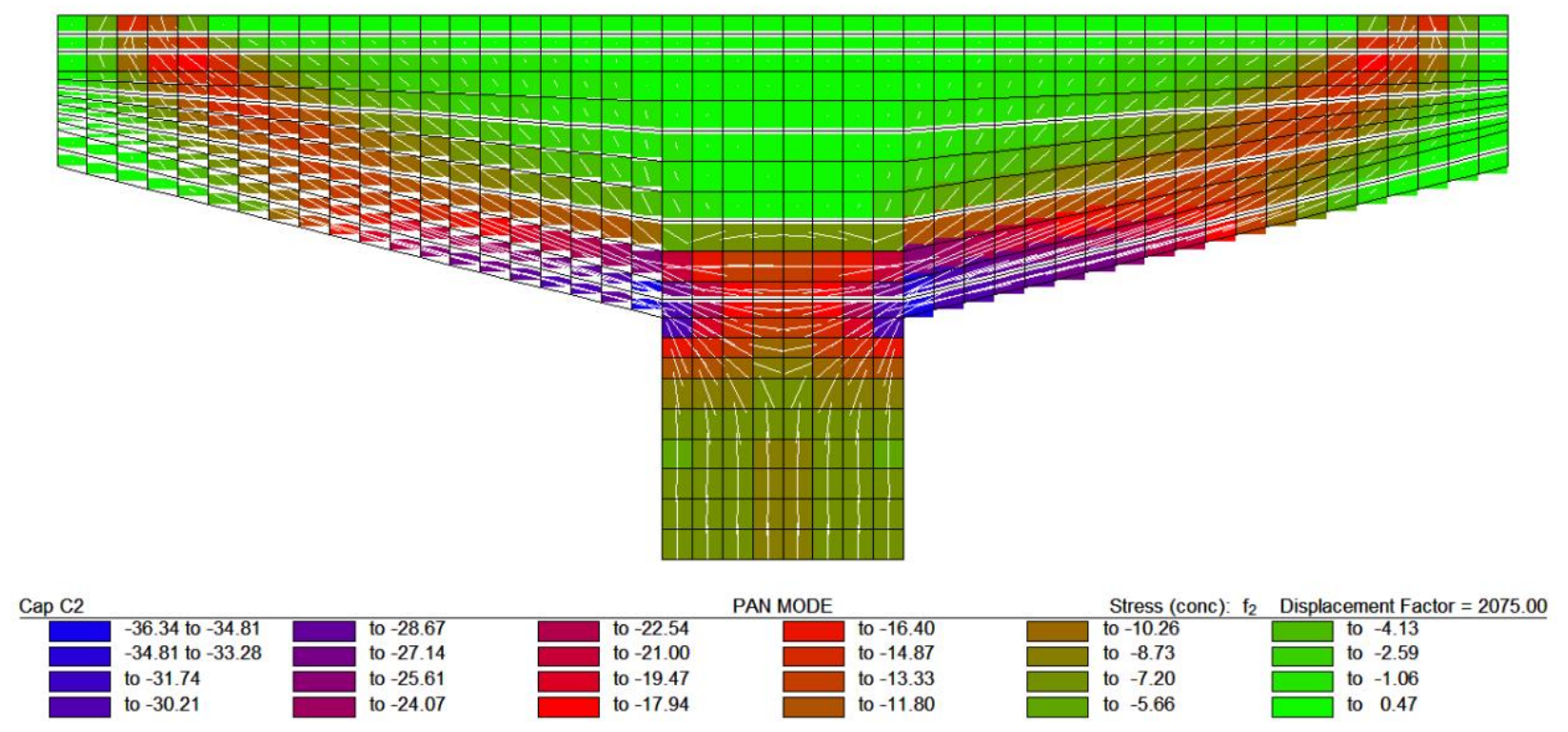

Figure 5.27: Predicted principal compressive stress for cap beam C2 at failure

\subsubsection{Pier Cap C2R}

The finite element model used for pier cap C2 was also used for pier cap C2R. The only difference was the external post-tensioning force of $600 \mathrm{kN}$, applied as horizontal compressive forces distributed over the loading plates as shown in Figure 5.28. Figure 5.29 shows the predicted cracking pattern of pier cap C2 at service loading after post-tensioning, which visually looked similar to pier cap C2. Figure 5.30 demonstrates the predicted crack widths at the service load level after post-tensioning, which were much smaller and scattered than in the other three cap beams. These predicted maximum crack widths were $0.13 \mathrm{~mm}$ for shear cracks in both cantilevers, $0.22 \mathrm{~mm}$ and $0.15 \mathrm{~mm}$ for flexural web cracks located just outside the column face in the north and south sides respectively, and $0.11 \mathrm{~mm}$ for flexural cracking in the region of concentrated tensile reinforcement in both cantilevers.

Figure 5.31 shows the predicting cracking pattern of pier cap $\mathrm{C} 2 \mathrm{R}$ at a predicted failure shear of $2200 \mathrm{kN}$. Figure 5.32 shows the predicted crack widths at failure. The largest crack widths were due to shear cracking in the north cantilever, predicted as $1.00 \mathrm{~mm}$. Maximum flexural web cracks were predicted to be $0.63 \mathrm{~mm}$ at the column-cantilever interface. Thus, the analysis predicted a failure due to shear combined with flexure. Figure 5.33 shows the predicted principal compressive stresses, $f_{2}$, in the concrete at failure. The largest principal compressive 
stresses were at the re-entrant corners, reaching maximum values of 34.8 to $36.3 \mathrm{MPa}$, with concrete cracking predicted at these locations.

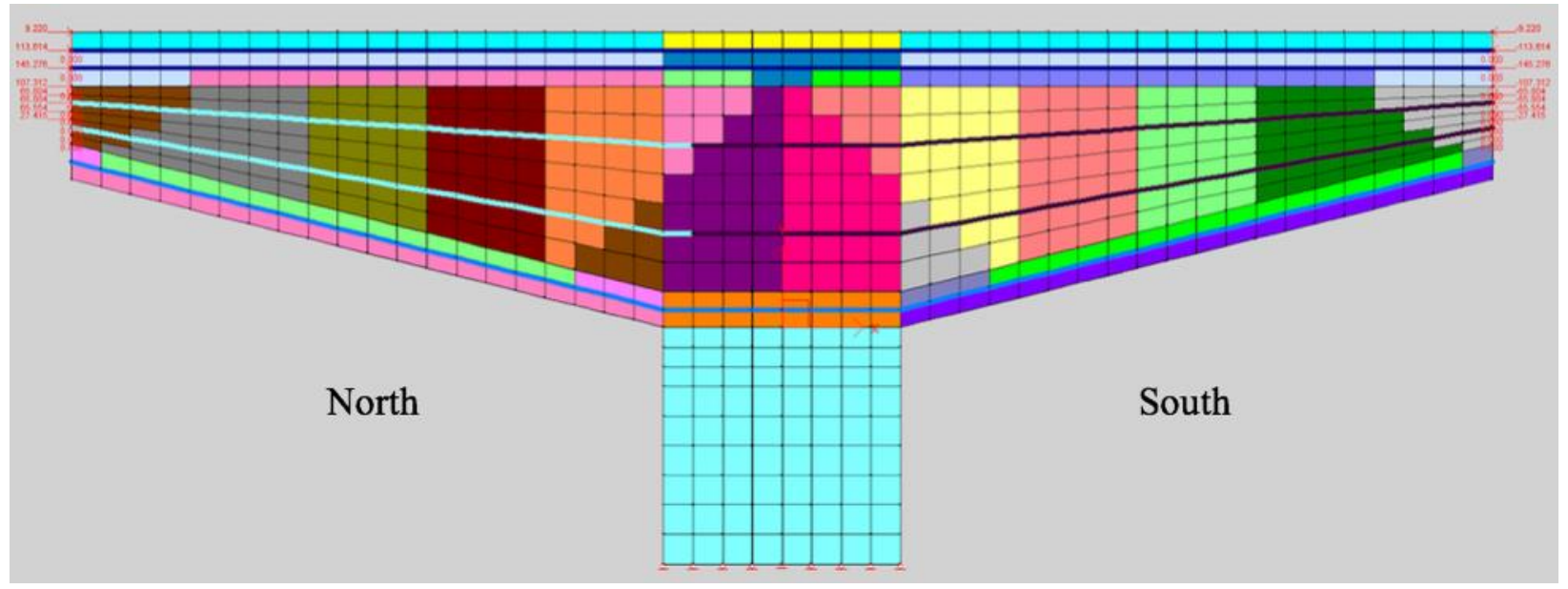

Figure 5.28: Finite element model for cap beam C2R indicating applied post-tensioning force (bearing loads not shown)

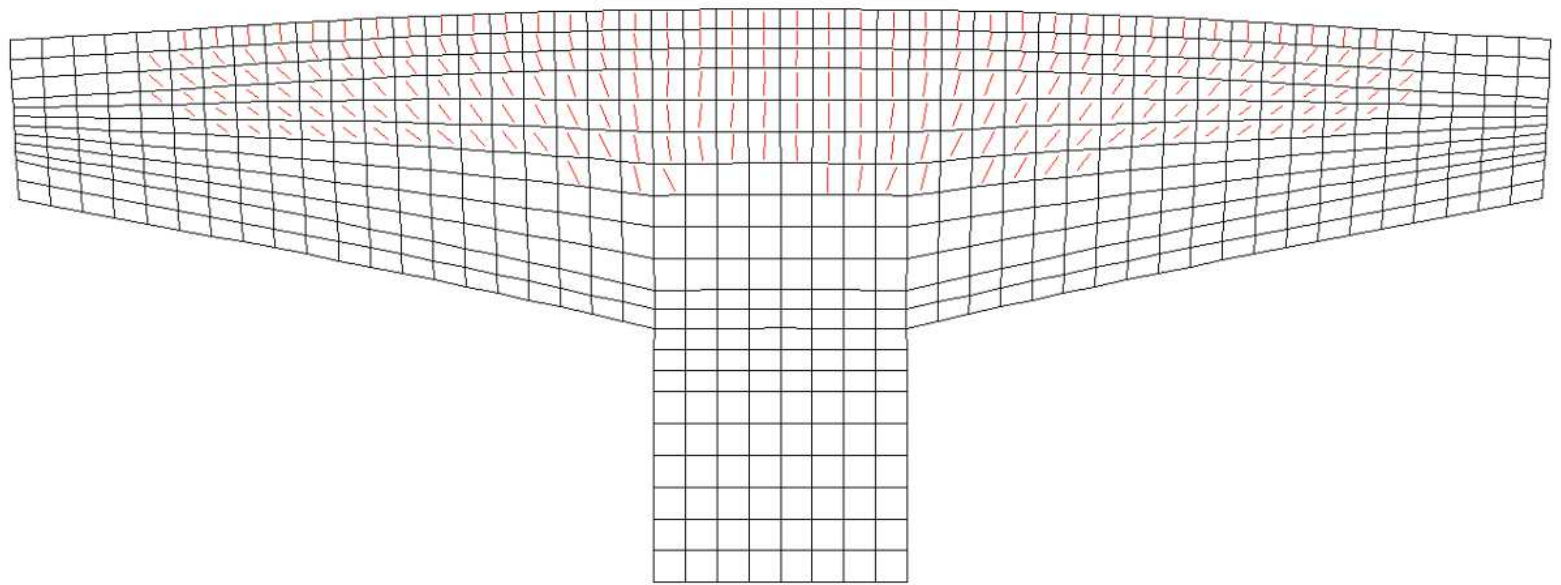

Cap C2R PAN MODE Displace/Cracks: Combined View Displacement Factor $=1050.00$

Figure 5.29: Predicted cracking pattern for cap beam C2R at service loading after post-tensioning 

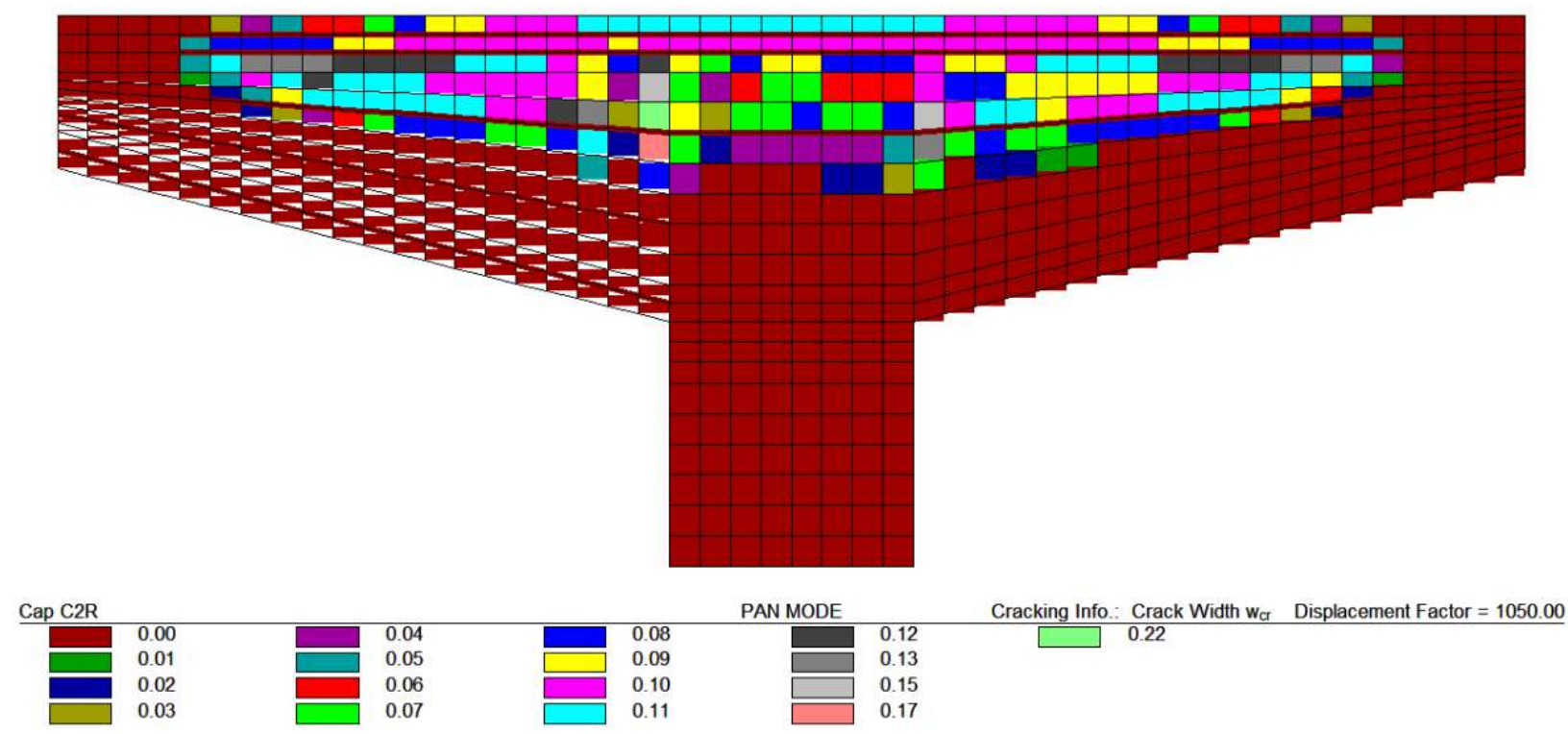

Figure 5.30: Predicted crack widths for cap beam C2R at service loading after post-tensioning

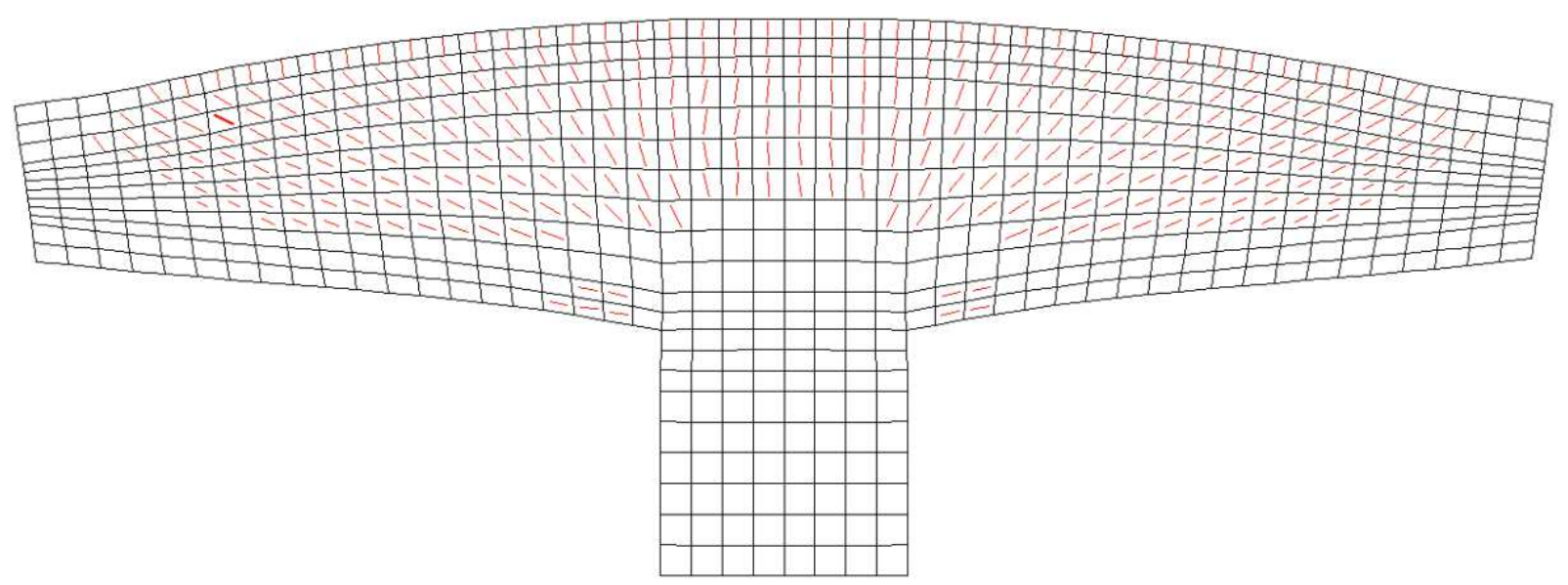

Cap C2R PAN MODE Displace/Cracks: Combined View Displacement Factor $=2200.00$

Figure 5.31: Predicted cracking pattern for cap beam $\mathrm{C} 2 \mathrm{R}$ at failure 


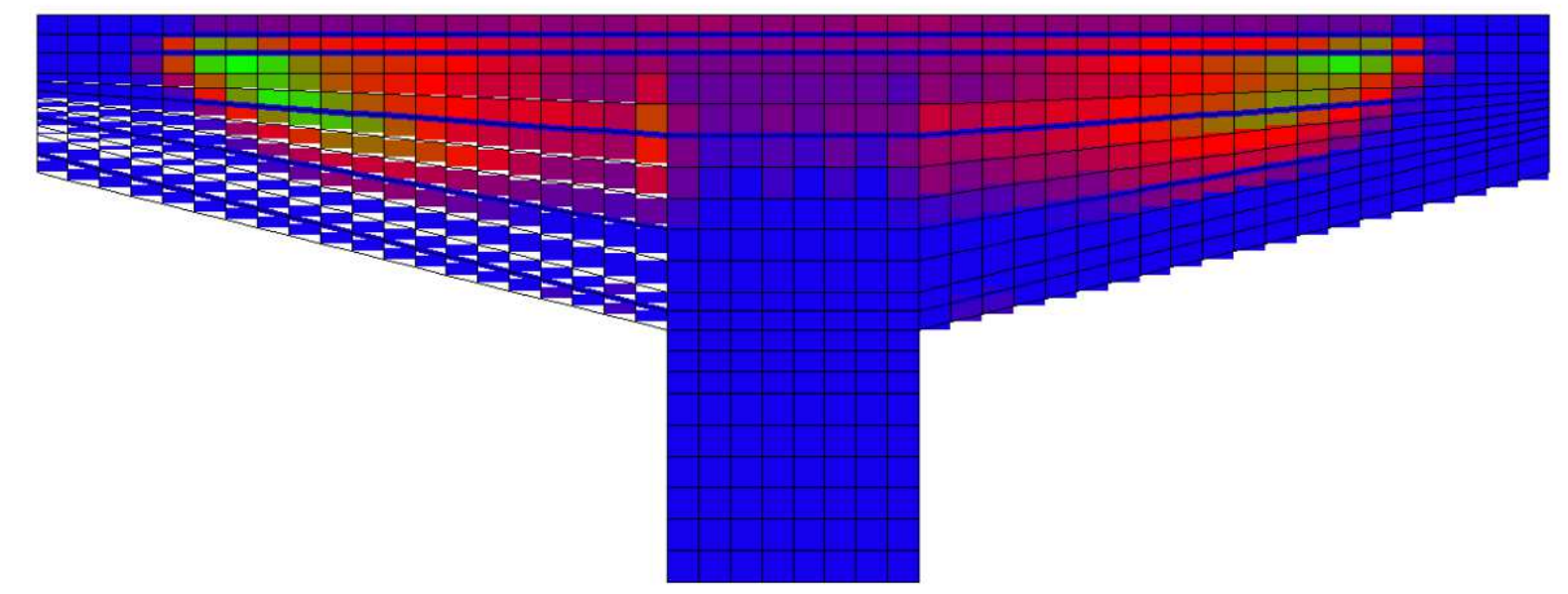

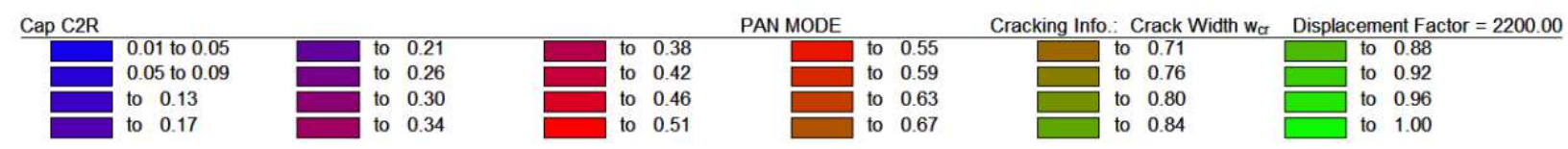

Figure 5.32: Predicted crack widths for cap beam C2R at failure
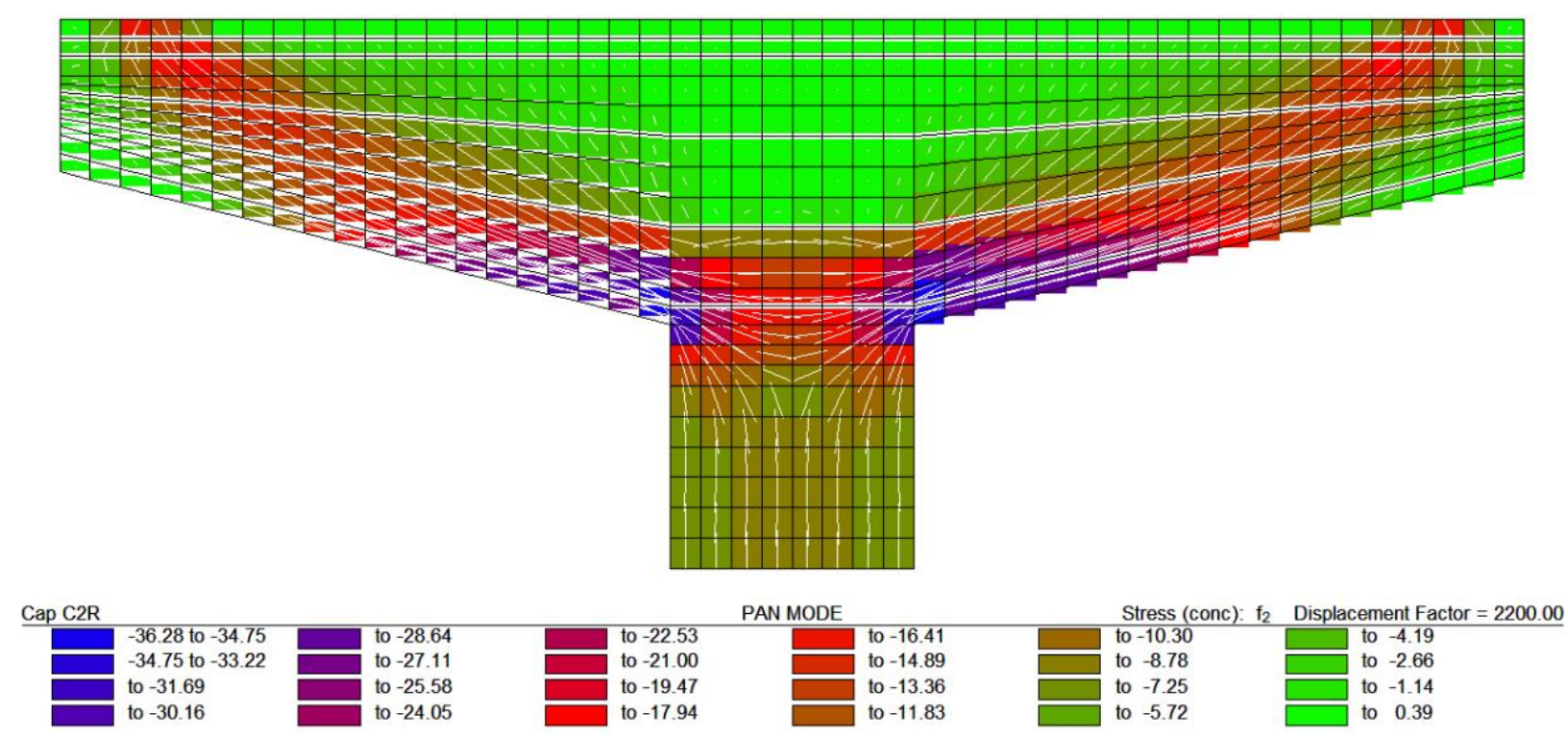

Figure 5.33: Predicted principal compressive stress for cap beam C2R at failure

\subsubsection{Summary of Non-Linear Finite Element Analysis Predictions}

Table 5.4 compares the predicted failure shears from the non-linear finite element analyses with the actual failure shears observed during testing. The model only gives information corresponding to the first failure, and so only the north side failure shears are compared. The 
$\mathrm{V}_{\text {test }} / \mathrm{V}_{\text {predicted }}$ ranges from 0.93 to 1.09 , with the pier caps $\mathrm{C} 1$ and $\mathrm{C} 1 \mathrm{R}$ models giving slightly more conservative predictions than the $\mathrm{C} 2$ and $\mathrm{C} 2 \mathrm{R}$ models. For reinforced concrete, these failure shear predictions are well within acceptable limits.

Table 5.4: Comparison of predicted shear capacities from non-linear finite element analyses with shear capacities achieved during testing

\begin{tabular}{|c|c|c|c|c|}
\hline & $\mathrm{C} 1$ & $\mathrm{C} 1 \mathrm{R}$ & $\mathrm{C} 2$ & $\mathrm{C} 2 \mathrm{R}$ \\
$\mathrm{N}$ & $\mathrm{N}$ & $\mathrm{N}$ & $\mathrm{N}$ \\
\hline $\mathrm{V}_{\text {predicted }}(\mathrm{kN})$ & 1750 & 1900 & 2075 & 2200 \\
\hline $\mathrm{V}_{\text {test }}(\mathrm{kN})$ & 1908 & 2017 & 2075 & 2050 \\
\hline $\mathrm{V}_{\text {test }} / \mathrm{V}_{\text {predicted }}$ & 1.09 & 1.06 & 1.00 & 0.93 \\
\hline
\end{tabular}

Table 5.5 to Table 5.7 compare the predicted maximum crack widths at the service load level from the non-linear finite element analyses with the actual maximum crack widths observed at service loading during testing. For the post-tensioned pier caps C1R and C2R these crack widths refer to those observed after post-tensioning. The crack widths predicted by the non-linear finite element analyses were consistently larger than those observed during testing. Shear crack predictions were generally closer to the test results than flexural web cracking, except for the case of pier cap C2 where the inverse was true. The predicted cracking at failure was consistent with the testing results in predicting that shear cracks would be the largest, controlling cracks. 
Table 5.5: Comparison of predicted maximum shear crack widths from the VecTor2 analysis with those observed during testing

\begin{tabular}{|c|c|c|c|c|c|c|c|c|}
\hline \multirow{2}{*}{ Shear } & \multicolumn{2}{|c|}{$\mathrm{C} 1$} & \multicolumn{2}{c|}{ C1R } & \multicolumn{2}{c|}{ C2 } & \multicolumn{2}{c|}{ C2R } \\
\cline { 2 - 9 } & $\mathrm{N}$ & $\mathrm{S}$ & $\mathrm{N}$ & $\mathrm{S}$ & $\mathrm{N}$ & $\mathrm{S}$ & $\mathrm{N}$ & $\mathrm{S}$ \\
\hline w $_{\text {predicted }}(\mathrm{mm})$ & 0.35 & 0.35 & 0.25 & 0.25 & 0.23 & 0.23 & 0.13 & 0.13 \\
\hline wtest $_{(\mathrm{mm})}$ & 0.20 & 0.15 & 0.15 & 0.10 & 0.05 & 0.05 & 0.10 & 0.05 \\
\hline w $_{\text {test }} /$ w $_{\text {predicted }}$ & 0.57 & 0.43 & 0.60 & 0.40 & 0.22 & 0.22 & 0.77 & 0.38 \\
\hline
\end{tabular}

Table 5.6: Comparison of predicted maximum flexural web crack widths from the VecTor2 analysis with those observed during testing

\begin{tabular}{|c|c|c|c|c|c|c|c|c|}
\hline \multirow{2}{*}{$\begin{array}{c}\text { Flexure } \\
(\mathrm{Web})\end{array}$} & \multicolumn{2}{|c|}{$\mathrm{C} 1$} & \multicolumn{2}{c|}{ C1R } & \multicolumn{2}{c|}{ C2 } & \multicolumn{2}{c|}{ C2R } \\
\cline { 2 - 9 } & $\mathrm{N}$ & $\mathrm{S}$ & $\mathrm{N}$ & $\mathrm{S}$ & $\mathrm{N}$ & $\mathrm{S}$ & $\mathrm{N}$ & $\mathrm{S}$ \\
\hline$w_{\text {predicted }}(\mathrm{mm})$ & 0.52 & 0.26 & 0.35 & 0.19 & 0.34 & 0.21 & 0.22 & 0.15 \\
\hline w $_{\text {test }}(\mathrm{mm})$ & 0.15 & 0.10 & 0.10 & 0.10 & 0.15 & 0.10 & 0.05 & 0.05 \\
\hline w $_{\text {test }} w_{\text {predicted }}$ & 0.29 & 0.38 & 0.29 & 0.53 & 0.44 & 0.48 & 0.23 & 0.33 \\
\hline
\end{tabular}

Table 5.7: Comparison of predicted maximum flexural crack widths in the region of concentrated tension reinforcement from the VecTor 2 analysis with those observed during testing

\begin{tabular}{|c|c|c|c|c|c|c|c|c|}
\hline \multirow{2}{*}{$\begin{array}{c}\text { Flexure } \\
\text { (Concentrated) }\end{array}$} & \multicolumn{2}{|c|}{ C1 } & \multicolumn{2}{c|}{ C1R } & \multicolumn{2}{c|}{ C2 } & \multicolumn{2}{c|}{ C2R } \\
\cline { 2 - 9 } & $\mathrm{N}$ & $\mathrm{S}$ & $\mathrm{N}$ & $\mathrm{S}$ & $\mathrm{N}$ & $\mathrm{S}$ & $\mathrm{N}$ & $\mathrm{S}$ \\
\hline$w_{\text {predicted }}(\mathrm{mm})$ & 0.24 & 0.24 & 0.15 & 0.15 & 0.17 & 0.17 & 0.11 & 0.11 \\
\hline$w_{\text {test }}(\mathrm{mm})$ & 0.10 & 0.10 & $\mathrm{~h}$ & 0.05 & 0.10 & 0.05 & 0.05 & 0.05 \\
\hline$w_{\text {test }} / w_{\text {predicted }}$ & 0.42 & 0.42 & $\mathrm{~N} / \mathrm{A}$ & 0.33 & 0.59 & 0.29 & 0.45 & 0.45 \\
\hline
\end{tabular}




\section{CHAPTER 6}

\section{CONCLUSIONS}

Based on the experimental results and analysis predictions the following conclusions were made:

1. The amount of crack control reinforcement was an important variable in controlling the crack widths at service load. Smaller shear and flexural web cracks were consistently observed on the south side. Compared to the north side the south side had three times the horizontal reinforcement for cap beams $\mathrm{C} 1$ and $\mathrm{C} 1 \mathrm{R}$, and twice the horizontal reinforcement for cap beams $\mathrm{C} 2$ and $\mathrm{C} 2 \mathrm{R}$.

2. The $45^{\circ}$ inclined reinforcing bars in cap beams $\mathrm{C} 2$ and $\mathrm{C} 2 \mathrm{R}$ were effective in resisting shear. Cap beams $\mathrm{C} 2$ and $\mathrm{C} 2 \mathrm{R}$ had a stiffer shear-deflection response and improved shear crack control when compared to cap beams $\mathrm{C} 1$ and $\mathrm{C} 1 \mathrm{R}$.

3. External horizontal post-tensioning reduced crack widths and increased the overall stiffness. However, it did not lead to significant increases in strength.

4. The sectional design procedure in the CSA S6-14 Canadian Highway Bridge Design Code gave conservative predictions of the failure shears, with $V_{\text {test }} / V_{\text {predicted }}$ ranging from 1.10 to 1.22 .

5. The strut-and-tie model gave a very conservative failure shear prediction for cap beam $\mathrm{C} 1$, with a $V_{\text {test }} / V_{\text {predicted }}$ of 1.45 .

6. The non-linear finite element analyses gave very reasonable predictions of the complete behavior and strength of the cap beams, with $V_{\text {test }} / V_{\text {predicted }}$ ranging from 0.93 to 1.09 .

7. The $45^{\circ}$ inclined bars were well anchored and did not experience slip at the hook ends. However, the inclined bars were confined by the vertical stirrups. More research would be required to observe the effectiveness of the $45^{\circ}$ inclined bars in the absence of vertical stirrups. 


\section{REFERENCES}

AASHTO (2014). AASHTO LRFD Bridge Design Specifications, $7^{\text {th }}$ Edition. Washington, DC: American Association of State Highway and Transportation Officials.

ACI Committee 318 (2014). Building Code Requirements for Structural Concrete (ACI 318-14). Detroit, MI: American Concrete Institute.

ACI Committee 318 (1983). Building Code Requirements for Reinforced Concrete (ACI 318-83). Detroit, MI: American Concrete Institute.

Al-Soufi, S. (1990). The Response of Reinforced Concrete Bridge Pier Caps, Master thesis. Montréal, QC: Department of Civil Engineering, McGill University.

ASTM 615/615M (2016). Standard Specification for Deformed and Plain Carbon-Steel Bars for Concrete Reinforcement. West Conshohocken, PA: American Society for Testing and Materials.

Bentz, E.C. (2003). Augustus: Finite Element Post-Processor for VecTor2 and TRIX. Toronto, ON: University of Toronto.

Bentz, E.C. and Collins, M.P. (2006). Development of the 2004 Canadian Standards Association (CSA) A23.3 shear provisions for reinforced concrete. Canadian Journal of Civil Engineering, 33(5), 521-534.

CEB-FIP (1978). Model Code for Concrete Structures: CEP-FIP International Recommendations. Paris: Comite Euro-International du Beton.

Collins, M.P., Mitchell, D., Adebar, P., and Vecchio, F.J. (1996). A General Shear Design Method. ACI Structural Journal, 93(1), 36-45.

Collins, M.P. and Mitchell, D. (1991). Prestressed Concrete Structures. Englewood Cliffs, NJ: Prentice Hall. 
Collins, M.P. and Mitchell, D. (1986). A Rational Approach to Shear Design - The 1984 Canadian Code Provisions. ACI Journal, 83(6), 925-933.

CSA (2014). Canadian Highway Bridge Design Code (CSA S6-14). Mississauga, ON: Canadian Standards Association.

CSA (2014). CSA A23.2-4C: Air Content of Plastic Concrete by the Pressure Method. Rexdale, ON: Canadian Standards Association.

CSA (2014). CSA A23.2-5C: Slump and Slump Flow of Concrete. Rexdale, ON: Canadian Standards Association.

CSA (2014). CSA A23.2-8C-14: Flexural Strength of Concrete (Using a Simple Beam with Third Point Loading). Rexdale, ON: Canadian Standards Association.

CSA (2014). CSA A23.2-9C-14: Compressive Strength of Cylindrical Concrete Specimens. Rexdale, ON: Canadian Standards Association.

CSA (2014). CSA A23.2-12C-14: Making, Curing and Testing Compressive Test Specimens. Rexdale, ON: Canadian Standards Association.

CSA (2014). CSA A23.2-13C-14: Splitting Tensile Strength of Cylindrical Concrete Specimens. Rexdale, ON: Canadian Standards Association.

CSA (2009). CSA G30.18: Carbon steel bars for concrete reinforcement. Rexdale, ON: Canadian Standards Association.

CSA Committee A23.3 (2014). Design of Concrete Structures (A23.3-14). Rexdale, ON: Canadian Standards Association.

CSA Committee A23.3 (1994). Design of Concrete Structures (A23.3-94). Rexdale, ON: Canadian Standards Association.

Delcan (2011). The Future of the Champlain Bridge. PJCCI Report, Contract 61445. 
Kani, M.W., Huggins, M.W., and Wittkopp, R.R. (1979). Kani on Shear in Reinforced Concrete. Toronto, ON: Department of Civil Engineering, University of Toronto.

Kupfer, H. (1964). Erweiterung der Mörschschen Fachwerkanalogie mit Hilfe des Prinzips vom minimum Formänderungarbeit (Extension to the Truss-Analogy of Mörsch using the Principle of Minimum Potential Energy). CEB Bulletin d'Imformation, No. 40.

MacLeod, G. (1997). Influence of Concrete Strength on the Behaviour of Bridge Pier Caps, Master thesis. Montréal, QC: Department of Civil Engineering, McGill University.

Mitchell, D. (2018). Non-linear Finite Element Analysis of Pier Cap Beams. PJCCI Report, Contract 62573.

Mitchell, D., Collins, M.P., Bhide, S., and Rabbat, B. (2004). AASHTO LRFD Strut-and-Tie Model Design Examples. Skokie, IL: Portland Cement Association.

Mitchell, D. and Collins, M.P. (1974). Diagonal Compression Field Theory - A Rational Model for Structural Concrete in Pure Torsion. ACI Journal, 71(8), 396-408.

Mörsch, E. (1909), Concrete-Steel Construction, translation by E.P. Goodrich of $3^{\text {rd }}$ Edition of Der Eisenbetonbau. New York, NY: McGraw-Hill Book Company.

PJCCI (1960). Drawings 12942-EE-4A and 12942-EE-5A by L. Warycha \& C. Skotecky, Consulting Engineers. Montreal, QC: Les Ponts Jacques Cartier et Champlain Incorporée

PJCCI (1960). Drawing 12942-L-168 by H.H.L. Pratley. Montreal, QC: Les Ponts Jacques Cartier et Champlain Incorporée.

Ritter, W. (1899). Die Bauweise Hennebique. Schweizerische Bauzeitung, 33(7), 59-61.

Schlaich, J., Schäfer, K. and Jennewein, M. (1987). Toward a Consistent Design of Structural Concrete. Journal of the Prestressed Concrete Institute, 32(3), 74-150.

Shioya, T., Iguro, M., Nojiri, Y., Akiyama, H. and Okada, T. (1990). Shear Strength of Large Reinforced Concrete Beams. ACI Special Publication, 118, 259-280. 
Vecchio, F.J. (2018). VecTor2 (Version 4.2) [Software]. Retrieved from http://www.civ.utoronto.ca/vector

Vecchio, F.J. (2000). Disturbed Stress Field Model for Reinforced Concrete: Formulation. ASCE Journal of Structural Engineering, 126(9), 1070-1077.

Vecchio, F.J. and Collins, M.P. (1988). Predicting the Response of Reinforced Concrete Beams Subjected to Shear Using Modified Compression Field Theory. ACI Structural Journal, 85(3), 258-268.

Vecchio, F. J. and Collins, M. P. (1986). The Modified Compression-Field Theory for Reinforced Concrete Elements Subjected to Shear. ACI Journal, 83(2), 219-231.

Walraven, J.C. (1981). Fundamental Analysis of Aggregate Interlock. Proceedings of the American Society of Civil Engineers, 107(11), 2245-2270.

Wong, P. S. (2002). User Facilities for 2D Nonlinear Finite Element Analysis of Reinforced Concrete, M.A.Sc. Thesis. Toronto, ON: Department of Civil Engineering, University of Toronto.

Wong, P. S., Vecchio, F. J. and Trommels, H. (2013). VecTor2 \& FormWorks User's Manual (Second Edition). Retrieved from http://www.civ.utoronto.ca/vector 